\title{
Liberalización del Comercio e Informalidad Laboral: Ajustes de Corto y Largo Plazo
}

\author{
Mariana Viollaz \\ Tesis Doctoral \\ Doctorado en Economía \\ Facultad de Ciencias Económicas \\ Universidad Nacional de La Plata \\ Director de Tesis: Dr. Guillermo Cruces \\ Director de Tesis Asociado: Dr. Guido Porto
}

La Plata, diciembre de 2013 



\section{Agradecimientos}

Agradezco muy especialmente a mi director y co-director de tesis por su apoyo, sugerencias, intercambio valioso de ideas para el desarrollo de este trabajo y respaldo durante todo el proceso de tesis. A las autoridades del Comité de Doctorado de la Universidad Nacional de La Plata por el aporte de ideas y sugerencias a lo largo de los distintos seminarios. A mis compañeros de Doctorado y a los participantes de seminarios del Departamento de Economía por sus valiosos comentarios. A Leonardo Gasparini por facilitar el uso de las bases de datos y el espacio del CEDLAS para desarrollar este trabajo de tesis. A David por su apoyo incondicional. 



\section{Índice general}

1. Transición hacia el equilibrio de largo plazo y comportamiento de $\begin{array}{lr}\text { las firmas } & \mathbf{1 3}\end{array}$

1.1. Liberalización del comercio y efectos en el corto y largo plazo . . . . 13

1.2. Informalidad laboral desde la perspectiva de las firmas . . . . . . . . 20

2. Definición de variables y fuentes de información 23

2.1. Definición de variables relevantes . . . . . . . . . . . . . . . 23

2.1.1. Medida de liberalización comercial . . . . . . . . . . 23

2.1.2. Definición de informalidad laboral . . . . . . . . . . 25

2.2. Fuentes de información . . . . . . . . . . . . . . 28

2.2.1. Datos sobre tasas arancelarias . . . . . . . . . . . . . 28

2.2.2. Datos sobre fuerza laboral . . . . . . . . . . . . . 30

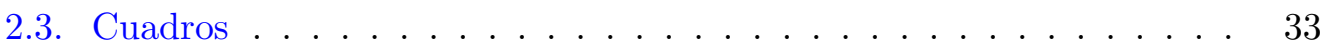

2.4. Gráficos . . . . . . . . . . . . . . . . . . 36

3. Informalidad laboral como mecanismo de ajuste de las firmas $\quad 39$

3.1. Revisión de literatura . . . . . . . . . . . . . . . . . 41

3.2. Modelo teórico . . . . . . . . . . . . . . . . 45

3.2.1. Efectos de la liberalización del comercio: Estáticas comparadas 50

3.3. Estrategia empírica . . . . . . . . . . . . . . . . . 54

3.3.1. Movilidad de trabajadores . . . . . . . . . . . . . . . 58

3.3.2. Endogeneidad de la política comercial . . . . . . . . . . 60

3.4. Reformas comerciales e informalidad laboral: Evidencia de corto plazo 64

3.4.1. Análisis de robustez . . . . . . . . . . . . . . . 67

3.5. Reformas comerciales e informalidad laboral: Evidencia de largo plazo 70

3.5.1. Análisis de robustez . . . . . . . . . . . . . . 75

3.6. Conclusiones . . . . . . . . . . . . . . . . 77

3.7. Apéndice . . . . . . . . . . . . . . . . . . 80

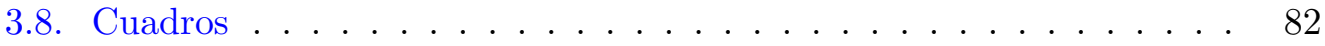

3.9. Gráficos ........................... 92

4. Análisis de transiciones laborales $\quad 96$

4.1. Fuentes de datos . . . . . . . . . . . . . . . . . . . . . . 98 98

4.2. Transiciones laborales: análisis descriptivo . . . . . . . . . . . . . 101

4.3. Reasignación de trabajadores entre sectores y categorías laborales . . 104 
4.3.1. Transiciones entre sectores . . . . . . . . . . . . . . 105

4.3.2. Transiciones entre categorías laborales . . . . . . . . . . 108

4.4. Conclusiones . . . . . . . . . . . . . . . . . . 112

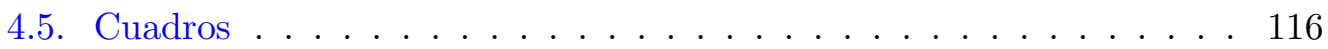

4.6. Gráficos . . . . . . . . . . . . . . . . . . . 141

5. Impacto sobre el diferencial salarial por informalidad 148

5.1. Diferencial salarial entre trabajadores formales e informales . . . . . 150

5.1.1. Aspectos teóricos . . . . . . . . . . . . . . . . 150

$5.1 .2 . \quad$ Evidencia empírica . . . . . . . . . . . . . . 153

5.2. Política comercial y diferencias salariales por informalidad: evidencia preliminar . . . . . . . . . . . . . . . 155

5.2.1. Estimación del diferencial salarial por informalidad . . . . . . 159

5.3. Efectos de la política comercial sobre los salarios: evidencia de corto plazo . . . . . . . . . . . . . . . . . . . 162

5.3.1. Efectos sobre la estructura industrial de salarios . . . . . . . 162

5.3.2. Efectos sobre el diferencial salarial por informalidad . . . . . 164

5.3.3. Ejercicios adicionales . . . . . . . . . . . . . . 168

5.4. Efectos de la política comercial sobre los salarios: evidencia de largo

plazo . . . . . . . . . . . . . . . . . . 170

5.4.1. Predicción . . . . . . . . . . . . . . . . . . 170

5.4.2. Modelo . . . . . . . . . . . . . . . . . . . . . 172

5.4.3. Evidencia empírica . . . . . . . . . . . . . . 177

5.5. Conclusiones . . . . . . . . . . . . . . . . . . 180

5.6. Apéndice $1 \ldots \ldots \ldots$. . . . . . . . . . . . . . . . . . . 183

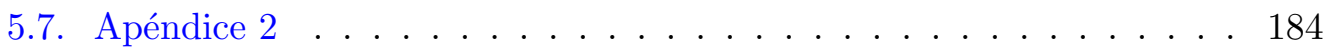

5.8. Cuadros . . . . . . . . . . . . . . . . . . . . . . . 188

5.9. Gráficos . . . . . . . . . . . . . . . . . . . . 198

$\begin{array}{lr}\text { 6. Conclusiones } & 199\end{array}$ 


\section{Introducción}

Durante las décadas del ochenta y noventa muchos países ingresaron en amplios procesos de liberalización del comercio como estrategia de desarrollo. Argentina mostró dos claros episodios de apertura comercial en este periodo. El primero a inicios de la década del ochenta y el segundo y más profundo a inicios de la década del noventa, cuando la reducción unilateral de barreras al comercio fue acompañada por la liberalización del comercio regional.

La teoría del comercio internacional predice que cuando las barreras al comercio son removidas los sectores que pierden protección reducen su nivel de producción y los factores se reasignan hacia aquellos sectores que poseen ventajas comparativas (modelo Ricardiano) o utilizan de manera intensiva el factor relativamente abundante en el país (modelo de Hecksher-Ohlin). La evidencia disponible para países en desarrollo indica que la movilidad entre sectores en respuesta a un cambio en la política comercial es limitada. El presente trabajo plantea como hipótesis que parte del ajuste en economías en desarrollo puede ocurrir al interior de cada sector. En particular, se propone que las firmas pertenecientes a los sectores que pierden protección disponen de un margen de ajuste adicional al poder sustituir trabajadores formales por informales. La evasión de impuestos, en la forma de no registración de trabajadores, actuaría como un mecanismo para absorber parte del shock generado por la reforma.

Existe una amplia literatura empírica que estudia la relación entre las reformas comerciales y los resultados del mercado laboral. Estos trabajos se han concentrado principalmente en analizar el impacto sobre los salarios y el empleo, ${ }^{1}$ pero el conocimiento de los efectos que los cambios en la política comercial pueden tener sobre la informalidad laboral y los mecanismos que operan en ese caso no es tan amplio. El objetivo de este trabajo es analizar el impacto de las reformas comerciales sobre la

\footnotetext{
${ }^{1}$ Goldberg y Pavcnik (2007) presentan una extensa revisión de literatura sobre el estudio de este tipo de relaciones.
} 
informalidad laboral, la transición de trabajadores entre la formalidad y la informalidad y sobre el diferencial salarial entre trabajadores formales e informales en las industrias del sector de manufacturas de Argentina durante el periodo 1980-2001, buscando identificar mecanismos de ajuste adicionales a los propuestos por la teoría del comercio internacional. Para esto se diferenciará entre un efecto de corto plazo, definido como un escenario donde el trabajo no se reasigna entre sectores y los salarios no ajustan, y un efecto de largo plazo, escenario donde el sector de bienes no transables también puede resultar afectado a través de efectos de equilibrio general. Esta distinción en la dimensión temporal del análisis resulta clave desde el punto de vista de la política económica. Comprender cómo reacciona la economía en el corto y mediano plazo luego de un episodio de liberalización del comercio es un insumo necesario para conocer cuánto tiempo demandará la transición hacia el equilibrio de largo plazo, quiénes son los ganadores y perdedores y, entonces, poder diseñar políticas orientadas a reducir costos de ajuste y compensar a los perdedores.

Varias son las razones que motivan el estudio de la relación causal entre los cambios en la política comercial y el empleo informal para el caso argentino. En primer lugar, los datos disponibles indican que en el año 2012 el $34 \%$ de la fuerza laboral argentina trabajó en la informalidad, y el fenómeno se ha incrementado en el tiempo pasando de un promedio de $25 \%$ en la década del ochenta, a $33 \%$ en la del noventa y $40 \%$ en la década del dos mil. ${ }^{2}$ Es decir, que la informalidad laboral es un fenómeno persistente en el mercado de trabajo local. En segundo lugar, constituye un aporte a la necesidad de comprender cómo los mercados laborales de los países en desarrollo ajustan ante reformas comerciales. Algunos trabajos han estudiado el impacto de la apertura comercial sobre los salarios en Argentina. Galiani y Porto (2010) encuentran que las barreras arancelarias protegen los salarios a nivel de industria, mientras que los resultados de Galiani y Sanguinetti (2003) no son concluyentes sobre este punto. Este trabajo busca ampliar la visión actual sobre el proceso de ajuste del mercado laboral argentino postulando un mecanismo de ajuste adicional a los propuestos por la teoría del comercio internacional y separando entre el ajuste que puede interpretarse como un efecto de corto plazo, el efecto de largo plazo y la caracterización del proceso de ajuste mediante el análisis de la movilidad de trabajadores entre sectores y entre la formalidad y la informalidad.

\footnotetext{
${ }^{2}$ Fuente: Socio-Economic Database for Latin America and the Caribbean (CEDLAS y Banco Mundial, 2013).
} 
El trabajo se ubica en el marco de la literatura que analiza el ajuste de los mercados laborales ante reformas comerciales. Esta literatura se ha focalizado especialmente en las predicciones de largo plazo de la teoría del comercio internacional, ${ }^{3}$ mientras que el análisis teórico y la cuantificación de los efectos de la liberalización del comercio en el corto y mediano plazo son de aparición reciente. Estos trabajos han incorporado, teórica y empíricamente, la idea de una transición hacia el equilibrio de largo plazo que es costosa en términos de tiempo y de recursos (Wacziarg y Wallack, 2004; Atolia, 2007; Artuç et al., 2010; Dix-Carneiro, 2011; Cosar, 2013). Dentro de esta literatura, este trabajo se relaciona, en primer lugar, con los estudios que estiman los efectos de corto y mediano plazo de los cambios en la exposición al comercio internacional sobre el mercado laboral aprovechando la existencia de barreras que impiden, al menos temporalmente, que el trabajo se reasigne entre industrias y sectores. ${ }^{4}$ Estos trabajos tienden a mostrar efectos negativos sobre el empleo y los salarios en respuesta a shocks comerciales (Goldberg y Pavcnik, 2005; Galiani y Porto, 2010; Menezes-Filho y Muendler, 2011). La literatura que analiza los efectos sobre la informalidad laboral es más escasa y, en general, no suele presentar los resultados como uno de los costos asociados a la liberalización del comercio en el corto plazo, ${ }^{5}$ mientras que la posibilidad de que el efecto se intensifique o revierta con el transcurso del tiempo no ha sido analizada. De manera similar, el ajuste del diferencial de salarios entre trabajadores formales e informales tampoco ha recibido suficiente atención en el contexto de un cambio de política comercial y de ajuste en la tasa de informalidad. En segundo lugar, el trabajo se vincula a la literatura que analiza la reasignación del trabajo en respuesta a shocks de política comercial. El resultado habitual de esta literatura para países en desarrollo indica la ausencia de movilidad del trabajo entre sectores luego de los episodios de apertura (Wacziarg y Wallack, 2004; Haltiwanger et al., 2004) y la ausencia de movilidad entre la formalidad y la informalidad, resultado disponible solo para el caso de Brasil (Menezes-Filho y Muendler, 2011; Bosch et al., 2012).

\footnotetext{
${ }^{3}$ Los modelos tradicionales de la teoría del comercio internacional consideran mercados de factores sin fricciones y con movilidad perfecta. Esta característica permite interpretarlos como predicciones de largo plazo.

${ }^{4}$ Otro grupo de estudios se ha concentrado en la estimación estructural de modelos de equilibrio general. Esta literatura se ha movido desde enfoques que asumen movilidad perfecta de factores entre sectores hacia modelos que admiten fricciones en el mercado laboral, como la reasignación costosa del trabajo.

${ }^{5}$ El trabajo de Goldberg y Pavcnik (2003) es una excepción. El capítulo 3 realiza la revisión de esta literatura.
} 
Por otro lado, el trabajo se relaciona con la literatura que analiza la informalidad laboral desde la perspectiva de las firmas (Rauch, 1991; de Paula y Scheinkman, 2011; Ulyssea, 2013). Estos trabajos enfatizan la relevancia de factores institucionales en las decisiones de las firmas acerca de emplear trabajadores formal o informalmente, como regulaciones laborales, tecnología de detección de la autoridad tributaria, magnitud de las penalidades. En línea con esta literatura, se desarrolla un modelo cuyo objetivo es mostrar cómo el proceso de decisión de las firmas acerca de contratar trabajadores informales puede ser afectado por un cambio en la política comercial. El modelo permite que exista un margen extensivo de evasión (las firmas deciden si registrar trabajadores o no) y un margen intensivo (las firmas deciden que proporción de su fuerza laboral no está registrada) implicando una innovación respecto a los modelos disponibles que vinculan la liberalización del comercio con la informalidad laboral.

Los principales resultados del estudio pueden resumirse de la siguiente manera: (i) la tasa de informalidad de las industrias aumentó en el corto plazo (cuando los trabajadores no se reasignan entre sectores y los salarios no ajustan) como consecuencia de la reducción en el nivel de protección arancelaria. Las firmas del sector de manufacturas que enfrentan un episodio de liberalización del comercio ajustan el tamaño de su fuerza laboral y modifican la composición de su fuerza de trabajo sustituyendo trabajadores formales por informales. La evasión de impuestos es un mecanismo de ajuste que pueden implementar las firmas para suavizar el impacto de un shock negativo; (ii) la magnitud de este efecto depende del tamaño de las firmas que componen cada industria: cuando las firmas son pequeñas la sustitución entre trabajadores formales e informales es un mecanismo presente, pero este efecto se diluye al considerar firmas de mayor tamaño. Esto puede racionalizarse a partir de los argumentos de la literatura de evasión de impuestos (el nivel de evasión es menor en firmas grandes que enfrentan una probabilidad alta de detección), el diferente comportamiento de las firmas según su exposición al comercio internacional (las firmas exportadoras que pueden acceder a nuevos mercados con la apertura tienden a ser grandes), y la incorporación de bienes de capital que permiten lograr mejoras de productividad (la evidencia muestra un patrón de mejoras de productividad creciente en el tamaño de las firmas); (iii) el proceso de ajuste ocurre a través del cambio en la naturaleza de relaciones laborales ya existentes (trabajadores formales que pierden los beneficios de la seguridad social) en el caso de industrias con firmas pequeñas 
en promedio y a través de la rotación laboral en el caso de industrias con firmas medianas en promedio; (iv) el efecto identificado para las industrias del sector de manufacturas en el corto plazo se revierte en el largo plazo, cuando los trabajadores se reasignan entre sectores, los salarios ajustan y se produce la salida de firmas que no logran competir. El sector de bienes no transables también es afectado por los episodios de liberalización del comercio a través de efectos de equilibrio general. La tasa de informalidad crece en este sector cuando el arancel promedio de la economía se reduce; (v) en el corto plazo el diferencial salarial de trabajadores formales e informales no ajusta ante la caída en el nivel de protección; (vi) en el largo plazo los trabajadores informales mejoran su salario en términos relativos y esa mejora se produce entre los no calificados. La explicación de este efecto se encuentra en la movilidad del trabajo entre los distintos sectores de la economía en el largo plazo, y no solo entre las industrias del sector de manufacturas, y en la existencia de un sector -sector exportador- que es intensivo en el uso de trabajo no calificado (donde el empleo informal tiene un mayor peso relativo) respecto al sector de manufacturas.

Este trabajo constituye un aporte a la literatura que analiza el ajuste del mercado laboral en el corto plazo. El vínculo entre la informalidad laboral y la liberalización del comercio ha sido analizado pero raramente interpretado como un efecto de corto plazo de las reformas que se puede revertir o intensificar con el transcurso del tiempo. El análisis realizado innova al permitir que existan efectos heterogéneos de acuerdo al tamaño promedio de las firmas en cada industria, resultado que es compatible con los argumentos de la literatura de evasión de impuestos y con los modelos de comercio con firmas heterogéneas. El análisis de la movilidad del trabajo indica que el proceso de ajuste tuvo diferentes características en industrias que difieren en el tamaño promedio de sus firmas.

La segunda innovación es la estimación de un efecto de largo plazo. No existen antecedentes en la literatura teórica y empírica que vinculen episodios de liberalización del comercio con cambios en la informalidad laboral distinguiendo entre el efecto que opera en el corto plazo y el efecto de largo plazo. Los resultados indican que cuando el trabajo puede moverse entre sectores, los salarios ajustan y se produce la salida y entrada de firmas al mercado, la tasa de informalidad se reduce en el sector de manufacturas junto con el arancel promedio nacional y el sector de bienes no transables también es afectado a través de efectos de equilibrio general. En este caso, el efecto es el opuesto indicando que la tasa de informalidad aumentó en este 
sector. Esta reversión en el efecto identificado para el sector de manufacturas permite interpretar la evidencia empírica en conflicto en la literatura existente. Parte de los trabajos disponibles encuentran un aumento en la informalidad laboral en respuesta a episodios de liberalización del comercio, otros encuentran una caída y otros concluyen que no existió ningún efecto. Los diferentes mecanismos que operan en el corto y largo plazo estarían detrás de estos resultados contrapuestos.

Otra contribución del trabajo es la presentación de un modelo sencillo que muestra el ajuste en la demanda de trabajo de las firmas de una industria que compite con las importaciones sin imponer ex-ante una segmentación por sector, con firmas totalmente formales o informales. En este caso se propone un escenario más parsimonioso y realista donde los trabajadores son homogéneos y su condición de informalidad depende de la decisión (óptima) de la firma de pagar o evadir las contribuciones a la seguridad social de sus trabajadores lo cual es función de los costos asociados a dicha decisión. Como consecuencia, las firmas pueden emplear simultáneamente a trabajadores registrados y no registrados. El modelo innova al permitir que exista tanto un margen extensivo de evasión (las firms deciden si registrar trabajadores o no) como un margen intensivo (las firmas deciden que proporción de su fuerza laboral no está registrada). Estas característica del modelo se ajustan al hecho estilizado que muestra una correlación negativa entre la informalidad laboral y el tamaño de las firmas, y permite racionalizar el impacto heterogéneo de las reformas comerciales que se encuentra en el análisis empírico.

Una última contribución del trabajo es el análisis del ajuste en el diferencial salarial por informalidad en el corto y largo plazo. Los resultados encontrados son compatibles con el supuesto de ausencia de ajuste de salarios en el corto plazo, mientras que la evidencia de largo plazo permiten interpretar la reversión en el impacto de la apertura sobre la tasa de informalidad en el sector de manufacturas. El resultado encontrado se racionaliza dentro de un modelo en línea con los modelos de largo plazo de la teoría del comercio internacional.

El trabajo se estructura de la siguiente manera. El capítulo 1 presenta una revisión detallada de la literatura a partir de la cual se construyen las principales contribuciones de este estudio. En primer lugar, discute los trabajos que analizan el ajuste del mercado de trabajo ante un cambio de política comercial en el corto y mediano plazo y los trabajos que estiman un efecto de largo plazo. En segundo lugar, detalla los trabajos de la literatura que modela la informalidad laboral desde 
la perspectiva de las firmas. El capítulo 2 introduce los datos que serán utilizados a lo largo del trabajo y discute las definiciones principales. El capítulo 3 presenta el estudio del efecto de la liberalización del comercio sobre la informalidad laboral. Para esto se desarrolla un modelo teórico que toma algunos elementos de la literatura de evasión de impuestos. El análisis empírico evalúa, en primer lugar, el impacto de los cambios en las política comercial sobre la informalidad laboral en las industrias del sector de manufacturas de Argentina durante el periodo 1980-2001 (efecto de corto plazo). En segundo lugar, se identifica el efecto de largo plazo para el sector de manufacturas y para el sector de bienes no transables a partir de la variabilidad temporal de los datos. El capítulo 4 realiza una caracterización del proceso de ajuste del mercado de trabajo a través de un análisis de transiciones laborales. Se evalúa, en primer lugar, la movilidad del trabajo entre industrias y sectores como consecuencia de la liberalización del comercio. En segundo lugar, se analiza la movilidad de trabajadores entre la formalidad y la informalidad dentro del sector de manufacturas. En el contexto de ausencia de reasignación del empleo, el ajuste de salarios también cobra relevancia. Los cambios en la producción y en la composición de la fuerza laboral puede determinar que el salario formal e informal se vean afectados de manera diferente. El capítulo 5 evalúa el impacto de las reformas sobre el diferencial salarial por informalidad en el corto y en el largo plazo. Para realizar este análisis se discuten las distintas teorías de informalidad laboral que tienen implicancias sobre la existencia de un diferencial salarial entre trabajadores formales e informales y se presentan un modelo en la línea con los modelos de la teoría de comercio internacional para realizar las predicciones de largo plazo. El capítulo 6 concluye con los comentarios finales. 


\section{Capítulo 1}

\section{Transición hacia el equilibrio de largo plazo y comportamiento de las firmas}

\subsection{Liberalización del comercio y efectos en el corto y largo plazo}

Uno de los resultados más aceptados de la teoría neoclásica es el aumento en el bienestar agregado como resultado de la liberalización del comercio. ${ }^{1}$ Los argumentos en favor de las ganancias de bienestar agregado se sostienen en modelos de largo plazo en los que solo se considera un estado inicial (autarquía) y un estado final (libre comercio o comercio con menos distorsiones), pero sin ninguna predicción de qué es lo que sucede durante el proceso de ajuste. Generalmente se asume movilidad perfecta de factores y en muy pocos casos se permite la existencia de desempleo. ${ }^{2}$ Sin embargo, mientras este proceso de ajuste ocurre, los trabajadores empleados en las industrias del sector de manufacturas que pierden protección pueden perder su empleo o la naturaleza de su relación laboral puede verse alterada, por ejemplo, pasando de la formalidad a la informalidad.

La literatura se ha focalizado especialmente en las predicciones de largo plazo de la teoría del comercio internacional (TCI), mientras que el análisis teórico y la

\footnotetext{
${ }^{1}$ El concepto de ventaja comparativa es el que permite explicar las ganancias derivadas del comercio en las teorías clásicas. Desarrollos posteriores han centrado la atención en aspectos como los retornos crecientes a escala (Krugman, 1979), la selección de las firmas en el sector que participa del comercio o modelos con firmas heterogéneas (Melitz, 2003), y efectos pro-competitivos (Melitz y Ottaviano, 2008).

${ }^{2}$ Son algunas excepciones Mussa (1984), Davidson et al. (1999), Helpman y Itskhoki (2009) y Helpman et al. (2010).
} 
cuantificación de los efectos de la liberalización del comercio en el corto y mediano plazo son de aparición reciente (Davidson y Matusz, 2004; Atolia, 2007; Artuç et al., 2010; Galiani y Porto, 2010; Dix-Carneiro, 2011; Menezes-Filho y Muendler, 2011; Cosar, 2013; Autor et al., 2013). Esta distinción en la dimensión temporal del análisis resulta clave desde el punto de vista de la política económica. Comprender cómo reacciona la economía en el corto y mediano plazo luego de un episodio de liberalización del comercio es un insumo necesario para conocer cuánto tiempo demandará la transición hacia el equilibrio de largo plazo, quiénes son los ganadores y perdedores y, entonces, poder diseñar políticas orientadas a reducir costos de ajuste y compensar a los perdedores.

Los trabajos que han analizado el proceso de ajuste al nuevo equilibrio de largo plazo encuentran que existe una respuesta del mercado de trabajo luego del shock, pero la transición puede tomar varios años (Atolia, 2007; Artuç et al., 2010; DixCarneiro, 2011; Cosar, 2013). El patrón de ajuste del mercado de trabajo puede ser caracterizado a través de tres puntos de acuerdo a estos estudios. En primer lugar, existe un proceso de creación y destrucción simultánea de empleos al interior de cada industria y una reasignación muy lenta de trabajo hacia las industrias con ventajas comparativas. La evidencia tiende a mostrar que el principal canal de reasignación del empleo en el corto plazo ocurre al interior de cada sector y no entre sectores. Roberts y Tybout (1996) muestran para un grupo de países en desarrollo que la entrada y salida de una industria (indicador de reasignación intersectorial del trabajo) no aumenta con la competencia de las importaciones. Papageorgiou et al. (1991) analizan 19 episodios de liberalización del comercio en países en desarrollo encontrando muy poca relación entre la apertura del comercio y los movimientos de empleo. La evidencia indica que hubo ganancias derivadas del comercio -el empleo total aumentó en casi todos los países analizados- en ausencia de transiciones de empleo entre sectores. Menezes-Filho y Muendler (2011) utilizan datos administrativos para seguir a los trabajadores entre distintos empleadores e industrias antes y después de la principal reforma comercial de Brasil. Encuentran que la apertura impulsó el desplazamiento de trabajadores, particularmente desde las industrias más protegidas, pero por varios años ni las firmas exportadoras ni las industrias con ventaja comparativa absorbieron a los trabajadores desplazados.

Para el caso particular de Argentina, Sanchez y Butler (2004) utilizan la Encuesta Industrial Mensual con información a nivel de firmas para el periodo 1990-2001 y 
estiman los efectos dinámicos de diferentes shocks de política sobre el empleo y la productividad en el sector de manufacturas. Para esto utilizan un modelo de vectores autorregresivos y obtienen funciones de impulso-respuesta para los flujos de trabajo. Estas funciones son luego regresadas en características de los sectores, entre ellas, el grado de exposición al comercio internacional captado a través de cambios en las tasas arancelarias. Los autores comparan el comportamiento de estas funciones ante distintos shocks de política evaluando la existencia de quiebres estructurales en los coeficientes en momentos de reforma. Sus hallazgos indican que la liberalización del comercio favoreció la reasignación de empleo al interior de las industrias en la medida que las firmas menos eficientes fueron desplazadas por otras más productivas.

Haltiwanger et al. (2004) evalúan la reasignación del empleo ante cambios en los aranceles a las importaciones y en el tipo de cambio real para un conjunto de países latinoamericanos (Argentina, Brasil, Chile, Colombia, Mexico y Uruguay) utilizando datos a nivel de firma. Esto les permite identificar el efecto a partir de la variación de las variables de interés (reasignación de puestos de trabajo y cambio neto en el número de puestos de trabajo) entre industrias, periodos de tiempo y países. Sus resultados muestran que las reformas comerciales, más específicamente, la reducción de aranceles a las importaciones, incrementó la reasignación de empleo al interior de las industrias. Este hallazgo, que los autores encuentran consistente con la mejora en la eficiencia asignativa que se espera después de las reformas, se produce al costo de una caída en la creación neta de empleo.

Wacziarg y Wallack (2004) evalúan de una manera directa la reasignación de empleo entre sectores (o industrias) luego de episodios de reformas comerciales. Los autores evalúan la predicción de los modelos tradicionales de la TCI para un conjunto de países en desarrollo que incluye a Argentina y para distintos niveles de agregación de las industrias. Utilizando tres medidas de reasignación del empleo entre sectores encuentran poca evidencia de movilidad cuando definen grandes grupos industriales (1 dígito). Cuando los sectores se definen a 3 dígitos encuentran evidencia de reasignación pero el efecto es pequeño en magnitud y no es robusto a la medida de liberalización y de reasignación de empleo utilizadas. Los resultados por país muestran para el caso de Argentina un efecto positivo pero no estadísticamente significativo utilizando industrias definidas a 3-dígitos. De acuerdo a los autores, este resultado es complementario a la evidencia de reasignación de empleo al interior de las industrias que encuentran los trabajos que utilizan datos a nivel de firma. 
Uno de los argumentos habituales para explicar la escasa respuesta del empleo a los cambios en la política comercial ha sido el de regulaciones restrictivas en el mercado de trabajo. Por ejemplo, Feliciano (2001), al igual que Revenga (1997), atribuyen la falta de reacción del empleo a la reforma comercial en México a las regulaciones laborales que dificultan el despido de trabajadores. Almeida y Poole (2013) muestran evidencia para Brasil que indica que en respuesta a la liberalización del comercio las firmas localizadas en ciudades con regulaciones laborales más restrictivas reducen la creación y aumentan la destrucción del empleo en mayor medida que firmas ubicadas en ciudades con regulaciones menos restrictivas. Currie y Harrison (1997), en cambio, se han focalizado en la competencia imperfecta para explicar el ajuste lento del mercado laboral de Marruecos. Las firmas ajustarían reduciendo el margen de beneficios y aumentando la productividad en lugar de despedir trabajadores. Otra explicación posible es la incertidumbre que enfrentan las firmas acerca de su demanda y productividad, lo que puede demorar el ajuste. Por ejemplo, las firmas serían más cautelosas en emplear nuevos trabajadores ante un shock positivo (Hopenhayn y Rogerson, 1993). La acumulación de capital humano específico también puede llevar a que los trabajadores prefieran permanecer en el mismo sector si esa experiencia acumulada no es fácilmente transferible. Otros costos que pueden demorar la movilidad de trabajadores entre sectores son la migración hacia otras ciudades, los costos monetarios de esa movilidad, la búsqueda de un empleo en un sector para el cual no tienen la calificación necesaria, la desutilidad por cambiar de empleo, etc. (Dix-Carneiro, 2012). De aquí se desprende la segunda característica del proceso de ajuste de una economía hacia el equilibrio de largo plazo que es el costo para los trabajadores que se desplazan.

Estos costos pueden tomar la forma de desempleo y pérdidas de ingreso al momentos de obtener un nuevo empleo. Por ejemplo, Krebs et al. (2008) muestran que la liberalización del comercio en México dio lugar a un aumento en el volatilidad de ingresos en el corto plazo. Para Estados Unidos, Krishna y Senses (2009) encuentran que una mayor penetración de importaciones en la industria original en la que se empleaba un trabajador se asocia a mayores shocks de ingreso si ese trabajador cambia de industria. El enfoque más reciente para estudiar este aspecto del ajuste ha sido el desarrollo de modelos de equilibrio dinámicos con costos de movilidad para los trabajadores. Este tipo de modelos permite captar algunas consideraciones relevantes para un análisis de bienestar que no habían sido tenidas en 
cuenta por estudios previos. ${ }^{3}$ Una de ellas es que un cambio en la política comercial puede tener efectos diferentes dependiendo de la dinámica de implementación. Otro punto relevante es que el cambio de salarios en cierto momento de tiempo no es suficiente para identificar el efecto sobre el bienestar de un trabajador a lo largo de toda su vida. Por último, un análisis de bienestar debe considerar el flujo bruto de empleo entre industrias. En esta línea de trabajo, Artuç et al. (2010) proponen un modelo dinámico de ajuste de trabajo con expectativas racionales y estiman costos de movilidad que superan en varias veces al ingreso laboral promedio anual de los trabajadores en Estados Unidos. Por este motivo encuentran una reacción lenta del mercado de trabajo a la liberalización del comercio (el $95 \%$ de la reasignación del empleo ocurre luego de 8 años de la reforma) y cambios bruscos de salarios. Al incluir heterogeneidades entre los trabajadores, encuentran que los de mayor edad enfrentan mayores costos. Para el caso de Argentina, Peluffo (2010) estima los costos de movilidad intersectorial del empleo durante el periodo 1996-2009 siguiendo la metodología de Artuç et al. (2010). Sus estimaciones reflejan que las características estructurales del mercado laboral de Argentina son consistentes con la escasa flexibilidad documentada para otros países en vías de desarrollo. Los resultados indican que el costo promedio de moverse entre sectores de empleo en el periodo analizado fue de entre 13 y 15 veces el salario semestral promedio, mientras que la simulación de ajuste de la economía ante un shock comercial muestra que el tiempo necesario para alcanzar el nuevo estado estacionario es de entre 24 y 27 semestres. En otro trabajo, Dix-Carneiro (2011) estima un modelo estructural de equilibrio dinámico para una economía pequeña y abierta (Brasil) con un sector no transable y con la opción de salir de la fuerza laboral. Sus resultados indican que el costo de cambiar de sector es de entre 1.4 y 2.7 veces el ingreso laboral anual, dependiendo del sector al cual ingresa el trabajador. La distribución de costos presenta una alta dispersión entre grupos de la población. Por ejemplo, las mujeres y los trabajadores menos educados enfrentan mayores costos y estos son crecientes con la edad. Otro resultado importante de este este estudio es que la experiencia laboral específica del sector se transfiere imperfectamente a otro sector de la economía, significando una barrera a la movilidad. Cosar (2013) también evalúa el caso de Brasil mediante un modelo de

\footnotetext{
${ }^{3}$ Estudios que analizan la relación entre liberalización del comercio y salarios, típicamente a través de regresiones del cambio en salarios en cambios en precio de las importaciones (Revenga, 1992), en los aranceles a las importaciones (Attanasio et al., 2004), o en índices de penetración de importaciones (Kletzer, 2002).
} 
equilibrio dinámico para una economía pequeña y abierta con generaciones superpuestas y capital humano específico. Encuentra que el ajuste del mercado de trabajo luego del shock (reducción de aranceles a las importaciones) puede llevar muchos años (80 años o dos generaciones) y eso se explica por la combinación de fricciones del mercado laboral, trabajadores que viven un número finito de periodos y capital humano específico de cada sector. La comparación de la transición con y sin capital humano indica que este factor constituye una barrera a la movilidad más fuerte que las fricciones de búsqueda.

Por último, una tercera característica de la transición de la economía hacia el equilibrio de largo plazo es el patrón de ciclo de vida que tiende a mostrar la reasignación de empleo. Los trabajadores de mayor edad son los que enfrentan un mayor riesgo de no obtener un empleo luego de ser desplazados de una industria que compite con las importaciones. Kletzer (2001) analiza el caso de Estados Unidos y encuentra que los trabajadores menores de 45 años tienen una mayor chance de ser re-empleados (11 puntos porcentuales) dos años después de haber sido desplazados en relación a los trabajadores que superan ese umbral de edad. Gonzaga et al. (2003) documentan un importante incremento en la probabilidad de pasar del desempleo al auto-empleo para trabajadores mayores de 40 años de edad en Brasil luego de 1990. Una consecuencia de esto es que los sectores que se expandieron lo hicieron contratando trabajadores jóvenes. El análisis de Pagés et al. (2009) muestra que la reasignación sectorial del empleo en Brasil entre 1990 y 2003 aumentó la demanda por trabajadores jóvenes. Boeri y Terrel (2002) evalúan la evidencia para países en desarrollo que liberalizaron sus economías y encuentran que los trabajadores de mayor edad perdieron espacio en relación a los trabajadores jóvenes por la caída en el valor de la experiencia adquirida con anterioridad a la reforma.

La literatura aquí discutida ha incorporado, teórica y empíricamente, la idea de una transición hacia el equilibrio de largo plazo que es costosa en términos de tiempo y de recursos. Sin embargo, ninguno de los trabajos ha incluido a la informalidad laboral como uno de los costos asociados a la liberalización del comercio en el corto y mediano plazo, i.e. la informalidad laboral puede ser un obstáculo al crecimiento económico, o al menos como una de las características de ese proceso de ajuste. Por ejemplo, la ausencia de reasignación del trabajo entre sectores luego de un episodio de liberalización del comercio es compatible con un cambio en la composición formalinformal de la fuerza laboral al interior de cada sector. Más concretamente, las 
firmas pertenecientes a las industrias que pierden protección y que compiten con las importaciones pueden encontrar en la informalidad laboral un mecanismo de ajuste adicional para absorber el shock negativo. Por otro lado, la literatura empírica que vincula este fenómeno del mercado de trabajo con los episodios de liberalización del comercio, en general, no ha enmarcado esta relación dentro del proceso de ajuste de la economía hacia un equilibrio de largo plazo. ${ }^{4}$ El trabajo de Goldberg y Pavcnik (2003) puede considerarse una excepción. En él se presenta un modelo teórico donde se hace explícito que se ignoran los efectos de equilibrio general que podrían alterar los resultados en el largo plazo. Sin embargo, esto no es incorporado en el análisis empírico. En este sentido, la distinción teórica y empírica entre el ajuste del mercado laboral que ocurre en el corto y en el largo plazo constituye una contribución de este trabajo.

Los efectos identificados en el corto plazo pueden constituir una desviación respecto de las predicciones de los modelos tradicionales de la TCI, modelos típicamente de largo plazo. Existen trabajos que analizan el efecto de la liberalización del comercio sobre la desigualdad salarial en países de América Latina logrando reconciliar un efecto identificado en el corto plazo que no es compatible con las predicciones de la teoría. Atolia (2007) elabora un modelo que simula una reforma típica para un país de América Latina. Con este modelo estima un incremento en la desigualdad salarial en el corto plazo que en el largo plazo se reduce, alcanzando un resultado compatible con la predicción de los modelos de la TCI. El aumento inicial en la desigualdad salarial es explicado a partir de asimetrías en la velocidad de ajuste de cada sector y por la complementariedad entre el capital y el trabajo calificado. La reversión de este resultado en el largo plazo se explica a partir de la movilidad del factor trabajo entre distintos sectores de la economía, y no solo entre industrias del sector de manufacturas que pierden protección. En particular, el sector exportador en su conjunto es intensivo en el uso de trabajo no calificado respecto al sector que compite con las importaciones, incluso cuando el sector que compite con las manufacturas importadas es intensivo en trabajo no calificado respecto al sector exportador de manufacturas. Galiani y Porto (2010) reportan un incremento en la desigualdad salarial en Argentina en el corto plazo como consecuencia de la liberalización del comercio. Su resultado de largo plazo muestra el efecto opuesto, compatibilizando el ajuste con las predicción de la TCI. Para explicar este resultado, el trabajo recurre

\footnotetext{
${ }^{4}$ El capítulo 3 presenta la revisión de esta literatura.
} 
a un mecanismo de determinación de salarios no competitivo a partir de la acción de sindicatos que protegen a los trabajadores no calificados distribuyendo parte de la renta tarifaria del sector que compite con las importaciones.

\subsection{Informalidad laboral desde la perspectiva de las fir- mas}

La mayor parte de la literatura que analiza la informalidad laboral lo hace desde una perspectiva del mercado de trabajo (Fields, 1975; Maloney, 2003; Perry et al., 2007), mientras que los estudios que analizan este fenómeno desde el punto de vista de la firma son más escasos. Son ejemplos de contribuciones en esta línea Rauch (1991), Fortin et al. (1997), Auriol y Walters (2005), de Paula y Scheinkman (2011) y Ulyssea (2011). En estos trabajos se enfatiza que las decisiones de las firmas acerca de emplear trabajadores formal o informalmente dependen crucialmente de las instituciones existentes, como las regulaciones laborales, la tecnología de detección por parte de la autoridad tributaria, el tamaño de la multa en caso de ser detectada evadiendo. En otras palabras, la informalidad surge de una decisión óptima de las firmas en respuesta al contexto institucional.

A continuación se describen algunos trabajos de la literatura de informalidad laboral y de evasión de impuestos que enfatizan en los aspectos institucionales como razón detrás de la existencia de la informalidad. ${ }^{5}$ Fortin et al. (1997) desarrollan un modelo de equilibrio general con firmas heterogéneas que es consistente con la segmentación del mercado de trabajo. La existencia de un costo marginal de la evasión de las regulaciones laborales e impuestos que es creciente con el tamaño de las firmas determina la aparición endógena de un sector formal y un sector informal en la economía. Estos dos sectores de la economía difieren en el tamaño de sus firmas. Las firmas pequeñas son informales, mientras que las firmas grandes son formales. Este size dualism en función del tamaño de las firmas es un resultado habitual en la literatura de informalidad laboral desde la perspectiva de las firmas. ${ }^{6}$

Hibbs y Piculescu (2010) proponen un modelo donde las decisiones óptimas de las firmas dependen de las regulaciones del gobierno, por ejemplo, del nivel de imposición. A diferencia de otros modelos donde las firmas cumplen o no cumplen

\footnotetext{
${ }^{5}$ Una revisión de la literatura de evasión impositiva puede encontrarse en Fuest y Schneider (2012).

${ }^{6}$ Esta característica aparece en los trabajos de Rauch (1991) y Galiani y Weinschelbaum (2011).
} 
con las obligaciones impositivas, este modelo predice que firmas maximizadoras de beneficios pueden operar simultáneamente en el mercado "oficial" y "no oficial". Esto depende de la existencia de un umbral de tolerancia a la imposición que es específico para cada firma, ayudando a entender cómo los niveles de evasión pueden diferir entre firmas que operan en el mismo contexto institucional enfrentando las mismas regulaciones y tasas impositivas.

Kleven et al. (2009) presentan un modelo de agencia con tres partes. En este modelo las firmas reportan el ingreso gravable a la autoridad tributaria (por ejemplo, el ingreso pagado a los trabajadores) actuando como una tercera parte entre los hogares y el gobierno. El cumplimiento de las obligaciones tributarias (por ejemplo, pago de las contribuciones a la seguridad social) será alto si esta tercera parte reporta los niveles de ingreso correctamente. En este contexto, la firma y los empleados puede acordar reportar un menor nivel de ingresos al fisco. En la práctica, este acuerdo puede romperse (conflictos entre las firmas y los empleados, preocupaciones morales de nuevos empleados) y esto es más probable que ocurra cuando la firma tiene muchos empleados. Este resultado se ajusta a la evidencia de size dualism entre los sectores formal e informal. Un resultado similar es encontrado por Kumler et al. (2012) quienes concluyen que una manera efectiva de lograr un mayor cumplimiento en el pago de las contribuciones a la seguridad social es el monitoreo de los empleadores por parte de los trabajadores.

Tonin (2011) analiza otro aspecto de la evasión de impuestos que no tiene que ver con la no registración de trabajadores en las seguridad social. En este trabajo se analiza la sub-declaración de ingresos y su interacción con la legislación de salario mínimo. En particular, se desarrolla un modelo donde las firmas y los trabajadores pueden acordar reportar a la autoridad tributaria un monto de ingresos menor al verdadero. Esto es posible en presencia de una tecnología de detección imperfecta. La introducción de un salario mínimo genera un quiebre en la distribución de ingresos declarados, aumentando la tasa de cumplimiento con la autoridad tributaria y reduciendo el ingreso disponible.

Por último, Ulyssea (2013) desarrolla un modelo que incluye el margen extensivo de evasión (las firmas deciden si registrarse al ingresar al mercado) y el margen intensivo (las firmas deciden si evadir costos laborales empleando trabajadores informalmente). La informalidad en este modelo es el resultado de firmas heterogéneas, de la selección de las firmas y del monitoreo imperfecto por parte de la autoridad 
tributaria. Estos elementos permiten explicar algunos hechos estilizados del mercado laboral de Brasil: firmas formales e informales conviviendo en una misma industria, firmas que deciden si registrarse o no al ingresar a la industria, firmas que deciden si evadir costos laborales o no, y ambos márgenes de informalidad se reducen con el tamaño de las firmas.

El modelo que se desarrolla en el capítulo 3 propone mostrar cómo el proceso de decisión de las firmas acerca de contratar trabajadores informales y, en ese caso, que proporción de los empleados mantener en la informalidad, puede resultar afectado a partir de un cambio en la política comercial. El modelo desarrollado busca evitar los casos extremos de firmas totalmente formales o firmas totalmente informales incorporando algunos elementos de la literatura de evasión de impuestos. El modelo innova al permitir que exista tanto un margen extensivo de evasión (las firmas deciden si registrar trabajadores o no) como un margen intensivo (las firmas deciden que proporción de su fuerza laboral no está registrada). Por otro lado, esta característica del modelo se ajusta al hecho estilizado que muestra una correlación negativa entre la informalidad laboral y el tamaño de las firmas, y permite racionalizar el impacto heterogéneo de las reformas comerciales que se encuentra en el análisis empírico. El análisis resalta la importancia de la no registración del empleo y de la evasión de impuestos como un canal de ajuste adicional de la demanda de trabajo. 


\section{Capítulo 2}

\section{Definición de variables y fuentes de información}

Este capítulo se concentra en los aspectos conceptuales relevantes para el desarrollo de este estudio. En primer lugar, se presenta una discusión sobre las medidas de liberalización comercial disponibles y su pertinencia para el propósito del trabajo. En segundo lugar, se analizan las definiciones alternativas de informalidad laboral y sus posibilidades de implementación de acuerdo a la información disponible. En la segunda parte de este capítulo se describen los datos que serán utilizados en el estudio y se exponen los elementos y relaciones claves para establecer una estrategia de identificación válida del efecto causal de las reformas comerciales sobre la informalidad laboral y el diferencial de salarios entre trabajadores formales e informales.

\subsection{Definición de variables relevantes}

\subsubsection{Medida de liberalización comercial}

La política comercial de un país es un evento difícil de captar empíricamente y de una manera adecuada a través de una medida o indicador. El uso de las importaciones, exportaciones o ambas como proxies de la apertura comercial presenta el problema de su determinación simultánea con las variables que habitualmente son objeto del análisis, por ejemplo, los salarios (Goldberg y Pavcnik, 2004).

Las barreras no arancelarias, como las licencias de importación y cuotas, constituyen una alternativa al uso de los flujos comerciales, aunque su definición práctica presenta algunas limitaciones. Usualmente, este tipo de medidas se captan mediante una razón de cobertura para algún nivel de agregación de la industria. La razón de cobertura mide la participación de las importaciones en cierta industria sujeta a 
barreras no arancelarias. Sin embargo, este indicador no captura la verdadera restricción de la medida ya que, por ejemplo, una industria puede registrar el mismo valor de razón de cobertura en dos años diferentes aunque las barreras no arancelarias pueden haber sido más restrictivas en alguno de esos años por diferentes condiciones de demanda (Goldberg y Pavcnik, 2007). Por lo tanto, la comparación entre industrias y en el tiempo es problemática en este caso.

Los aranceles sobre las importaciones, en cambio, son una expresión de la política comercial de un país que es fácil de medir y es comparable en el tiempo. Los aranceles representan un impuesto ad-valorem sobre los bienes importados, es decir, son una forma de protección comercial basada en el precio. Como tal, es más transparente, relativamente más fácil de medir, comparable entre industrias y en el tiempo y su magnitud refleja la verdadera restricción de la medida (Goldberg y Pavcnik, 2003, 2007). Y aún cuando el país emplee barreras no arancelarias, su razón de cobertura y los cambios en el tiempo tienden a estar positivamente correlacionados con los aranceles. Galiani y Porto (2010) encuentran que la correlación entre los aranceles sobre las importaciones y barreras no arancelarias en el caso de Argentina es positiva y baja (alrededor de 0.03). Esto significa, por un lado, que la omisión de las medidas no arancelarias de protección comercial en un modelo econométrico sería menos problemática en términos de la consistencia de los estimadores. Por otro lado, que la correlación sea positiva garantiza que una reducción de los aranceles sobre las importaciones no sea acompañada de un aumento simultáneo en las barreras no arancelarias, anulando el efecto de la primera medida. Si bien el impacto de la política comercial sobre el empleo informal estará sobreestimado, éste representará el efecto conjunto de la política comercial y no sólo de las tasas arancelarias.

Más allá de estas ventajas en el uso de los aranceles sobre las importaciones para captar la política comercial, pueden presentarse algunos problemas de medición. El más importante está vinculado al nivel de agregación de los datos sobre tasas arancelarias y de los datos sobre la variable de interés. Los gobiernos nacionales generalmente establecen los aranceles con niveles muy amplios de desagregación. Esto genera la necesidad de agregar esta información de modo que coincida con el grado de apertura industrial para el cual está expresada la variable sobre la cual se intenta medir el impacto de la política comercial. Este procedimiento puede generar errores de medición en los aranceles a nivel de industria (Goldberg y Pavcnik, 2007). Por otro lado, las tasas arancelarias sobre bienes finales no captan verdaderamente 
la protección que recibe cada industria al no tener en cuenta la protección indirecta dada por los aranceles que recaen sobre los bienes intermedios. El efecto completo podría captarse mediante la construcción de una medida efectiva de protección. Sin embargo, este dato no están disponibles en el caso de Argentina y su construcción presentaría problemas adicionales de medición y compatibilidad.

A pesar de esto, las características de los episodios de apertura comercial para el caso argentino determinan que el uso de los aranceles sobre las importaciones resulte en ventajas adicionales vinculadas a la estrategia de identificación del efecto de interés. Como se verá en secciones siguientes, los aranceles han variado notablemente entre industrias durante los episodios de liberalización. Esto significa que la apertura comercial no solo redujo el nivel de las tasas arancelarias sino que también alteró la estructura de protección entre industrias: aquellas que tradicionalmente recibieron alta protección, experimentaron los mayores recortes, mientras que las industrias con bajos aranceles enfrentaron reducciones menores. Este recorte diferencial de tasas arancelarias entre industrias es una fuente de variabilidad que puede utilizarse para identificar el impacto de la política comercial sobre el empleo informal y sobre el diferencial de salarios entre trabajadores formales e informales.

Los aranceles sobre las importaciones son, entonces, la manifestación de la política comercial con mayores ventajas en la tarea de medición y en la determinación empírica de la relación de interés. Es por ello que en este trabajo se utilizarán datos sobre tasas arancelarias aplicadas en las distintas industrias del sector manufacturero durante el período 1980-2001. Estos datos provienen del trabajo de Galiani y Porto (2010). Su definición y construcción se describe de manera detallada en la sección siguiente. Adicionalmente, se utilizarán medidas de flujos comerciales para evaluar la robustez de los resultados principales.

\subsubsection{Definición de informalidad laboral}

La informalidad laboral es un término ambiguo desde el punto de vista teórico y difícil de hacer operativo empíricamente. En la literatura pueden encontrarse al menos dos definiciones de informalidad laboral que hacen referencia a distintos fenómenos del mercado de trabajo. Por un lado, la definición "productiva" se basa en el tipo de firma y de empleo, mientras que la definición "legalista" o de seguridad social hace referencia al cumplimiento de ciertas normas laborales (Gasparini y Tornarolli, 2009). 
Bajo la noción "productiva" y de acuerdo a la definición de la Organización Internacional del Trabajo (1991), las firmas informales son aquellas que poseen una baja dotación de capital, que utilizan tecnologías primitivas, emplean trabajo no calificado y, por lo tanto, tienen baja productividad. Teniendo en cuenta que la dotación de capital no es habitualmente reportada en las encuestas, que la definición de tecnología primitiva es difícil de precisar y la productividad no es directamente observable, resulta difícil determinar esta noción de informalidad laboral en la práctica. Dadas estas restricciones informativas, la manera en que normalmente se hace operativa esta definición es recurriendo a datos sobre el tipo de empleo, tipo de firma y calificación de los trabajadores.

Alternativamente, la definición de seguridad social califica como informales a aquellas firmas que no cumplen con las normativas vinculadas a contratos, impuestos y regulaciones laborales y sus empleados no poseen protección laboral o beneficios de la seguridad social vinculados al empleo. La dificultad de implementación en este caso tiene que ver con la posibilidad de comparación entre países. Por un lado, la protección laboral y seguridad social comprenden numerosas dimensiones que difieren entre países, dependiendo del diseño y funcionamiento de sus sistemas. ${ }^{1}$ Por el otro, las encuestas de hogares difieren en la cobertura dada a estos temas. Por ejemplo, algunas encuestas preguntan sobre la modalidad de trabajo mediante contrato mientras que otras no hacen referencia a este punto. Asimismo, el tipo de pregunta formulada para captar cierto tema puede ser muy diferente limitando las posibilidades de comparación (Gasparini y Tornarolli, 2009).

El derecho a percibir una jubilación a partir del momento de retiro es el beneficio de la seguridad social más frecuentemente preguntado en las encuestas de hogares de países de América Latina. Esto ha determinado que en la práctica se defina como un trabajador informal a aquel que no posee este derecho vinculado a su empleo.

Dadas las limitaciones para abordar empíricamente la noción "productiva" de informalidad y que solo se analizará el caso argentino, en este trabajo se adoptará la noción de seguridad social, definiendo a un trabajador como informal cuando no posea el derecho a percibir una jubilación al momento de su retiro.

Más allá de la definición teórica y tratamiento empírico del concepto de infor-

\footnotetext{
${ }^{1}$ Las dimensiones comprendidas por la protección laboral incluyen: contrato de trabajo, indemnización por despido, aviso anticipado de despido, derecho de sindicalización, seguro por accidente de trabajo, vacaciones pagas, límite de horas de trabajo. Los beneficios de la seguridad social incluyen jubilación, seguro de salud y otros seguros y beneficios (Gasparini y Tornarolli, 2009).
} 
malidad laboral, existe un aspecto controvertido de este fenómeno que tiene que ver con la habitual asociación a menores niveles de salarios y a condiciones laborales inferiores. Muchos estudios han encontrado que trabajadores con las mismas características observables ganan menos cuando son empleados informales. ${ }^{2}$ Sin embargo, esta relación negativa no puede interpretarse en un sentido causal y las comparaciones de bienestar derivadas de este tipo de resultados pueden conducir a conclusiones equivocadas. Un trabajador informal difiere de uno formal en otras dimensiones más allá del salario recibido. En un mercado sin distorsiones los trabajadores igualarían la utilidad derivada de cada empleo, es decir, el conjunto de beneficios, no solo los salarios (Maloney, 2003). Si el salario fuese el mismo entre dos empleos donde uno de ellos es formal y el otro informal, el trabajo informal podría ser considerado inferior porque no permite acceder a los beneficios de la seguridad social. Pero para algunos trabajadores podría ser más valioso dado que la informalidad usualmente está vinculada a una mayor flexibilidad y esa puede ser considerada una amenidad. Asimismo, un mayor salario en el empleo formal puede estar compensando a esos trabajadores por los impuestos pagados que sostienen la provisión de bienes y servicios públicos de la cual los trabajadores informales no pueden ser excluidos. Por todo esto, la informalidad no necesariamente es una opción inferior.

Vinculado a esto, aparece la doble perspectiva de la informalidad laboral. Por un lado, como exclusión de los beneficios estipulados por el Estado y, por el otro, como escape o elección del propio trabajador. Muchos trabajadores, mediante un análisis implícito de costo-beneficio sobre la decisión de cruzar el margen hacia la informalidad, pueden elegir no pertenecer a las instituciones formales privilegiando la flexibilidad y el mayor consumo presente (Perry et al., 2007). Para el caso de Argentina, sin embargo, esta doble perspectiva no parece adecuada para describir la condición de informalidad de los trabajadores. Existe evidencia que indica que la mayor parte de los trabajadores informales está en dicha situación porque tienen restricciones para acceder a un trabajo formal (Waisgrais y Sarabia, 2008). Estos trabajadores tienden a estar insatisfechos con sus empleos más allá de la categoría ocupacional a la que pertenezcan. De aquí se desprende que los trabajadores informales desearían ingresar a la formalidad pero encuentran limitaciones para hacerlo. El capítulo 5 aborda en mayor detalle este punto.

\footnotetext{
${ }^{2}$ Gasparini y Tornarolli (2009) para el caso de América Latina; Ulyssea (2010) para Brasil; Marcouiller et al. (1997) para Perú y El Salvador.
} 


\subsection{Fuentes de información}

\subsubsection{Datos sobre tasas arancelarias}

Siguiendo las conclusiones de la sección anterior, los aranceles sobre las importaciones aplicados en cada industria del sector manufacturero será la medida utilizada para captar los cambios en la política comercial y su impacto sobre la informalidad laboral y sobre el diferencial de salarios entre trabajadores formales e informales. Los datos sobre tasas arancelarias ad-valorem provienen del trabajo de Galiani y Porto (2010). Las mismas fueron construidas a partir de información de la Guía Práctica del Exportador e Importador, una publicación con datos sobre tasas arancelarias con el mayor nivel de desagregación de la Nomenclatura Arancelaria y Derechos de Importación (NADI) y del Sistema Armonizado, según el periodo considerado. ${ }^{3}$

Dado que a lo largo del periodo analizado existieron distintos arreglos institucionales (como la adopción del Mercosur durante los noventa) y se aplicaron diferentes medidas de política comercial, los autores construyen, utilizando el arancel vigente a la mitad de cada año, una medida hasta el año 1991 que comprende la tasa arancelaria más la tasa estadística, ${ }^{4}$ y desde el año 1992 la medida se compone del arancel extra-Mercosur, la tasa estadística, un derecho de importación mínimo específico ${ }^{5}$ y un factor de convergencia en el año $2001{ }^{6}$

Para que la información sobre tasas arancelarias sea compatible con la apertura industrial que posee la Encuesta Permanente de Hogares (EPH) de Argentina ${ }^{7}$ y que se basa en la clasificación ISIC (International Standard Industrial Classification), los autores agregan las tasas arancelarias hasta obtener una medida compatible con la clasificación ISIC a 3 dígitos. Para esto, siguen un proceso iterativo donde se computa el arancel mediano de las subcategorías comprendidas en cada categoría principal de los datos sobre aranceles, donde previamente se buscó la correspondencia entre

\footnotetext{
${ }^{3}$ La NADI tuvo vigencia hasta el año 1992 cuando fue reemplazada por la Nomenclatura del Comercio Exterior (NCE). En 1993 se adoptó el Sistema Armonizado de Designación y Codificación de Mercancías. Con posterioridad, los estados parte del Mercosur adoptaron una nomenclatura común basada en la nomenclatura internacional bajo la denominación de Nomenclatura Común del Mercosur (NCM).

${ }^{4}$ La tasa estadística es una carga ad-valorem adicional aplicada por el gobierno sobre ciertos bienes para financiar la recolección de datos estadísticos.

${ }^{5}$ El derecho de importación mínimo específico es una medida anti-dumping aplicada sobre ciertos bienes importados.

${ }^{6} \mathrm{El}$ factor de convergencia fue establecido por ley en junio del año 2001. Fue calculado como $f c=1-\frac{1+e}{2}$ donde $e$ es el precio en dólares de un euro.

${ }^{7}$ La Encuesta Permanente de Hogares de Argentina es llevada a cabo por el Instituto Nacional de Estadísticas y Censos y es la fuente de microdatos que se utilizará en este trabajo.
} 
cada una de ellas y las categorías de la clasificación ISIC. El Instituto Nacional de Estadísticas y Censos de Argentina (INDEC) empleó hasta el año 1991 la clasificación ISIC revisión 2 y desde entonces, la clasificación ISIC revisión 3. Esto resulta en dos series de aranceles sobre las importaciones dependiendo de la clasificación ISIC con la cual fueron compatibilizadas y es por esta razón que los autores finalmente construyen una serie final que abarca todo el periodo y que combina ambas clasificaciones industriales. Los aranceles son finalmente ajustados para tener en cuenta el proceso progresivo de ajuste aplicado para las importaciones procedentes de los países miembros del Mercosur de acuerdo a lo establecido en el Tratado de Asunción del año 1991.

Esta serie de aranceles sobre las importaciones proveniente de los datos de Galiani y Porto (2010) fue luego combinada con las bases correspondientes a la EPH para el periodo 1980-2001 obteniendo entonces información sobre protección comercial y microdatos para 24 industrias del sector manufacturero de Argentina. ${ }^{8}$

En el cuadro 2.2 se presentan, para cada uno de los años considerados, las estadísticas descriptivas de la medida de aranceles sobre las importaciones. La evolución temporal muestra que el arancel promedio cayó un 54\% entre los años 1980 y 2000 y $38 \%$ entre 1980 y 2001, año en que se produjo una recuperación en el nivel de aranceles. El gráfico 2.1 permite observar los cambios en la política comercial a partir de la distribución de la medida de aranceles para cada año. De la observación de las distribuciones es posible distinguir tres etapas en la política comercial de acuerdo a los niveles de aranceles aplicados. Los años 1980 y 1985, caracterizados por los niveles más alto de protección de todo el periodo analizado, con un arancel promedio cercano al 40\%, e industrias con un nivel de protección de hasta el 55\%. Entre 1986 y 1989 el arancel promedio fue 10 puntos porcentuales inferior y toda la distribución se desplazó hacia abajo. Con excepción del año 1989, el percentil 75 estuvo por debajo del percentil 25 del año 1980. Si bien existió un proceso continuo de reducción de tasas arancelarias, este fue un periodo caracterizado por el uso de barreras no arancelarias al comercio que comenzaron a ser eliminadas hacia el año $1988 .{ }^{9}$ Se destaca también la reversión de este proceso de reducción de aranceles hacia el año 1989, coincidiendo con la crisis hiperinflacionaria. A partir del año 1990 Argentina

\footnotetext{
${ }^{8}$ El cuadro 2.1 presenta la definición de cada una de las 24 industrias.

${ }^{9} \mathrm{Si}$ bien la construcción de una medida que capte la protección no arancelaria es difícil de obtener, los registros históricos indican que esta fue una etapa donde el uso de este tipo de medidas se reinstaló para luego ser eliminado a inicios de la década del noventa como requisito para iniciar las negociaciones del Mercosur (Galiani y Porto, 2010).
} 
implementó un amplio programa de liberalización comercial. La reducción unilateral de aranceles fue acompañada por la liberalización del comercio regional mediante el establecimiento del Mercado Común del Sur (Mercosur) entre Argentina, Brasil, Paraguay y Uruguay en el año 1991. A través de este acuerdo comercial se dispuso eliminar los impuestos a las importaciones entre los países miembros y se estableció un programa de reducciones progresivas para alcanzar este objetivo. También se acordó un arancel común para la importación de bienes provenientes de los países extra-región. De acuerdo a lo establecido por el Tratado de Asunción del año 1991 mediante el cual los Estados Parte deciden crear el Mercosur, el Mercado Común debería estar conformado al 31 de diciembre de $1994 .{ }^{10}$ En esta etapa el arancel promedio descendió otros 10 puntos porcentuales y también se verificó una menor variabilidad de tasas arancelarias entre industrias. Por último, en el año 2001 se produjo un aumento en el nivel de aranceles, posiblemente explicado por un intento de prevenir la crisis fiscal (Galiani y Porto, 2010).

El gráfico 2.2 muestra el cambio en el nivel de protección de cada industria del sector de manufacturas entre los años 1980 y 2000. En el panel izquierdo del gráfico se observa una reducción de aranceles para todas las industrias entre los años mencionados y un cambio en la estructura de protección. La apertura comercial no impactó de igual manera en todas ellas. Las industrias con un mayor nivel inicial de aranceles experimentaron los mayores recortes (fabricación de prendas de vestir, fabricación de productos de la refinación del petróleo y combustible nuclear, fabricación de vehículos automotores, remolques y semirremolques), mientras que las que recibían un menor nivel inicial de protección enfrentaron cambios menores (elaboración de productos alimenticios, elaboración de bebidas). Esto puede verse en el panel derecho del gráfico. Como se verá en el capítulo siguiente, este recorte diferencial de aranceles entre industrias será clave para identificar los efectos de interés.

\subsubsection{Datos sobre fuerza laboral}

Los microdatos sobre características de los trabajadores y sus hogares provienen de la Encuesta Permanente de Hogares, llevada adelante por el Instituto Nacional de Estadísticas y Censos desde el año 1974. Hasta el año 1991 la cobertura de la encuesta se limitó al aglomerado del Gran Buenos Aires, entre los años 1992 y 1997

\footnotetext{
${ }^{10} \mathrm{El}$ periodo de tiempo transcurrido entre el año 1991 y el 31 de diciembre de 1994 se considera una etapa de transición o adecuación durante la cual los Estados Parte debían ajustar sus aranceles de acuerdo a lo establecido en el Tratado de Asunción.
} 
se extendió a las 15 principales ciudades y desde entonces se ha encuestado a los 28 mayores aglomerados urbanos, extendiéndose luego a 31.

Dados los cambios en la cobertura geográfica de la encuesta a lo largo del tiempo, se trabajará sólo con el aglomerado del Gran Buenos Aires, pudiendo entonces extender el periodo de análisis a los años anteriores a 1992. Si bien esta decisión implica perder observaciones a partir de ese año, el aglomerado del Gran Buenos Aires representó, en promedio, el $72 \%$ de la población total encuestada en el periodo 1992-1997 y $53 \%$ en el periodo 1998-2001. Asimismo, este aglomerado ha registrado a lo largo de los años la mayor participación de la actividad industrial respecto a las restantes regiones encuestadas, promediando $20 \%$. La limitación de datos disponibles sobre características laborales de los individuos en las encuestas previas a 1980 determinó que el periodo a considerar sea el comprendido entre los años 1980 y 2001. Durante este periodo la encuesta fue llevada a cabo dos veces al año, en los meses de mayo y octubre, recibiendo el nombre de EPH-Puntual. El cuadro 2.3 presenta información sobre las bases utilizadas y su tamaño. ${ }^{11}$

En el cuadro 2.4 se muestra la caracterización de los trabajadores formales e informales del sector manufacturero de acuerdo a la información proveniente de las EPH y para los años seleccionados. Se consideran individuos de entre 15 y 65 años de edad, empleados en el sector de manufacturas y que son asalariados. Sobre este último punto, es importante aclarar que la EPH de Argentina solo pregunta acerca del derecho a recibir una jubilación al momento del retiro a los trabajadores que son asalariados, pero no realiza esta pregunta a los trabajadores que son auto-empleados. Una posible implicancia de esta característica de la encuesta es el impacto de la implementación del régimen de monotributo en el tamaño de la muestra. Si las firmas eligieran eludir el pago de las contribuciones a la seguridad social modificando la naturaleza de la relación laboral con sus trabajadores, ${ }^{12}$ esto significará una reducción en el tamaño de la muestra con la que se trabaja. Dado que este régimen impositivo se implementó en el año 1998 y la serie de datos en este trabajo se extiende hasta el año 2001, no se espera que esto afecte los resultados.

Los resultados indican que aquellos trabajadores informales de las industrias manufactureras han percibido un salario horario promedio (a precios del año 1999) persistentemente inferior al recibido por los trabajadores formales. Lo mismo ocurre

\footnotetext{
${ }^{11}$ La reducción en el tiempo del tamaño de las bases se explica por la pérdida de participación del sector de manufacturas en la población de ocupados.

${ }^{12}$ Los trabajadores pasan de ser asalariados a ser contratados bajo el régimen de monotributo.
} 
con las horas semanales de trabajo. En este caso se observa una ampliación de la brecha desde el año 1992, cuando alcanzó el mínimo de 1.27 horas semanales de trabajo, hasta el 2001 cuando los trabajadores formales trabajaron 8 horas semanales más respecto a los informales.

Los trabajadores informales también se caracterizan por contar con una mayor proporción de mujeres respecto a los empleados formales, por tener un menor promedio de edad y una menor proporción de jefes de hogar. El número de niños menores a 15 años tiende a ser superior en los hogares de individuos empleados en condiciones de informalidad, mientras que el ingreso por adulto equivalente, expresado a precios del año 1999, siempre ha sido inferior. Si se considera que el cónyuge del jefe de hogar es un trabajador secundario, se encuentra que, en concordancia con la hipótesis de Galiani y Weinschelbaum (2011), los trabajadores secundarios tienen mayor participación entre los empleados informales.

En cuanto a los niveles educativos, tanto el grupo de trabajadores formales como informales del sector de manufacturas, se caracterizan por tener una mayor proporción de individuos no calificados, aunque esta es superior entre los empleados informales. 


\subsection{Cuadros}

\section{Cuadro 2.1: Industrias del sector de manufacturas Clasificación según ISIC a 3 dígitos}

\begin{tabular}{ll}
\hline \hline Industria 1 & Elaboración de productos alimenticios \\
Industria 2 & Elaboración de bebidas \\
Industria 3 & Elaboración de productos de tabaco \\
Industria 4 & Fabricación de productos textiles \\
Industria 5 & Fabricación de prendas de vestir, excepto calzado \\
Industria 6 & Curtido y adobo de cueros; fabricación de maletas, bolsos de mano \\
& y artículos de talabartería y guarnicionería \\
Industria 7 & Fabricación de calzado \\
Industria 8 & Producción de madera y fabricación de productos de madera y corcho, \\
& excepto muebles; fabricación de artículos de paja y de materiales trenzables \\
Industria 9 & Fabricación de muebles \\
Industria 10 & Fabricación de papel y de productos de papel \\
Industria 11 & Editoriales e imprentas \\
Industria 12 & Fabricación de sustancias y productos químicos \\
Industria 13 & Fabricación de productos de la refinación del petróleo y combustible nuclear \\
Industria 14 & Fabricación de productos de caucho \\
Industria 15 & Fabricación de productos de plástico \\
Industria 16 & Fabricación de vidrio y productos de vidrio \\
Industria 17 & Fabricación de otros productos minerales no metálicos \\
Industria 18 & Fabricación de metales comunes \\
Industria 19 & Fabricación de productos elaborados de metal, excepto maquinaria y equipo \\
Industria 20 & Fabricación de maquinaria, excepto eléctrica \\
Industria 21 & Fabricación de maquinaria y aparatos eléctricos n.c.p. \\
Industria 22 & Fabricación de vehículos automotores, remolques y semirremolques \\
Industria 23 & Fabricación de instrumentos médicos, ópticos y de precisión \\
Industria 24 & Industrias manufactureras n.c.p. \\
\hline &
\end{tabular}

Fuente: Elaboración en base a Galiani y Porto (2010). 
Cuadro 2.2: Estadísticas descriptivas

Arancel mediano, industrias según ISIC a 3 dígitos

\begin{tabular}{cccc}
\hline \hline Año & Media & Mediana & $\begin{array}{c}\text { Desvío } \\
\text { estándar }\end{array}$ \\
\hline 1980 & 40.95 & 39.50 & 10.17 \\
1985 & 31.55 & 33.75 & 6.37 \\
1986 & 29.98 & 28.50 & 6.98 \\
1987 & 29.39 & 28.00 & 7.55 \\
1988 & 29.42 & 28.00 & 7.54 \\
1989 & 31.65 & 32.00 & 8.03 \\
1990 & 20.56 & 20.31 & 4.64 \\
1991 & 15.33 & 14.00 & 5.51 \\
1992 & 17.43 & 17.75 & 4.95 \\
1993 & 21.34 & 22.08 & 6.27 \\
1994 & 20.29 & 21.25 & 5.73 \\
1995 & 18.52 & 17.80 & 3.91 \\
1996 & 19.21 & 18.37 & 3.73 \\
1997 & 19.23 & 18.24 & 3.98 \\
1998 & 18.80 & 17.58 & 4.00 \\
1999 & 18.60 & 17.43 & 3.96 \\
2000 & 18.73 & 18.72 & 3.46 \\
2001 & 25.51 & 24.86 & 5.28 \\
\hline
\end{tabular}

Fuente: Elaboración en base a Galiani y Porto (2010). 
Cuadro 2.3: Encuestas y tamaño de la muestra

Individuos de entre 15 y 65 años, asalariados, empleados en el sector de manufacturas

\begin{tabular}{ccc}
\hline \hline Año & Onda mayo & Onda octubre \\
\hline 1980 & - & 1041 \\
1985 & - & 1048 \\
1986 & - & 1146 \\
1987 & 1215 & 1131 \\
1988 & 1215 & 1216 \\
1989 & 1228 & 1231 \\
1990 & 714 & 753 \\
1991 & 785 & 798 \\
1992 & 836 & 793 \\
1993 & 839 & 795 \\
1994 & 772 & 705 \\
1995 & 656 & 689 \\
1996 & 646 & 635 \\
1997 & 715 & 664 \\
1998 & 699 & 660 \\
1999 & 610 & 620 \\
2000 & 589 & 595 \\
2001 & 568 & 517 \\
\hline Total & 12087 & 15037 \\
\hline
\end{tabular}

Fuente: Elaboración propia en base a EPH. 


\subsection{Gráficos}

Gráfico 2.1

Distribución del arancel mediano

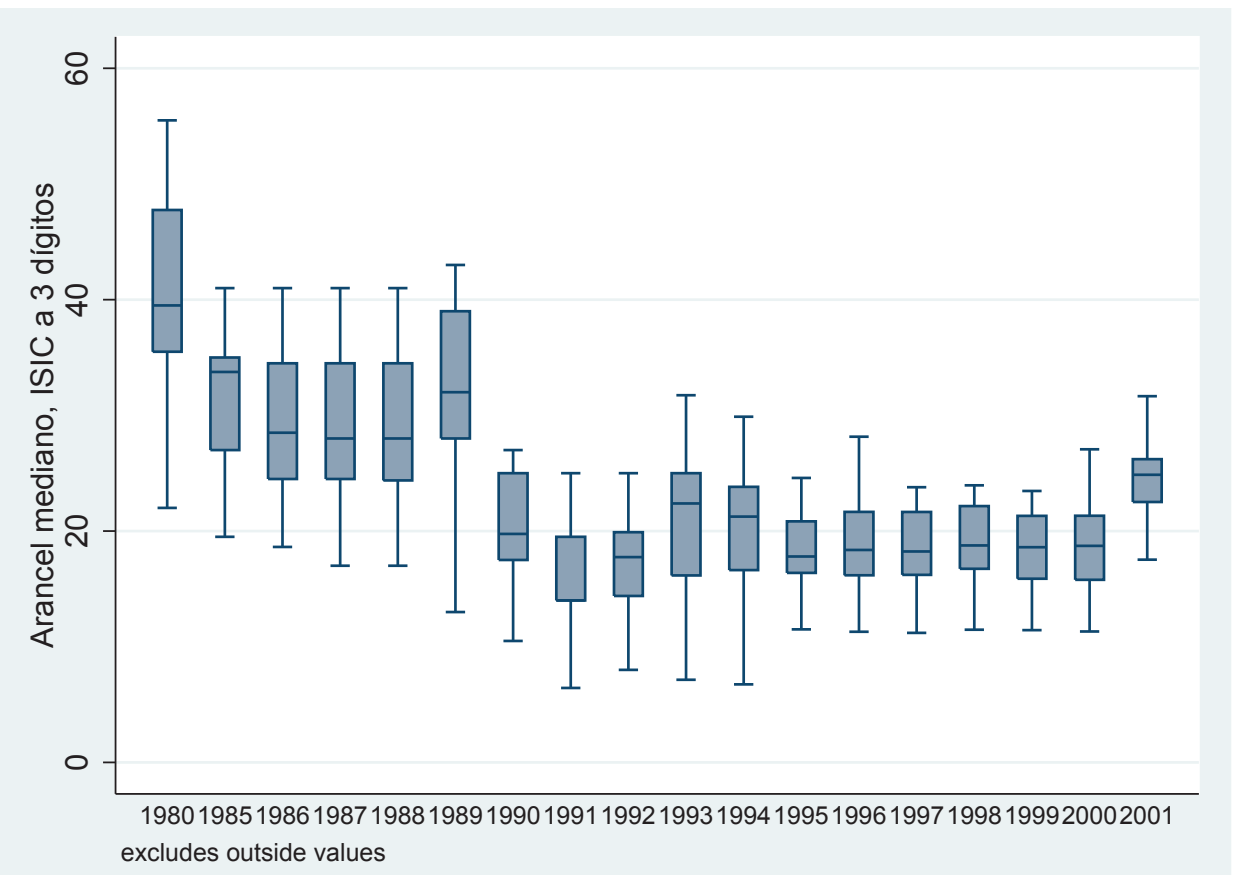

Fuente: Elaboración propia en base a Galiani y Porto (2010).

Nota: Los extremos de cada box corresponden a los percentiles 25 y 75 , respectivamente; la línea dentro de cada box representa el valor mediano de la distribución de tarifas; cada industria está ponderada por su nivel de empleo. 


\section{Cuadro 2.4: Caracterización de trabajadores en el sector de manufacturas}

Individuos asalariados de entre 15 y 65 años de edad según condición de informalidad

\begin{tabular}{|c|c|c|c|c|c|c|c|}
\hline & & 1980 & 1988 & 1992 & 1996 & 2000 & 2001 \\
\hline Salario horario & $\begin{array}{l}\text { Informal } \\
\text { Formal }\end{array}$ & $\begin{array}{c}2.670 \\
(0.147) \\
4.103 \\
(0.134)\end{array}$ & $\begin{array}{c}1.947 \\
(0.118) \\
3.560 \\
(0.130)\end{array}$ & $\begin{array}{c}2.780 \\
(0.185) \\
3.657 \\
(0.123)\end{array}$ & $\begin{array}{c}2.906 \\
(0.163) \\
4.179 \\
(0.221)\end{array}$ & $\begin{array}{c}2.728 \\
(0.218) \\
4.616 \\
(0.242)\end{array}$ & $\begin{array}{c}3.225 \\
(0.324) \\
4.546 \\
(0.225)\end{array}$ \\
\hline $\begin{array}{l}\text { Horas } \\
\text { semanales } \\
\text { de trabajo }\end{array}$ & $\begin{array}{l}\text { Informal } \\
\text { Formal }\end{array}$ & $\begin{array}{c}44.250 \\
(1.308) \\
47.764 \\
(0.460)\end{array}$ & $\begin{array}{c}44.492 \\
(0.900) \\
47.426 \\
(0.378)\end{array}$ & $\begin{array}{l}45.823 \\
(1.087) \\
47.089 \\
(0.469)\end{array}$ & $\begin{array}{l}42.208 \\
(1.322) \\
46.991 \\
(0.473)\end{array}$ & $\begin{array}{l}42.888 \\
(1.415) \\
48.267 \\
(0.533)\end{array}$ & $\begin{array}{l}39.385 \\
(1.500) \\
47.408 \\
(0.646)\end{array}$ \\
\hline Hombres ( \%) & $\begin{array}{l}\text { Informal } \\
\text { Formal }\end{array}$ & $\begin{array}{c}61.061 \\
(3.879) \\
76.896 \\
(1.420)\end{array}$ & $\begin{array}{c}57.729 \\
(2.797) \\
78.383 \\
(1.371)\end{array}$ & $\begin{array}{c}66.446 \\
(3.298) \\
77.015 \\
(1.738)\end{array}$ & $\begin{array}{c}61.444 \\
(3.383) \\
79.752 \\
(1.945)\end{array}$ & $\begin{array}{c}61.854 \\
(3.461) \\
78.087 \\
(2.079)\end{array}$ & $\begin{array}{l}62.438 \\
(3.682) \\
76.328 \\
(2.299)\end{array}$ \\
\hline Edad & $\begin{array}{l}\text { Informal } \\
\text { Formal }\end{array}$ & $\begin{array}{c}30.202 \\
(1.075) \\
35.477 \\
(0.408)\end{array}$ & $\begin{array}{l}30.601 \\
(0.748) \\
37.067 \\
(0.410)\end{array}$ & $\begin{array}{l}29.991 \\
(0.860) \\
37.033 \\
(0.516)\end{array}$ & $\begin{array}{l}31.699 \\
(0.872) \\
37.444 \\
(0.571)\end{array}$ & $\begin{array}{l}32.364 \\
(0.849) \\
37.073 \\
(0.566)\end{array}$ & $\begin{array}{l}32.571 \\
(0.872) \\
37.113 \\
(0.627)\end{array}$ \\
\hline No calificados (\%) & $\begin{array}{l}\text { Informal } \\
\text { Formal }\end{array}$ & $\begin{array}{c}80.870 \\
(3.129) \\
75.630 \\
(1.446)\end{array}$ & $\begin{array}{l}82.205 \\
(2.165) \\
70.629 \\
(1.517)\end{array}$ & $\begin{array}{c}80.538 \\
(2.765) \\
66.982 \\
(1.943)\end{array}$ & $\begin{array}{l}75.834 \\
(2.975) \\
63.667 \\
(2.328)\end{array}$ & $\begin{array}{l}71.909 \\
(3.202) \\
54.456 \\
(2.503)\end{array}$ & $\begin{array}{l}68.535 \\
(3.531) \\
48.824 \\
(2.703)\end{array}$ \\
\hline Semicalificados (\%) & $\begin{array}{l}\text { Informal } \\
\text { Formal }\end{array}$ & $\begin{array}{c}18.598 \\
(3.095) \\
20.003 \\
(1.348)\end{array}$ & $\begin{array}{l}14.406 \\
(1.988) \\
23.042 \\
(1.402)\end{array}$ & $\begin{array}{l}16.491 \\
(2.592) \\
25.510 \\
(1.801)\end{array}$ & $\begin{array}{l}21.223 \\
(2.842) \\
29.947 \\
(2.217)\end{array}$ & $\begin{array}{c}25.023 \\
(3.086) \\
31.880 \\
(2.342)\end{array}$ & $\begin{array}{l}26.850 \\
(3.369) \\
40.353 \\
(2.653)\end{array}$ \\
\hline Jefe de hogar $(\%)$ & $\begin{array}{l}\text { Informal } \\
\text { Formal }\end{array}$ & $\begin{array}{c}31.567 \\
(3.698) \\
58.245 \\
(1.661)\end{array}$ & $\begin{array}{c}30.610 \\
(2.609) \\
63.113 \\
(1.607)\end{array}$ & $\begin{array}{l}38.739 \\
(3.402) \\
59.287 \\
(2.030)\end{array}$ & $\begin{array}{l}35.758 \\
(3.331) \\
61.685 \\
(2.353)\end{array}$ & $\begin{array}{c}37.368 \\
(3.447) \\
61.654 \\
(2.443)\end{array}$ & $\begin{array}{l}41.029 \\
(3.740) \\
58.789 \\
(2.662)\end{array}$ \\
\hline Cónyuge (\%) & $\begin{array}{l}\text { Informal } \\
\text { Formal }\end{array}$ & $\begin{array}{c}15.26 \\
(0.029) \\
6.23 \\
(0.008)\end{array}$ & $\begin{array}{c}16.05 \\
(0.021) \\
8.24 \\
(0.009)\end{array}$ & $\begin{array}{c}13.54 \\
(0.024) \\
10.45 \\
(0.013)\end{array}$ & $\begin{array}{c}16.25 \\
(0.023) \\
8.87 \\
(0.014)\end{array}$ & $\begin{array}{c}16.99 \\
(0.027) \\
11.56 \\
(0.016)\end{array}$ & $\begin{array}{c}16.53 \\
(0.028) \\
13.13 \\
(0.018)\end{array}$ \\
\hline $\begin{array}{l}\text { Número } \\
\text { de niños } \\
\text { en el hogar }\end{array}$ & $\begin{array}{l}\text { Informal } \\
\text { Formal }\end{array}$ & $\begin{array}{c}1.124 \\
(0.100) \\
1.155 \\
(0.045)\end{array}$ & $\begin{array}{c}1.325 \\
(0.090) \\
1.110 \\
(0.043)\end{array}$ & $\begin{array}{c}1.356 \\
(0.110) \\
1.204 \\
(0.059)\end{array}$ & $\begin{array}{c}1.400 \\
(0.110) \\
1.038 \\
(0.060)\end{array}$ & $\begin{array}{c}1.465 \\
(0.121) \\
0.966 \\
(0.060) \\
\end{array}$ & $\begin{array}{c}1.544 \\
(0.130) \\
0.917 \\
(0.062)\end{array}$ \\
\hline $\begin{array}{l}\text { Ingreso adulto } \\
\text { equivalente } \\
\text { del hogar }\end{array}$ & $\begin{array}{l}\text { Informal } \\
\text { Formal }\end{array}$ & $\begin{array}{c}314.280 \\
(15.936) \\
381.299 \\
(9.647)\end{array}$ & $\begin{array}{l}286.802 \\
(12.125) \\
410.216 \\
(17.376)\end{array}$ & $\begin{array}{l}363.478 \\
(19.415) \\
425.345 \\
(14.519)\end{array}$ & $\begin{array}{l}302.282 \\
(15.826) \\
443.428 \\
(27.189)\end{array}$ & $\begin{array}{l}311.161 \\
(24.256) \\
531.622 \\
(36.278)\end{array}$ & $\begin{array}{l}305.162 \\
(27.349) \\
481.615 \\
(27.469)\end{array}$ \\
\hline
\end{tabular}

Fuente: Elaboración propia en base a EPH.

Notas: Error estándar entre paréntesis. Salario horario e ingreso del hogar en pesos a precios del año 1999. Son individuos calificados aquellos con nivel educativo superior completo, semicalificados los que poseen superior incompleto o secundario completo y no calificados aquellos con secundario incompleto o inferior. 
Gráfico 2.2

Cambio en el nivel de protección de cada industria
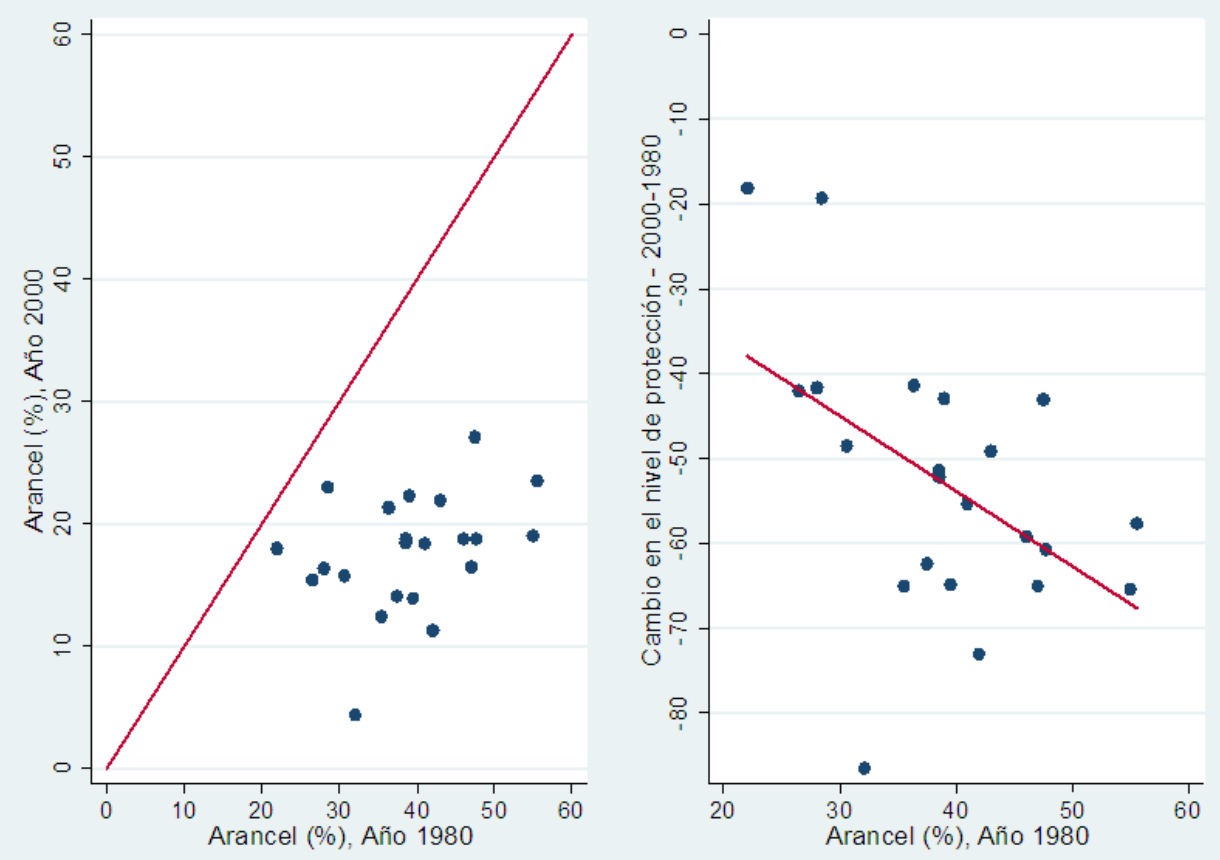

Fuente: Elaboración propia en base a EPH y Galiani y Porto (2010). 


\section{Capítulo 3}

\section{Informalidad laboral como mecanismo de ajuste de las firmas}

El punto de partida de este capítulo es la revisión de la literatura empírica que analiza el vínculo entre la liberalización del comercio y la informalidad laboral en países en desarrollo. Los resultados no son concluyentes respecto a cuál es la relación existente entre ambos fenómenos. Ante estos resultados en conflicto la distinción que se realiza en este trabajo entre mecanismos que operan en el corto y largo plazo cobra relevancia.

Una de las contribuciones de este capítulo es la presentación de un modelo teórico sencillo que muestra el ajuste en la demanda de trabajo de las firmas de una industria del sector de manufacturas que compite con las importaciones ante un cambio en la política comercial. El objetivo es mostrar formalmente cuáles son los mecanismos que operan detrás de la relación entre la informalidad laboral y los episodios de liberalización del comercio, modelados como una reducción en los aranceles a las importaciones. Para esto se incorporan elementos de la literatura de evasión de impuestos que permiten que exista tanto un margen extensivo de evasión (las firmas deciden si registrar trabajadores o no) como un margen intensivo (las firmas deciden que proporción de su fuerza laboral no está registrada). Otra característica importante del modelo es que se ajusta al hecho estilizado que muestra una correlación negativa entre la informalidad laboral y el tamaño de las firmas. El modelo predice que en el corto plazo, cuando los factores son inmóviles, las firmas reducen el tamaño de su fuerza laboral en respuesta al menor nivel de protección, y entre aquellos trabajadores que permanecen empleados la proporción de informales aumenta, 
mostrando que las firmas pueden absorber parte del shock negativo aumentando los niveles de evasión para atenuar la pérdida de ingresos. En el equilibrio de largo plazo se produce una nueva reasignación de trabajadores entre empleos formales e informales una vez que los factores pueden reasignarse entre sectores y los salarios ajustan. En el equilibrio final la tasa de informalidad del sector de manufacturas cae respecto al ajuste de corto plazo y el sector de bienes no transables puede resultar afectado a través de efectos de equilibrio general.

En la sección empírica del capítulo se indaga sobre la relación entre los episodios de liberalización del comercio, captados a través de cambios en los aranceles a las importaciones, y la informalidad laboral en las industrias del sector de manufacturas durante el periodo 1980-2001. Este análisis separa entre el efecto que puede identificarse a partir de la variabilidad de corte transversal de los datos a lo largo del tiempo (efecto de corto plazo) de aquel que se obtiene utilizando la variabilidad temporal de la información (efecto de largo plazo). Esta es una contribución importante de la investigación que, a diferencia de estudios previos, brinda evidencia de distinto tipo con el objetivo de alcanzar una mejor comprensión del proceso de ajuste del mercado de trabajo en respuesta a cambios en la política comercial. ${ }^{1}$

Los resultados de este capítulo muestran que la tasa de informalidad aumentó en las industrias del sector de manufacturas en el corto plazo como resultado de la reducción en los aranceles a las importaciones, mostrando que las firmas utilizaron un mecanismo de ajuste adicional a los propuestos por los modelos de la TCI. Esto significa que el tipo de relación laboral entre las firmas y los trabajadores se modificó, con firmas que recortaron el pago de las contribuciones a la seguridad social para parte de sus empleados cuya alternativa era el desempleo, o que despidieron trabajadores para incorporar a otros de modo informal. Este efecto identificado a nivel de industria se diluye para la tendencia. Luego de controlar por la estructura sectorial de protección, los resultados muestran que la informalidad en el sector de manufacturas se movió junto con los aranceles a lo largo del tiempo, mientras que en el sector de bienes no transables el efecto fue el opuesto.

El capítulo se estructura de la siguiente manera. En la sección 3.1 se revisan los trabajos más destacados y recientes que pueden encontrarse en la literatura que analiza el impacto de las reformas comerciales sobre la informalidad laboral.

\footnotetext{
${ }^{1} \mathrm{El}$ trabajo de Bosch et al. (2012) estima un efecto de largo plazo aunque no discute los mecanismos de ajuste en este caso. La sección siguiente provee detalles acerca de la estimación en este trabajo.
} 
La sección 3.2 desarrolla un modelo teórico sencillo con el objetivo de formalizar la relación de interés y presentar los mecanismos a través de los cuales opera la relación entre los fenómenos analizados. La sección 3.3 expone la estrategia empírica que será implementada en secciones siguientes. Los resultados obtenidos se presentan en las secciones 3.4 y 3.5, mientras que la sección 3.6 concluye con los comentarios finales.

\subsection{Revisión de literatura}

El ajuste de los mercados de trabajo en respuesta a cambios en la política comercial ha sido ampliamente documentado en países desarrollados. En general, los episodios de apertura comercial han tenido escaso efecto sobre los salarios en estos países y un importante impacto sobre la reasignación de empleo entre sectores productivos (Grossman, 1987; Freeman y Katz, 1991; Gaston y Trefler, 1993).

Para los países en desarrollo la evidencia no es concluyente y aun quedan aspectos sin resolver respecto a cómo los mercados laborales de estos países ajustan ante reformas comerciales. Los estudios que analizan estas experiencia han encontrado efectos pequeños sobre el nivel de empleo. Por otro lado, los trabajos que analizan la relación empírica entre liberalización comercial e informalidad laboral son escasos y se limitan a la experiencia de ciertos países. Gran parte de la evidencia disponible en la literatura se refiere a los casos de Brasil, México, Colombia, Marruecos y recientemente Argentina, países donde existen fuentes de información suficientes para realizar este tipo de estudio.

El primer trabajo dentro de esta literatura es el de Currie y Harrison (1997) quienes analizan el impacto de las reformas comerciales sobre el empleo en las firmas manufactureras de Marruecos durante la década del ochenta. Este estudio no analiza el impacto directo de la apertura comercial sobre la informalidad pero ofrece algunas ideas acerca del rol de las políticas de protección sobre la composición del empleo. A partir de datos provenientes de firmas manufactureras con más de diez empleados sus resultados muestran que el empleo en la firma promedio no resultó afectado por la reducción de aranceles y la eliminación de cuotas a las importaciones. El efecto nulo en promedio se explica por una caída en el empleo de las firmas exportadoras y más afectadas por las reformas y un aumento en las firmas para-estatales que se expandieron contratando trabajadores de manera temporaria.

Goldberg y Pavcnik (2003) utilizan información proveniente de encuestas de 
hogares de Brasil y Colombia para analizar la relación existente entre los fenómenos de liberalización comercial e informalidad laboral en estos países durante las décadas del ochenta y noventa. Sus resultados no brindan evidencia de que las reformas comerciales hayan contribuido a la expansión de la informalidad. En el caso de Brasil no encuentran ningún tipo de relación entre estos dos fenómenos, mientras que para Colombia los resultados indican que las reducciones arancelarias están asociadas con un aumento en el empleo informal, pero solo en el periodo previo a las reformas laborales y la magnitud de este efecto es pequeña. Las autoras desarrollan un modelo dinámico de salarios de eficiencia donde la apertura comercial genera un aumento en el costo marginal de contratar trabajadores formales determinando una reducción en el tamaño óptimo de la planta formal de empleados. La magnitud de este efecto depende inversamente de la probabilidad de detectar actividades de "shirking" y esa probabilidad es inferior en presencia de normas laborales rígidas. Como resultado, el impacto de la apertura comercial sobre la informalidad será más fuerte antes de una reforma laboral que flexibilice las reglas de contratación y despido. Este resultado sugiere que las instituciones laborales tienen un rol importante en cómo las reformas comerciales afectan el empleo informal. En particular, cuando las firmas operan en mercados laborales rígidos es más probable que reaccionen mediante reducciones en el empleo formal ante la mayor competencia internacional.

Alemán-Castilla (2006) utiliza la experiencia del North American Free Trade Agreement (NAFTA) para analizar la relación entre informalidad laboral y apertura comercial en México para el periodo 1989-2002. Mediante un modelo dinámico de industrias con heterogeneidad de firmas, el autor concluye que la eliminación de los aranceles a las importaciones puede reducir la incidencia de la informalidad al ser más rentable para algunas firmas ingresar a la formalidad abandonando las prácticas informales, forzando a las firmas menos productivas a dejar la industria e induciendo a las firmas formales más productivas a participar del comercio. Las predicciones de este modelo son testeadas a partir de información sobre tasas arancelarias mexicanas y estadounidenses y datos provenientes de la Encuesta Nacional de Empleo Urbano. El autor encuentra que la reducción de aranceles mexicanos se asocia significativamente con menores niveles de informalidad laboral en el sector transable de la economía.

Ambos estudios implementan una estrategia de estimación en dos etapas. En primer lugar, estiman un modelo lineal de la probabilidad de empleo informal para 
cada año controlando por características de los trabajadores y variables indicadoras de la afiliación industrial de cada uno de ellos. Los coeficientes asociados a estas variables reciben el nombre de industry informality differentials y captan toda aquella parte de la variación en el empleo informal que no puede ser explicada por las características personales de los trabajadores pero sí por la industria a la que pertenecen. Los industry informality differentialas son luego agrupados para todos los años y regresados en las variables de política comercial de cada industria mediante Mínimos Cuadrados Ponderados, corrigiendo los errores estándar por heterocedasticidad y correlación serial a nivel de industria. La justificación para el uso de esta metodología es la imposibilidad de realizar estimaciones en primeras diferencias con datos de corte transversal agrupados.

A partir de un panel de datos de firmas y trabajadores, Menezes-Filho y Muendler (2011) analizan la transición de trabajadores formales luego de la mayor reforma comercial implementada en Brasil en la década del noventa. Para esto utilizan modelos logit-multinomial y logit-condicional. El análisis de transición entre sectores de empleo indica que la reducción del arancel a las importaciones aplicado sobre el producto final aumenta las chances de reasignación a otra firma del mismo sector, a otro sector y al desempleo. La reducción del arancel aplicados sobre los insumos muestra el resultado opuesto generando un efecto neto que indica que la mayor parte de la reasignación ocurre al interior de las industrias. El análisis de transición entre categorías laborales muestra que los cambios en los aranceles no tuvieron ningún efecto sobre las transiciones desde la formalidad hacia la informalidad, mientras que aumentaron las chances de desempleo o salida de la fuerza laboral.

Para este mismo país y a partir de una estrategia empírica diferente, Bosch et al. (2012) estudian los flujos brutos de trabajadores a nivel de industria (flujos de entrada y salida de la informalidad) para explicar el aumento en la tasa de informalidad en los mercados laborales metropolitanos de Brasil entre 1983 y 2002. Este periodo abarca dos ciclos económicos, diversos planes de estabilización macroeconómica, la apertura comercial y varios cambios en la legislación laboral de este país. Proponen tres estrategias de estimación alternativas: (i) modelo estático estimado por MCO, (ii) modelo que se abstrae de la dimensión temporal de los datos para corregir por la no independencia de los datos a ambos lados de la discontinuidad que se produce en 1988 por la reforma constitucional, (iii) sistema de ecuaciones dinámico que incluye la variable dependiente rezagada como control y es estimado por GMM. Los autores 
distinguen entre un efecto de corto y uno de largo plazo a partir de la inclusión de la variable dependiente rezagada como control adicional. El efecto estimado en el modelo que controla por dicha variable es interpretado como un efecto de corto plazo (la transición hacia y desde la informalidad es afectada por el valor del periodo anterior cuando el mercado aun no ajustó) mientras que el efecto estimado en el modelo que no controla por la variable dependiente rezagada se interpreta como el efecto de largo plazo. Sus resultados indican que la liberalización del comercio tuvo un impacto pequeño sobre el aumento en la tasa de informalidad de Brasil, tanto en el corto como en el largo plazo. En cambio, la reforma constitucional que introdujo cambios en regulaciones relacionadas a costos de despido, horas extras y poder de los sindicatos tuvo mayor capacidad para explicar dicho aumento. En particular, los mayores costos de despido no tuvieron ningún impacto sobre el flujo de salidas de la informalidad pero afectaron positivamente el flujo de entrada a la informalidad, resultado consistente con la caída en la contratación de trabajadores formales.

Paz (2013) presenta un modelo para una economía pequeña y abierta donde la política comercial afecta el cumplimiento de las obligaciones tributarias que definen la condición de formalidad o informalidad de los trabajadores. Las predicciones muestran un efecto ambiguo de la reducción del arancel nacional sobre la tasa de informalidad, mientras que la reducción de aranceles por parte de los socios comerciales la reduce. El modelo también predice que la caída del arancel nacional reducirá el salario formal. Estas predicciones son evaluadas para Brasil utilizando datos del periodo 1989-2001. Las estimaciones por MCO y variables instrumentales muestran un aumento en la tasa de informalidad laboral como respuesta a la reducción de aranceles a las importaciones, aunque los efectos encontrados son débiles estadísticamente.

Fiess y Fugazza (2008) se encuentran entre los pocos estudios que analizan la relación empírica entre apertura comercial e informalidad laboral para un conjunto de países. Utilizando fuentes de datos alternativas, ${ }^{2}$ encuentran que las correlaciones

\footnotetext{
${ }^{2}$ Los autores utilizan, en primer lugar, datos sobre empleo informal provenientes de la OIT para construir un panel no balanceado para 32 países durante el periodo 1990-2004. En segundo lugar, recurren a las estimaciones de empleo informal presentadas por Schneider en el año 2007 que surgen de la combinación del Currency Demand Approach y el método DYMIMIC de Giles, y obtienen una serie de tiempo para 110 países durante el periodo 2000-2004. Por último, a partir del enfoque macroeconómico de Kaufmann y Kaliberda que atribuye toda diferencia entre el crecimiento del consumo de electricidad y del PBI a cambios en el tamaño del sector informal, construyen un panel balanceado para 66 países durante el periodo 1990-2004 con datos provenientes del World Development Indicators y el FMI.
} 
no condicionadas entre países respaldan la visión de que la liberalización comercial reduce la informalidad laboral, mientras que los resultados alcanzados a partir de datos de un panel de países indican lo contrario.

Como antecedente para la economía argentina se encuentra el trabajo de Acosta y Montes-Rojas (2010). Este estudio analiza el impacto de la liberalización del comercio a partir de datos de industrias del sector de manufacturas para el periodo 1992-2003 y de distintas medidas de apertura comercial como aranceles sobre las importaciones y el valor de las importaciones y exportaciones. Los autores aplican la metodología de estimación en dos etapas mencionada previamente y encuentran, en primer lugar, que la informalidad laboral aumentó como consecuencia de la reducción de aranceles a las importaciones. Las variables de importaciones y exportaciones muestran signos opuestos indicando que la situación de la industria en los mercados internacionales (importadora o exportadora) es relevante para explicar su tasa de informalidad. En particular, las industrias con mayores exportaciones tendrían menores tasas de informalidad. En segundo lugar, aquellas industrias con mayor nivel de inversión lograron neutralizar e incluso revertir el efecto positivo de la liberalización del comercio sobre la informalidad laboral. Los autores interpretan este resultado como un efecto de equilibrio general.

El presente capítulo se diferencia del trabajo de Acosta y Montes-Rojas (2010) en tres puntos importantes. Primero, analiza un periodo más extenso de tiempo (1980-2001) que abarca más de un episodio de quiebre en la evolución de la política comercial. Esto implica contar con mayor variabilidad en la variable de aranceles, mientras que en el periodo 1992-2003 se mantuvo estable alrededor del valor establecido en el Mercosur. Segundo, separa entre un efecto de corto plazo y un efecto de largo plazo y entre los mecanismos que operan en cada caso. En tercer lugar, estima el efecto de la apertura del comercio sobre la informalidad laboral en el sector no transable de la economía, afectado mediante efectos de equilibrio general.

\subsection{Modelo teórico}

En esta sección se introduce un modelo teórico sencillo para describir la relación entre la informalidad laboral y la liberalización del comercio. El objetivo es estudiar cómo las firmas de una industria del sector de manufacturas que compite con las importaciones ajustan la composición de su fuerza laboral al enfrentar un cambio en el nivel de protección arancelaria. Lógicamente, las industrias del sector de ma- 
nufacturas también están compuestas por firmas exportadoras. Este modelo intenta describir el proceso de ajuste de las firmas que se ven directamente afectadas por el cambio en la política comercial (las firmas que compiten con los bienes importados), mientras que el análisis empírico de este capítulo estará captando el efecto neto de la liberalización del comercio sobre la informalidad laboral en industrias formadas por firmas que producen para el mercado doméstico compitiendo con las importaciones y firmas que exportan.

A diferencia de otros estudios, en este modelo no se impone ex-ante una segmentación de las firmas por sector, con firmas totalmente formales o totalmente informales. En este caso se propone un escenario más parsimonioso y realista donde los trabajadores son homogéneos y su condición de informalidad depende de la decisión (óptima) de la firma de pagar o evadir las contribuciones a la seguridad social de sus trabajadores lo cual es función de los costos asociados a dicha decisión. Como consecuencia, las firmas pueden emplear simultáneamente a trabajadores registrados y no registrados. Se asume que los trabajadores son homogéneos para un mismo nivel de calificación. Aquellos que son formales poseen los beneficios de la seguridad social (y la firma paga las contribuciones e impuestos respectivos), mientras que las firmas evaden el pago de las contribuciones y cargas sociales en el caso de los trabajadores informales quienes no reciben esos beneficios.

Por definición, los trabajadores formales son más costosos. Sin embargo, la informalidad tiene un costo asociado que es el de incrementar la probabilidad de enfrentar auditorías y pagar multas. De aquí surge que puede ser óptimo para las firmas combinar trabajadores formales e informales en su fuerza laboral. En el modelo de Goldberg y Pavcnik (2003) las firmas se comportan de manera similar pero contratan trabajadores de dos grupos bien diferenciados -el grupo de trabajadores formales y el grupo de trabajadores informales-. En el modelo desarrollado por Alemán-Castilla (2006), las firmas no contratan simultáneamente trabajo formal e informal. Esta misma característica aparece en Paz (2013) donde existen dos tipos de contratos posibles (formal e informal), las firmas eligen óptimamente y esa decisión depende de la posición respecto al comercio internacional (las firmas exportadoras contratan trabajadores formalmente y las que compiten con las importaciones contratan trabajadores formal o informalmente) y del salario que pagan (el modelo incorpora una estructura de salarios de eficiencia). En el modelo desarrollado por Becker (2013) las firmas eligen operar en el sector formal o informal en función de 
los beneficios esperados en cada una de estas opciones. Las firmas más productivas, grandes y que pagan mayores salarios son formales y las firmas menos productivas, pequeñas y que pagan salarios menores son informales.

Intuitivamente, una mayor competencia internacional como consecuencia de una reducción en los aranceles a las importaciones implica una pérdida de beneficios para las firmas. En el corto plazo, las firmas reducen el nivel de producción y la demanda de trabajo, y también pueden sustituir trabajadores formales por trabajadores informales, ${ }^{3}$ aumentando la evasión de impuestos para absorber parte del shock negativo. En el largo plazo, cuando el trabajo puede moverse entre sectores y los salarios ajustan, una nueva reasignación de trabajadores entre la formalidad y la informalidad puede ocurrir, afectando también la tasa de informalidad del sector de bienes no transables a través de efectos de equilibrio general.

Las firmas de esta industria que compite con las importaciones producen un bien transable homogéneo $y$ enfrentando un precio internacional $p^{*}$ y una tasa arancelaria $t$. La función de producción combina un parámetro de tecnología a con el factor trabajo $L$ en una función de producción Cobb-Douglas

$y(a, L)=a^{\beta} L^{(1-\beta)}=a^{\beta}\left(l_{i}+l_{f}\right)^{(1-\beta)}$,

donde $l_{i}$ y $l_{f}$ son el número de trabajadores informales y formales, respectivamente. Existe un continuo de firmas que difieren en su nivel de productividad $a \cdot{ }^{4}$ Las firmas obtienen su parámetro de productividad $a$ de una distribución $g(a)$ con soporte positivo en en $(0, \infty)$ función de distribución acumulada $G(a)$.

Para un mismo nivel de calificación el trabajo es homogéneo y las firmas pueden elegir pagar las contribuciones a la seguridad social o no hacerlo. Si las firmas realizan el pago de las contribuciones, los trabajadores serán 'formales' $\left(l_{f}\right)$. Si las firmas evaden este pago los trabajadores serán 'informales' $\left(l_{i}\right)$ y las firmas enfrentarán una probabilidad de ser detectadas y multadas. La probabilidad de detección depende del tamaño de la firma y de la composición de fuerza laboral (formal-informal). La probabilidad aumenta con el tamaño de la firma y, dado un tamaño, cae con la proporción de trabajadores formales respecto a los informales. Dado el tamaño de la

\footnotetext{
${ }^{3}$ A efectos de simplificar la presentación se hace referencia a la sustitución de trabajadores formales por informales. Estrictamente, en el contexto de trabajadores homogéneos, las firmas reducen el número de empleos que poseen los beneficios de la seguridad social y aumentan el número de empleos en los cuales evaden impuestos.

${ }^{4} \mathrm{El}$ parámetro $a$ también puede ser interpretado como el stock de 'habilidad empresarial' de la firma. Ver Galiani y Weinschelbaum (2011).
} 
firma, es más difícil "engañar" al fisco cuanto mayor es la participación del empleo informal en su fuera laboral (Kleven et al., 2009). Por simplicidad, se asume que cuando el tamaño de la firma supera cierto umbral $\bar{L}$, la detección es segura. El valor $\bar{L}$ refleja la tecnología de detección utilizada por la autoridad tributaria. Esto se modela de la siguiente manera: ${ }^{5}$

$q\left(l_{i}, l_{f}\right)= \begin{cases}q_{1}\left(l_{i}, l_{f}\right)+q_{2}\left(l_{i}, l_{f}\right) & \text { si } L<\bar{L} \\ 1 & \text { si } L \geqslant \bar{L}\end{cases}$

con

$\frac{\partial q_{1}}{\partial l_{i}}=\frac{\partial q_{1}}{\partial l_{f}}>0$

$\frac{\partial q_{2}}{\partial l_{i}}>0, \frac{\partial q_{2}}{\partial l_{f}}<0$

El componente $q_{1}\left(l_{i}, l_{f}\right)$ capta el efecto tamaño de la firma y $q_{2}\left(l_{i}, l_{f}\right)$ captura el efecto composición de la fuerza laboral. ${ }^{6}$ Una unidad adicional de $l_{i}$ genera el mismo incremento en la probabilidad de detección mediante el efecto tamaño de la firma que una unidad adicional de $l_{f}$. Pero el impacto mediante el efecto composición posee el signo opuesto y la reducción en la probabilidad de detección por una unidad adicional de $l_{f}$ no necesariamente compensa el incremento por la incorporación de una unidad adicional de $l_{i}$. Se supondrá que el efecto tamaño de la firma es mayor al efecto composición para el trabajo formal o, lo que es lo mismo, la probabilidad de detección es estrictamente creciente en $l_{i}$ y $l_{f}$ :

$$
\frac{\partial q_{1}}{\partial l_{f}}>-\frac{\partial q_{2}}{\partial l_{f}}
$$

Cuando una firma es detectada evadiendo, enfrenta una penalidad monetaria $m$ sobre cada trabajador informal.

Desde el punto de vista de la producción, los trabajadores formales e informales son sustitutos perfectos, ${ }^{7}$ pero el costo de contratar uno u otro no es el mismo para la firma. El salario de los trabajadores formales es $w_{f}$ y el costo de la seguridad social es una fracción $s$ del salario, entonces el costo de contratar un trabajador formal es $w_{f}(1+s) .{ }^{8}$ El salario de los trabajadores informales es $w_{i}$ y la firma paga una

\footnotetext{
${ }^{5}$ La relación entre la probabilidad de detección, el tamaño de la firma y la composición del empleo es modelada tomando algunos elementos de Levy (2008).

${ }^{6}$ Tanto $q_{1}\left(l_{i}, l_{f}\right)$ como $q_{2}\left(l_{i}, l_{f}\right)$ dependen linealmente de $l_{i}$ y $l_{f}$

${ }^{7}$ Con esto se intenta capturar la idea de que el mismo trabajador puede ser contratado de manera formal o informal.

${ }^{8}$ La fracción $s$ puede incluir otro tipo de costos laborales como el pago de indemnizaciones.
} 
multa $m$ con probabilidad $q\left(l_{i}, l_{f}\right)$ sobre cada uno de ellos. El costo de contratar un trabajador informal es entonces $w_{i}+q\left(l_{i}, l_{f}\right) m$. Las firmas contratan trabajadores informales cuando la ganancia de evadir las contribuciones a la seguridad social excede los costos. La ganancia está dada por la diferencia de costo laboral entre ambos tipos de trabajadores $\left(w_{f}(1+s)>w_{i}+q\left(l_{i}, l_{f}\right) m\right)$, mientras que el costo es la multa que la firma paga sobre cada trabajador informal. ${ }^{9}$ Para cada tamaño posible de una firma existe una combinación óptima $\left(l_{i}, l_{f}\right)$. Esa combinación óptima privilegia la incorporación de unidades de $l_{f}$ a mayor tamaño de la fuerza laboral. Esto se explica por los costos marginales crecientes, ya que la incorporación de más trabajadores aumenta la probabilidad de detección. El trabajo formal permitirá reducir $q\left(l_{i}, l_{f}\right)$ a través del efecto composición captado por $q_{2}\left(l_{i}, l_{f}\right)$, pero la firma continuará contratando $l_{i}$ porque el costo esperado de este tipo de empleo es inferior al costo del empleo formal.

Una firma contratará solo trabajadores formales cuando su tamaño supera el umbral $\bar{L}$ y la probabilidad de detección iguala la unidad. Este es un equilibrio solo si el tamaño de la multa es lo suficientemente alto, dada la diferencia salarial entre trabajadores formales e informales. Se asume que ese es el caso. ${ }^{10}$ La maximización de beneficios implica que estas firmas contratan trabajo formal hasta igualar el valor del producto marginal del trabajo a su costo marginal (salario más contribuciones):

$l_{f}^{*}=\left(\frac{p(1+t) a^{\beta}(1-\beta)}{w_{f}(1+s)}\right)^{\frac{1}{\beta}}$.

Para las firmas debajo del umbral $\bar{L}$, la combinación óptima $\left(l_{i}, l_{f}\right)$ maximiza los beneficios:

$$
\max _{\left(l_{i}, l_{f}\right)} \pi=p(1+t) a^{\beta}\left(l_{i}+l_{f}\right)^{1-\beta}-w_{f}(1+s) l_{f}-\left[w_{i}+q\left(l_{i}, l_{f}\right) m\right] l_{i} .
$$

Las condiciones de primer orden son:

$p(1+t) a^{\beta}(1-\beta)\left(l_{i}+l_{f}\right)^{-\beta}-w_{f}(1+s)-m l_{i} \frac{\partial q}{\partial l_{f}}=0$

\footnotetext{
${ }^{9}$ Ulyssea (2011) discute ampliamente cómo las decisiones de las firmas acerca de emplear trabajadores formal o informalmente son una respuesta óptima al contexto institucional dado por las regulaciones laborales, el sistema impositivo, la tecnología de detección de la autoridad tributaria, etc. Este punto también es discutido y modelado por Hibbs y Piculescu (2010).

${ }^{10}$ Por ejemplo, si no existen diferencias salariales $\left(w_{f}=w_{i}\right)$ el equilibrio requiere que $m>w_{f} s$. La multa debe ser superior que las contribuciones a la seguridad social pagadas sobre los trabajadores formales.
} 
$p(1+t) a^{\beta}(1-\beta)\left(l_{i}+l_{f}\right)^{-\beta}-w_{i}-q\left(l_{i}, l_{f}\right) m-m l_{i} \frac{\partial q}{\partial l_{i}}=0$.

Este sistema de condiciones de primer orden define implícitamente la combinación óptima de factores. En el Apéndice a este capítulo se presenta la expresión correspondiente a la elección óptima de la firma.

Con esta estructura simple el modelo se ajusta a las características diferenciales de firmas formales e informales descriptas en la literatura. Las firmas grandes y más productivas enfrentan una mayor probabilidad de detección y contratan trabajo formalmente (Tybout, 2000; Perry et al., 2007). Las firmas pequeñas y menos productivas operan contratando trabajadores de manera informal (de Paula y Scheinkman, 2011; La Porta y Shleifer, 2008).

\subsubsection{Efectos de la liberalización del comercio: Estáticas compara- das}

Como se discutió previamente, las firmas enfrentan la liberalización del comercio en el sector de manufacturas como una pérdida de beneficios. El impacto que tenga el recorte de tasas arancelarias puede diferir de acuerdo al plazo de tiempo considerado. Mientras que el modelo presentado en la sub-sección anterior es estático, la distinción entre corto y largo plazo se realiza a partir de supuestos acerca de la naturaleza del ajuste. Específicamente, se asume que en el corto plazo el trabajo no puede moverse entre sectores y los salarios son fijos. Ante un aumento en el grado de exposición al comercio internacional por una caída en $t$, todas las firmas pertenecientes a esta industria que compite con las importaciones reducen su nivel de producción y, consecuentemente, su demanda de trabajo, y modifican la combinación óptima $\left(l_{i}, l_{f}\right)$. En el corto plazo, los trabajadores que pierden su empleo no pueden desplazarse a otras industrias o sectores de la economía. En el largo plazo, en cambio, el trabajo es móvil. En la medida que el trabajo se reasigna y los salarios ajustan, los desempleados obtienen empleo y las ganancias del comercio se materializan alcanzando un nuevo equilibrio.

Para derivar el impacto de corto plazo se calcula la estática comparada de un cambio en la tasa arancelaria $t$. El caso de las firmas totalmente formales es sencillo. El trabajo informal, por definición, no resulta afectado en este caso, y el empleo 
formal se reduce como consecuencia del recorte de aranceles:

$\frac{\partial l_{f}^{*}}{\partial t}=\frac{1}{\beta(1+t)} l_{f}^{*}>0$.

Para las firmas mixtas, aquellas que combinan trabajo formal e informal, la solución analítica es más compleja. Asumiendo una tecnología de detección lineal, las expresiones de lo cambios en $l_{i}$ y $l_{f}$ son:

$\frac{\partial l_{i}}{\partial t}=-\phi\left[m\left(\frac{\partial q_{1}}{\partial l_{f}}+\frac{\partial q_{2}}{\partial l_{f}}\right)\right]<0$

y

$\frac{\partial l_{f}}{\partial t}=-\phi\left[-2 m\left(\frac{\partial q_{1}}{\partial l_{i}}+\frac{\partial q_{2}}{\partial l_{i}}\right)+m\left(\frac{\partial q_{1}}{\partial l_{f}}+\frac{\partial q_{2}}{\partial l_{f}}\right)\right]>0$,

donde $\phi=\frac{1}{|H|} p a^{\beta}(1-\beta)\left(l_{i}+l_{f}\right)^{-\beta}$ y $|H|>0$ es el determinante de la matriz Hessiana asociada al problema de maximización de beneficios. ${ }^{11}$

$\mathrm{Al}$ enfrentar una pérdida de protección comercial, las firmas reducen su demanda total de trabajo (la suma de (3.8) y (3.9) es positiva) y cambian la composición de su fuerza laboral sustituyendo trabajo formal por trabajo informal. Esto puede ocurrir a través del despido y contratación de trabajadores con diferentes condiciones frente a los beneficios de la seguridad social, o a través del cambio en la naturaleza de una relación laboral ya existente. ${ }^{12}$ Las firmas pueden absorber parte del shock negativo aumentando los niveles de evasión para mitigar la pérdida de beneficios. ${ }^{13}$ La informalidad introduce un mecanismo adicional de ajuste de las firmas ante cambios en la política comercial. De hecho, la reducción en la demanda de trabajo es menor a la que hubiese tenido lugar en ausencia del margen de ajuste que la informalidad representa. Matemáticamente, la suma de (3.8) y (3.9) es menor que (3.7).

\footnotetext{
${ }^{11}$ Bajo una función de detección más general, es necesario imponer restricciones sobre las derivadas segundas de $q\left(l_{i}, l_{f}\right)$ para obtener el signo de las respuestas de $l_{i}$ y $l_{f}$ ante un cambio en el arancel a las importaciones.

${ }^{12}$ Esto último puede surgir de una negociación entre las partes dado que la alternativa para el trabajador es el desempleo. Bérgolo y Cruces (2013) presentan evidencia de colusión entre empleados y empleadores en el caso de Uruguay.

${ }^{13} \mathrm{El}$ modelo discute el caso de trabajadores asalariados formales e informales pero es posible su extensión a otro tipo de relaciones laborales como el régimen de monotributo implementado en Argentina en el año 1998. En este caso, la sustitución de trabajo formal por informal estaría dada por el cambio en el tipo de relación laboral, desde una relación donde el trabajador es asalariado formal a una donde es contratado bajo este régimen impositivo y el pago de las contribuciones a la seguridad social quedan a cargo del trabajador.
} 
En el análisis empírico se estudia la relación entre las tasas arancelarias y la probabilidad de empleo informal para un trabajador aleatorio empleado en cierta industria. Esto puede explicarse, en parte, por la disponibilidad de datos a nivel de individuo pero no a nivel de firma. Para ajustar el modelo a los datos que se utilizarán en secciones siguientes, es necesario derivar el cambio teórico en la tasa de informalidad de la industria $j$. La tasa de informalidad se define como la fracción de trabajadores informales $\left(L_{i}^{j}\right)$ en la fuerza laboral total de la industria $j\left(L_{i}^{j}+L_{f}^{j}\right)$ : $I^{j}=\frac{L_{i}^{j}}{L_{i}^{j}+L_{f}^{j}}$.

En industrias cuyas firmas son grandes en promedio (su tamaño está por encima del umbral $\bar{L}$ ), la tasa de informalidad no será afectada por el cambio en el nivel de protección. En cambio, para industrias donde prevalecen las firmas con un tamaño menor a $\bar{L}$ el impacto de un cambio en $t$ será:

$\frac{\partial I^{j}}{\partial t}=\frac{\partial L_{i}^{j}}{\partial t}\left[\frac{L_{f}^{j}}{\left(L_{i}^{j}+L_{f}^{j}\right)^{2}}\right]-\frac{\partial L_{f}^{j}}{\partial t}\left[\frac{L_{i}^{j}}{\left(L_{i}^{j}+L_{f}^{j}\right)^{2}}\right]<0$.

Esto muestra que una reducción en la tasa arancelaria aumenta la tasa de informalidad porque el empleo total se reduce mientras que el empleo informal aumenta. Este efecto también depende del tamaño de las firmas en la industria $j$ porque el tamaño determina la intensidad de sustitución entre trabajadores formales e informales. Por ejemplo, firmas que superan $\bar{L}$ antes y después del cambio en $t$ no experimentarán ningún cambio en la composición de su fuerza laboral, mientras que firmas de menor tamaño emplearán más trabajo informal de acuerdo al cambio en la probabilidad de detección que enfrenten. Para ver esto, es posible derivar (3.8) y (3.9) respecto al tamaño. El efecto de primer orden es:

$\frac{\partial\left[\partial l_{i} / \partial t\right]}{\partial\left(l_{f}+l_{i}\right)}=\frac{\phi \beta}{\left(l_{i}+l_{f}\right)}\left[m\left(\frac{\partial q_{1}}{\partial l_{f}}+\frac{\partial q_{2}}{\partial l_{f}}\right)\right]>0$

$\frac{\partial\left[\partial l_{f} / \partial t\right]}{\partial\left(l_{f}+l_{i}\right)}=\frac{\phi \beta}{\left(l_{i}+l_{f}\right)}\left[-2 m\left(\frac{\partial q_{1}}{\partial l_{i}}+\frac{\partial q_{2}}{\partial l_{i}}\right)+m\left(\frac{\partial q_{1}}{\partial l_{f}}+\frac{\partial q_{2}}{\partial l_{f}}\right)\right]<0$

El aumento (caída) en la demanda de trabajadores informales (formales) se diluye con el tamaño de la firma. El efecto de los aranceles sobre la tasa de informalidad de la industria $j$ será menor a mayor tamaño de las firmas en esta industria. 
El gráfico 3.1 ilustra estos mecanismos para la industria $j$. Debajo del umbral $\bar{L}$, el arancel impacta negativamente en la tasa de informalidad de la industria y este efecto es creciente en el tamaño de las firmas que la componen. ${ }^{14}$ Para una industria donde predominan las firmas con un tamaño por encima de $\bar{L}$, por ejemplo $\left(L_{2}\right)$, el impacto sobre la tasa de informalidad será despreciable. Para industrias con firmas de menor tamaño $\left(L_{1}\right)$ el impacto será negativo y estadísticamente más fuerte. Este análisis supone que la tecnología de detección de la evasión no se ve alterada durante el proceso de ajuste. Si, por ejemplo, ante la pérdida de recaudación como resultado del mayor nivel de evasión la autoridad tributaria endurece los controles, el aumento en la informalidad laboral será menor. Si, por el contrario, los controles se vuelven más laxos, ${ }^{15}$ el efecto de la reducción arancelaria sobre la informalidad laboral será más pronunciado.

En el largo plazo los factores productivos pueden moverse entre sectores y los salarios ajustan. Parte de la fuerza laboral desempleada en las industrias que compiten con las importaciones será absorbida en el mismo sector a un menor salario. Esto reduce el costo del empleo formal y, consecuentemente, la tasa de informalidad en el largo plazo debería reducirse en el sector de manufacturas. ${ }^{16}$ La dinámica de firmas también es relevante para explicar este resultado. En el largo plazo las firmas más pequeñas y menos productivas (firmas informales) que no pueden sobrevivir a la competencia extranjera abandonan el mercado. El aumento de la oferta de trabajo en el sector no transable debería, por el mismo argumento, reducir los salarios y la tasa de informalidad en este sector. Sin embargo, la liberalización del comercio genera un efecto riqueza positivo en términos reales a través de las ganancias del comercio y de la eficiencia. Esto podría traducirse en un mayor nivel de gasto y una mayor demanda en el sector de bienes no transables, lo que implicaría una mayor demanda de trabajo. Este efecto opera en dirección contraria al de una mayor oferta laboral. El efecto final sobre la tasa de informalidad en el sector de bienes no transable dependerá de qué efecto domine. Si existe un efecto riqueza positivo que es mayor, la tasa de informalidad aumentará en el sector de bienes no transables

\footnotetext{
${ }^{14} \mathrm{El}$ efecto del arancel sobre la tasa de informalidad es negativo y crece con el tamaño de las firmas en la industria a un ritmo decreciente: $\frac{\partial^{2} I^{j} / \partial t}{\partial\left(L_{i}+L_{f}\right)^{2}}<0$. Esto se puede consultar en el Apéndice a este capítulo.

${ }^{15}$ Esto puede ocurrir, por ejemplo, porque la autoridad tributaria conoce la situación de mayor competencia que enfrentan las firmas domésticas y suaviza los controles para posibilitar su permanencia.

${ }^{16}$ El capítulo 5 analiza en detalle el ajuste de salarios formal e informal.
} 
por los mayores costos de la formalización que implica un mayor nivel de salarios. La dinámica de firmas también operaría en favor de este resultado. Una expansión de este sector daría lugar a la entrada de nuevas firmas que pueden comenzar siendo pequeñas e informales impactando positivamente en la tasa de informalidad del sector no transable de la economía.

\subsection{Estrategia empírica}

El gráfico 3.2 muestra la evolución en el tiempo del promedio de los aranceles a las importaciones en todas las industrias, ponderado por el nivel de empleo de cada una de ellas, y de la tasa de informalidad laboral. El gráfico permite distinguir las etapas en la evolución de la política comercial descriptas en el capítulo 2: un periodo inicial de alta protección, seguido de un proceso de liberalización y estancamiento de los aranceles durante los ochenta con una reversión hacia el final de la década y, por último, un nuevo proceso de apertura en los noventa.

La tasa de informalidad laboral, en cambio, tuvo una evolución creciente a lo largo de todo el periodo, mostrando un aumento de más del $100 \%$ entre los años 1980 y 2001. Mientras que el mayor incremento se dio en las primeras dos etapas, durante los noventa continuó la tendencia creciente aunque a un menor ritmo. Una particularidad interesante en la trayectoria de la tasa de informalidad es la reducción que mostró entre el año 1991 y 1994. En este último año, considerado como el más importante en término de reformas laborales, ${ }^{17}$ la tasa de informalidad comenzó a crecer nuevamente, alcanzando picos de $32.4 \%$ (año 1996) y $33.5 \%$ (año 1999). ${ }^{18}$

Si se compara la evolución de la tasa de informalidad en el sector de manufacturas con la registrada en el sector de bienes no transables, ${ }^{19}$ se encuentra una tendencia similar y un mayor nivel en el segundo caso, con una muy baja variabilidad en la discrepancia entre ambos sectores. Esta similar evolución de la tasa de informalidad

\footnotetext{
${ }^{17}$ De acuerdo a Torre y Gerchunoff (1999), hacia principios de 1994 los avances del gobierno en torno al objetivo de flexibilización laboral habían sido escasos y poco efectivos. Fue entonces que se ingresó en un proceso más gradualista y concertado con los sindicatos y empresarios que permitió destrabar la marcha de la flexibilización a través de la elaboración de varios proyectos de ley que luego se tradujeron en cambios efectivos: la proporción del empleo asalariado cubierto por modalidades flexibles de contratación se incrementó desde $6.3 \%$ en 1995 a $17 \%$ en 1997 . A pesar de esto, el sistema de relaciones laborales fue el ámbito donde con más dificultad y menor alcance penetraron las medidas de liberalización promovidas por el gobierno en la década del noventa.

${ }^{18} \mathrm{El}$ registro de estos valores coincide temporalmente con sucesos de crisis financieras externas que repercutieron en la economía doméstica.

${ }^{19}$ La tasa de informalidad en el sector de bienes no transables se computó sin incluir al sector público.
} 
en el sector de manufacturas y de bienes no transables podría sugerir que los cambios en los aranceles no fueron relevantes para explicar estas tendencias o que si lo fueron, su efecto fue poco importante en magnitud. Sin embargo, el sector de bienes no transables puede resultar afectado por el cambio en las tasas arancelarias a través de efectos de equilibrio general. Por ejemplo, ante un episodio de apertura comercial las firmas manufactureras que pierden protección reducen el tamaño de su fuerza laboral y también pueden sustituir trabajadores formales por informales como una estrategia adicional de ajuste. Los trabajadores despedidos pueden desplazarse al sector no transable donde serán empleados de manera formal o informal.

Con esta primera aproximación se observa una correlación negativa entre los aranceles sobre las importaciones y la informalidad laboral a lo largo del periodo analizado o, equivalentemente, una correlación positiva entre los eventos de liberalización comercial e informalidad. Sin embargo, de este primer resultado no se puede inferir que exista una relación causal entre los fenómenos analizados. La identificación del efecto causal de los episodios de liberalización comercial sobre la informalidad requiere de una estrategia válida que permita aislar el impacto de la política comercial de otros factores. La política comercial es el resultado de un proceso político y, por lo tanto, es una variable endógena cuando se modela el empleo informal. El desafío será separar el impacto de la política comercial de otros factores, principalmente de política económica, como fueron, por un lado, los cambios simultáneos a la apertura comercial -la reforma monetaria, las privatizaciones y desregulación de los mercados, incluyendo el laboral, durante la década del noventa (Cruces y Gasparini, 2009)- y, por el otro, la reacción de las industrias ante el ciclo económico.

La estrategia de identificación del impacto de la apertura comercial sobre la informalidad laboral se basa en la combinación de datos de los aranceles sobre las importaciones que se aplicaron en las distintas industrias del sector manufacturero y la tasa de informalidad en estas industrias durante el periodo que se extiende desde el año 1980 hasta el año 2001. Como se mostró en el gráfico 2.2 en el capítulo 2, la liberalización comercial no solo redujo los aranceles sino que también alteró la estructura de protección entre industrias. La naturaleza de las reformas comerciales durante este periodo fue tal que su impacto sobre la informalidad laboral puede ser identificado a partir de la variabilidad a nivel de industria de la política comercial.

Otra ventaja de la información disponible tiene que ver con la extensión del periodo de análisis que permite contar con más de un episodio de cambio en la política 
comercial. La comparación antes-después de un único episodio de liberalización comercial no estaría teniendo en cuenta que la comparación es entre una situación de protección y una de menor grado de protección y no entre un escenario de autarquía y uno de libre comercio (Goldberg y Pavcnik, 2007). Es por esto que un periodo extenso de tiempo refuerza la estrategia de identificación al ser posible comparar la evolución de las variables de interés durante esos cambios de política.

El análisis formal plantea un modelo simple donde los aranceles sobre las importaciones afectan el empleo informal de cada industria del sector de manufacturas. Para esto se utilizan los datos resultantes de la agregación de las EPH para el periodo 1980-2001 y se estima un modelo lineal de la probabilidad de empleo informal para el individuo $i$, empleado en la industria $j$ en el momento $t\left(Y_{i j t}\right)$, en el logaritmo de los aranceles que afectaron a esa industria en el momento $t\left(l n \tau_{j t}\right)$, características individuales como sexo, edad y su cuadrado, estado civil, variables indicadoras de jefe de hogar y nivel educativo y características del hogar como número de niños e ingreso total familiar, todas ellas incluidas en el vector $X_{i j t}{ }^{20}$ El modelo básico incluye efectos fijos por periodo de tiempo e industria:

$Y_{i j t}=\mathbf{x}_{i j t}^{\prime} \beta_{x}+\beta_{\tau} \ln \tau_{j t}+I_{j}+T_{t}+\varepsilon_{i j t}$,

La evidencia para países en desarrollo que muestra la ausencia de reasignación del empleo entre industrias y sectores luego de los episodios de liberalización del comercio conduce a interpretar el parámetro $\beta_{\tau}$ (efecto a nivel de industria) como un efecto de corto plazo. El corto plazo queda entonces definido como un escenario donde los factores no se mueven y los salarios no ajustan. Por lo tanto, el mecanismo de ajuste es el nivel de empleo y su composición: en cada industria las firmas reducen su demanda de trabajo -en ausencia de movilidad esto resultará en la aparición de desempleo- y también pueden sustituir trabajadores formales por informales.

De acuerdo al modelo desarrollado en la sección 3.2, el tamaño de las firmas es relevante para explicar la tasa de informalidad de una industria. Las firmas grandes son más visibles y enfrentan una mayor probabilidad de detección. Esto determina que existan pocos trabajadores informales en su fuerza laboral. Lo contrario ocurre en firmas pequeñas que con una baja probabilidad de detección evaden en mayor medida las contribuciones a la seguridad social. Se espera, entonces, que el efecto de los cambios en la política comercial sea diferente dependiendo del tamaño de las

\footnotetext{
${ }^{20}$ Angrist y Pishke (2008) muestran que los efectos marginales estimados a partir de un modelo lineal no difieren sustancialmente de los obtenidos mediante una especificación no lineal.
} 
firmas que componen cada industria. En particular, se espera que para las industrias formadas por firmas de menor tamaño exista un impacto mayor de la reducción de aranceles sobre su tasa de informalidad laboral. Para captar esta heterogeneidad, las industrias fueron clasificadas en pequeñas, medianas y grandes a partir del tamaño promedio de sus firmas en el año $1980 .{ }^{21}$ Se consideró a una industria como inicialmente pequeña cuando el tamaño promedio de sus firmas en 1980 no supera los 15 empleados; mediana cuando el tamaño promedio de las firmas se encuentra entre 16 y 50 empleados; y grande cuando el tamaño promedio de las firmas es superior a los 50 empleados. ${ }^{22}$ El modelo (3.14) se expande incorporando estas variables indicadoras del tamaño inicial de cada industria interactuadas con la variable de interés $\ln \tau_{j t}$. El modelo expandido es el siguiente:

$Y_{i j t}=\mathbf{x}_{i j t}^{\prime} \beta_{x}+\beta_{\tau} l n \tau_{j t}+\sum_{g} \beta_{g \tau} S_{g j} l n \tau_{j t}+\sum_{g} \beta_{g} S_{g j}+I_{j}+T_{t}+\varepsilon_{i j t}$,

donde $g$ indexa el tamaño inicial de las industria. El coeficiente de las interacciones, $\beta_{g \tau}$, puede interpretarse como el impacto diferencial del comercio sobre el empleo informal en industrias que difieren en su tamaño inicial.

La inclusión de efectos fijos por industria y periodo de tiempo permite controlar por características específicas de las industrias y por shocks agregados derivados del ciclo económico o decisiones de política. Por ejemplo, si el gobierno aumenta los aranceles durante una recesión y los trabajadores se desplazan de la formalidad hacia la informalidad como reacción ante los movimientos de la actividad económica, el coeficiente de la variable $l n \tau$ podría estar sesgado hacia arriba al captar el impacto del ciclo económico. Los efectos fijos de periodo de tiempo permitirán captar cambios de política económica vinculados al mercado laboral como variaciones en los regímenes impositivos y de aportes, modalidades de contratación, aseguramiento de riesgos de trabajo, etc. Por otro lado, atributos inobservables de las industrias como su productividad, la capacidad de lobby, la intensidad en el uso del capital pueden afectar la determinación de los aranceles y el empleo formal en cada una de ellas. La inclusión de estos efectos fijos permite controlar por factores inobservables que

\footnotetext{
${ }^{21}$ Las industrias fueron clasificadas de acuerdo al tamaño de sus firmas en el primer año de la serie utilizando información de la EPH. La variable que identifica el tamaño de las firmas en esta encuesta es categórica siendo los tamaños posibles: 1 empleado, [2,5], [6,15], [16,25], [26,50], $[51,100],[101,500],[501,+)$. Una mejor clasificación con representación a nivel de industria podría obtenerse del Censo Nacional Económico. Sin embargo el CNE no fue realizado en 1980 (los años más cercanos fueron 1974 y 1985) y utiliza la clasificación industrial a 1 dígito permitiendo identificar solo 9 industrias del sector de manufacturas.

${ }^{22}$ Más adelante se analiza la robustez de los resultados a la definición del tamaño de las industrias.
} 
podrían estar correlacionados con las aranceles y tener algún efecto independiente sobre el empleo informal. Vinculado a este punto, debe mencionarse que no es posible controlar por la afiliación sindical de los trabajadores, aunque bajo el supuesto de que la sindicalización se mantuvo estable en el tiempo este factor estaría captado con el efecto fijo por industria. Sin embargo, existe evidencia que indica que durante el periodo considerado el modelo de determinación de la afiliación sindical habría sufrido modificaciones dando indicios de variaciones en la sindicalización a lo largo del tiempo (Marshall y Groisman, 2005). De esta manera, la ausencia de información sobre sindicalización se transforma en un factor que puede sesgar los resultados. Por ejemplo, si las industrias con sindicatos más fuertes logran un mayor nivel de protección arancelaria y también obtienen mejores condiciones laborales para los trabajadores asegurando empleos formales, el coeficiente de la variable de aranceles estará sesgado hacia abajo. En secciones siguientes se testea la existencia de efectos de este tipo.

Como el regresor de interés varía a nivel de grupo (en este caso cada grupo está dado por la combinación de industrias y periodos de tiempo), la inferencia se realiza estimando errores estándar robustos agrupados por periodo de tiempo e industria. En caso contrario, se estaría sobreestimando la precisión al ignorar la correlación del término de error al interior de cada grupo.

\subsubsection{Movilidad de trabajadores}

La identificación del impacto de las reformas comerciales sobre la informalidad laboral a partir del cambio diferencial de aranceles entre industrias se apoya en la premisa de que la movilidad de trabajadores entre la formalidad y la informalidad fue superior al interior de cada industria respecto a la movilidad entre industrias. Esto puede ser respaldado mediante el análisis de la descomposición del cambio en el tiempo de la tasa de informalidad en cambios que se dieron al interior de cada industria (efecto within) y cambios que tuvieron lugar entre industrias (efecto between). El cambio en la tasa de informalidad entre los años $1980\left(t_{0}\right)$ y $2001\left(t_{1}\right)$ puede descomponerse de la siguiente manera (Goldberg y Pavcnik, 2003):

$\Delta_{t} I=\sum_{j} \Delta_{t} i_{j} \theta_{j}^{E}+\sum_{j} \Delta_{t} E_{j} \theta_{j}^{I}$

donde $I$ representa la tasa de informalidad del sector de manufacturas, $i_{j}$ y $E_{j}$ son la tasa de informalidad y la participación del empleo de la industria $j$ en el empleo 
total, respectivamente, y los parámetros $\theta_{j}^{I}$ y $\theta_{j}^{E}$ se computan como:

$\theta_{j}^{I}=\frac{1}{2}\left(i_{j, t_{0}}+i_{j, t_{1}}\right)$

$\theta_{j}^{E}=\frac{1}{2}\left(E_{j, t_{0}}+E_{j, t_{1}}\right)$.

El primer componente de la expresión (3.16) es el cambio en la tasa de informalidad laboral que se explica por movimientos desde la formalidad hacia la informalidad al interior de cada industria y el segundo, el cambio en la tasa de informalidad que se explica por movimiento de trabajadores entre industrias.

El cuadro 3.1 presenta los resultados de esta descomposición. El cambio en la tasa de informalidad del sector de manufacturas entre los años 1980 y 2001 fue de 18 puntos porcentuales (en el año 1980 esta tasa fue del $16 \%$ y alcanzó el $34 \%$ en el año 2001). Prácticamente la totalidad del cambio se explica por el efecto within. De hecho, el signo negativo del efecto between indica que los movimientos de trabajadores entre industrias condujeron a una reducción en la tasa de informalidad. Entonces la principal fuente de variación en la informalidad a lo largo del periodo fue la movilidad de trabajadores desde empleos formales hacia empleos informales dentro de cada industria del sector. Este resultado es compatible con la evidencia que muestra la ausencia de reasignación del trabajo entre industrias y sectores luego de episodios de apertura comercial. Como se mencionó anteriormente, la hipótesis es que ante un episodio de apertura las firmas disponen de un margen adicional de ajuste dado por la informalidad laboral. De acuerdo al resultado de esta descomposición, la incorporación de trabajadores provenientes de otras industrias como empleados informales no parece haber sido la reacción más frecuente. En cambio, la interrupción del pago de las contribuciones a la seguridad social y la rotación del empleo en la misma industria (despido e incorporación de trabajadores formales e informales en distinta medida) habría sido la estrategia aplicada más extensamente.

Cuando esta descomposición se realiza incorporando al sector de bienes no transables, la conclusión general se mantiene pero la fracción del cambio en la tasa de informalidad que se explica por el efecto between es superior. El cambio en la tasa de informalidad para la sectores de manufacturas y el sector no transable conjuntamente fue de 19 puntos porcentuales (19\% en 1980 y $38 \%$ en 2001) y el $94.7 \%$ de ese cambio se explica por el efecto within (5.3\% por el efecto between). Teniendo en cuenta la evolución creciente de la tasa de informalidad en el sector de bienes no transables (gráfico 3.2) y la pérdida de participación en el empleo del sector de ma- 
nufacturas a lo largo del tiempo, se puede postular que parte de los trabajadores que quedaron ociosos en el sector manufacturero fueron incorporados como informales por el sector no transable de la economía.

La estabilidad de la participación del empleo de cada industria en el empleo total del sector es otra evidencia que respalda la estrategia de identificación. La estimación de un modelo para la participación del empleo controlando por los aranceles de cada industria y variables indicadoras de industria y tiempo arroja un coeficiente para la variable de política comercial que es pequeño en magnitud y no significativo estadísticamente. ${ }^{23}$ Esta estabilidad en el nivel de empleo es consistente con la experiencia de países en desarrollo reportada en el capítulo 1. La evidencia encontrada podría estar indicando la presencia de imperfecciones en el mercado laboral y costos de movilidad. Una explicación adicional es que el empleo informal provee de un margen de ajuste al interior de cada industria no contemplado por la TCI.

\subsubsection{Endogeneidad de la política comercial}

La evidencia existente permite sostener una estrategia de identificación basada en la variabilidad entre industrias de los cambios en la política comercial. Resta argumentar respecto de la posible endogeneidad de este cambio diferencial en el patrón de protección. Existen varias razones que podrían conducir a la endogeneidad de los cambios en la política comercial en un modelo de informalidad laboral. En primer lugar, las reformas comerciales son parte del proceso económico y político por lo que el cambio diferencial en el nivel de protección entre industrias puede estar reflejando factores de política económica. Por ejemplo, las industrias menos productivas o con mayor capacidad de lobby pueden tener los mayores niveles de protección. Si estas industrias son las que poseen mayores niveles de informalidad laboral, se encontrará una relación positiva entre protección e informalidad aunque la verdadera relación entre estas variables puede ser otra. En segundo lugar, la reducción inicial de aranceles pudo haber acompañado una tendencia previa hacia la liberalización del comercio (Topalova, 2010). En tercer lugar, el poder de los sindicatos para influir en el nivel de protección de una industria también es una posible fuente de sesgo, especialmente si la afiliación sindical presenta variabilidad temporal (Marshall y Groisman, 2005). Otra potencial fuente de sesgo es la omisión

\footnotetext{
${ }^{23}$ La estimación por MCO arroja un coeficiente de 0.003 con un error estándar robusto igual a 0.002 .
} 
de otros instrumentos de política comercial, como las barreras no arancelarias. ${ }^{24}$ La imposibilidad de medir la capacidad de control de la autoridad tributaria también podría afectar los resultados si ella cambia en el tiempo. Por ejemplo, si la reducción de aranceles genera una pérdida de recaudación que da lugar a un endurecimiento en la tecnología de detección de evasores, esto podría conducir a una subestimación del efecto de interés. Por último, con la reducción de aranceles cae el costo de acceso a nuevas tecnologías a través de la caída en el costo de bienes de capital importados (Acosta y Gasparini, 2007). A través del cambio tecnológico las firmas pueden lograr mejoras de productividad, aumentando su tamaño y la formalización de su fuerza de trabajo. ${ }^{25}$

La variación en el tiempo de los datos es un factor importante respecto a este punto. La inclusión de variables indicadoras de periodo de tiempo permite controlar por shocks agregados vinculados a decisiones de política económica que afectaron de igual manera a todas las industrias, como cambios en otros instrumentos de política comercial o ajustes en la tecnología de detección de la evasión. Además de esto, el nivel de aranceles, al menos en la etapa del Mercosur, fue negociado dentro del marco de este acuerdo comercial, reduciendo el espacio para la acción de lobbies industriales. Aquellos factores que afectaron de manera diferencial a cada industria, que presentaron variabilidad en el tiempo y que son relevantes para explicar la informalidad a nivel de industria permanecerán inobservados. Este podría ser el caso de la acción de los sindicatos, un factor específico de cada industria, que según la evidencia de Marshall y Groisman (2005) ha variado en el tiempo. De esta manera, si el cambio diferencial de aranceles entre industrias presenta algún grado de correlación con estos factores, no será posible sostener la exogeneidad de la variable de interés.

Ante esta posibilidad, se propone analizar la relación entre los cambios en las tasas arancelarias y variables que reflejan las características "políticas" de cada industria. Usando información de la EPH se estimaron modelos del cambio de aranceles en cada industria controlando por características industriales como el tamaño de su fuerza laboral, salario promedio, concentración y proporción de trabajadores calificados (Topalova, 2007). Si estos son factores "políticos" relevantes para explicar

\footnotetext{
${ }^{24}$ La evidencia indica la existencia de una pequeña correlación positiva entre las barreras arancelarias y no arancelarias en el caso argentino (Galiani y Porto, 2010).

${ }^{25}$ Acosta y Montes-Rojas (2010) utilizan un argumento de salarios de eficiencia que indica que al acceder a mejoras tecnológicas las firmas ofrecerán mejores condiciones laborales a sus trabajadores para poder mantener a los mejores.
} 
el cambio en el nivel de protección, se espera que una mayor fuerza laboral esté asociada con mayores niveles de tasas arancelarias y menores recortes ya que una mayor fuerza laboral se traduce en un mayor poder electoral. El salario promedio y la proporción de trabajadores calificados tendrían una relación negativa con el nivel de protección ya que los policy makers protegerían a las industrias con trabajadores más vulnerables. El grado de concentración de una industria, aproximado por el tamaño promedio de sus firmas, capta la capacidad de los productores para formar grupos de presión que intentan obtener una mayor protección.

Los modelos se estimaron para el cambio de aranceles en el periodo completo (1980-2001) controlando por las características industriales en 1980, para el cambio en las tasas arancelarias en el periodo en que la reducción en el nivel de protección fue mayor (1989-2001) controlando por las características industriales de 1989 y, por último, se estimó un modelo del cambio de aranceles entre años consecutivos $(t$ y $t-$ 1) utilizando las características del año inicial $(t-1)$ como variables de control. Todos los modelos incluyen variables indicadoras del tipo de industria (bienes de capital, bienes de consumo durables, bienes de consumo no durables y bienes intermedios) y ponderan por la raíz cuadrada del nivel de empleo en cada una de ellas. El último modelo también incluye variables indicadoras de periodo de tiempo.

Los resultados en el cuadro 3.2 muestran que los cambios en los aranceles no están correlacionados con factores políticos a nivel industrial. La única excepción está dada por los salarios para el modelo del cambio de aranceles en el periodo 19802001 que incluye a todos los factores como variables de control. Sin embargo, el signo no coincide con el esperado, ya que un mayor salario promedio se asocia a menores recortes de aranceles. En términos generales, la evidencia presentada muestra que el cambio diferencial de aranceles entre industrias no puede ser explicado por los factores políticos incluidos en estos modelos.

Aun con esta evidencia parcial que conduce a rechazar la endogeneidad de los cambios en la política comercial por motivos de política económica, pueden existir otros factores con capacidad para sesgar los resultados. ${ }^{26}$ Ante esta posibilidad se proponen dos variables instrumentales con el objetivo de generar cambios exógenos

\footnotetext{
${ }^{26}$ Factores no capturados en los modelos previos, por ejemplo, tendencias previas hacia la liberalización del comercio, ajustes en la tecnología de detección de evasores, el uso de otros instrumentos de política económica y la incorporación de bienes de capital. Sobre esto último, Acosta y MontesRojas (2010) encuentran evidencia que muestra un menor aumento en la informalidad laboral en industrias con mayor inversión en bienes de capital como consecuencia de la reducción en los aranceles a las importaciones entre 1992 y 2003.
} 
en la política comercial. En primer lugar, se construye una medida del tipo de cambio promedio que enfrenta cada industria (Park et al., 2010; Brambilla, 2012): ${ }^{27}$

$z_{j t}^{1}=\sum_{c} t c_{t}^{c} * \vartheta_{j t 0}^{c}$

$t c_{t}^{c}$ es el tipo de cambio real del país $c$ (respecto al peso argentino) en el año $t$ y $\vartheta_{j t 0}^{c}$ es la participación del socio comercial $c$ en las importaciones argentinas del producto $j$ en 1980. Dada esa participación, un mayor tipo de cambio del país $c$ (o, equivalentemente, una reducción en el precio en moneda local de los productos importados) generará mayores importaciones provenientes de ese país. Ante esto, los aranceles pueden aumentar para proteger a la industria $j$, limitando la caída en el precio de las importaciones de ese producto. O pueden caer, haciendo efectivas las ganancias del comercio.

Este instrumento se basa en la variación del tipo de cambio de los socios comerciales, un cambio enteramente exógeno al modelo, y en la exposición de cada industria a esos cambios, captada mediante la participación de ese país en las importaciones argentinas del producto $j$ en el periodo inicial. La especificación de la participación $\vartheta_{j}^{c}$ en el primer periodo de la muestra busca predeterminar ese valor para cada $t$ asegurando la exogeneidad del cambio en los aranceles generado a través de la variación en el tipo de cambio del país $c$.

El segundo instrumento interactúa los aranceles industriales del momento inicial (1980) con una variable que contiene tres categorías. Cada una de ellas corresponde a una de las tres etapas en la evolución de la política comercial que se describió anteriormente (Topalova, 2007): ${ }^{28}$

$z_{j t}^{2}=\ln \tau_{j 1980} *$ Post $_{t}$

La validez de este instrumento puede establecerse mediante la evidencia presentada en el gráfico 2.2 en el capítulo 2. El cambio en los aranceles de cada industria estuvo linealmente relacionado con el nivel inicial de protección. Aquellas industrias inicialmente más protegidas enfrentaron los mayores recortes de aranceles y las inicialmente menos protegidas tuvieron reducciones menores. Por otro lado, el

\footnotetext{
${ }^{27}$ Se consideran como socios comerciales para la construcción de este instrumento a Brasil, Chile, Estados Unidos y la Unión Europea. Los datos sobre el valor de las importaciones provienen de UN Comtrade y el tipo de cambio de World Development Indicators (WDI, 2012).

${ }^{28}$ La primera etapa comprende los años 1980-1985 con los niveles más altos de protección. La segunda se extiende desde 1986 hasta 1989 y la última, desde 1990 hasta 2001.
} 
nivel inicial de aranceles es un valor determinado fuera del modelo y, por lo tanto, exógeno.

La validez de los instrumentos también exige que se cumpla la restricción de exclusión. Esta podría ser violada en el caso del primer instrumento si la variación en el tipo de cambio de los socios comerciales tuviera algún efecto directo sobre la informalidad. La inclusión de variables indicadoras de periodo de tiempo permite controlar por efectos de este tipo.

El cuadro 3.3 muestra los resultados de la primera etapa donde el logaritmo de los aranceles y su interacción con las variables indicadoras del tamaño de las industrias

en 1980 se instrumentan con $z_{j t}^{1}, z_{j t}^{2}$ y su interacción con el tamaño de las industrias en el momento inicial. Un aumento en el tipo de cambio que enfrentan las industrias se traduce en una reducción de las tasas arancelarias en todas las industrias, con un impacto menor en las industrias medianas. Por otro lado, un mayor arancel inicial se asocia a menores tasas arancelarias y el efecto es mayor en las industrias inicialmente grandes. Estos resultados confirman que el cambio observado en las tasas arancelarias está correlacionado con el nivel inicial de protección y también con el tamaño de las industrias.

\subsection{Reformas comerciales e informalidad laboral: Evi- dencia de corto plazo}

El cuadro 3.4 presenta los resultados obtenidos a partir de la estimación de los modelos (3.14) y (3.15) por MCO y por variables instrumentales (VI). El efecto de la reducción de aranceles sobre la informalidad laboral a nivel de industria es indistinguible de cero utilizando el modelo (3.14) (columna 1). Cuando no se permite que la reacción de la tasa de informalidad sea diferentes según el tamaño inicial de las firmas en cada industria, los efectos se compensan hasta desaparecer. Al permitir efectos heterogéneos por tamaño de industria la evidencia muestra un aumento en la tasa de informalidad que es estadísticamente significativo en las industrias inicialmente pequeñas y medianas (columna 2). ${ }^{29}$ Una reducción del $10 \%$ en las tasas arancelarias se asocia a un incremento de 1.2 puntos porcentuales en la tasa de informalidad de las industrias inicialmente pequeñas, tanto en la estimación por MCO como por VI, y entre 0.35 (MCO) y 0.65 (VI) puntos porcentuales en las industrias

\footnotetext{
${ }^{29}$ Los resultados hacen referencia a industrias que difieren en su tamaño inicial. Estrictamente, las industrias difieren en el tamaño promedio de sus firmas en el año 1980.
} 
medianas (al $10 \%$ de significatividad individual). Esto se traduce en un incremento de 4.5 puntos porcentuales en una industria que experimentó una reducción del $39 \%$ en su arancel a lo largo de todo el periodo, como fue el caso de la fabricación de pendas de vestir (industria inicialmente pequeña). Teniendo en cuenta que el aumento en la tasa de informalidad de esta industria fue de 15 puntos porcentuales (pasó de $40 \%$ en el año 1980 a $55 \%$ en el 2001), la apertura comercial estaría explicando, en este caso, el $30 \%$ del cambio observado en la informalidad laboral. En el caso de las industrias inicialmente grandes el efecto es estadísticamente nulo, tanto en las estimaciones por MCO como por VI. Los resultado muestran un patrón de ajuste al interior de las industrias que decrece con el tamaño de las firmas en cada una de ellas. Este resultado es compatible con los efectos esperados de acuerdo al planteo teórico del capítulo 3.1. La ausencia de efecto en las industrias con firmas grandes podría explicarse a partir de los argumentos de la literatura de evasión de impuestos. Las firmas grandes enfrentan una probabilidad de detección muy alta y no recurren a la informalidad laboral como mecanismo de ajuste. Una explicación adicional puede encontrarse en el comportamiento de las firmas exportadoras. Las firmas exportadoras tienden a ser más productivas y más grandes que las firmas que en la misma industria producen para el mercado doméstico (Bernard y Jensen, 1999). Con esta evidencia se espera que las industrias grandes tengan una mayor presencia de firmas exportadoras. Con la liberalización del comercio estas firmas pueden acceder a nuevas mercados expandiendo su tamaño y reduciendo el peso del trabajo informal. Bustos (2011) provee evidencia de que con la liberalización del comercio hubo una mayor entrada de firmas al segmento exportador de las industrias en el periodo 1992-1996. Este tipo de comportamiento pudo haber neutralizado cualquier aumento en el empleo informal por parte de las firmas que en industrias grandes producen para el mercado doméstico compitiendo con las importaciones.

Otro patrón interesante que surge de estos resultados es el del cambio en el signo y magnitud de los coeficientes al pasar de las estimaciones por MCO a las estimaciones por VI. Una de las principales fuentes de endogeneidad de la variable de aranceles es la incorporación de nuevas tecnologías a partir de la reducción en el costo de los bienes de capital. Acosta y Gasparini (2007) presentan evidencia de acumulación de capital y cambios tecnológicos en la economía argentina durante el periodo 1992-2001. Las mejoras tecnológicas permiten que las firmas alcancen mejoras de productividad, expandiendo su tamaño y reduciendo la incidencia del 
empleo informal. De la comparación de los resultados de la columna 2 en el cuadro 3.4 surge que el patrón de mejoras tecnológicas habría sido creciente en el tamaño de las firmas en cada industria. El efecto identificado para las industrias inicialmente pequeñas prácticamente no se modifica al pasar de MCO a VI. El impacto en las industrias medianas se acentúa al aislar el efecto de la incorporación de bienes de capital. Para las industrias grandes el efecto sigue siendo estadísticamente nulo pero el signo se revierte. Es decir, que el signo positivo en la estimación por MCO podría estar explica por la incorporación de bienes de capital y mejoras de productividad que actúan en favor de una menor tasa de informalidad. Bustos (2011) presenta evidencia en favor de esta hipótesis al mostrar que la apertura condujo a las firmas exportadoras a incorporar nuevas tecnologías logrando mejoras de productividad.

Estos mismos modelos fueron estimados incluyendo al salario promedio de cada industria como una variable de control adicional. La hipótesis es que si el ajuste de salarios asociado a un episodio de apertura comercial es un mecanismo que actúa reduciendo la tasa de informalidad (tal como se propuso en el modelo presentado en la sección 3.2) el efecto estimado sería mas acentuado al controlar por esta variable. Las columnas 3 y 4 de la tabla 3.4 muestran la evidencia obtenida mediante esta nueva especificación. El efecto de una reducción de aranceles sobre la informalidad laboral no difiere respecto de los resultados obtenidos anteriormente. Esto puede ser interpretado como evidencia de que el ajuste de salarios es un mecanismo de ajuste que opera en el largo plazo y, por lo tanto, no es posible identificar su efecto completo utilizando la variabilidad de corte transversal de los datos.

Estos resultados, que se interpretan como el ajuste de corto plazo luego de los episodios de apertura comercial, se ajustan a las predicciones presentadas en la sección 3.2. Ante la pérdida de protección arancelaria, los niveles de evasión en el pago de las contribuciones a la seguridad social se incrementan. La informalidad laboral es un mecanismo de ajuste que utilizan las firma para enfrentar el shock negativo que representa el cambio en la política comercial. El uso de este mecanismo difiere dependiendo del tamaño de las firmas que componen cada industria. En particular, el efecto se diluye al considerar firmas de mayor tamaño y que enfrentan una mayor probabilidad de detección por parte de la autoridad tributaria. Este último resultado también puede interpretarse en el marco de los modelos con firmas heterogéneas. Las firmas exportadoras, que tienden a ser más grandes y más productivas, se expanden al poder acceder a nuevos mercados y la incorporación de bienes de capital permite 
lograr mejoras de productividad. La evidencia indica que con la liberalización del comercio hubo una mayor entrada de firmas al segmento exportador y estas mismas firmas incorporaron nuevas tecnologías. Estos mecanismos que actúan en favor de una menor tasa de informalidad habrían operado en el grupo de industrias con firmas grandes en promedio.

\subsubsection{Análisis de robustez}

Para evaluar la robustez de los resultados obtenidos anteriormente se proponen algunos ejercicios adicionales. El primero de ellos busca investigar la posibilidad de que existan variables omitidas en el modelo que puedan estar generando los resultados obtenidos hasta el momento. Para esto se incluyen en el modelo principal algunas características iniciales de cada industria interactuadas con la variable categórica que indica las distintas etapas en la evolución de la política comercial. Con esto se busca controlar por tendencias específicas por industria. El modelo estimado es el siguiente:

$$
\begin{aligned}
Y_{i j t}=\mathbf{x}_{i j t}^{\prime} \beta_{x}+\beta_{\tau} \ln \tau_{j t}+\sum_{g} \beta_{g \tau} S_{g j} & \ln \tau_{j t} \\
& +\sum_{g} \beta_{g} S_{g j}+\mathbf{w}_{j 1980}^{\prime} \beta_{w}+I_{j}+T_{t}+\varepsilon_{i j t},
\end{aligned}
$$

En el vector w se incluyó la proporción de trabajadores calificados y el tamaño de la fuerza laboral en 1980. El modelo se estimó por MCO y por VI, utilizando los instrumentos introducidos previamente. Los resultados muestran un impacto algo superior en esta especificación respecto a los modelos estimados con anterioridad (primera columna del cuadro 3.5). En las estimaciones por MCO el efecto para las industrias inicialmente pequeñas pasa de -0.116 a -0.150 y para las industrias inicialmente medianas la estimación se acentúa desde -0.035 a -0.047. Esos cambios son de -0.118 a -0.178 y de -0.064 a -0.079 para las industrias inicialmente pequeñas y medianas, respectivamente, en las estimaciones por VI. Las estimaciones previas pueden interpretarse entonces como un límite inferior del impacto de la liberalización del comercio sobre la informalidad laboral a nivel de industria. De acuerdo a estas estimaciones que corrigen por tendencias por industrias, la reducción de los aranceles sobre las importaciones generó un aumento de la informalidad laboral de 1.8 y 0.8 puntos porcentuales en las industrias inicialmente pequeñas y medianas, respectivamente, y ningún efecto en las industrias inicialmente grandes. 
El segundo ejercicio consiste en incluir otras medidas de exposición al comercio además del logaritmo de los aranceles. El capítulo 2 presentó los argumentos por los cuales los aranceles a las importaciones captan de mejor manera el efecto de la política comercial sobre la informalidad laboral. La inclusión de otras variables se realiza a los efectos de evaluar la robustez de los resultados obtenidos anteriormente. Para esto se construyó una medida de penetración de importaciones y una medida de orientación hacia las exportaciones para cada industria y cada momento de tiempo. ${ }^{30}$

La columna 2 del cuadro 3.5 muestra los resultados obtenidos al incluir estas variables con un rezago. ${ }^{31}$ La inclusión de estos factores de política comercial no altera las conclusiones principales. La reducción de aranceles genera un aumento en la informalidad laboral en las industrias pequeñas de magnitud similar al estimado previamente, aunque el efecto es estadísticamente nulo en el caso de las industrias medianas. El impacto directo de estos nuevos regresores posee el signo esperado. Una mayor penetración de importaciones se asocia a mayores niveles de informalidad (el efecto no es estadísticamente significativo) y lo contrario ocurre en industrias con una mayor orientación hacia las exportaciones (el efecto solo es significativo en la estimación por MCO).

Las fluctuaciones del tipo de cambio pueden afectar la rentabilidad del sector transable respecto del no transable (tipo de cambio real) y del sector que compite con las importaciones respecto del sector exportador (tipo de cambio nominal). Por ejemplo, dado el tipo de cambio nominal, una devaluación del tipo de cambio real mejora la rentabilidad del sector transable respecto del no transable. Al expandirse, el sector transable reduciría sus niveles de informalidad de acuerdo a los mecanismos discutidos previamente. Una devaluación del tipo de cambio nominal mejora la rentabilidad del sector exportador respecto del sector sustitutivo de importaciones. En ese caso, el resultado dependerá de qué sector domine. Si el sector sustitutivo de importaciones tiene un mayor peso relativo en la totalidad del sector de manufacturas, su contracción resultará en un incremento en la informalidad. Las columnas 3

\footnotetext{
${ }^{30}$ La medida de penetración de importaciones se construyó como el valor de las importaciones de cada industria sobre el valor del producto más las importaciones menos sus exportaciones. La medida de exportaciones se construyó como el valor de las exportaciones sobre el valor del producto de cada industria. El valor de las importaciones y exportaciones para cada industria proviene de UN Comtrade y el valor de la producción se construyó a partir de datos sobre el índice de producción industrial del Centro de Estudios de la Producción y sobre el Estimador Mensual Industrial del Instituto Nacional de Estadísticas y Censos.

${ }^{31} \mathrm{La}$ inclusión del valor rezagado para estas variables se justifica en la posible determinación simultánea de los flujos comerciales con la variable de resultado.
} 
y 4 del cuadro 3.5 muestran los resultados obtenidos al incluir estas variables como control adicional junto con su interacción con las variables de penetración de importaciones y orientación hacia las exportaciones. ${ }^{32}$ Esto último se justifica en que el tipo de cambio solo presenta variabilidad en el tiempo pero no a nivel de industria. $\mathrm{Al}$ igual que en el ejercicio presentado anteriormente, la inclusión del tipo de cambio como control adicional no altera las conclusiones principales. La reducción de aranceles impacta positivamente sobre la informalidad laboral en industrias pequeñas. El efecto estimado en industrias medianas y grandes es estadísticamente nulo. Las variables de tipo de cambio muestran el signo esperado. Un mayor tipo de cambio real reduce la tasa de informalidad, mientras que un mayor tipo de cambio nominal genera el efecto opuesto, indicando que domina la retracción del sector sustitutivo de importaciones. Las interacciones con las variables de penetración de importaciones y orientación hacia las exportaciones no son estadísticamente distintas de cero, con la única excepción del índice de penetración de importaciones interactuado con el tipo de cambio nominal, indicando la ausencia de efectos diferenciales de acuerdo a la orientación importadora/exportadora de cada industria.

Las estimaciones previas se basan en una definición de tamaño que es arbitraria. Las industrias fueron clasificadas como pequeñas cuando el tamaño promedio de sus firmas en 1980 no superaba los 15 empleados; mediana, cuando el tamaño promedio de las firmas se encontraba entre 16 y 50 empleados; y grandes cuando las firmas tenían en promedio más de 50 empleados. El último test busca evaluar la robustez de los resultados a distintas definiciones de tamaño de industrias.

En primer lugar, se modificó la definición de industrias de tamaño mediano y grande. Bajo esta nueva definición una industria es mediana cuando sus firmas, en promedio, tuvieron en 1980 una fuerza laboral de entre 16 y 100 empleados y grande cuando el tamaño promedio de las firmas superó los 100 empleados. La segunda definición también mueve el límite que separa a las industrias pequeñas de las medianas. En este caso, se clasifica a una industria como pequeña en 1980 cuando sus firmas tuvieron en promedio hasta 25 empleados; medianas, cuando tuvieron entre 26 y 100 y grandes cuando el tamaño promedio de sus firmas superó los 100 empleados en 1980. La última definición amplía aun más el grupo de industrias con firmas pequeñas en el periodo inicial incluyendo a aquellas que no superaban los 50

\footnotetext{
${ }^{32}$ La serie de tipo de cambio se obtuvo de World Development Indicators (WDI), Banco Mundial, 2012 .
} 
empleados. Las industrias medianas quedan definidas como las que en 1980 tuvieron firmas con una fuerza laboral promedio de entre 51 y 100 trabajadores.

Los resultados obtenidos se muestran en el cuadro 3.6. Para cada definición de industria la columna 1 muestra los resultados del modelo (3.15) y la columna 2 los del modelo que incluye el salario promedio de la industria como control adicional. Los resultados por MCO muestran que el efecto en las industrias pequeñas se mantiene, indicando que la tasa de informalidad aumentó como consecuencia de la reducción del arancel a las importaciones, mientras que en las industrias medianas el efecto deja de ser significativo estadísticamente. La única excepción es la tercera definición donde el efecto desaparece. Es interesante notar que la magnitud del efecto se reduce a medida que la definición utilizada amplía el tamaño de las industrias con firmas pequeñas. De hecho, en el último caso, donde se define como industria pequeña a aquella cuyas firmas en promedio no superaban los 50 empleados en 1980 el efecto estimado es nulo. Esto estaría mostrando que la sustitución de trabajadores formales por informales es un mecanismo que operó en las firmas más pequeñas. Las estimaciones por VI muestran un aumento en la informalidad en industrias pequeñas bajo cualquiera de las definiciones alternativas y ningún efecto en las industrias medianas. La magnitud de los efectos estimados es algo superior a la obtenida en los resultados principales, con un incremento de entre 1.2 y 1.7 puntos porcentuales por cada reducción del $10 \%$ en el arancel de las industrias pequeñas. Para todas las definiciones aparece nuevamente el patrón profundización de la magnitud del efecto y reversión en el signo de los coeficientes al pasar de las estimaciones por MCO a VI. Esto se interpreta como evidencia de la incorporación de bienes de capital y nuevas tecnologías que incrementan la productividad de las firmas contrarrestando el efecto de la mayor competencia de los bienes importados.

\subsection{Reformas comerciales e informalidad laboral: Evi- dencia de largo plazo}

La evidencia de corte transversal ha mostrado que en el periodo 1980-2001 existió una relación positiva entre los eventos de liberalización del comercio y la informalidad laboral, particularmente en las industrias inicialmente pequeñas. La identificación de este efecto se basó en el cambio diferencial de aranceles entre industrias y, dada la evidencia de ausencia de movilidad de factores luego de los episodios de apertura, se interpretó como un efecto de corto plazo. 
Este efecto de corto plazo puede revertirse o intensificarse con el transcurso del tiempo una vez que los factores pueden desplazarse entre industrias y sectores y los salarios ajustan. Para evaluar este efecto se propone utilizar la variabilidad de los datos en el tiempo para identificar el impacto de la liberalización del comercio en el sector de manufacturas en conjunto, condicional en la estructura sectorial de protección y en los restantes controles que afectan la informalidad. Más concretamente, se evaluará el efecto del arancel promedio nacional sobre la tendencia de la tasa de informalidad dado el efecto de los aranceles industriales (efecto de corto plazo). Si después de controlar por la estructura sectorial de aranceles aun existe un efecto sobre la tendencia en la tasa de informalidad, este será identificado como un efecto de largo plazo o de equilibrio general que se produce cuando los factores pueden desplazarse y los salarios también ajustan.

La estrategia de estimación consta de dos etapas. La primera consiste en estimar el modelo (3.15) donde el impacto del comercio es captado a través de los aranceles industriales. En la segunda etapa se utiliza la dimensión temporal de los datos y se especifica un modelo para los efectos de periodo de tiempo estimados en la primera etapa como función del arancel promedio de la economía (Galiani y Porto, 2010). Los efectos de periodo de tiempo pueden interpretarse como la tasa de informalidad residual en cada periodo una vez que se controló por todos los regresores crosssection, en particular, por la estructura sectorial de protección. Esto implica que es la tasa de informalidad neta del efecto de las fricciones del mercado laboral que impidieron la reasignación del trabajo en el corto plazo:

$\hat{T}_{t}=\mathbf{x}_{t}^{\prime} \alpha_{x}+\alpha_{\tau} \ln \tau_{t}+\nu_{t}$

El vector $\mathbf{x}_{t}$ incluye la relación de fuerza laboral entre el sector de manufacturas y el no transable (para captar los cambios en la estructura productiva de la economía), la relación entre el salario promedio que reciben los trabajadores formales e informales en cada sector (para captar el ajuste de salarios luego de un episodio de apertura comercial), la composición formal/informal de la oferta de trabajadores calificados y no calificados en toda la economía, ya que los trabajadores migran de sector en función de su nivel educativo y esta es una característica en la que difieren ambos tipos de trabajadores, y la proporción de firmas pequeñas en cada sector ya que se espera que esta fracción sufra variaciones a lo largo del tiempo impactando en la tasa de informalidad. 
Como la variable dependiente en la segunda etapa es una variable estimada, se utiliza el método de Mínimos Cuadrados Ponderados con la inversa de la varianza de los efectos temporales estimados en la primera etapa como ponderadores. Para obtener las estimaciones por VI se utilizaron, al igual que en la sección previa, los instrumentos $z_{j t}^{1}$ y $z_{j t}^{2}$ para instrumentar el logaritmo de los aranceles en la primera etapa y sus interacciones con las variables indicadoras del tamaño inicial de cada industria. En la segunda etapa se utilizó el tipo de cambio real promedio de los socios comerciales como instrumento para el arancel promedio nacional. Para analizar los efectos de equilibrio general, esta estrategia de estimación también se implementó para el sector no transable de la economía. En este caso la primera etapa no incluye variables de política comercial.

El cuadro 3.7 presenta los resultados de la segunda etapa para el sector de manufacturas y para cuatro especificaciones alternativas. ${ }^{33}$ Las estimaciones por MCO muestran que no existe una relación estadísticamente significativa entre la tendencia en la tasa de informalidad del sector de manufacturas y el arancel promedio nacional. En las estimaciones por VI, en cambio, aparece una relación positiva y significativa en todas las especificaciones. Una vez que se controla por la estructura sectorial de aranceles (efecto de corto plazo) la liberalización del comercio reduce la tasa de informalidad en este sector. Las estimaciones oscilan entre 0.08 y 0.28 , por lo que una reducción del $10 \%$ en el arancel promedio genera una caída de entre 0.8 y 2.8 puntos porcentuales en la tasa de informalidad del sector de manufacturas. Es interesante notar el signo de las restantes variables de control. La expansión del sector de manufacturas respecto al sector de bienes no transable, medido en número de empleados, reduce la tasa de informalidad. Esto es compatible con el modelo de la sección 3.2. Dado el número de firmas, un incremento en su tamaño aumenta la probabilidad de detección siendo óptimo modificar la combinación de empleo formal-informal, aumentando la participación de los trabajadores formales. La evolución temporal de la tasa de informalidad en el sector de manufacturas está determinada por el número de trabajadores informales no calificados, indicando que la informalidad en este sector se da principalmente entre los trabajadores que poseen este nivel educativo. Por último, un aumento en la participación de firmas pequeñas en el sector no transable impacta positivamente en la tendencia de la tasa de informalidad en el sector de manufacturas. Esto puede explicarse a partir de la expansión e ingreso de nuevas

\footnotetext{
${ }^{33}$ Los resultados de la primera etapa son los presentados en el cuadro 3.4.
} 
firmas a este sector y la migración de trabajadores desde el sector de manufacturas. Si estos trabajadores son formales, la movilidad puede resultar en una mayor tasa de informalidad en el sector de manufacturas.

En el cuadro 3.8 se muestran los resultados de la segunda etapa para el sector de bienes no transables de la economía. La evidencia en este caso muestra una relación negativa entre el arancel promedio nacional y la tendencia de la tasa de informalidad en este sector. Las estimaciones por VI muestran un efecto de entre - 0.113 y -0.133 , indicando que una reducción del $10 \%$ en el arancel promedio se traduce en un incremento de alrededor de 1 punto porcentual en la tasa de informalidad. El signo de las restantes variables de control coincide con el esperado. La expansión del sector no transable aumenta la tasa de informalidad en este sector. De acuerdo a la discusión presentada en la sección 3.2, el efecto de una mayor oferta relativa se contrapone a un posible efecto riqueza positivo resultante de las ganancias derivadas del comercio y el efecto de la entrada de nuevas firmas que comienzan siendo pequeñas e informales. Una mayor oferta relativa de trabajadores informales calificados y no calificados en toda la economía se asocia positivamente con la tendencia en la tasa de informalidad del sector no transable, indicando que la informalidad en este sector se da tanto entre trabajadores no calificados como entre calificados. Por último, una mayor proporción de firmas pequeñas en este sector impacta positivamente sobre la tendencia de la tasa de informalidad.

Esta evidencia indica que el efecto positivo de la apertura comercial sobre la informalidad laboral a nivel de industria que se identificó a partir de la variabilidad de corte transversal de los datos, se revierte con el transcurso del tiempo para el sector de manufacturas en conjunto. Esto significa que, en promedio, la informalidad aumentó en las industrias con firmas pequeñas como consecuencia de los episodios de apertura comercial, pero una vez que los factores se reasignan entre sectores y los salarios ajustan, la tasa de informalidad en el sector de manufacturas se redujo junto con el arancel promedio. En términos del gráfico 3.2, la pendiente de la curva que muestra la evolución de la informalidad en el sector de manufacturas hubiese sido más pronunciada en ausencia de los episodios de liberalización del comercio. Detrás de este resultado también se encuentra la dinámica de firmas. Con el transcurso del tiempo las firmas que no pueden competir abandonan el mercado. Esta son las firmas menos productivas, pequeñas e informales. La evidencia también muestra que el sector de bienes no transables fue afectado por los cambios en los aranceles 
sobre las importaciones. En ausencia de reducciones en el arancel promedio de la economía, la tendencia de la informalidad laboral en este sector hubiese sido menor.

Existen distintos mecanismos que pueden explicar por qué la liberalización del comercio generó cambios en la tasa de informalidad del sector de bienes no transables: (i) la reducción de aranceles generó cambios en el precio de los insumos importados por este sector; (ii) el impacto de la apertura comercial sobre las industrias del sector de manufacturas dio lugar al desplazamiento de trabajadores entre sectores y al ajuste de su salario; (iii) la liberalización del comercio genera un incremento en la riqueza real que puede traducirse en un aumento en la demanda de bienes del sector no transable de la economía; (iv) si el sector no transable se expande durante el proceso de ajuste, esto puede determina el ingreso de nuevas firmas al sector. La primera hipótesis no parece haber dominado. Recurriendo a la misma lógica detrás de la reasignación de trabajadores entre la formalidad y la informalidad en el sector de manufacturas, una caída en el costo de los insumos no generaría incentivos a reducciones adicionales de costos mediante la eliminación de las contribuciones a la seguridad social. Los restantes argumentos parecen más apropiados. Se vio en la sección 3.3 que la descomposición del cambio en la tasa de informalidad en cambios que se dieron al interior de cada industria y cambios que se dieron entre industrias arrojó una mayor participación del efecto between al incorporar al sector no transable en el análisis. Esto significa que existieron desplazamientos de trabajadores entre el sector de manufacturas y el de bienes no transables y esos movimientos generaron aumentos en la tasa de informalidad de ambos sectores conjuntamente. Si bien una mayor oferta de trabajadores reduciría su precio y, entonces, el costo de la formalidad, el efecto de una mayor demanda de bienes, explicada por la mayor riqueza real de la economía, daría lugar al efecto neto positivo sobre la informalidad laboral en el sector no transable que muestra la evidencia empírica. La dinámica de firmas también puede ser un factor detrás de la relación positiva entre la apertura y el tasa de informalidad en el sector de bienes no transables. El gráfico 3.3 muestra en el panel izquierdo el cambio neto en el número de firmas para el sector de manufacturas y el sector no transable. Los datos corresponden a empresas registradas (que pueden emplear trabajadores formal e informalmente) y solo están disponibles para los últimos años de la serie. Estos datos muestran que el sector de manufacturas tuvo una evolución negativa en el número de firmas que se intensificó a partir del 
año $1998 .{ }^{34}$ El sector no transable, en cambio, tuvo una variación neta positiva entre 1996 y 1998 y negativo a partir de entonces cuando la economía se vio afectada por una serie de crisis de origen internacional. El panel derecho del gráfico muestra la relación entre el número de firmas y el número de puestos de trabajo asalariados. Este cociente es un indicador del tamaño promedio de los establecimientos en cada sector. En el sector de manufacturas no se observa variación significativa. Es posible que en este sector, que sufrió el impacto directo de la reducción de aranceles, el ajuste en el tamaño de los establecimientos se haya producido con anterioridad al año 1996. Asimismo, la salida de establecimientos reportada en el gráfico izquierdo habría dado lugar a una recuperación en el tamaño promedio de las firmas que permanecieron si las que abandonaron el mercado fueron las firmas pequeñas. En el sector de bienes no transables se produjo una reducción notoria en el tamaño promedio de los establecimientos. La evidencia de la dinámica de firmas estaría indicando que en este sector se produjo el ingreso de pequeños establecimientos y de acuerdo a los argumentos del modelo de la sección 3.1, esas firmas tendrían una alta proporción de su fuerza laboral en la informalidad. El gráfico 3.4 provee evidencia adicional al respecto. Este gráfico compara, para el sector de manufacturas y el de bienes no transables, la distribución del tamaño de firmas en el primer año de la serie (1980) y la distribución promedio para todo el periodo. Para el sector de manufacturas se observa un aumento en la participación de las firmas con menor número de empleados. Esta evidencia es compatible con la reducción de tamaño de las firmas que permanecieron en el mercado, efecto que habría dominado por sobre la salida de establecimientos reportada en el gráfico 3.3. Para el sector no transable también se observa un aumento en la participación de las firmas de menor tamaño. Esto es compatible con el ingreso de firmas reportado en el gráfico anterior y estaría indicando que aquellas que ingresaron fueron firmas pequeñas e informales.

\subsubsection{Análisis de robustez}

Con el objetivo de evaluar la robustez de los resultados obtenidos para la tendencia de la tasa de informalidad en el sector de manufacturas se proponen dos ejercicios en línea con el análisis de robustez realizado en las estimaciones cross-section.

El primero de ellos consiste en la inclusión de otras medidas de exposición al

\footnotetext{
${ }^{34}$ Sanchez y Butler (2004) muestran evidencia de salida de las firmas menos productivas del sector de manufacturas en el periodo 1990-2001 como consecuencia de la reducción de aranceles.
} 
comercio internacional. En primer lugar se incorporó el tipo de cambio real como control adicional. Como se explicó anteriormente, las fluctuaciones en el tipo de cambio real afectan la rentabilidad del sector transable en relación al sector no transable de la economía. Los resultados obtenidos para el sector de manufacturas se presentan en el panel superior del cuadro 3.9 y muestran, nuevamente, que las estimaciones no difieren estadísticamente de cero cuando la estimación se realiza por MCO y la relación es positiva y estadísticamente significativa bajo VI bajo las especificaciones 1 y 4 en este caso. En segundo lugar, se construyó, para cada periodo de tiempo, una medida de penetración de importaciones y otra de orientación hacia las exportaciones. Esto se hizo calculando el promedio de estas medidas para todas las industrias, ponderado por el nivel de empleo en cada una de ellas. ${ }^{35}$ Los resultandos se presentan en el panel inferior del cuadro 3.9 e indican que la caída en la tasa de informalidad en el sector de manufacturas en el largo plazo cuando el arancel promedio de la economía se reduce es robusta a la inclusión de estas medidas, con excepción de la especificación 2. La magnitud del efecto es superior al obtenido previamente, indicando que ante una reducción del $10 \%$ en el arancel promedio de la economía, la tasa de informalidad se reduce entre 2 y 3 puntos porcentuales.

El segundo ejercicio replica las estimaciones para el sector de manufacturas utilizando las definiciones alternativas de tamaño de industria introducidas previamente. Los resultados obtenidos se presentan en el cuadro 3.10. El primer panel muestra los resultados cuando se utiliza la primera clasificación alternativa de tamaño de industrias en la primera etapa. Al igual que en las estimaciones principales, los resultados muestran que en el largo plazo la tasa de informalidad del sector de manufacturas se reduce junto con el arancel promedio nacional cuando la estimación se realiza por VI. La magnitud de los efectos es similar a los obtenidos previamente y muestran un impacto que oscila entre 0.09 y 0.3. Bajo la segunda definición, en cambio, no se obtiene ningún efecto significativo estadísticamente, mientras que en la definición 3 las estimaciones indican nuevamente una reducción en la informalidad en el sector de manufacturas.

\footnotetext{
${ }^{35}$ Como se indicó en la sub-sección que realiza ejercicios de robustez para la evidencia de corto plazo, estas medidas se rezagan un periodo por la posible determinación simultánea de los flujos comerciales con la variable de resultado.
} 


\subsection{Conclusiones}

En este capítulo se analizó la relación entre la liberalización del comercio y la informalidad laboral en Argentina utilizando una extensa serie de datos que cubre el periodo 1980-2001. Este fue un periodo de importante cambios en la política comercial, capturados a través del cambios en los aranceles a las importaciones en industrias del sector de manufacturas, y de incrementos en la tasa de informalidad.

A lo largo del capítulo se postularon varios mecanismos a través de los cuales esta relación puede darse. En primer lugar, las firmas del sector de manufacturas que enfrentan un episodio de liberalización del comercio y compiten con las importaciones reducen el tamaño de su fuerza laboral y al mismo tiempo modifican la composición de su fuerza de trabajo, sustituyendo trabajadores formales por informales. La evasión de impuestos es una estrategia que pueden implementar las firmas para suavizar el impacto del shock negativo. En segundo lugar, el sector de bienes no transables también puede ser afectado a través de efectos de equilibrio general. Los trabajadores desplazados del sector de manufacturas pueden moverse a un sector no transable en expansión donde pueden ser empleados formal o informalmente. Por último, la dinámica de las firmas también puede estar detrás de la evolución de la tasa de informalidad en ambos sectores a partir de la salida y entrada de firmas pequeñas e informales.

Estas relaciones fueron evaluadas empíricamente y los principales hallazgos mostraron, primero, que la liberalización del comercio impactó positivamente sobre la informalidad laboral de las industrias en el corto plazo, cuando los trabajadores no se desplazan entre sectores y los salarios no ajustan. La magnitud de este efecto depende del tamaño de las firmas en cada industria. Cuando las firmas pequeñas son las que predominan, la sustitución de trabajadores formales por informales es un mecanismo presente, pero este efecto se diluye con el tamaño de las firmas. Detrás de este patrón decreciente en el tamaño de las firmas se encuentran los argumentos de la literatura de evasión de impuestos (el nivel de evasión es menor en firmas grandes que enfrentan una probabilidad alta de detección), el diferente comportamiento de las firmas según su exposición al comercio internacional (las firmas exportadoras que pueden acceder a nuevos mercados con la apertura tienden a ser grandes), y la incorporación de bienes de capital que permiten lograr mejoras de productividad (la evidencia muestra un patrón de mejoras de productividad creciente en el tamaño de 
las firmas).

En segundo lugar, la evidencia obtenida a partir de la variabilidad de los datos en el tiempo permitió identificar un efecto de largo plazo, una vez que los factores pueden desplazarse entre sectores y los salarios ajustan. Los resultados obtenidos mostraron que, condicional en la estructura sectorial de protección, la tendencia de la informalidad en el sector de manufacturas se movió junto con el arancel promedio nacional, y lo contrario ocurrió en el sector de bienes no transables. Esta es una contribución importante del trabajo. El efecto identificado para las industrias del sector de manufacturas en el corto plazo se revierte en el largo plazo, y el sector de bienes no transables también es afectado por el episodio de liberalización del comercio a través de efectos de equilibrio general. Estos resultados pueden racionalizarse a partir de la movilidad del trabajo desde el sector de manufacturas hacia el de bienes no transables, el ajuste de salarios, la salida de las firmas pequeñas e informales que no pudieron competir en el sector de manufacturas y el ingreso de nuevas firmas pequeñas al sector de bienes no transables.

Esta relación entre informalidad laboral y cambios en la política comercial fue formalizada a través de un modelo para una industria que compite con las importaciones. El modelo permite que exista evasión de impuestos, el trabajo formal e informal son sustitutos perfectos en la producción, y en el corto plazo los trabajadores no puede moverse entre sectores y el salario no ajusta. Para cada tamaño posible de firma en esta industria, existe una combinación óptima de trabajo formal e informal. Al enfrentan un aumento en el grado de exposición al comercio internacional, las firmas reducen el tamaño de su fuerza laboral y también modifican su composición, aumentando la participación del empleo informal en función de la probabilidad de detección por parte de la autoridad tributaria. En el largo plazo, cuando el trabajo puede moverse entre sectores y los salarios ajustan, la tasa de informalidad en el sector de manufacturas se reduce, mientras que un efecto riqueza puede aumentar la tasa de informalidad en el sector de bienes no transables.

El modelo y los resultados empíricos permiten racionalizar algunos de los ajustes de corto y largo plazo observados en países en desarrollo luego de episodios de liberalización del comercio. También se valida empíricamente la intuición de que el canal de evasión-informalidad es relevante como mecanismo de ajuste de la demanda de trabajo de las firmas, permitiendo suavizar el impacto del shock. Esta puede ser una de las razones detrás de la resistencia de los gobiernos en países en desarrollo a 
aumentar los esfuerzos para mejorar el cumplimiento de las regulaciones, al menos en momentos de reforma. Si bien los trabajadores sufren un costo en términos de trabajos de menor calidad, este margen de ajuste adicional permite mantener el nivel de empleo, siendo este uno de los trade-offs que enfrentan los policy makers. La distinción entre el ajuste de corto y largo plazo muestra otra dimensión de este trade-off. Para el caso particular de Argentina, la tasa de informalidad se reduce en el largo plazo en el sector de manufacturas, pero aumenta en el sector de bienes no transables.

La movilidad del trabajo entre sectores es usualmente evaluada como deseable, y este trabajo indicó que existe una dimensión adicional en la que sería beneficiosa para permitir el ajuste hacia el equilibrio de largo plazo a un menor costo. En este caso, permitiría una transición más suave hacia el equilibrio final, evitando aumentos transitorios en la informalidad laboral y la aparición de desempleo. Una red de protección social más amplia no asociada al empleo (como es el caso de la mayoría de los sistema de seguro social en América Latina) ayudaría a mitigar los costos para aquellos trabajadores que pierden los beneficios de la seguridad social durante el proceso de ajuste. 


\subsection{Apéndice}

\section{Problema de optimización de las firmas}

Las firmas maximizan la función de beneficios:

$\max _{\left(l_{i}, l_{f}\right)} \pi=p(1+t) a^{\beta}\left(l_{i}+l_{f}\right)^{1-\beta}-w_{f}(1+s) l_{f}-\left[w_{i}+q\left(l_{i}, l_{f}\right) m\right] l_{i}$

Condiciones de primer orden del problema de maximización:

$\frac{\partial \pi}{\partial l_{f}}=p(1+t) a^{\beta}(1-\beta)\left(l_{i}+l_{f}\right)^{-\beta}-w_{f}(1+s)-m l_{i} \frac{\partial q}{\partial l_{f}}=0$

$\frac{\partial \pi}{\partial l_{i}}=p(1+t) a^{\beta}(1-\beta)\left(l_{i}+l_{f}\right)^{-\beta}-w_{i}-q\left(l_{i}, l_{f}\right) m-m l_{i} \frac{\partial q}{\partial l_{i}}=0$

De esas condiciones se obtiene:

$\frac{\partial q / \partial l_{f}}{\partial q / \partial l_{i}}=\frac{p(1+t) a^{\beta}(1-\beta)\left(l_{i}+l_{f}\right)^{-\beta}-w_{f}(1+s)}{p(1+t) a^{\beta}(1-\beta)\left(l_{i}+l_{f}\right)^{-\beta}-w_{i}-m q\left(l_{i}, l_{f}\right)}=\sigma<1$

$\left(l_{i}+l_{f}\right)^{*}=a\left[\frac{p(1+t)(1-\beta)(1-\sigma)}{w_{f}(1+s)-\sigma\left(w_{i}+m q\right)}\right]^{\frac{1}{\beta}}$

\section{Cambio en la composición de la fuerza laboral}

La firma que enfrenta una reducción en la tasa arancelaria $(t)$ ajusta su demanda por $l_{i}$ y $l_{f}$ :

$\frac{\partial l_{i}^{d}}{\partial t}=\frac{-\partial \Pi / \partial t}{|H|}\left[\frac{\partial \Pi_{f}}{\partial l_{f}}-\frac{\partial \Pi_{i}}{\partial l_{f}}\right]$

$\frac{\partial l_{f}^{d}}{\partial t}=\frac{-\partial \Pi / \partial t}{|H|}\left[\frac{\partial \Pi_{i}}{\partial l_{i}}-\frac{\partial \Pi_{f}}{\partial l_{i}}\right]$

donde

$\Pi_{f}=\frac{\partial \pi}{\partial l_{f}}, \Pi_{i}=\frac{\partial \pi}{\partial l_{i}}, \frac{\partial \Pi}{\partial t}=\frac{\partial \Pi_{i}}{\partial t}=\frac{\partial \Pi_{f}}{\partial t}$

$|H|=\lambda_{1}+\lambda_{2} \frac{\partial q}{\partial l_{f}}+\lambda_{3}\left(\frac{\partial q}{\partial l_{f}}\right)^{2}$

$\operatorname{con} \lambda_{1}=-2 m p(1+t) \frac{\partial^{2} f\left(l_{i}, l_{f}\right)}{\partial l_{f}^{2}} \frac{\partial q}{\partial l_{i}}, \lambda_{2}=2 m p(1+t) \frac{\partial^{2} f\left(l_{i}, l_{f}\right)}{\partial l_{f} \partial l_{i}}, \lambda_{3}=-m^{2}$.

$|H|$ es una forma cuadrática en $\partial q / \partial l_{f}$ con una raíz positiva $\left(r_{1}\right)$ y una negativa $\left(r_{2}\right)$. Entonces $|H|>0$ y la combinación óptima $\left(l_{i}, l_{f}\right)$ es un máximo si $\partial q / \partial l_{f} \epsilon\left(0, r_{1}\right]$. 
Reemplazando las derivadas de segundo orden y considerando que $q\left(l_{i}, l_{f}\right)$ depende linealmente de $l_{i}$ y $l_{f}$ :

$$
\begin{aligned}
& \frac{\partial l_{i}^{d}}{\partial t}=\frac{-p a^{\beta}(1-\beta)\left(l_{i}+l_{f}\right)^{-\beta}}{|H|}\left[m\left(\frac{\partial q_{1}}{\partial l_{f}}+\frac{\partial q_{2}}{\partial l_{f}}\right)\right]<0 \\
& \frac{\partial l_{f}^{d}}{\partial t}=\frac{-p a^{\beta}(1-\beta)\left(l_{i}+l_{f}\right)^{-\beta}}{|H|}\left[-2 m\left(\frac{\partial q_{1}}{\partial l_{i}}+\frac{\partial q_{2}}{\partial l_{i}}\right)+m\left(\frac{\partial q_{1}}{\partial l_{f}}+\frac{\partial q_{2}}{\partial l_{f}}\right)\right]>0
\end{aligned}
$$

\section{Relación con el tamaño de las firmas}

Recurriendo a las expresiones 3.12 y 3.13, el efecto de primer orden del tamaño de las firmas sobre el cambio en la tasa de informalidad de la industria $j$ cuando cambia $t$ es:

$\frac{\partial\left[\partial I^{j} / \partial t\right]}{\partial\left(L_{f}^{j}+L_{i}^{j}\right)}=\frac{\partial\left[\partial L_{i}^{j} / \partial t\right]}{\partial\left(L_{f}^{j}+L_{i}^{j}\right)} \Theta_{f}-\frac{\partial\left[\partial L_{f}^{j} / \partial t\right]}{\partial\left(L_{f}^{j}+L_{i}^{j}\right)} \Theta_{i}>0$,

donde $\Theta_{f}=\frac{L_{f}^{j}}{\left(L_{i}^{j}+L_{f}^{j}\right)^{2}}, \Theta_{i}=\frac{L_{i}^{j}}{\left(L_{i}^{j}+L_{f}^{j}\right)^{2}}$ y ambas fracciones se asumen fijas.

El efecto del arancel sobre la tasa de informalidad es negativo y crece con el tamaño de las firmas en la industria (se aproxima a cero). Este aumento se produce a un ritmo decreciente:

$$
\frac{\partial^{2}\left[\partial I^{j} / \partial t\right]}{\partial\left(L_{f}^{j}+L_{i}^{j}\right)^{2}}=\frac{\partial^{2}\left[\partial L_{i}^{j} / \partial t\right]}{\partial\left(L_{f}^{j}+L_{i}^{j}\right)^{2}} \Theta_{f}-\frac{\partial^{2}\left[\partial L_{f}^{j} / \partial t\right]}{\partial\left(L_{f}^{j}+L_{i}^{j}\right)^{2}} \Theta_{i}<0 .
$$




\subsection{Cuadros}

Cuadro 3.1: Descomposición del cambio en la tasa de informalidad Años 1980-2001

\begin{tabular}{cccccc}
\hline \hline \multicolumn{2}{c}{ Sector de manufacturas } & \multicolumn{3}{c}{ Sectores de manufacturas y no transable } \\
\hline $\begin{array}{c}\text { Cambio en la } \\
\text { informalidad }\end{array}$ & $\begin{array}{c}\text { Efecto } \\
\text { Within }\end{array}$ & $\begin{array}{c}\text { Efecto } \\
\text { Between }\end{array}$ & $\begin{array}{c}\text { Cambio en la } \\
\text { informalidad }\end{array}$ & $\begin{array}{c}\text { Efecto } \\
\text { Within }\end{array}$ & $\begin{array}{c}\text { Efecto } \\
\text { Between }\end{array}$ \\
\hline 18.01 & 18.04 & -0.03 & 18.67 & 17.69 & 0.98 \\
& $(100.15 \%)$ & $(-0.15 \%)$ & & $(94.74 \%)$ & $(5.26 \%)$ \\
\hline
\end{tabular}

Fuente: Elaboración propia en base a EPH. 


\section{Cuadro 3.2: Cambio en los aranceles industriales y factores de política económica}

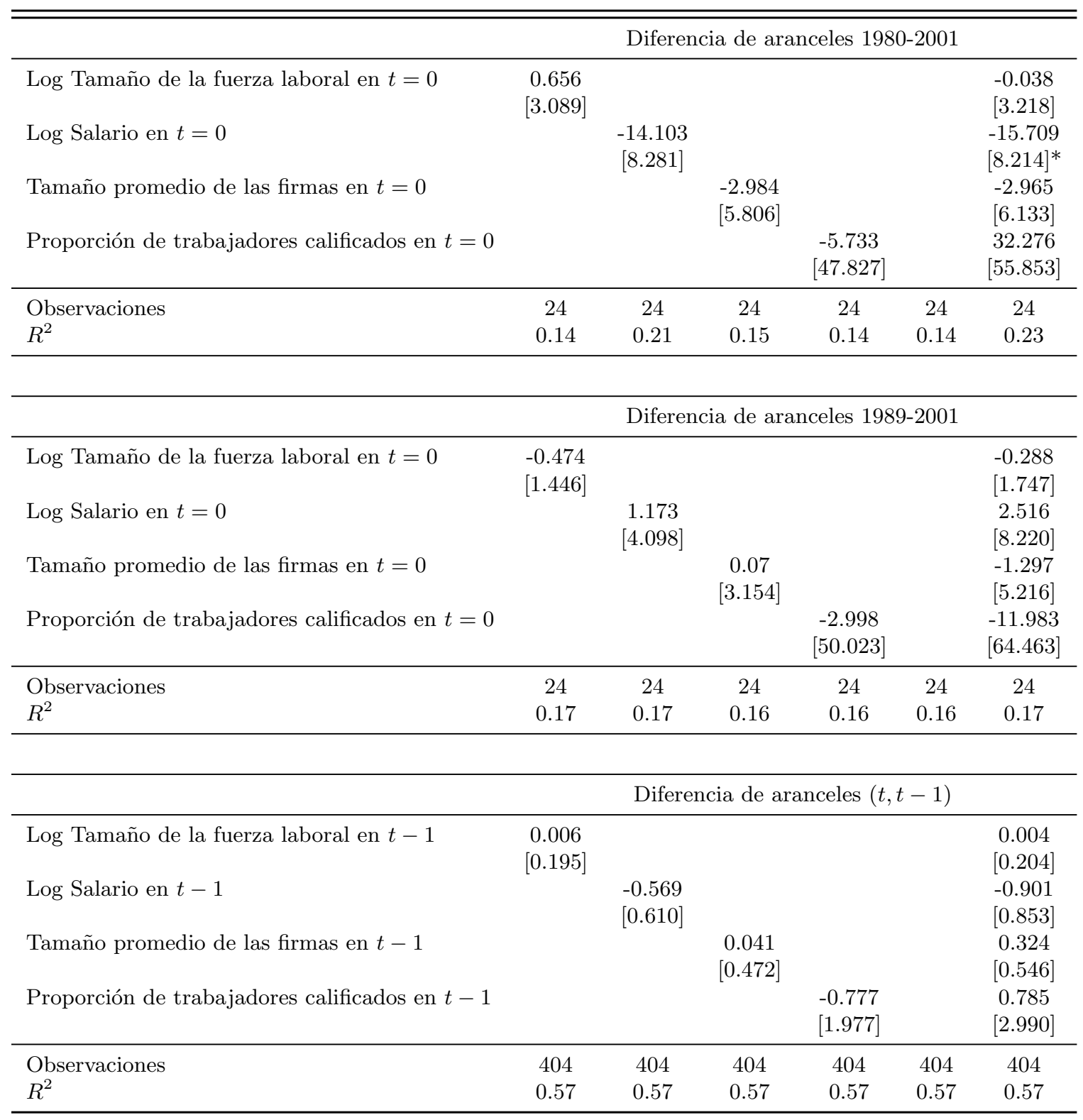

Fuente: Elaboración propia en base a EPH y Galiani y Porto (2010).

Notas: Estimaciones por MCO. Errores estándar robustos entre corchetes. Todos los modelos incluyen variables indicadoras del tipo de industria (bienes de capital, bienes de consumo durables, bienes de consumo no durables y bienes intermedios) y ponderan por la raíz cuadrada del nivel de empleo en cada una de ellas. El último modelo también incluye variables indicadoras de periodo de tiempo.

*** significativo al $1 \%$; ** significativo al $5 \%$; $*$ significativo al $10 \%$. 


\section{Cuadro 3.3: Resultados de la primera etapa}

\begin{tabular}{lccc}
\hline \hline & $\begin{array}{c}\text { Log de } \\
\text { aranceles }\end{array}$ & $\begin{array}{c}\text { Log de } \\
\text { aranceles } I_{P}\end{array}$ & $\begin{array}{c}\text { Log de } \\
\text { aranceles* } I_{M}\end{array}$ \\
\hline$z_{j t}^{1}$ & -0.271 & -0.021 & 0.048 \\
$z_{j t}^{1} * I_{P}$ & {$[0.020]^{* * *}$} & {$[0.002]^{* * *}$} & {$[0.006]^{* * *}$} \\
& -0.239 & -0.328 & 0.077 \\
$z_{j t}^{1} * I_{M}$ & {$[0.022]^{* * *}$} & {$[0.017]^{* * *}$} & {$[0.007]^{* * *}$} \\
& 0.168 & 0.002 & 0.014 \\
$z_{j t}^{2}$ & {$[0.011]^{* * *}$} & {$[0.001]^{* *}$} & {$[0.007]^{* *}$} \\
& -0.094 & -0.005 & -0.048 \\
$z_{j t}^{2} * I_{P}$ & {$[0.007]^{* * *}$} & {$[0.001]^{* * *}$} & {$[0.004]^{* * *}$} \\
& 0.025 & -0.085 & 0.004 \\
$z_{j t}^{2} * I_{M}$ & {$[0.001]^{* * *}$} & {$[0.001]^{* * *}$} & {$[0.000]^{* * *}$} \\
& 0.020 & 0.000 & -0.089 \\
\hline Observaciones & {$[0.001]^{* * *}$} & {$[0.000]$} & {$[0.001]^{* * *}$} \\
$R^{2}$ & 26795 & 26795 & 26795 \\
Test F & 0.74 & 1.00 & 1.00 \\
p-valor & 164.53 & 1754.73 & 2043.56 \\
\hline
\end{tabular}

Fuente: Elaboración propia en base a EPH y Galiani y Porto (2010).

Nota: Errores estándar agrupados por año e industria entre corchetes. $z_{j t}^{1}$ es el tipo de cambio que enfrenta cada industria; $z_{j t}^{2}$ es el arancel inicial interactuado con una variable que identifica las tres etapas en la política comercial argentina. Ver texto para más detalles. $I_{P}$ e $I_{M}$ son variables indicadoras de industrias inicialmente pequeñas y medianas, respectivamente.

*** significativo al $1 \%$; ** significativo al $5 \%$; ${ }^{*}$ significativo al $10 \%$. 


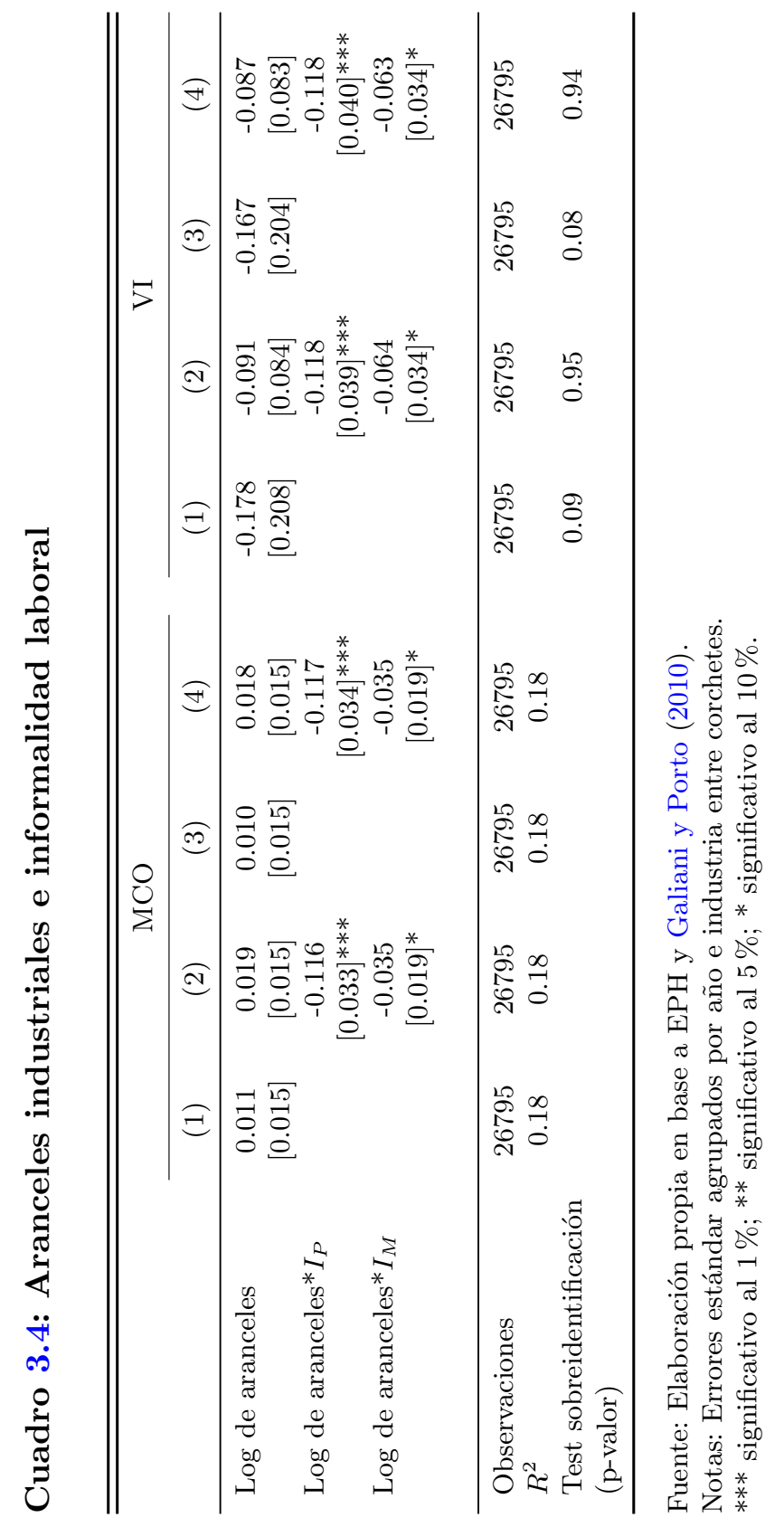




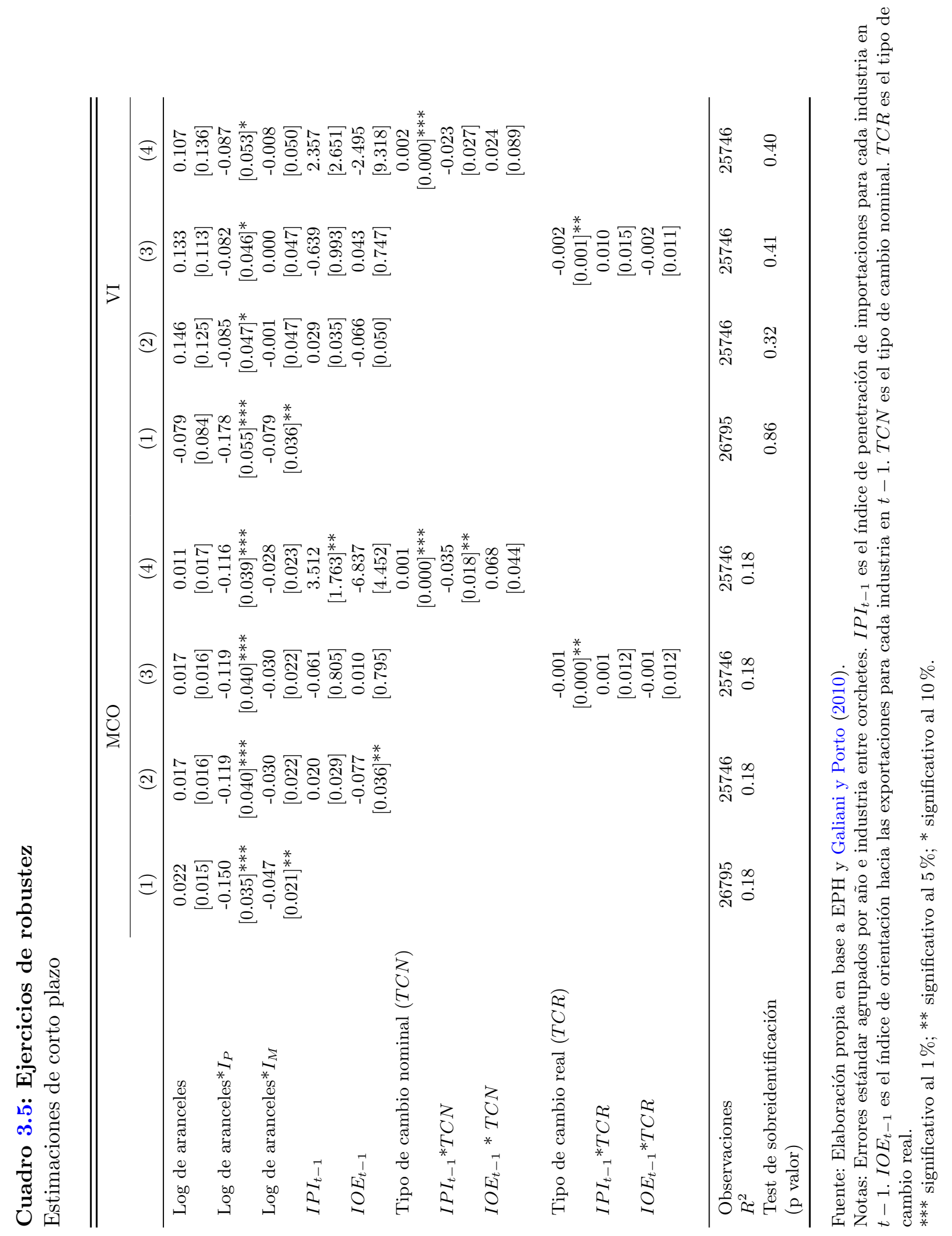




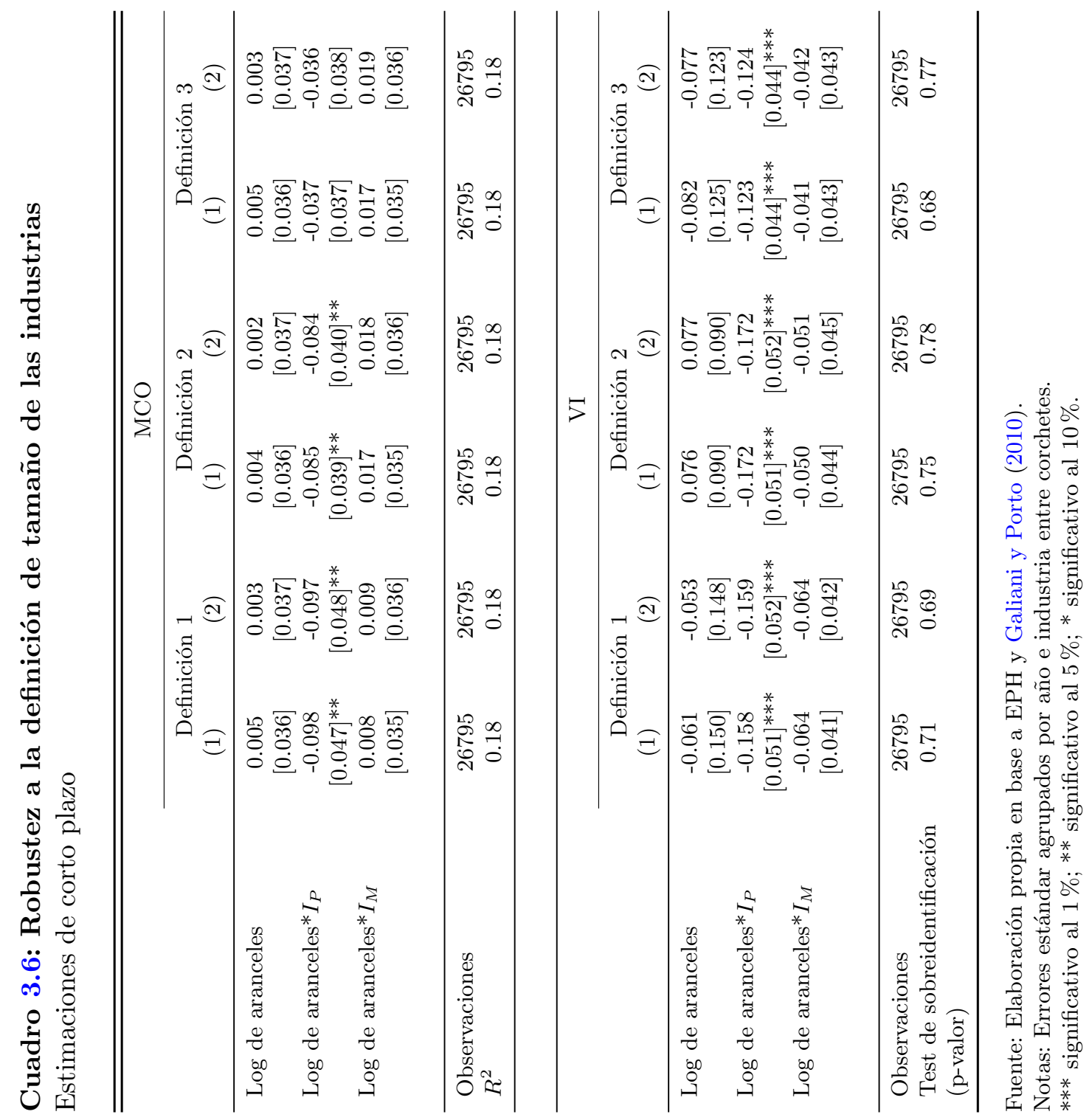




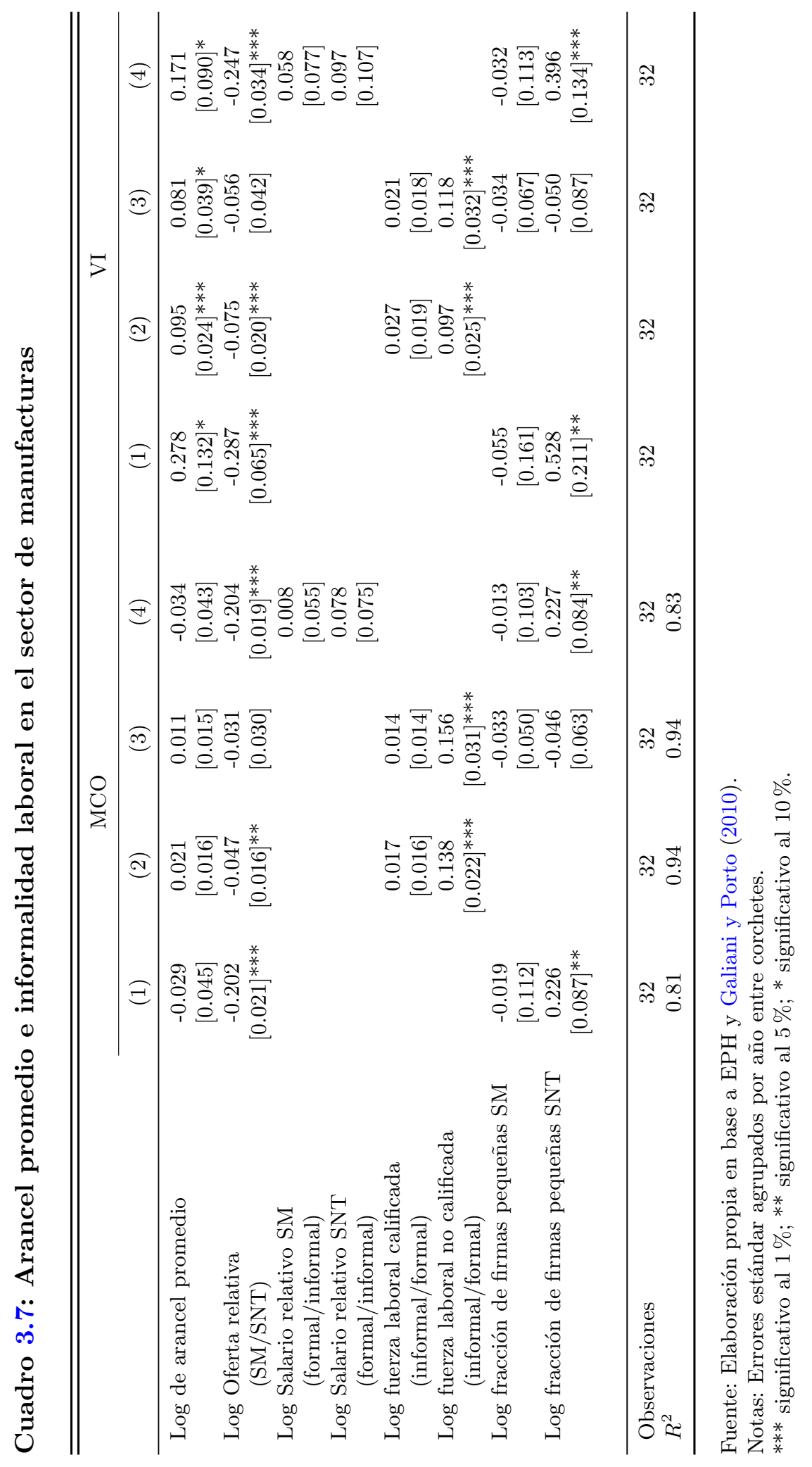




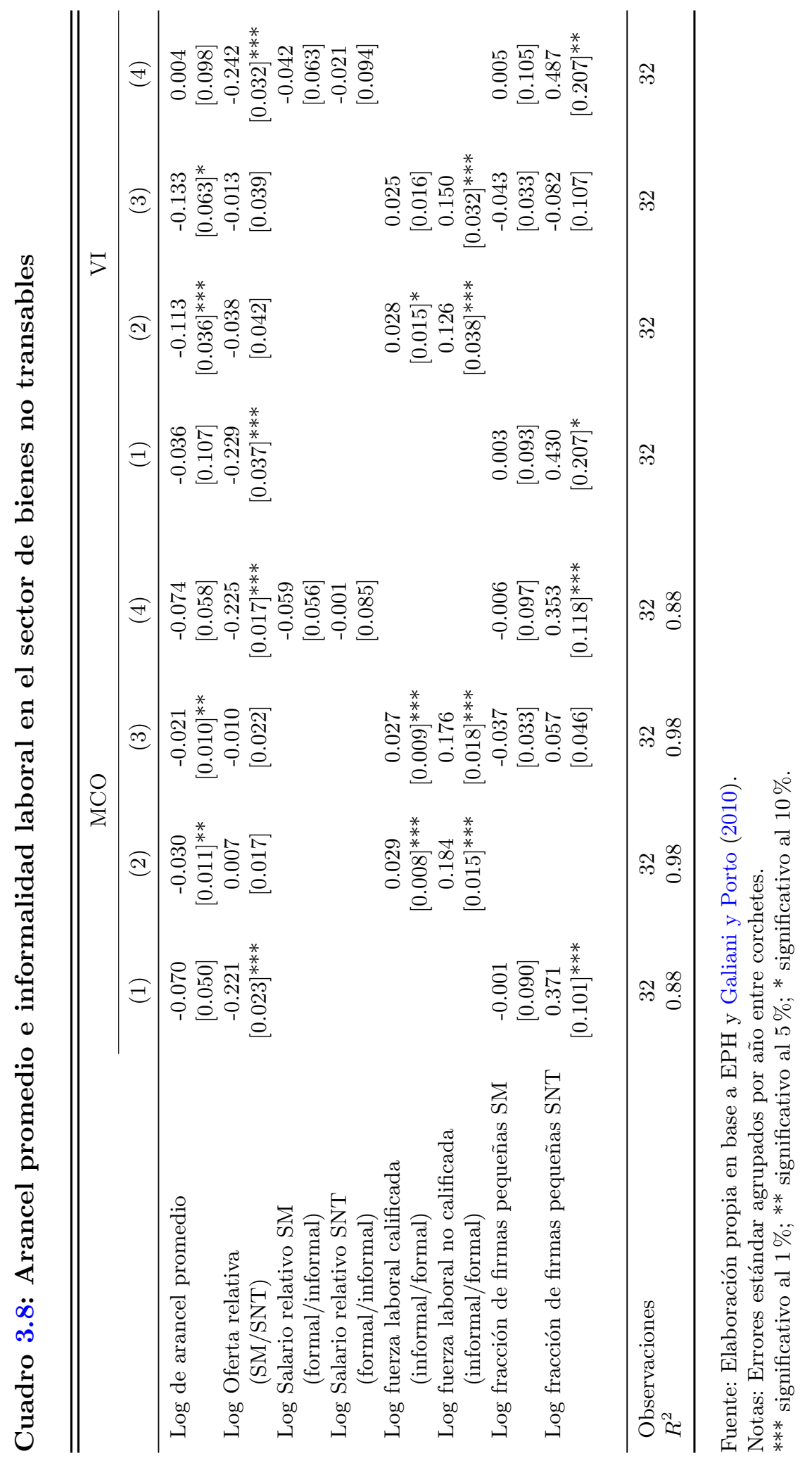




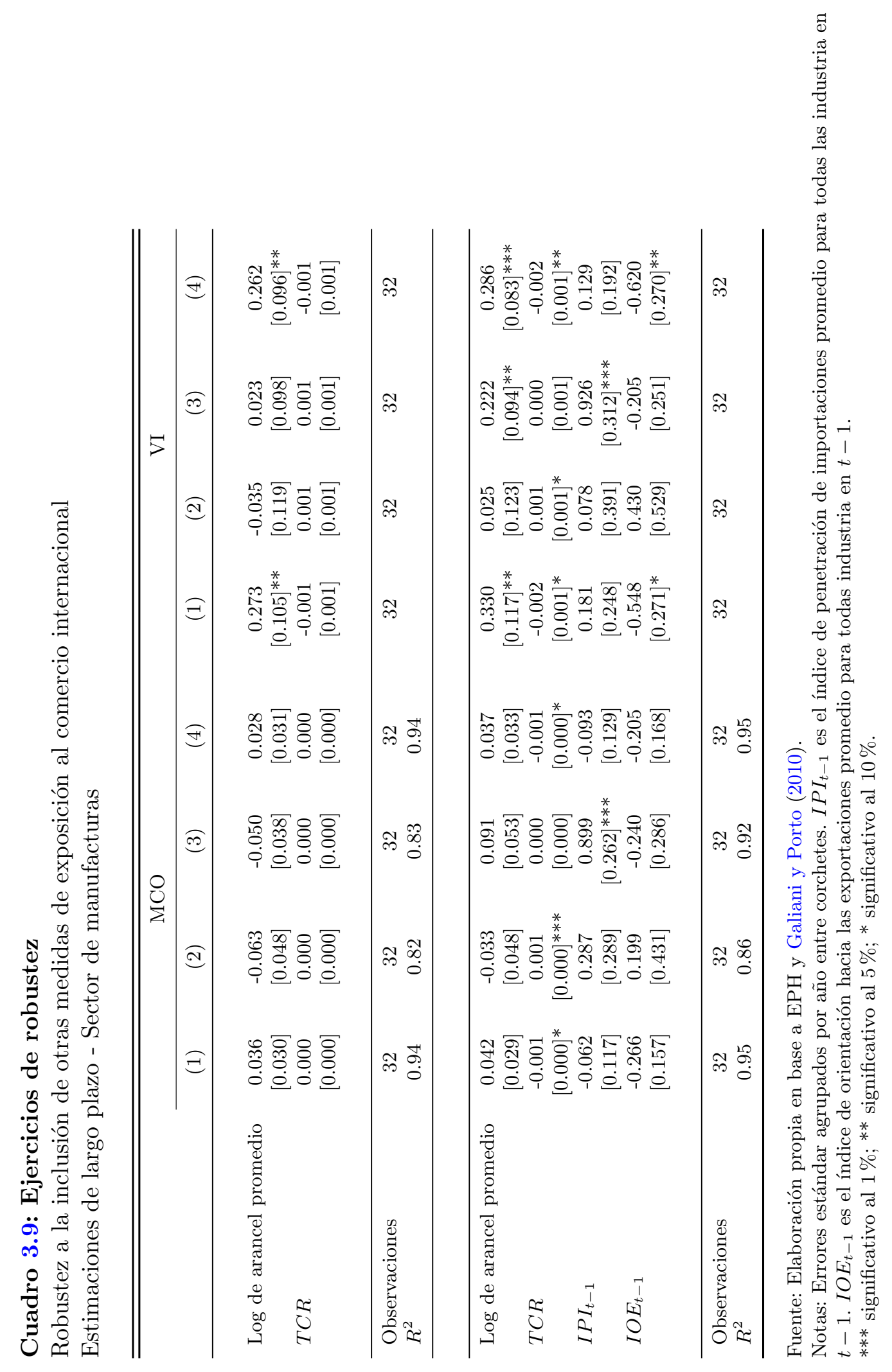




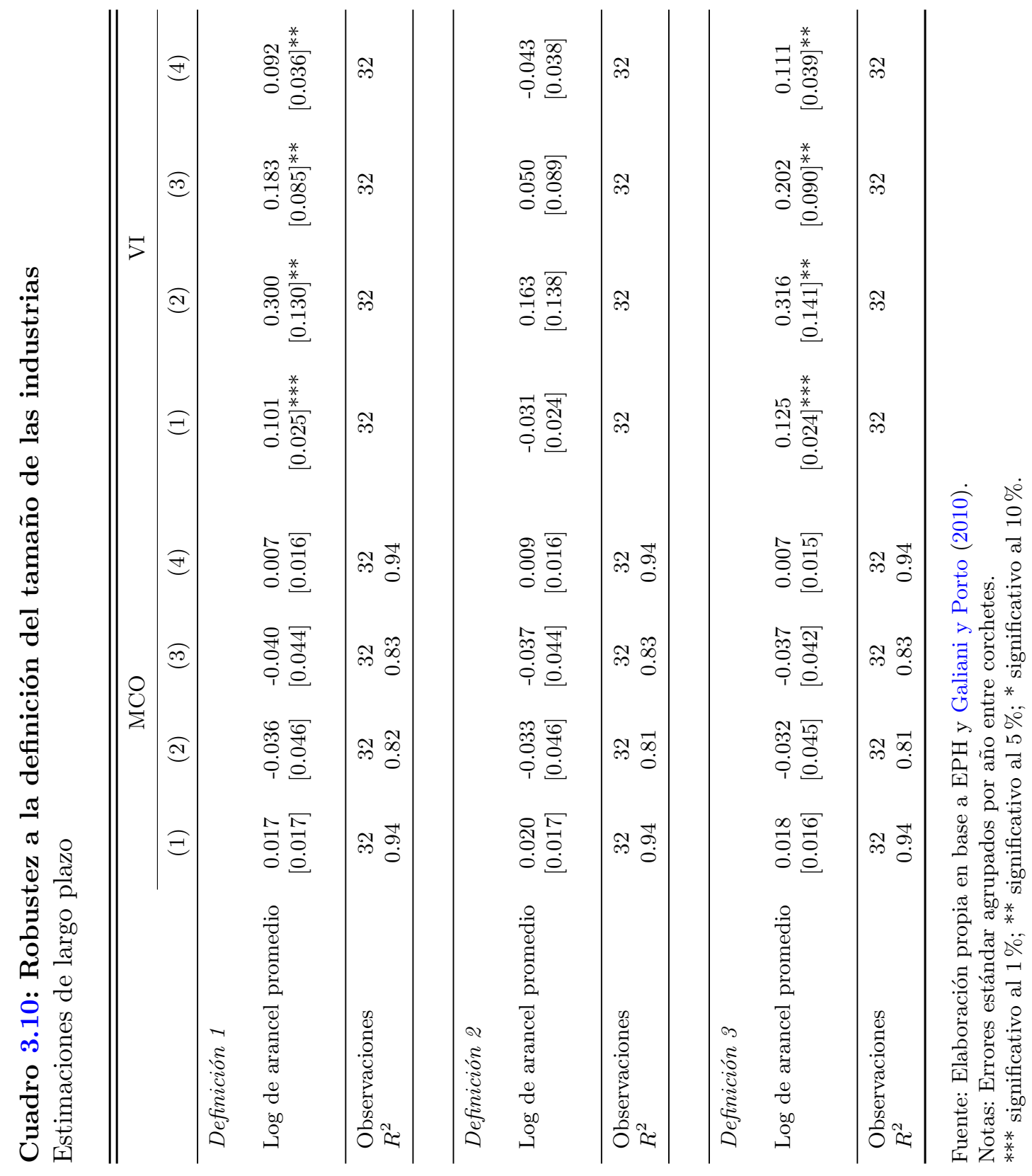




\subsection{Gráficos}

\section{Gráfico 3.1}

Cambio en la tasa de informalidad y Tamaño de las industrias

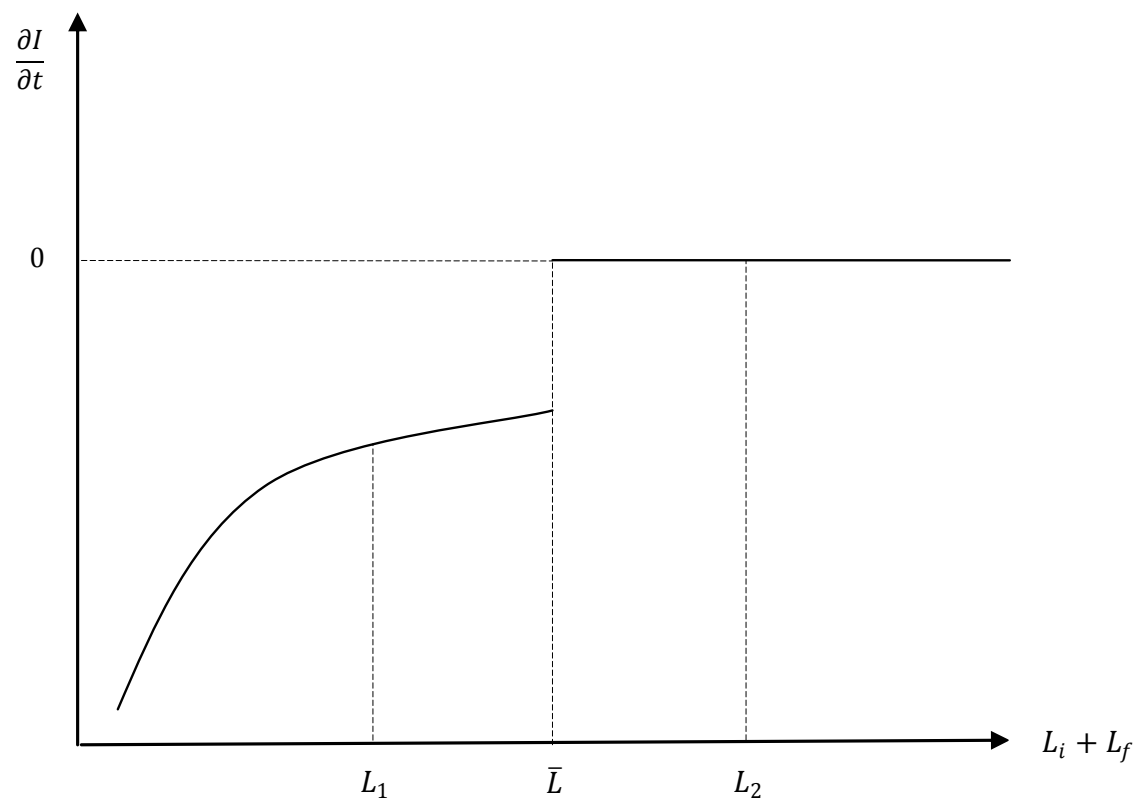

Fuente: Elaboración propia. 
Gráfico 3.2

Informalidad laboral y aranceles sobre las importaciones

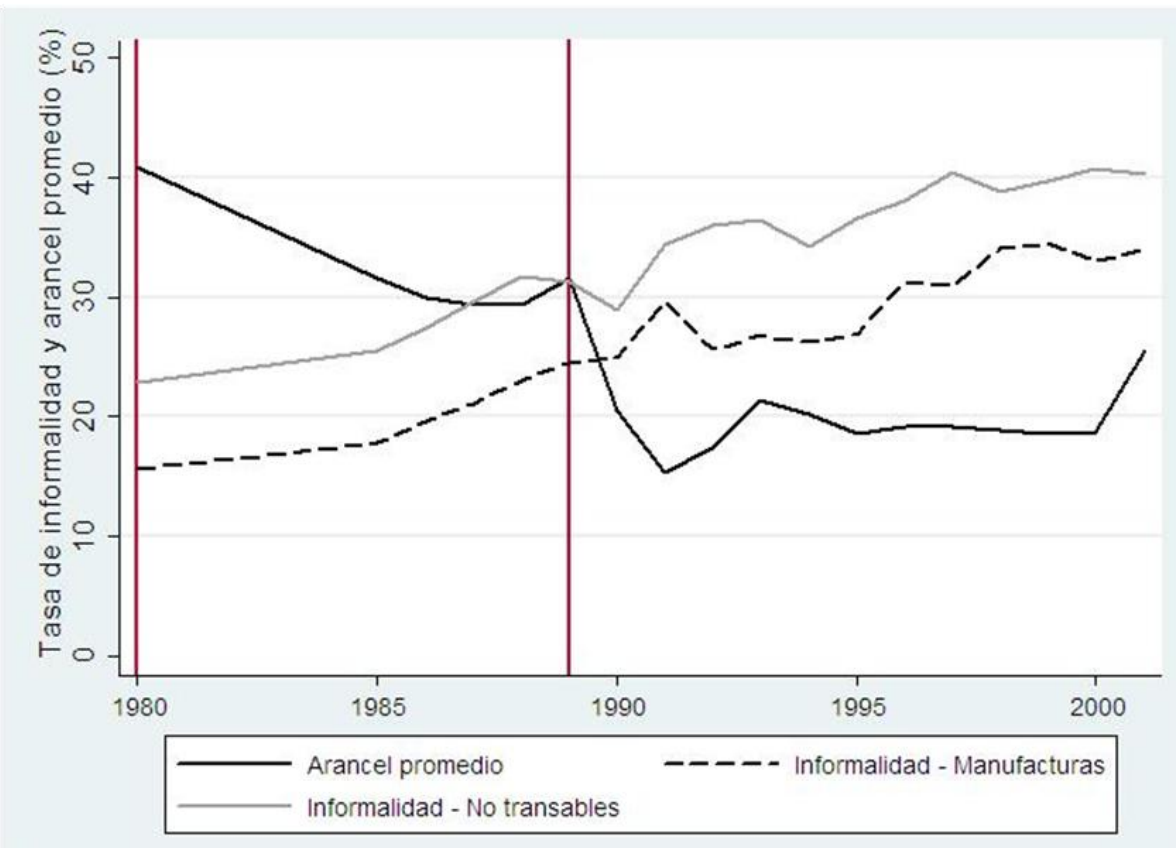

Fuente: Elaboración propia en base a EPH y Galiani y Porto (2010). 


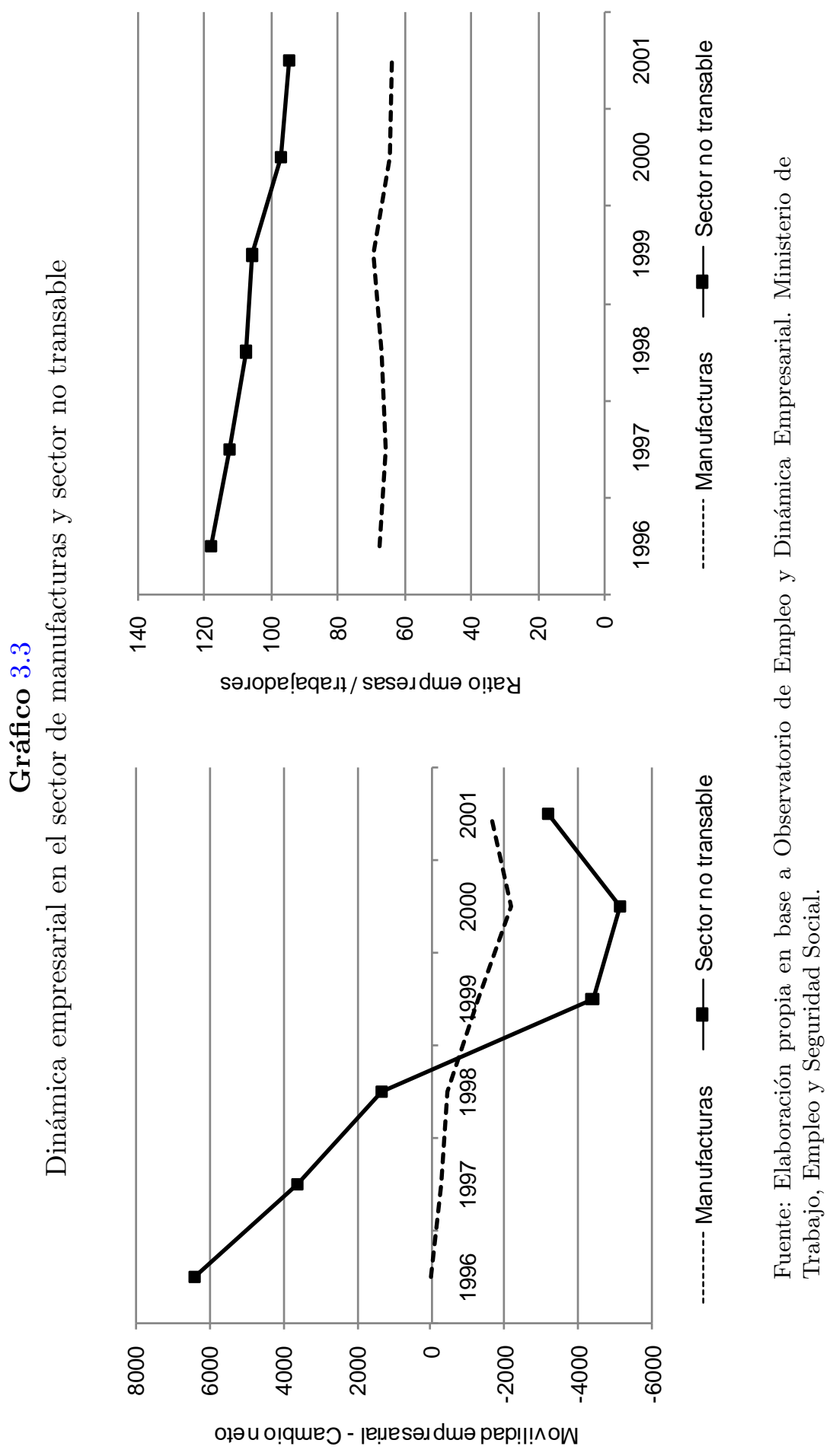




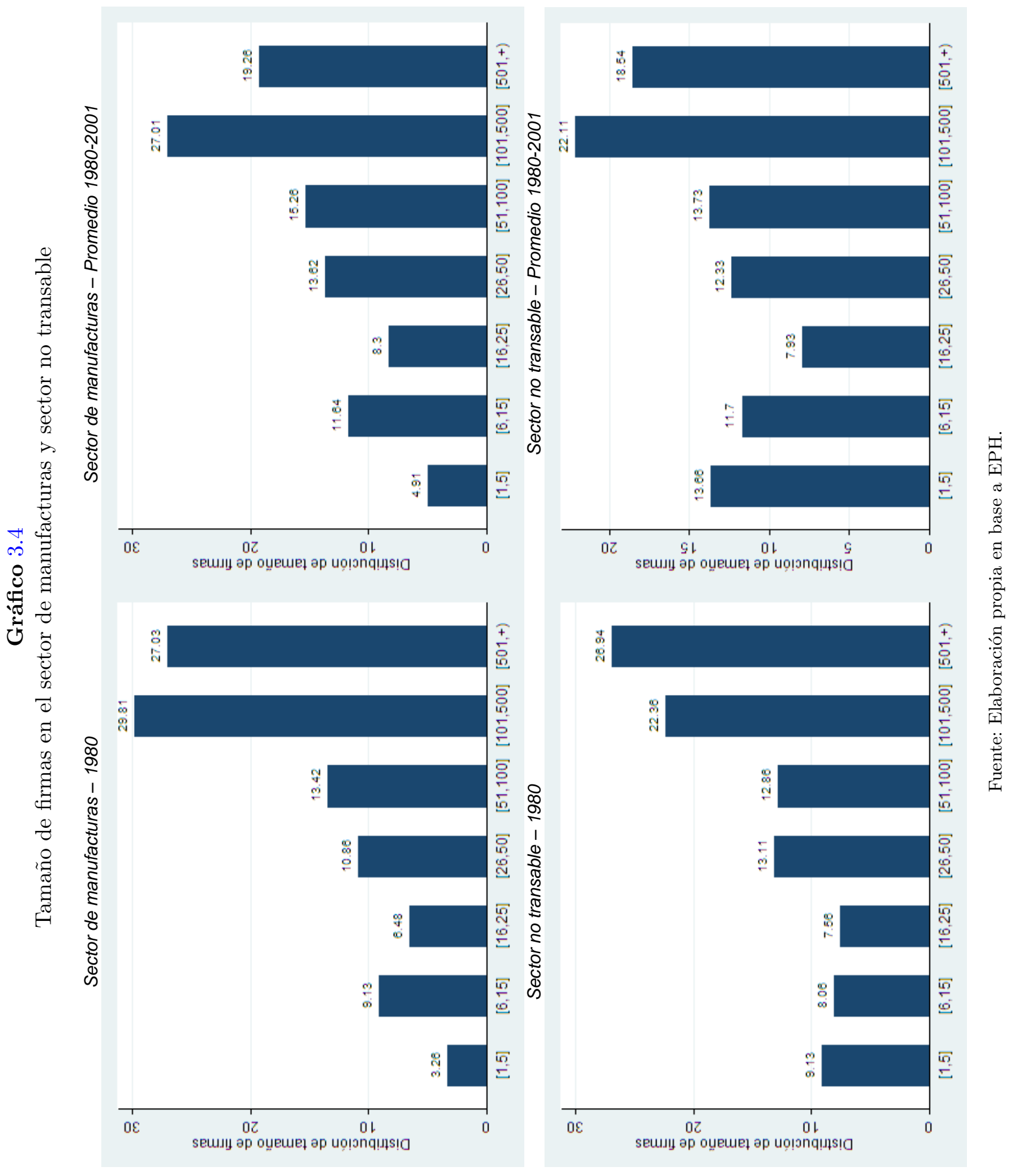




\section{Capítulo 4}

\section{Análisis de transiciones laborales}

Los mercados laborales de países en desarrollo han mostrado procesos de ajuste complejos ante eventos de liberalización del comercio. Los modelos tradicionales de la TCI predicen que si se eliminan las barreras al comercio los factores deberían reasignarse desde los sectores que pierden protección hacia los que poseen ventaja comparativa (modelo Ricardiano) o hacia los que utilizan de manera intensiva el factor relativamente abundante en el país (modelo de Hecksher-Ohlin). La evidencia indica que este proceso de ajuste se caracteriza por la creación y destrucción simultánea de empleos al interior de cada industria y por una reasignación muy lenta entre sectores. En efecto, el ajuste al nuevo equilibrio puede durar varios años (Cosar, 2013; Dix-Carneiro, 2011; Atolia, 2007). La evidencia para Argentina es consistente con el patrón común a los países en desarrollo al mostrar que el principal canal de reasignación del empleo durante la transición se da al interior de cada industria y no entre industrias como predice la teoría.(Wacziarg y Wallack, 2004; Haltiwanger et al., 2004; Sanchez y Butler, 2004). ${ }^{1}$

Los resultados presentados en el capítulo 3 constituyen evidencia adicional en favor de procesos de ajuste de este tipo. La evidencia encontrada mostró que la informalidad laboral aumentó en industrias con firmas inicialmente pequeñas y medianas como consecuencia de los episodios de liberalización del comercio. Estos efectos fueron identificados a partir de la variabilidad de las tasas arancelarias entre industrias a lo largo del tiempo. La evidencia de ausencia de reasignación del empleo entre industrias y sectores luego de los episodios de apertura comercial permitió interpretar

\footnotetext{
${ }^{1}$ El capítulo 1 presentó la revisión de esta literatura.
} 
este resultado como un efecto de corto plazo. Como consecuencia, la informalidad laboral sería un mecanismo de ajuste adicional a los propuestos por la TCI y que las firmas pueden utilizar para enfrentan un shock de política comercial.

Los cambios en la tasa de informalidad a nivel de industria son compatibles con distintos comportamiento por parte de las firmas. Uno de ellos es la rotación del empleo. Las firmas pueden cambiar la composición de la fuerza laboral despidiendo y contratando trabajadores formales e informales en distinta medida. Algunas firmas estarán reduciendo el tamaño de su planta de empleados mientras que otras se estarán expandiendo, típicamente las firmas exportadoras y las que logran mejoras de productividad con la apertura comercial. Esto podría implicar, por ejemplo, la incorporación de formales por parte de las firmas que se expanden y el despido de informales por parte de las que reducen el tamaño de la fuerza laboral con diferentes implicancias en la tasa de informalidad a nivel de industria. Otro comportamiento posible es el cambio en la naturaleza de una relación laboral ya existente. En este caso el mismo trabajador cambiaría su condición pasando de la formalidad a la informalidad al perder los beneficios de la seguridad social. Esta segunda opción no necesariamente implica una decisión unilateral por parte de las firmas. Las dos partes, empleado y empleador, pueden alcanzar un acuerdo que es beneficio para ambos. La firma logra reducir sus costos laborales, mientras que el trabajador logra conservar su empleo. ${ }^{2}$ Este capítulo propone analizar la relevancia de cada uno de estos mecanismos en el proceso de ajuste del mercado de trabajo. Para esto se utiliza la estructura de panel de la EPH que permite observar la situación ocupacional de un mismo individuo en dos años consecutivos. La EPH Puntual, encuesta llevada a cabo por el INDEC durante el periodo de tiempo que abarca este trabajo, se llevó a cabo con un esquema de panel rotativo. Bajo este esquema los hogares son encuestados durante cuatro ondas consecutivas (mayo y octubre) permitiendo la construcción de paneles cortos que siguen a un mismo individuo durante un periodo máximo de un año y medio. La posibilidad de observar las trayectorias laborales de los individuos y vincularlas a la evolución de variables de política comercial permite complementar el análisis del capítulo 3 caracterizando el proceso de ajuste del mercado laboral. En ese caso se identificó un efecto de corto plazo a nivel de industria mientras que en este capítulo se abordan las transiciones laborales a nivel individual.

\footnotetext{
${ }^{2}$ Existe evidencia que muestra que este tipo de negociaciones entre empleadores y trabajadores existe. Bérgolo y Cruces (2013) presentan evidencia de colusión entre empleadores y empleados para el caso de Uruguay donde ambas partes acuerdan la subdeclaración de ingresos.
} 
Son pocos los estudios que han analizado la movilidad ocupacional entre la formalidad e informalidad en respuesta a cambios en la política comercial a nivel individual. ${ }^{3}$ Menezes-Filho y Muendler (2011) utilizan datos administrativos para seguir a los trabajadores entre distintos empleadores e industrias antes y después de la principal reforma comercial de Brasil. Encuentran que la apertura impulsó el desplazamiento de trabajadores, particularmente desde las industrias más protegidas, pero por varios años ni las firmas exportadoras ni las industrias con ventaja comparativa absorbieron a los trabajadores desplazados. El patrón de transición para este país indica que la movilidad se dio desde empleos formales en el sector de manufacturas hacia el sector de servicios, hacia el desempleo y fuera de la fuerza laboral. No encuentran evidencia de reasignación desde la formalidad hacia la informalidad. El trabajo de Bosch et al. (2012) también analiza el caso de Brasil y vincula los flujos brutos de trabajadores a nivel de industria (entradas y salidas hacia y desde la informalidad) con variables de política comercial y con variables que capturan los cambios en los costos laborales que implicó la reforma constitucional. No encuentran que los cambios en los aranceles a las importaciones y en la penetración de importaciones explique las transiciones entre la formalidad e informalidad. En cambio, el aumento en la tasa de informalidad de Brasil se explicaría principalmente por el cambio en las regulaciones laborales.

Este capítulo se estructura de la siguiente manera. La sección 2 detalla los datos utilizados. La sección 3 describe las transiciones laborales de los trabajadores entre distintos sectores y categorías laborales (formalidad e informalidad). La sección 4 evalúa econométricamente la reasignación del empleo y su relación con los cambios en la política comercial y la sección 5 presenta las conclusiones del análisis.

\subsection{Fuentes de datos}

La fuente de datos utilizada en este capítulo es la EPH para el periodo 19952003. La encuesta de hogares de Argentina posee una estructura de panel rotativo. Antes del año 2003 era implementada en dos ondas, mayo y octubre (EPH Puntual), y durante 2003 se incorporaron importantes cambios metodológico que incluyeron modificaciones en los cuestionarios y en el periodo de captación de la información (EPH Continua). Estos cambios implicaron la interrupción de la evolución del pa-

\footnotetext{
${ }^{3}$ La literatura mencionada en capítulos anteriores corresponde mayormente a estudios donde la industria es la unidad de análisis.
} 
nel inicial. El código que permite seguir a los individuos en las distintas encuestas está disponible públicamente desde la onda de mayo del año 1995. Estas características restringen el inicio del periodo de análisis al año 1995. A fines de poder extender en el tiempo esta serie de datos se utilizará el año 2003 como última observación en el análisis descriptivo y el 2001 para el análisis condicional, ya que la serie de aranceles con variabilidad por industria se extiende hasta ese año.

En este esquema de panel rotativo los hogares son encuestados durante cuatro ondas consecutivas (mayo y octubre). En cada onda se renueva aproximadamente el $25 \%$ de la muestra, determinando que entre dos ondas consecutivas se pueda seguir al $75 \%$ de los individuos incluidos en la muestra inicial. Un panel de cuatro ondas representa aproximadamente el $25 \%$ de la muestra inicial, mientras que un panel anual (misma onda en dos años consecutivos) representa el $50 \%$ de la muestra inicial. El objetivo de este capítulo es vincular las trayectorias de empleo individual a los cambios en los aranceles a las importaciones. Los datos de tasas arancelarias están disponibles de manera anual por lo que los paneles son construidos a partir de las observaciones de individuos encuestados en la misma onda de dos años consecutivos. Para esto se eligió la onda de octubre ya que el dato de tasas arancelarias corresponde al valor vigente a mitad de cada año. ${ }^{4}$ Dada esa característica de los datos, toda transición de empleo entre $t$ y $t+1$ será posterior al cambio de aranceles en el mismo periodo. Para el periodo 1995-2003 es posible construir 8 paneles anuales.

En el análisis también se incluyen otras variables de política comercial que presentan variabilidad entre industrias. Ellas son el índice de penetración de importaciones $(I P I)$, el índice de orientación de exportaciones $(I O E)$ y el tipo de cambio real enfrentado por cada una de las industrias. Al igual que en el capítulo anterior, el IPI se construye como el valor de las importaciones en cada industria y año sobre la suma del valor de su producción e importaciones menos el valor de las exportaciones. El IOE es el valor de las exportaciones industriales anuales sobre el valor de su producción. ${ }^{5}$ Por último, la medida de tipo de cambio real se construyó como un promedio ponderado del tipo de cambio de los principales socios comerciales en cada periodo de tiempo, siendo los ponderadores la participación de cada socio comercial en las importaciones argentinas de cada producto en el año 1995 (primer año de la

\footnotetext{
${ }^{4}$ El capítulo 2 detalla la construcción de esta serie de datos.

${ }^{5} \mathrm{El}$ valor de las importaciones y exportaciones para cada industria proviene de UN Comtrade y el valor de la producción se construyó a partir de datos sobre el índice de producción industrial del Centro de Estudios de la Producción y sobre el Estimador Mensual Industrial del Instituto Nacional de Estadísticas y Censos.
} 
serie de datos). ${ }^{6}$

El cuadro 4.1 muestra el número de observaciones en cada uno de los paneles anuales disponibles. ${ }^{7}$ La primera columna muestra el total de individuos de entre 15 y 64 años para los cuales es posible definir su condición de informalidad en caso de haber estado empleados en el sector de manufacturas. Estos valores incluyen trabajadores del sector de manufacturas formales o informales, trabajadores de otros sectores incluyendo asalariados y trabajadores independientes, desocupados e inactivos. La segunda columna muestra el total de individuos que estuvieron empleados en al menos una de los dos periodos de cada panel. La columna siguiente indica el número que estuvo empleado en el sector de manufacturas en al menos uno de los periodos. De estas dos columnas surge que entre el $11 \%$ y $15 \%$ de los ocupados en alguno de los dos periodos de cada panel estuvo empleado en el sector de manufacturas. La cuarta columna muestra el número de empleados en el sector de manufacturas que fue informal en alguno de los dos periodos. Este porcentaje oscila entre 27 y 39 y es creciente en el tiempo. La última columna indica el número de individuos que estuvo desocupados en al menos uno de los años comprendidos en cada panel. Esa cifra representa entre un $12 \%$ y $17 \%$ del total.

El gráfico 4.1 muestran la evolución de las variables de política comercial desde 1996 hasta 2003. El arancel promedio ponderado aplicado sobre las industrias del sector de manufacturas creció entre 1995 y 1998, a partir de entonces tuvo una caída de más de 5 puntos porcentuales y desde 2001 comenzó a crecer nuevamente. ${ }^{8}$ Este aumento sobre el final del periodo coincide con el patrón observado en el capítulo anterior utilizando la serie construida por Galiani y Porto (2010). El gráfico siguiente muestra para cada año el promedio del tipo de cambio real promedio ponderado enfrentado por cada una de las industrias. La tendencia a la apreciación cambiaria a lo largo del periodo se interpreta como una medida de apertura comercial. A partir del año 2001 la medida de tipo de cambio real promedio ponderado aumenta con un correlato sobre los flujos comerciales de las industrias. Esto puede observarse en

\footnotetext{
${ }^{6}$ Se consideran como socios comerciales a Brasil, Chile, Estados Unidos y la Unión Europea. Los datos sobre el valor de las importaciones provienen de UN Comtrade y el tipo de cambio de World Development Indicators (WDI, 2012).

${ }^{7}$ En este capítulo se trabaja con datos correspondientes a todos los aglomerados encuestados por la EPH a diferencia del capítulo anterior donde el análisis se restringió al aglomerado del Gran Buenos Aires.

${ }^{8} \mathrm{El}$ arancel promedio ponderado del sector de manufacturas para el periodo 1995-2003 proviene de World Development Indicators (WDI, 2012). La serie es computada como el promedio ponderado por la participación de cada producto en las importaciones totales.
} 
el último gráfico que muestra el promedio del $I P I$ y del $I O E$ de todas las industrias para cada año. Entre 1995 y 2001 el IPI promedio creció mientras el tipo de cambio enfrentado por las industrias se apreciaba. En el 2001 este comportamiento se revierte y el IPI promedio cae, mientras que el IOE crece.

\subsection{Transiciones laborales: análisis descriptivo}

Utilizando la información de los paneles anuales de la EPH se construyeron cinco categorías laborales de interés. Ellas son: (i) empleo formal en el sector de manufacturas; (ii) empleo informal en el sector de manufacturas; (iii) empleo en otros sectores de la economía. Esta categoría incluye tanto al empleo asalariado (formal o informal) como al auto-empleo. A lo largo del capítulo se hace referencia a esta categoría como "otro sector"; (iv) desempleo e (v) inactividad. Estas categorías fueron identificadas en el primer y segundo periodo de cada panel anual. De la comparación de la situación laboral de cada individuo en ambos periodos se obtuvieron las transiciones entre las cinco categorías analizadas. Lógicamente, estas transiciones capturan el cambio en la situación laboral de los individuos entre la onda de octubre en el año $t$ y la onda de octubre del año siguiente. Durante ese año el individuo puede haber cambiado su categoría inicial a otra diferente a la reportada en $t+1$. El análisis de este capítulo se concentra en las transiciones anuales dado que la variación en las variables de política comercial no puede ser observada en intervalos de tiempo menores al año, mientras que las trayectorias laborales podría extenderse a un año y medio solo para la mitad de las observaciones de cada panel anual.

Los cuadros 4.2 a 4.5 muestran las transiciones entre el empleo en el sector de manufacturas, formal e informal, el empleo en el resto de la economía, el desempleo y la inactividad. Los resultados se presentan para cada par de años desde 1995 y hasta el año 2003 y para el promedio a lo largo de todo el periodo. Mientras que los cuadros 4.2 y 4.3 muestra las transiciones como porcentajes calculados sobre el total de individuos en cada categoría de origen, los cuadros 4.4 y 4.5 repiten el ejercicio computando los porcentaje sobre el total de individuos en cada categoría de destino. El cuadro 4.6 resume esta información para el promedio del periodo.

La informalidad es una categoría laboral más transitoria que la formalidad. Del total de informales del sector de manufacturas en $t$ el $38.6 \%$ conserva su categoría en el periodo siguiente. Esta cifra es el $77 \%$ entre los formales. Las principales categorías de destino de los trabajadores informales del sector de manufacturas son 
el empleo en otro sector de la economía $(28.8 \%$ ) y el desempleo o la inactividad $(19.3 \%)$.

El $6.5 \%$ de los trabajadores informales empleados en el sector de manufacturas pierden su empleo en el periodo siguiente, representando esta categoría un $1.3 \%$ del total de desempleados en $t+1$. Entre los formales del sector de manufacturas en $t$, el $1.9 \%$ pierde su empleo y el peso de esta categoría en los desempleados de $t+1$ es de solo $0.9 \%$.

El desempleo es la categoría menos estable entre todas las analizadas. El 31.2\% de los desempleados de $t$ continúan en esa situación en $t+1$. La inserción laboral de los desempleados de $t$ se da principalmente en el resto de la economía. Este resultado es razonable teniendo en cuenta la pérdida de participación del sector de manufacturas en el empleo total a lo largo del periodo analizado. Entre los desocupados en $t$ que ingresan al sector de manufacturas en $t+1$ es superior el porcentaje que lo hace como trabajadores informales. Del total de trabajadores informales del sector de manufacturas en $t+1$, el $10 \%$ tiene origen en el desempleo. Del total de trabajadores formales, solo el $1.7 \%$ proviene del desempleo.

Del análisis de las transiciones entre la formalidad y la informalidad surge que un $13.3 \%$ de los informales del sector de manufacturas en $t$ se mueve a la formalidad en el periodo siguiente. Esto puede ocurrir en el mismo empleo o en otro empleo dentro del sector siempre que el trabajador se haya reasignado durante el año que transcurre entre la primera y la segunda encuesta. Del total de trabajadores formales en el sector de manufacturas en $t+1$ los de origen informal representan un $5.4 \%$. La transición desde la formalidad hacia la informalidad es de $3.6 \%$. Desde el punto de vista de la categoría de destino, un $8 \%$ de los informales de $t+1$ provienen de un empleo formal en el sector de manufacturas en el periodo anterior.

Los gráficos 4.2 a 4.5 permiten observar algunas de estas transiciones para todos los años bajo análisis. El gráfico 4.2 muestra la transición desde el empleo en el sector de manufacturas al desempleo, distinguiendo entre trabajadores formales e informales. Esta transición fue creciente en el tiempo, especialmente para los trabajadores informales, alcanza un pico en el panel 2001-2002. Para el total de empleados del sector de manufacturas el porcentaje que perdió su empleo en el periodo siguiente pasó de 1.7 entre 1995-96 a 5.6 en 2001-02. Entre los informales estos valores fueron desde $4.1 \%$ (1995-96) y $12.2 \%$ (2001-02), duplicando el aumento para la totalidad del sector. Entre 1995 y 1998 se observa, en términos generales, una correlación po- 
sitiva entre el arancel promedio y la transición hacia el desempleo. A partir de ese año y hasta el final de la serie el comportamiento es el opuesto. A medida que el arancel cae el porcentaje de trabajadores que pasa al desempleo se incrementa (con la excepción de la transición desde el empleo formal en el panel 1999-2000) y lo contrario ocurre hacia el final cuando el aumento del arancel promedio se corresponde con una caída en estas transiciones.

Las transiciones al desempleo de los trabajadores formales e informales del sector de manufacturas no son comparables entre sí ya que esas magnitudes están condicionadas en la categoría de origen. De acuerdo al cuadro 4.6, del total de desempleados en $t+1$ el $2 \%$ proviene del sector de manufacturas. El gráfico 4.3 permite observar en cuánto contribuyen los trabajadores formales e informales al total de desempleados en $t+1$ que tuvieron origen en el sector de manufacturas. Esta descomposición muestra que en promedio el $59 \%$ proviene de la informalidad y el $41 \%$ restante de la formalidad. La variación de esas contribuciones a lo largo del tiempo indica que el peso de los informales nunca estuvo por debajo del $50 \%$. El valor mínimo fue $51 \%$ en 1998-99 y el máximo $78 \%$ en 2002-03.

El gráfico 4.4 muestra la transición desde la formalidad hacia la informalidad en el sector de manufacturas. La altura de las barras indica en qué porcentaje contribuyen los trabajadores formales para explicar la totalidad de trabajadores informales en $t+1$. Esta contribución tuvo un valor promedio de $8 \%$ a lo largo del periodo. Entre 1995 y 1998 la fracción de informales con origen en la formalidad mostró un descenso mientras el arancel promedio crecía. Durante el periodo de reducción en el arancel promedio (1998-2001) la contribución de los trabajadores formales a la informalidad en el sector de manufacturas tuvo un comportamiento errático, con una caída muy importante en 1999-2000 cuando este porcentaje estuvo muy por debajo del promedio. Del análisis de la matriz de transición surge que esta caída en la contribución de los trabajadores formales fue sustituida por la mayor participación de los mismos trabajadores informales que mantuvieron su categoría entre ambos años. Por último, entre 2001 y 2002 el arancel promedio creció y la transición desde la formalidad a la informalidad mostró el mismo comportamiento.

El gráfico 4.5 resume la información de la movilidad desde el desempleo hacia el empleo en el sector de manufacturas. En promedio, solo el $3 \%$ de los desempleados obtuvo un empleo en el sector de manufacturas en el periodo siguiente. Entre aquellos que se insertaron en este sector la fracción que lo hizo en un empleo informal fue 
muy superior respecto a la que lo hizo en un empleo formal. En promedio el $72 \%$ ingresó en un empleo informal y este porcentaje creció a lo largo del periodo, desde $60 \%$ en $1995-96$ hasta $85 \%$ en $2002-03$.

Del análisis de estas transiciones surgen las siguientes observaciones: (i) los trabajadores informales del sector de manufacturas tienen un mayor peso en el desempleo del periodo siguiente en relación a los formales; (ii) la formalidad es la categoría que posee menor peso en el total de informales de $t+1$; (iii) los desempleados de $t$ que obtienen un empleo en el periodo siguiente ingresan a otro sector de la economía principalmente.

\subsection{Reasignación de trabajadores entre sectores y ca- tegorías laborales}

En esta sección se analizan las transiciones de empleo y su vínculo con los cambios en la política comercial. El objetivo es caracterizar el proceso de ajuste del mercado de trabajo identificando movimientos entre industrias y sectores productivos y entre la formalidad y la informalidad. Para esto se proponen dos ejercicios econométricos. En primer lugar, se analiza la reasignación de los individuos entre distintos sectores en respuesta a la liberalización del comercio. El objetivo de este primer ejercicio es conocer qué efecto tuvo la apertura sobre la reasignación de trabajadores entre distintas industrias del sector de manufacturas, entre el sector de manufacturas y el resto de los sectores de la economía y sobre la transición al desempleo y a la inactividad. Con esto se busca testear con los datos disponibles la conclusión habitual para economías en desarrollo que indica la ausencia de reasignación del empleo entre sectores luego de un shock de política comercial. El segundo ejercicio amplía el análisis para incluir la movilidad entre empleos formales y informales en el sector de manufacturas.

La disponibilidad de paneles anuales solo permite evaluar la reasignación del empleo durante el transcurso de un año. En ese año los trabajadores pueden haber cambiado su situación de empleo inicial a otra diferente a la reportada en $t+1$ y pueden volver a modificar su condición de empleo con posterioridad a esa observación. El cambio en las variable de política comercial es capturado de manera anual imposibilitando el análisis para periodos de tiempo más cortos, mientras que la extensión del análisis a un periodo más prolongado (un año y medio) solo es posible para la mitad de la muestra (25\% de la muestra inicial) de acuerdo a las características del 
esquema de rotación del panel. En ambos ejercicios se trabaja con modelos logitmultinomiales ya que existen más de dos categorías de destino que son mutuamente excluyentes y las variables explicativas no dependen de dichas categorías. ${ }^{9}$

\subsubsection{Transiciones entre sectores}

El análisis de la transición entre sectores de empleo en respuesta a cambios en las variables de política comercial define a $S$ como el conjunto de sectores de empleo, $s=0, \ldots S$. La probabilidad de que el individuo $i$ se mueva al sector $s$ en $t+1$ condicional en su sector actual es:

$\operatorname{Pr}\left(s_{i t+1}=s \mid s_{i t} ; \mathbf{x}, \mathbf{w}\right)=\frac{\exp \left(\mathbf{x}_{i j t}^{\prime} \beta_{x}^{s}+\mathbf{w}_{j t}^{\prime} \beta_{w}^{s}\right)}{\left[1+\sum_{h=1}^{S} \exp \left(\mathbf{x}_{i j t}^{\prime} \beta_{x}^{h}+\mathbf{w}_{j t}^{\prime} \beta_{w}^{h}\right)\right]} \quad s=1, \ldots, S$.

donde $\mathbf{x}$ es un vector de características del individuo $i$ empleado en la industria $j$ en el año $t$, y el vector $\mathbf{w}$ contiene las variables de política comercial para la industria $j$ en $t$.

Para un individuo empleado en el sector de manufacturas en el momento $t$ se define el siguiente conjunto de sectores de destino en $t+1$ : (i) empleado en la misma industria del sector de manufacturas; (ii) empleado en otra industria del sector de manufacturas; (iii) empleado en otro sector de la economía; (iv) desempleado o inactivo. La distinción entre conservar el empleo en la misma industrias o moverse a otra industria del sector de manufacturas permite testear el resultado habitual de ausencia de reasignación del empleo encontrado por otros autores. Como se mencionó anteriormente, Wacziarg y Wallack (2004) encuentran evidencia de ausencia de reasignación del trabajo entre industrias del sector de manufacturas como consecuencia de la apertura comercial en países en desarrollo.

En este modelo se define como categoría base al empleo en la misma industria. Esto implica que los efectos parciales del cambio en el arancel a las importaciones serán interpretados como el cambio en la probabilidad de moverse al sector $s_{t+1}$ respecto a permanecer en la misma industria.

El vector $\mathbf{x}$ incluye características individuales como el sexo de los individuos, la edad y su cuadrado, el nivel educativo y el estado civil en $t$, variables indicadoras de región de residencia, efectos fijos de periodo de tiempo y de industria. El vector $\mathbf{w}$ incluye el arancel enfrentado por cada industria en $t$. Dado el número reducido

\footnotetext{
${ }^{9}$ Esta característica distingue a los modelos logit-multinomial de los modelos logit-condicional (Wooldridge, 2010).
} 
de observaciones ${ }^{10}$ las industrias fueron agrupadas a 2 dígitos de la clasificación industrial internacional. El número total de industrias en este capítulo se reduce de 24 a 9 . El arancel de cada grupo industrial fue calculado como el arancel promedio ponderado por el empleo de cada industria. Los modelos luego se expanden incluyendo otras variables de política comercial en el vector $\mathbf{w}$ como el tipo de cambio real enfrentado por cada industria, y el IPI e IOE. ${ }^{11}$

En el cuadro 4.7 se presentan los resultados obtenidos para el modelo de reasignación entre sectores. El resultado principal muestra que con la reducción de aranceles cae la probabilidad de reasignación desde el sector de manufacturas hacia otro sector de la economía. Este resultado se mantiene al controlar por tendencias por grupos de industria y por otras variables de política comercial. Con la reducción de aranceles aumenta la probabilidad de desempleo o inactividad respecto a permanecer en la misma industria (especificación 3), pero este resultado no es robusto a la inclusión de otras variables de política comercial. El coeficiente asociado a la probabilidad de migrar hacia otra industria del sector de manufacturas es positivo (indicando que con la apertura se reducen la movilidad entre industrias) pero no estadísticamente significativo. Este resultado es compatible con la evidencia que indica que el patrón de movilidad de trabajadores previsto por la TCI no se verifica. La evidencia aquí presentada estaría indicando que la probabilidad de permanecer en la misma industria respecto a desplazarse a otra no se ve alterada con la reducción de los aranceles. Además de esto, la probabilidad de cambiar de sector caería respecto a la probabilidad de permanecer en la industria inicial. Una posible explicación podría estar en la expansión de cierto grupo de firmas, como las exportadoras y las que logran mejoras de productividad con la apertura al incorporar nuevas tecnologías (ahora más barata). Sin embargo, el sub-periodo que se analiza en este capítulo (1995-2001) comprende una etapa de fuerte retracción de la economía a raíz de una serie de crisis de origen internacional. A partir del año 1998 las exportaciones mostraron un retroceso al igual que la inversión en bienes de capital (gráfico 4.6). Esto conduce a evaluar la reasignación del empleo para la etapa previa y posterior al años 1998. Los resultados se muestran en el cuadro 4.8 e indican que la caída en la probabilidad de reasignación a otro sector de la economía solo ocurre en la etapa

\footnotetext{
${ }^{10}$ Este modelo se estima para los empleados del sector de manufacturas en $t$, mientras que los apartados siguientes realizan el análisis para la sub-muestra de trabajadores formales e informales del sector de manufacturas en $t$.

${ }^{11} \mathrm{La}$ inclusión de otras medidas de exposición al comercio internacional se realiza para evaluar la robustez de los coeficientes obtenidos para la variable de aranceles y no se fundamenta en la TCI.
} 
1998-2001. ${ }^{12}$ En esta etapa es estadísticamente más probable el desempleo que la reasignación entre sectores de la economía. Lo que esto indicaría es que en momentos de crisis la movilidad del trabajo entre sectores económicos se reduce, mientras que la movilidad hacia el desempleo o inactividad se incrementa con la liberalización del comercio.

Estos modelos fueron expandidos incorporando la posibilidad de que los efectos difieran según las características de los trabajadores y de las industrias. El cuadro 4.9 presenta los resultados del modelo que interactúa el arancel de las industrias con el nivel educativo de los trabajadores y con su antigüedad laboral. Los resultados no difieren a los encontrados previamente cuando el modelo permite heterogeneidades por nivel educativo. En cambio, indican que la menor probabilidad de cambiar de sector es más fuerte para los trabajadores con mayor antigüedad en su puesto de trabajo. ${ }^{13}$

Los resultados de los modelos que permiten que el efecto difiera según las características de las industrias tampoco varían respecto a los resultados iniciales (cuadro 4.10). Las estimaciones indican que con la reducción de aranceles cae la probabilidad de cambiar de sector (respecto a permanecer en la misma industria) y el efecto es el mismo para industrias que difieren en su tamaño ${ }^{14}$ y en su medida de ventaja comparativa revelada (Balassa, 1965). ${ }^{15}$ La única excepción es el efecto nulo en industrias medianas cuando se utiliza la primera especificación, aunque este efecto no es robusto a la inclusión de tendencias por industria y otras medidas de política comercial.

Los resultados encontrados son consistentes con la evidencia que rechaza el patrón de reasignación del empleo predicho por los modelos clásicos de la TCI (Wacziarg y Wallack, 2004). La probabilidad de reasignación a otra industria del sector de manufacturas no se ve alterada ante una reducción de las tasas arancelarias. La evidencia adicional que aporta este análisis es la caída en la probabilidad de

\footnotetext{
${ }^{12}$ El sub-periodos 1995-1998 comprende los paneles 95-96, 96-97 y 97-98 mientras que el subperiodo 1998-2001 abarca los paneles 98-99, 99-00, 00-01.

${ }^{13}$ Dado el bajo nivel educativo de los trabajadores del sector de manufacturas, se define como calificado al individuo que posee al menos nivel secundario completo. Se considera que un trabajador posee un nivel alto de experiencia laboral cuando los años de antigüedad en su empleo están por encima del promedio de su industria para cada año.

${ }^{14}$ La clasificación de industrias de acuerdo a su tamaño coincide con la utilizada en el capítulo 3.

${ }^{15}$ Este indicador se define como $\left(E_{i j} / E_{i t}\right) /\left(E_{n j} / E_{n t}\right)$ donde $E$ es el valor de las exportaciones, $i$ representa Argentina, $n$ el resto del mundo, $j$ una industria y $t$ el conjunto de todos los productos. Se considera que una industria posee ventaja comparativa revelada cuando el valor de este indicador está por encima de la media para cada periodo de tiempo.
} 
reasignación a otro sector de la economía (típicamente, el sector no transable). La explicación de este resultado se encuentra en la retracción de la economía desde el año 1998 vinculada a la serie de crisis de origen internacional que afectaron a la economía local.

\subsubsection{Transiciones entre categorías laborales}

En esta sub-sección se analiza la movilidad de los trabajadores distinguiendo entre las opciones de empleo formal e informal dentro del sector de manufacturas. La resultados de la sub-sección anterior mostraron que no hay reasignación de trabajadores entre las industrias de este sector como consecuencia de la liberalización del comercio. Dado ese resultado las alternativas de empleo de destino en este apartado no distinguen entre industrias, si no que se analiza al sector de manufacturas en conjunto.

Para un trabajador informal del sector de manufacturas en el periodo $t$ se define el siguiente conjunto de sectores de destino en $t+1$ : (i) empleado informal en el sector de manufacturas; (ii) empleado formal en el sector de manufacturas; (iii) empleado en otro sector de la economía; (iv) desempleado o inactivo. Las mismas categorías de destino en $t+1$ se definen para los trabajadores formales del sector de manufacturas en $t$ y para los desempleados.

Las categorías de empleo (i) y (ii) para los trabajadores inicialmente empleados en el sector de manufacturas incluyen la posibilidad de que el trabajador se mueva entre la informalidad y la formalidad en la misma industria o en otra industria del sector. Dada la evidencia previa, se considerará que estos efectos estarán capturando la reasignación entre categorías laborales dentro de la misma industria. Asimismo, al interior de cada industria el trabajador puede moverse entre distintas firmas. La ausencia de información acerca de la historia laboral de cada individuo no permite observar cambios de este tipo. Como consecuencia, si los resultados indican, por ejemplo, que con la reducción de aranceles aumentó la probabilidad de empleo informal para los trabajadores formales del sector de manufacturas en $t$, ese efecto será interpretado como un cambio en la naturaleza de la relación laboral, incluso cuando el trabajador haya cambiado de empleador durante el año de referencia. Dicho de otra manera, el año calendario que transcurre entre la primera y la segunda encuesta se considerará un lapso de tiempo lo suficientemente corto para interpretar a los cambios de ese tipo como variaciones en una relación laboral ya existente. 
Los modelos coinciden con los estimados previamente. El modelo para los trabajadores informales (formales) del sector de manufacturas en $t$ toma como categoría base al empleo informal (formal) en el mismo sector en $t+1$. El modelo para los desempleados en $t$ toma como categoría base el desempleo o inactividad en $t+1$. La ausencia de información acerca de la historia laboral de los desempleados impide vincularlos a un sector de empleo previo y, entonces, a un arancel a las importaciones. Dada esta restricción, en el modelo para los desempleados en $t$ se utilizan variables de política comercial que solo presentan variabilidad en el tiempo.

Los cuadros 4.11 y 4.12 muestran los resultados del modelo de categorías laborales para los desempleados en $t$. Las estimaciones difieren sustancialmente al pasar de la primera especificación, que solo incluye el logaritmo del arancel promedio ponderado como variable de política comercial, a las restantes que incorporan el tipo de cambio real (especificación 2), el IPI e IOE (especificación 3) y todas estas variables conjuntamente (especificación 4). Como se mencionó anteriormente, el modelo para los desempleados en $t$ solo incorpora variable de comercio con variabilidad en el tiempo pero no entre industrias. Dada esa restricción de datos, las especificaciones 2 a 4 se considerarán superiores en términos de capturar más adecuadamente los cambios en la política comercial.

Los resultados indican que con la apertura comercial cae la probabilidad de que un desempleado en $t$ obtenga un empleo en el sector de manufacturas (formal o informal) o en otro sector de la economía, con excepción de la última especificación donde la probabilidad de ingreso a otro sector no se modifica respecto a la probabilidad de permanecer en el desempleo. La menor reducción en la probabilidad de ingreso a otro sector de la economía implica que de obtener un empleo, es estadísticamente más probable que ello ocurra en otro sector diferente al de manufacturas. $\mathrm{Al}$ interior del sector de manufacturas, las chances de empleo formal son superiores a las de empleo informal estadísticamente, aunque la magnitud del efecto es pequeña. En el panel inferior de los mismos cuadros se muestran los resultados obtenidos al permitir que el efecto difiera según el nivel educativo de los desocupados. Para los no calificados las estimaciones indican que la reducción de aranceles se asocia a menores chances de obtener un empleo respecto a permanecer desempleado. En caso de obtener un empleo, es superior la probabilidad de hacerlo en otro sector respecto al sector de manufacturas y dentro de este último sector no hay diferencia estadísticamente significativa entre el empleo formal e informal. Para los calificados, 
en cambio, la apertura aumenta la probabilidad de ingresar a otro sector de la economía (especificaciones 3 y 4) en relación a permanecer en el desempleo, y dentro del sector de manufacturas es mayor la chance de obtener un empleo formal.

En el cuadro 4.13 se presentan las estimaciones de la especificación 4 separando el periodo en dos etapas de igual duración. Los resultados difieren de acuerdo a la etapa considerada. Entre 1995-1998, cuando la economía estaba en crecimiento, la reducción de aranceles se asocia a un aumento en la probabilidad de que un desocupado abandone ese condición y obtenga un empleo en el periodo siguiente. El empleo en el sector de manufacturas fue más probable que el empleo en otro sector de la economía en esta etapa y, dentro del sector de manufacturas, el empleo informal fue más probable que el empleo formal con la reducción de aranceles. La distinción por niveles educativos muestra que para los no calificados fue más probable el empleo informal, mientras que para los calificados ocurrió lo opuesto. En la etapa de retracción (1998-2001) los resultados se revierten y la caída del arancel promedio a las importaciones se traduce en una mayor probabilidad de que el desocupado en $t$ permanezca en esa situación al periodo siguiente. La distinción por niveles educativos no muestra ninguna diferencia en este caso. ${ }^{16}$

El cuadro 4.14 muestra los resultados de reasignación para los trabajadores informales del sector de manufacturas en $t$. Todas las especificaciones muestran que con la reducción de aranceles a las importaciones cae la probabilidad de reasignación a cualquiera de las opciones consideradas. En momentos de liberalización del comercio, la informalidad en el sector de manufacturas es una alternativa más viable a las otras, incluso al desempleo. De la comparación entre los coeficientes obtenidos para las distintas categorías laborales de destino surge que no hay diferencia estadísticamente significativa entre el desempleo y las opciones restantes. ${ }^{17}$ La distinción por sub-periodos (cuadro 4.15) muestra que este efecto corresponde enteramente a la etapa 1998-2001. Cuando la economía está en retracción, para los empleados informales del sector de manufacturas es más probable conservar su categoría que moverse a la formalidad e incluso que ir al desempleo.

El panel siguiente del cuadro 4.16 muestra que los resultados anteriores no dependen del nivel educativo del trabajador informal en $t$ en las especificaciones 1, 2

\footnotetext{
${ }^{16} \mathrm{La}$ única excepción es la caída levemente mayor en la probabilidad de ingresar al sector de manufacturas como trabajador informal para los calificados. Este efecto es significativo solo al $10 \%$.

${ }^{17}$ Esto puede verificarse estimando el mismo modelo y utilizando al desempleo como categoría omitida.
} 
y 4. En las especificaciones 3 y 5, que incluyen la variación en el tipo de cambio real como variable de control, la inmovilidad del empleo informal es más pronunciada para los calificados, resultado estadísticamente significativo solo al $10 \%$. No hay diferencias estadísticamente significativas en la probabilidad de moverse de categoría laboral o sector respecto a irse al desempleo tanto para calificados como para no calificados. La caída en la probabilidad de reasignación a un empleo formal en el sector de manufacturas o a un empleo en otro sector es más pronunciada para los trabajadores de mayor antigüedad laboral (cuadro 4.17). Para estos trabajadores es más probable el desempleo que el cambio de sector, mientras que para los de menor antigüedad este ratio de probabilidades no se modifica con el cambio en los aranceles. $^{18}$

En los cuadros 4.17 y 4.18 se presentan los resultados obtenidos diferenciando entre industrias de acuerdo a sus características. En primer lugar se analiza la reasignación de trabajadores informales del sector de manufacturas empleados en industrias de diferente tamaño. Los resultados indican que la caída en la probabilidad de migrar hacia un empleo formal en el mismo sector es igual para todas las industrias. La menor probabilidad de moverse a otro sector decrece con el tamaño de la industria, es decir, que en una industria grande es más probable que el trabajador informal conserve su empleo y su categoría en relación a lo que sucede en una industria chica. La evidencia estaría indicando que las firmas grandes se encuentran en una mejor posición para mantener su planta de empleados (informales). Esto podría suceder, por ejemplo, por tener un mayor acceso al crédito. En industrias con firmas medianas la liberalización del comercio aumenta la probabilidad de desempleo para los trabajadores informales, mientras que para ningún tamaño de industria la apertura modifica la probabilidad relativa entre pasar a la formalidad o al desempleo. El cuadro 4.19 muestra los resultados para industrias que difieren en su indicador de ventaja comparativa revelada. La caída en la probabilidad de migrar a otro sector corresponde enteramente a industrias con mayor ventaja comparativa. Esto es compatible con la evidencia de mayor tamaño de las firmas exportadoras. Las industrias con ventaja comparativa revelada son aquellas con mayor peso relativo en las exportaciones totales. Dentro de esas industrias se espera una mayor presencia de firmas grandes.

El cuadro 4.20 presenta las estimaciones de reasignación para los trabajadores

\footnotetext{
${ }^{18}$ Este resultado se obtiene al considerar al desempleo como categoría base en el mismo modelo.
} 
formales del sector de manufacturas en $t$. El resultado principal indica que con la reducción de aranceles no se modifican las probabilidades de reasignación hacia la informalidad, hacia otro sector de la economía o hacia el desempleo. La única excepción es la última especificación donde la apertura reduce la probabilidad de moverse a la informalidad al $10 \%$ de significatividad individual. El análisis por sub-periodos (cuadro 4.21) muestra que esta ausencia de efecto corresponde a la etapa 1995-1998, mientras que en 1998-2001 la liberalización del comercio redujo la probabilidad de reasignación de los trabajadores formales en $t$ a la informalidad y a otro sector de la economía. Esto es compatible con la evidencia previa de ausencia de movilidad en periodos de crisis. La distinción por nivel educativo de los trabajadores indica que para los calificados formales se reduce la probabilidad de desempleo, mientras que los resultados no difieren según la antigüedad laboral en el puesto de trabajo (cuadros 4.22 y 4.23 ).

En el cuadro 4.24 se muestran los resultados obtenidos al permitir que los efectos difieran según el tamaño de las industrias. Para los trabajadores formales en industrias grandes la probabilidad de pasar a la informalidad se reduce con la apertura, es decir, que los trabajadores formales conservan su categoría. En industrias medianas el efecto es un poco más pronunciado mientras que en industrias pequeñas es el opuesto. Los trabajadores formales en industrias pequeñas tienen mayores chances de moverse a la informalidad con la reducción de aranceles (especificaciones 1, 2 y 3). En industrias medianas los trabajadores formales tienen una mayor chance de pasar al desempleo que a la informalidad. ${ }^{19}$ Por último, el cuadro 4.25 muestra que los resultados no difieren según el indicador de ventaja comparativa revelada de las industrias.

\subsection{Conclusiones}

Con el objetivo de caracterizar el proceso de ajuste del mercado laboral, en este capítulo se analizó la movilidad de los trabajadores entre distintos sectores y entre categorías laborales como resultado del cambio en los aranceles a las importaciones. La estructura de panel rotativo de la EPH permitió observar las transiciones individuales de los trabajadores del sector de manufacturas entre pares de años consecutivos a lo largo del periodo 1995-2001. Coincidiendo con la evidencia disponible

\footnotetext{
${ }^{19}$ Este resultado se obtiene utilizando las especificaciones 4 y 5 y el desempleo como categoría base.
} 
para países en desarrollo, los resultados indicaron que el trabajo no se reasigna hacia otras industrias como predicen los modelos tradicionales de la TCI. La evidencia adicional que aportó este análisis es la caída en la probabilidad de reasignación a otro sector de la economía (típicamente, el sector no transable). El análisis por subperiodos mostró que este resultado corresponde a la etapa de fuerte retracción de la economía a raíz de una serie de crisis de origen internacional (1998-2001). Lo que esto indicaría es que en momentos de crisis la movilidad del trabajo entre sectores de la economía se reduce haciendo del desempleo una alternativa más probable con la liberalización del comercio.

El patrón de movilidad entre categorías laborales mostró que para los desocupados cayó la probabilidad de obtener un empleo al periodo siguiente, tanto en el sector de manufacturas como en otro sector de la economía. Las estimaciones por sub-periodos indicaron que este patrón de transición se dio en la etapa de retracción de la economía (1998-2001), mientras que en la etapa de expansión (1995-1998) la liberalización del comercio tuvo el efecto opuesto. De ingresar al sector de manufacturas, el nivel de calificación es determinante de la categoría de empleo. Las chances de empleo formal son mayores para los calificados y las de empleo informal para los no calificados.

Los resultados para los trabajadores informales del sector de manufacturas indicaron que esta es una categoría estable ante shocks de política comercial. Los trabajadores informales tienen mayores chances de permanecer en esa categoría que de moverse a cualquier otra, incluso al desempleo. Este efecto se explica por el patrón de (in)movilidad del sub-periodo 1998-2001. La caída en las chances de formalización para estos trabajadores no depende del tamaño de las firmas en cada industria, mientras que la reducción en la probabilidad de moverse a otro sector es más pronunciada en industrias con firmas grandes y en industrias con un mayor índice de ventaja comparativa. Esto puede explicarse por la mejor posición de las firmas grandes para conservar su planta de empleados, por ejemplo, por un mayor acceso al crédito. En industrias con firmas medianas, en cambio, las chances de desempleo se incrementaron para los trabajadores informales. El patrón de transición para los trabajadores formales del sector de manufacturas indicó que la movilidad se dio hacia la informalidad en industrias con firmas chicas. Por el contrario, la reducción de aranceles produjo una caída en la probabilidad de que un trabajador formal se mueva a la informalidad en una industria con firmas grandes o medianas. 
En estas últimas, fue más probable el desempleo que la informalidad.

La evidencia de ausencia de reasignación del empleo entre industrias y sectores como consecuencia de la liberalización del comercio es compatible con la definición de corto plazo utilizada en el capítulo 3. Dado este resultado, los hallazgos de este capítulo permiten entender a través de qué mecanismos se produjo el aumento en la tasa de informalidad en industrias pequeñas y medianas reportado previamente. Como se mencionó en la introducción, la tasa de informalidad de una industria puede resultar afectada a través de dos canales en el contexto de la apertura de la economía al comercio internacional. El primero de ellos es el del empleo/desempleo. El segundo, el cambio en la condición de informalidad en una relación laboral ya existente. Un ejemplo extremo del primer canal es el ajuste del tamaño de la fuerza laboral de las firmas pertenecientes a cierta industria mediante el despido de trabajadores formales o la incorporación de trabajadores informales únicamente. El caso extremo del segundo canal sería un ajuste en el tamaño de la fuerza laboral que es neutral desde el punto de vista de la tasa de informalidad de la industria y el cambio en la categoría laboral de algunos trabajadores que se mueven de la formalidad a la informalidad. En el medio de estos casos extremos aparecen opciones intermedias donde las firmas ajustan el tamaño de su fuerza laboral despidiendo/incorporando nuevos empleados que pueden ser formales o informales y alterando la tasa de informalidad de la industria, cambian la condición de informalidad de algunos de sus trabajadores, y rotan el plantel de empleados más allá del proceso de ajuste en el tamaño. Los resultados de este capítulo indicaron que en industrias pequeñas el proceso de ajuste se dio a través del cambio en la naturaleza de las relaciones laborales, ya sea por decisión unilateral de la firma o por un acuerdo entre las partes. La evidencia indica que en estas industrias el patrón de movilidad se dio desde la formalidad hacia la informalidad, mientras que la probabilidad de que un trabajador informal pasara a ser un trabajador protegido se redujo. En industrias medianas el mecanismo habría sido el de la rotación laboral. Los trabajadores formales e informales de estas industrias vieron aumentar sus chances de desempleo respecto a permanecer en la misma categoría (en el caso de los informales) o moverse a la informalidad (en el caso de los formales), mientras que no se detectó ningún patrón de movilidad entre categorías laborales. Más exactamente, cayó la probabilidad de que ocurran movimientos entre la formalidad y la informalidad. El aumento en la tasa de informalidad de las industrias medianas se explicaría entonces por un mecanismo de rotación laboral, 
donde el despido de trabajadores formales en mayor medida habría resultado en un aumento en la informalidad de estas industrias. Por último, en las industrias grandes la probabilidad de que un trabajador se mueva entre la formalidad y la informalidad se redujo, al igual que la probabilidad de que un trabajador informal se cambie de sector. Esto indica que los trabajadores conservaron su categoría explicando la ausencia de efecto de los aranceles sobre la informalidad laboral en industrias grandes reportado en el capítulo 3 .

Estos resultados refuerzan la evidencia previa de reacciones heterogéneas de acuerdo al tamaño de las firmas en cada industria. La tasa de informalidad aumentó en el corto plazo en industrias con firmas inicialmente pequeñas y medianas como consecuencia de la liberalización del comercio. Este comportamiento diferencial se explica por los argumentos de la literatura de evasión de impuestos (mayor probabilidad de detección en firmas grandes) y por la posición de las firmas respecto al comercio internacional (firmas que compiten con las importaciones versus firmas exportadoras). La evidencia presentada en este capítulo permitió caracterizar el proceso de ajuste indicando que los mecanismos utilizados por estas industrias también fue diferente. En industrias con firmas suficientemente pequeñas la estrategia de supervivencia fue el recorte del pago de las contribuciones a la seguridad social. En industrias con firmas medianas el despido de trabajadores formales e informales en distinta medida fue el margen de ajuste utilizado con implicancias sobre la tasa de informalidad. 


\subsection{Cuadros}

\section{Cuadro 4.1: Número de observaciones}

\begin{tabular}{lccccc}
\hline \hline Panel & Total & Empleados & Empleados en SM & Informales & Desempleados \\
\hline $1995-1996$ & 20,083 & 12,230 & 1,730 & 465 & 2,671 \\
$1996-1997$ & 20,380 & 12,576 & 1,847 & 564 & 2,765 \\
$1997-1998$ & 17,936 & 11,266 & 1,634 & 508 & 2,251 \\
$1998-1999$ & 16,128 & 10,104 & 1,383 & 419 & 1,889 \\
$1999-2000$ & 15,223 & 9,595 & 1,282 & 407 & 1,995 \\
$2000-2001$ & 14,098 & 8,928 & 1,111 & 377 & 2,066 \\
$2001-2002$ & 15,088 & 9,335 & 1,155 & 368 & 2,568 \\
$2002-2003$ & 10,275 & 6,395 & 731 & 285 & 1,619 \\
\hline Total & 129,211 & 80,429 & 10,873 & 3,393 & 17,824 \\
\hline
\end{tabular}

Fuente: Elaboración propia en base a EPH.

Nota: En el panel 2002-2003 se utiliza la onda de octubre para 2002 y mayo para 2003. 


\section{Cuadro 4.2: Matriz de transición}

Porcentajes sobre categoría de origen

\begin{tabular}{|c|c|c|c|c|c|c|}
\hline \multirow[b]{2}{*}{$\begin{array}{l}\text { Condición } \\
\text { en } t\end{array}$} & \multicolumn{5}{|c|}{ Condición en $t+1$} & \multirow[b]{2}{*}{ Total } \\
\hline & $\begin{array}{c}\text { Informal } \\
\text { SM }\end{array}$ & $\begin{array}{c}\text { Formal } \\
\text { SM }\end{array}$ & $\begin{array}{l}\text { Otro } \\
\text { sector }\end{array}$ & $\begin{array}{l}\text { Desemple } \\
\text { ado }\end{array}$ & Inactivo & \\
\hline \multicolumn{7}{|l|}{ Todo el periodo } \\
\hline Informal SM & 38.61 & 13.27 & 28.79 & 6.50 & 12.82 & 100.00 \\
\hline Formal SM & 3.62 & 76.69 & 15.65 & 1.85 & 2.18 & 100.00 \\
\hline Otro sector & 1.19 & 1.55 & 82.42 & 7.43 & 7.42 & 100.00 \\
\hline Desempleado & 2.26 & 0.88 & 40.58 & 31.19 & 25.10 & 100.00 \\
\hline Inactivo & 0.99 & 0.34 & 11.57 & 8.25 & 78.84 & 100.00 \\
\hline \multicolumn{7}{|l|}{$1995-1996$} \\
\hline Informal SM & 34.59 & 27.36 & 26.48 & 3.69 & 7.88 & 100.00 \\
\hline Formal SM & 3.45 & 76.77 & 15.93 & 0.69 & 3.15 & 100.00 \\
\hline Otro sector & 1.08 & 1.98 & 81.65 & 7.64 & 7.65 & 100.00 \\
\hline Desempleado & 1.74 & 1.16 & 36.18 & 29.68 & 31.25 & 100.00 \\
\hline Inactivo & 0.66 & 0.39 & 9.29 & 7.49 & 82.17 & 100.00 \\
\hline \multicolumn{7}{|l|}{$1996-1997$} \\
\hline Informal SM & 46.21 & 19.11 & 19.51 & 5.14 & 10.03 & 100.00 \\
\hline Formal SM & 3.98 & 79.36 & 12.78 & 2.03 & 1.84 & 100.00 \\
\hline Otro sector & 1.29 & 1.65 & 82.59 & 6.95 & 7.52 & 100.00 \\
\hline Desempleado & 3.22 & 1.51 & 40.17 & 32.15 & 22.95 & 100.00 \\
\hline Inactivo & 1.09 & 0.56 & 11.99 & 9.63 & 76.73 & 100.00 \\
\hline \multicolumn{7}{|l|}{$1997-1998$} \\
\hline Informal SM & 37.48 & 13.53 & 33.07 & 4.79 & 11.14 & 100.00 \\
\hline Formal SM & 3.24 & 77.09 & 15.85 & 1.51 & 2.30 & 100.00 \\
\hline Otro sector & 1.30 & 1.71 & 84.77 & 5.77 & 6.46 & 100.00 \\
\hline Desempleado & 3.20 & 1.42 & 40.12 & 29.73 & 25.53 & 100.00 \\
\hline Inactivo & 1.77 & 0.35 & 11.58 & 6.82 & 79.48 & 100.00 \\
\hline \multicolumn{7}{|l|}{ 1998-1999 } \\
\hline Informal SM & 32.59 & 12.97 & 34.20 & 5.35 & 14.91 & 100.00 \\
\hline Formal SM & 3.22 & 76.54 & 16.10 & 2.44 & 1.70 & 100.00 \\
\hline Otro sector & 1.31 & 1.12 & 82.97 & 6.45 & 8.16 & 100.00 \\
\hline Desempleado & 1.98 & 1.08 & 40.75 & 31.94 & 24.23 & 100.00 \\
\hline Inactivo & 0.68 & 0.42 & 12.13 & 7.41 & 79.36 & 100.00 \\
\hline
\end{tabular}

Fuente: Elaboración propia en base a EPH. 
Cuadro 4.3: Matriz de transición - Continuación

Porcentajes sobre categoría de origen

\begin{tabular}{|c|c|c|c|c|c|c|}
\hline \multirow[b]{2}{*}{$\begin{array}{l}\text { Condición } \\
\text { en } t\end{array}$} & \multicolumn{5}{|c|}{ Condición en $t+1$} & \multirow[b]{2}{*}{ Total } \\
\hline & $\begin{array}{l}\text { Informal } \\
\text { SM }\end{array}$ & $\begin{array}{c}\text { Formal } \\
\text { SM }\end{array}$ & $\begin{array}{l}\text { Otro } \\
\text { sector }\end{array}$ & $\begin{array}{l}\text { Desemple } \\
\text { ado }\end{array}$ & Inactivo & \\
\hline \multicolumn{7}{|l|}{ 1999-2000 } \\
\hline Informal SM & 44.59 & 7.54 & 24.36 & 5.96 & 17.55 & 100.00 \\
\hline Formal SM & 1.61 & 76.65 & 18.99 & 1.54 & 1.20 & 100.00 \\
\hline Otro sector & 1.31 & 1.68 & 82.73 & 7.45 & 6.82 & 100.00 \\
\hline Desempleado & 1.68 & 0.50 & 41.86 & 30.77 & 25.19 & 100.00 \\
\hline Inactivo & 0.77 & 0.44 & 11.45 & 7.30 & 80.04 & 100.00 \\
\hline \multicolumn{7}{|l|}{ 2000-2001 } \\
\hline Informal SM & 45.54 & 8.88 & 27.01 & 7.01 & 11.56 & 100.00 \\
\hline Formal SM & 4.88 & 76.03 & 15.23 & 2.46 & 1.41 & 100.00 \\
\hline Otro sector & 1.21 & 1.66 & 83.61 & 7.47 & 6.06 & 100.00 \\
\hline Desempleado & 2.55 & 0.86 & 41.47 & 29.70 & 25.43 & 100.00 \\
\hline Inactivo & 0.93 & 0.27 & 13.01 & 8.79 & 77.00 & 100.00 \\
\hline \multicolumn{7}{|l|}{ 2001-2002 } \\
\hline Informal SM & 32.81 & 2.65 & 37.27 & 11.50 & 15.78 & 100.00 \\
\hline Formal SM & 3.61 & 72.03 & 16.90 & 3.09 & 4.38 & 100.00 \\
\hline Otro sector & 1.15 & 1.44 & 77.28 & 11.76 & 8.37 & 100.00 \\
\hline Desempleado & 1.01 & 0.37 & 30.77 & 39.26 & 28.60 & 100.00 \\
\hline Inactivo & 0.86 & 0.23 & 9.79 & 9.63 & 79.49 & 100.00 \\
\hline \multicolumn{7}{|l|}{ 2002-2003 } \\
\hline Informal SM & 34.35 & 16.58 & 28.91 & 8.32 & 11.83 & 100.00 \\
\hline Formal SM & 5.77 & 79.03 & 12.53 & 1.34 & 1.33 & 100.00 \\
\hline Otro sector & 0.90 & 1.22 & 84.06 & 5.60 & 8.22 & 100.00 \\
\hline Desempleado & 2.64 & 0.46 & 49.70 & 27.53 & 19.67 & 100.00 \\
\hline Inactivo & 1.21 & 0.09 & 13.12 & 8.78 & 76.80 & 100.00 \\
\hline
\end{tabular}

Fuente: Elaboración propia en base a EPH. 
Cuadro 4.4: Matriz de transición

Porcentajes sobre categoría de destino

\begin{tabular}{|c|c|c|c|c|c|c|}
\hline \multirow[b]{2}{*}{$\begin{array}{l}\text { Condición } \\
\text { en } t\end{array}$} & \multicolumn{5}{|c|}{ Condición en $t+1$} & \multirow[b]{2}{*}{ Total } \\
\hline & $\begin{array}{c}\text { Informal } \\
\text { SM }\end{array}$ & $\begin{array}{c}\text { Formal } \\
\text { SM }\end{array}$ & $\begin{array}{l}\text { Otro } \\
\text { sector }\end{array}$ & $\begin{array}{c}\text { Desemple } \\
\text { ado }\end{array}$ & Inactivo & \\
\hline \multicolumn{7}{|l|}{ Todo el periodo } \\
\hline Informal SM & 35.74 & 8.02 & 27.53 & 10.04 & 18.67 & 100.00 \\
\hline Formal SM & 5.38 & 74.44 & 15.66 & 1.71 & 2.80 & 100.00 \\
\hline Otro sector & 1.13 & 1.47 & 80.55 & 7.64 & 9.21 & 100.00 \\
\hline Desempleado & 1.26 & 0.86 & 36.05 & 29.18 & 32.64 & 100.00 \\
\hline Inactivo & 0.67 & 0.27 & 9.61 & 6.27 & 83.19 & 100.00 \\
\hline \multicolumn{7}{|l|}{ 1995-1996 } \\
\hline Informal SM & 32.25 & 11.72 & 30.56 & 10.04 & 15.44 & 100.00 \\
\hline Formal SM & 7.13 & 72.80 & 15.65 & 1.87 & 2.55 & 100.00 \\
\hline Otro sector & 0.88 & 1.92 & 82.00 & 7.43 & 7.77 & 100.00 \\
\hline Desempleado & 0.60 & 0.41 & 37.90 & 30.10 & 30.98 & 100.00 \\
\hline Inactivo & 0.31 & 0.46 & 9.21 & 7.69 & 82.34 & 100.00 \\
\hline \multicolumn{7}{|l|}{ 1996-1997 } \\
\hline Informal SM & 40.90 & 7.56 & 22.90 & 11.44 & 17.20 & 100.00 \\
\hline Formal SM & 8.02 & 71.45 & 13.82 & 2.54 & 4.16 & 100.00 \\
\hline Otro sector & 0.94 & 1.32 & 79.67 & 7.78 & 10.29 & 100.00 \\
\hline Desempleado & 1.14 & 0.97 & 30.98 & 28.76 & 38.16 & 100.00 \\
\hline Inactivo & 0.62 & 0.24 & 9.28 & 5.68 & 84.18 & 100.00 \\
\hline \multicolumn{7}{|l|}{$1997-1998$} \\
\hline Informal SM & 29.13 & 7.30 & 24.78 & 11.30 & 27.49 & 100.00 \\
\hline Formal SM & 4.63 & 76.39 & 14.36 & 2.20 & 2.42 & 100.00 \\
\hline Otro sector & 1.28 & 1.78 & 80.86 & 7.07 & 9.01 & 100.00 \\
\hline Desempleado & 1.13 & 1.04 & 33.55 & 31.92 & 32.36 & 100.00 \\
\hline Inactivo & 0.59 & 0.35 & 8.42 & 6.14 & 84.50 & 100.00 \\
\hline \multicolumn{7}{|l|}{ 1998-1999 } \\
\hline Informal SM & 37.20 & 7.85 & 33.59 & 7.59 & 13.76 & 100.00 \\
\hline Formal SM & 6.10 & 76.83 & 11.89 & 1.71 & 3.47 & 100.00 \\
\hline Otro sector & 1.49 & 1.50 & 81.64 & 5.97 & 9.40 & 100.00 \\
\hline Desempleado & 1.36 & 1.32 & 36.84 & 27.16 & 33.32 & 100.00 \\
\hline Inactivo & 0.88 & 0.21 & 10.87 & 4.81 & 83.23 & 100.00 \\
\hline
\end{tabular}

Fuente: Elaboración propia en base a EPH. 
Cuadro 4.5: Matriz de transición - Continuación

Porcentajes sobre categoría de destino

\begin{tabular}{|c|c|c|c|c|c|c|}
\hline \multirow[b]{2}{*}{$\begin{array}{l}\text { Condición } \\
\text { en } t\end{array}$} & \multicolumn{5}{|c|}{ Condición en $t+1$} & \multirow[b]{2}{*}{ Total } \\
\hline & $\begin{array}{l}\text { Informal } \\
\text { SM }\end{array}$ & $\begin{array}{c}\text { Formal } \\
\text { SM }\end{array}$ & $\begin{array}{l}\text { Otro } \\
\text { sector }\end{array}$ & $\begin{array}{l}\text { Desemple } \\
\text { ado }\end{array}$ & Inactivo & \\
\hline \multicolumn{7}{|l|}{ 1999-2000 } \\
\hline Informal SM & 44.10 & 3.60 & 31.17 & 7.20 & 13.93 & 100.00 \\
\hline Formal SM & 3.26 & 74.84 & 17.45 & 0.94 & 3.50 & 100.00 \\
\hline Otro sector & 1.00 & 1.75 & 81.24 & 7.43 & 8.58 & 100.00 \\
\hline Desempleado & 1.31 & 0.76 & 39.28 & 29.30 & 29.35 & 100.00 \\
\hline Inactivo & 1.00 & 0.15 & 9.31 & 6.21 & 83.33 & 100.00 \\
\hline \multicolumn{7}{|l|}{ 2000-2001 } \\
\hline Informal SM & 35.44 & 9.29 & 27.63 & 10.58 & 17.07 & 100.00 \\
\hline Formal SM & 3.48 & 73.01 & 19.21 & 1.80 & 2.51 & 100.00 \\
\hline Otro sector & 0.88 & 1.22 & 80.58 & 7.24 & 10.08 & 100.00 \\
\hline Desempleado & 1.17 & 1.00 & 36.69 & 26.43 & 34.70 & 100.00 \\
\hline Inactivo & 0.54 & 0.16 & 8.30 & 6.30 & 84.70 & 100.00 \\
\hline \multicolumn{7}{|l|}{ 2001-2002 } \\
\hline Informal SM & 33.84 & 8.55 & 32.80 & 5.33 & 19.48 & 100.00 \\
\hline Formal SM & 1.23 & 76.89 & 18.61 & 0.87 & 2.40 & 100.00 \\
\hline Otro sector & 1.44 & 1.50 & 82.69 & 6.07 & 8.31 & 100.00 \\
\hline Desempleado & 1.52 & 0.94 & 43.08 & 26.49 & 27.97 & 100.00 \\
\hline Inactivo & 0.73 & 0.47 & 10.79 & 6.79 & 81.22 & 100.00 \\
\hline \multicolumn{7}{|l|}{ 2002-2003 } \\
\hline Informal SM & 31.85 & 9.61 & 20.14 & 15.40 & 23.00 & 100.00 \\
\hline Formal SM & 8.60 & 73.66 & 15.29 & 1.49 & 0.96 & 100.00 \\
\hline Otro sector & 1.09 & 0.85 & 76.26 & 11.73 & 10.08 & 100.00 \\
\hline Desempleado & 1.67 & 0.48 & 27.14 & 34.69 & 36.02 & 100.00 \\
\hline Inactivo & 0.62 & 0.13 & 10.41 & 6.48 & 82.37 & 100.00 \\
\hline
\end{tabular}

Fuente: Elaboración propia en base a EPH. 


\section{Cuadro 4.6: Matriz de transición}

Resumen para todo el periodo

\begin{tabular}{|c|c|c|c|c|c|c|}
\hline \multirow[b]{2}{*}{$\begin{array}{l}\text { Condición } \\
\text { en } t\end{array}$} & \multicolumn{5}{|c|}{ Condición en $t+1$} & \multirow[b]{2}{*}{$\begin{array}{c}\text { Total } \\
\text { fila }\end{array}$} \\
\hline & $\begin{array}{l}\text { Informal } \\
\text { SM }\end{array}$ & $\begin{array}{c}\text { Formal } \\
\text { SM }\end{array}$ & $\begin{array}{l}\text { Otro } \\
\text { sector }\end{array}$ & $\begin{array}{l}\text { Desemple } \\
\text { ado }\end{array}$ & Inactivo & \\
\hline \multicolumn{7}{|l|}{ Informal SM } \\
\hline \% fila & 38.61 & 13.27 & 28.79 & 6.50 & 12.82 & 100.00 \\
\hline$\%$ columna & 35.74 & 5.38 & 1.13 & 1.26 & 0.67 & \\
\hline \multicolumn{7}{|l|}{ Formal SM } \\
\hline$\%$ fila & 3.62 & 76.69 & 15.65 & 1.85 & 2.18 & 100.00 \\
\hline$\%$ columna & 8.02 & 74.44 & 1.47 & 0.86 & 0.27 & \\
\hline \multicolumn{7}{|l|}{ Otro sector } \\
\hline$\%$ fila & 1.19 & 1.55 & 82.42 & 7.43 & 7.42 & 100.00 \\
\hline$\%$ columna & 27.53 & 15.66 & 80.55 & 36.05 & 9.61 & \\
\hline \multicolumn{7}{|l|}{ Desempleado } \\
\hline$\%$ fila & 2.26 & 0.88 & 40.58 & 31.19 & 25.10 & 100.00 \\
\hline$\%$ columna & 10.04 & 1.71 & 7.64 & 29.18 & 6.27 & \\
\hline \multicolumn{7}{|l|}{ Inactivo } \\
\hline$\%$ fila & 0.99 & 0.34 & 11.57 & 8.25 & 78.84 & 100.00 \\
\hline$\%$ columna & 18.67 & 2.80 & 9.21 & 32.64 & 83.19 & \\
\hline Total columna & 100.00 & 100.00 & 100.00 & 100.00 & 100.00 & \\
\hline
\end{tabular}

Fuente: Elaboración propia en base a EPH. 


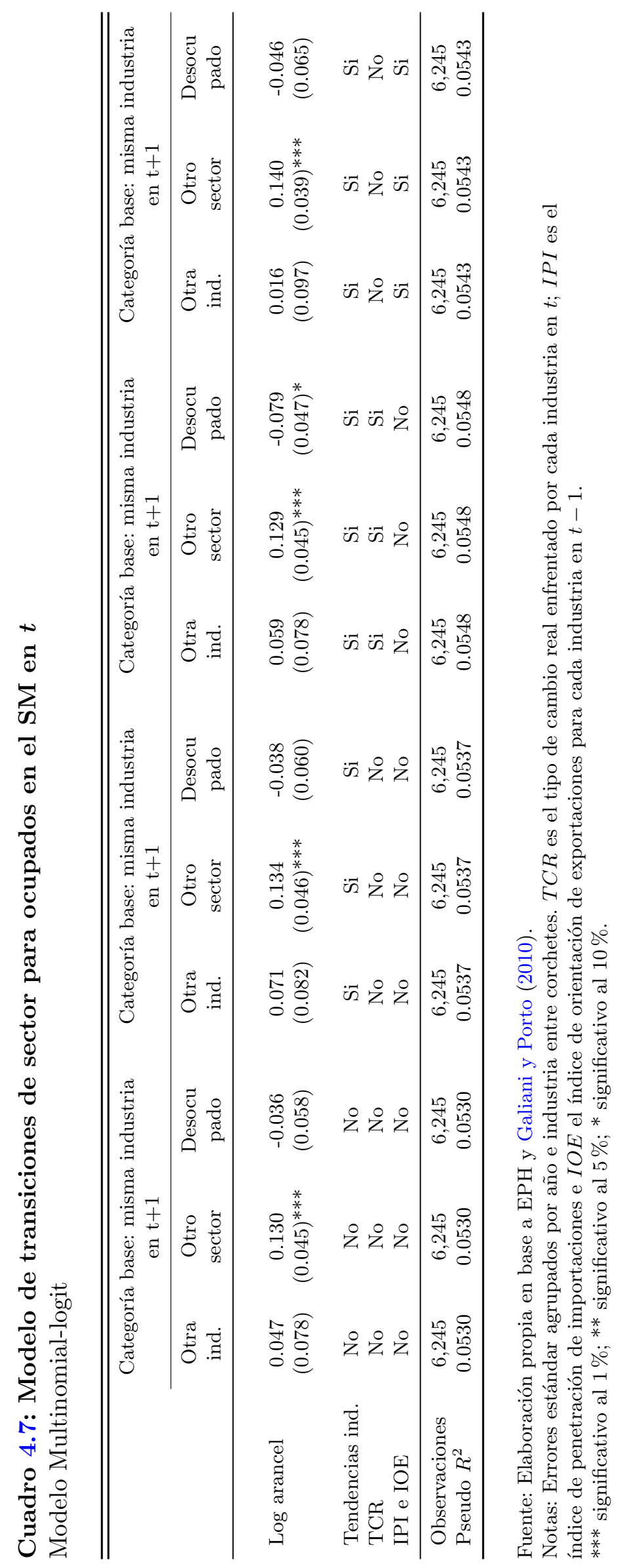


Cuadro 4.8: Modelo de transiciones de sector para ocupados en el SM en $t$

Modelo Multinomial-logit - Sub-periodos 1995-1998 y 1998-2001

\begin{tabular}{lcccccc}
\hline \hline & \multicolumn{3}{c}{ 1995-1998 } & \multicolumn{3}{c}{$1998-2001$} \\
\cline { 2 - 7 } & \multicolumn{2}{c}{ Categoría base: misma industria } & \multicolumn{2}{c}{ Categoría base: misma industria } \\
en t+1
\end{tabular}

Fuente: Elaboración propia en base a EPH y Galiani y Porto (2010).

Notas: Errores estándar agrupados por año e industria entre corchetes. $T C R$ es el tipo de cambio real enfrentado por cada industria en $t$; IPI es el índice de penetración de importaciones e $I O E$ el índice de orientación de exportaciones para cada industria en $t-1$.

El periodo 1995-1998 comprende los paneles 95-96, 96-97 y 97-98; el periodo 1998-2001 abarca los paneles 98-99, 99-00, 00-01.

*** significativo al $1 \%$; ** significativo al $5 \%$; $*$ significativo al $10 \%$. 


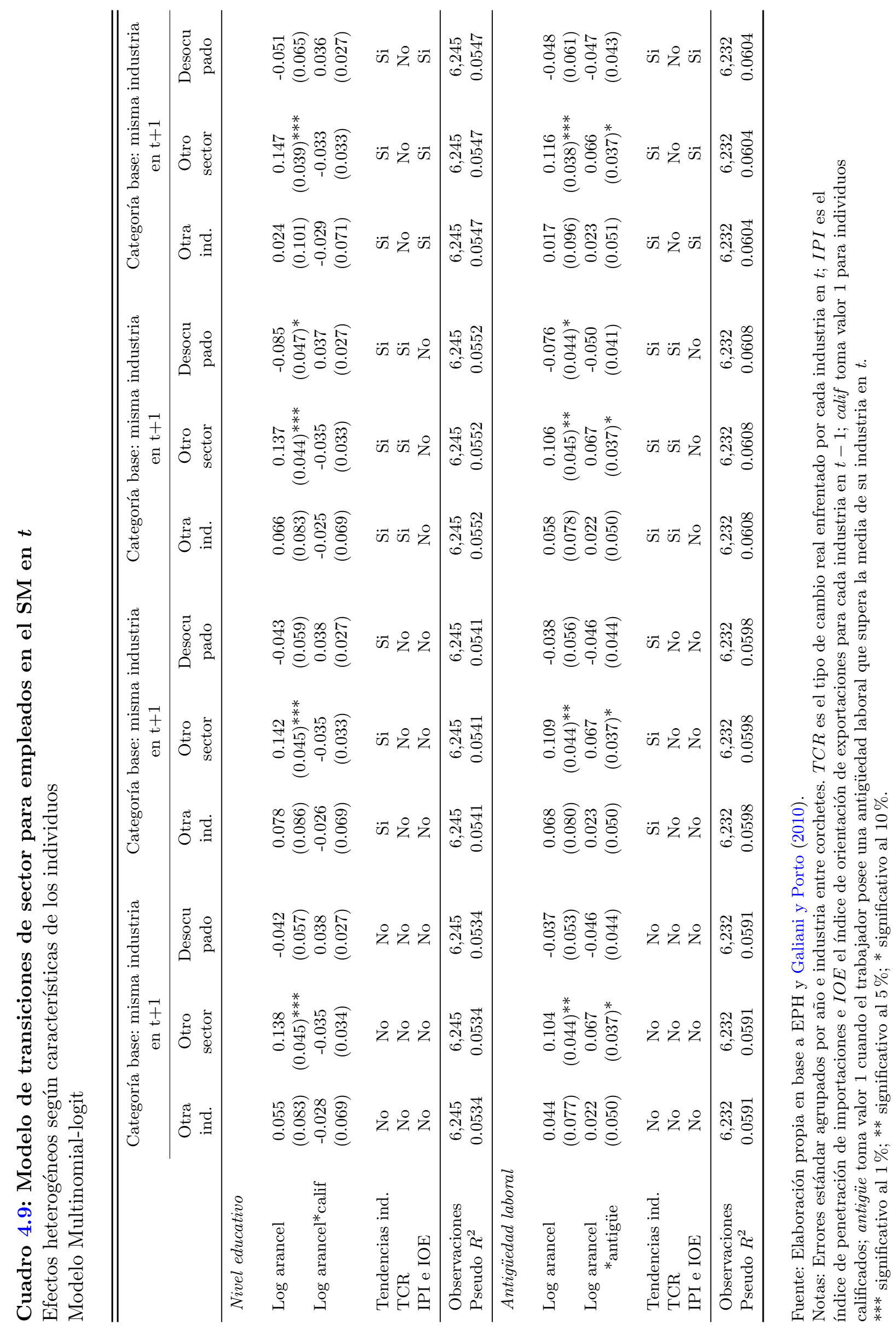




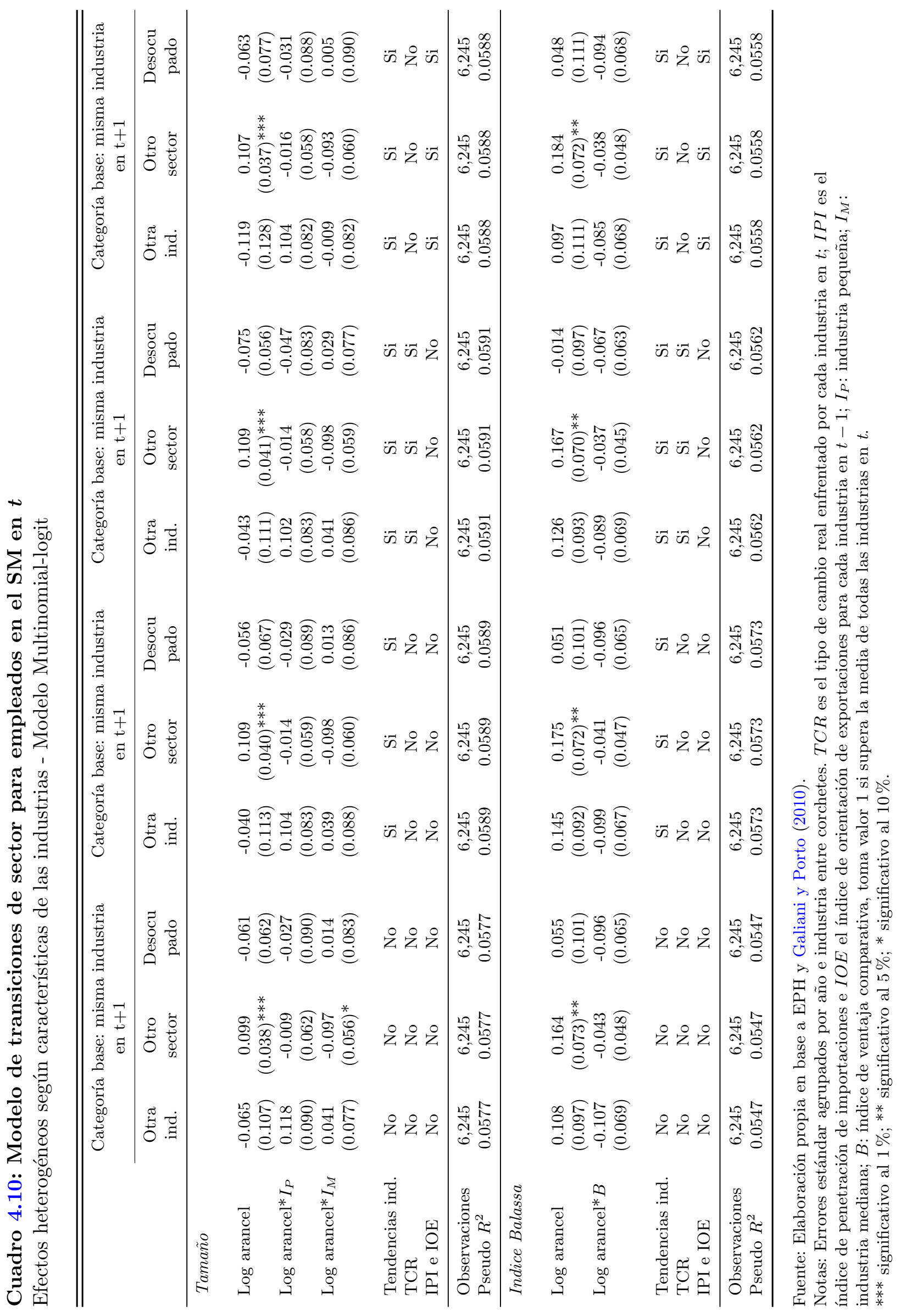




\section{Cuadro 4.11: Modelo de transiciones de categoría laboral para desocupados en $t$ \\ Modelo Multinomial-logit}

\begin{tabular}{|c|c|c|c|c|c|c|}
\hline & \multicolumn{3}{|c|}{ Categoría base: desocupado en $t+1$} & \multicolumn{3}{|c|}{ Categoría base: desocupado en $t+1$} \\
\hline & $\begin{array}{l}\text { Informal } \\
\text { SM }\end{array}$ & $\begin{array}{l}\text { Formal } \\
\text { SM }\end{array}$ & $\begin{array}{l}\text { Otro } \\
\text { sector }\end{array}$ & $\begin{array}{l}\text { Informal } \\
\text { SM }\end{array}$ & $\begin{array}{l}\text { Formal } \\
\text { SM }\end{array}$ & $\begin{array}{l}\text { Otro } \\
\text { sector }\end{array}$ \\
\hline $\begin{array}{c}\text { Log. arancel } \\
\text { prom. }\end{array}$ & $\begin{array}{c}-0.665 \\
(0.046)^{* * *}\end{array}$ & $\begin{array}{c}-0.999 \\
(0.076)^{* * *}\end{array}$ & $\begin{array}{c}-0.022 \\
(0.008)^{* * *}\end{array}$ & $\begin{array}{c}0.248 \\
(0.019)^{* * *}\end{array}$ & $\begin{array}{c}0.159 \\
(0.032)^{* * *}\end{array}$ & $\begin{array}{c}0.028 \\
(0.004)^{* * *}\end{array}$ \\
\hline $\begin{array}{l}\text { TCR } \\
\text { IPI e IOE }\end{array}$ & $\begin{array}{l}\text { No } \\
\text { No }\end{array}$ & $\begin{array}{l}\text { No } \\
\text { No }\end{array}$ & $\begin{array}{l}\text { No } \\
\text { No }\end{array}$ & $\begin{array}{c}\mathrm{Si} \\
\mathrm{No}\end{array}$ & $\begin{array}{c}\mathrm{Si} \\
\mathrm{No}\end{array}$ & $\begin{array}{l}\mathrm{Si} \\
\mathrm{No}\end{array}$ \\
\hline $\begin{array}{l}\text { Observaciones } \\
\text { Pseudo } R^{2}\end{array}$ & $\begin{array}{c}7,641 \\
0.0561\end{array}$ & $\begin{array}{c}7,641 \\
0.0561\end{array}$ & $\begin{array}{c}7,641 \\
0.0561\end{array}$ & $\begin{array}{c}7,641 \\
0.0561\end{array}$ & $\begin{array}{c}7,641 \\
0.0561\end{array}$ & $\begin{array}{c}7,641 \\
0.0561\end{array}$ \\
\hline Nivel educativo & & & & & & \\
\hline $\begin{array}{l}\text { Log. arancel } \\
\text { prom. } \\
\text { Log. arancel } \\
\text { prom*calif }\end{array}$ & $\begin{array}{c}-0.660 \\
(0.050)^{* * *} \\
-0.025 \\
(0.075)\end{array}$ & $\begin{array}{c}-0.969 \\
(0.077)^{* * *} \\
-0.191 \\
(0.100)^{*}\end{array}$ & $\begin{array}{c}-0.012 \\
(0.005)^{* *} \\
-0.045 \\
(0.017)^{* * *}\end{array}$ & $\begin{array}{c}0.258 \\
(0.034)^{* * *} \\
-0.025 \\
(0.075)\end{array}$ & $\begin{array}{c}0.260 \\
(0.082)^{* * *} \\
-0.191 \\
(0.100)^{*}\end{array}$ & $\begin{array}{c}0.046 \\
(0.007)^{* * *} \\
-0.045 \\
(0.017)^{* * *}\end{array}$ \\
\hline $\begin{array}{l}\text { TCR } \\
\text { IPI e IOE }\end{array}$ & $\begin{array}{l}\text { No } \\
\text { No }\end{array}$ & $\begin{array}{l}\text { No } \\
\text { No }\end{array}$ & $\begin{array}{l}\text { No } \\
\text { No }\end{array}$ & $\begin{array}{l}\mathrm{Si} \\
\mathrm{No}\end{array}$ & $\begin{array}{l}\mathrm{Si} \\
\mathrm{No}\end{array}$ & $\begin{array}{l}\mathrm{Si} \\
\mathrm{No}\end{array}$ \\
\hline $\begin{array}{l}\text { Observaciones } \\
\text { Pseudo } R^{2}\end{array}$ & $\begin{array}{c}7,641 \\
0.0570\end{array}$ & $\begin{array}{c}7,641 \\
0.0570\end{array}$ & $\begin{array}{c}7,641 \\
0.0570\end{array}$ & $\begin{array}{c}7,641 \\
0.0570\end{array}$ & $\begin{array}{c}7,641 \\
0.0570\end{array}$ & $\begin{array}{c}7,641 \\
0.0570\end{array}$ \\
\hline
\end{tabular}

Fuente: Elaboración propia en base a EPH y Galiani y Porto (2010).

Notas: Errores estándar agrupados por año entre corchetes. TCR es el tipo de cambio real en $t$; $I P I$ es el índice de penetración de importaciones e $I O E$ el índice de orientación de exportaciones en $t-1$; calif toma valor 1 para individuos calificados.

*** significativo al $1 \%$; ** significativo al $5 \%$; ${ }^{*}$ significativo al $10 \%$. 
Cuadro 4.12: Modelo de transiciones de categoría laboral para desocupados en $\boldsymbol{t}$ - Continuación

Modelo Multinomial-logit

\begin{tabular}{|c|c|c|c|c|c|c|}
\hline & \multicolumn{3}{|c|}{ Categoría base: desocupado en $t+1$} & \multicolumn{3}{|c|}{ Categoría base: desocupado en $\mathrm{t}+1$} \\
\hline & $\begin{array}{l}\text { Informal } \\
\text { SM }\end{array}$ & $\begin{array}{l}\text { Formal } \\
\text { SM }\end{array}$ & $\begin{array}{l}\text { Otro } \\
\text { sector }\end{array}$ & $\begin{array}{l}\text { Informal } \\
\text { SM }\end{array}$ & $\begin{array}{l}\text { Formal } \\
\text { SM }\end{array}$ & $\begin{array}{l}\text { Otro } \\
\text { sector }\end{array}$ \\
\hline $\begin{array}{c}\text { Log. arancel } \\
\text { prom. }\end{array}$ & $\begin{array}{c}0.111 \\
(0.005)^{* * *}\end{array}$ & $\begin{array}{c}0.068 \\
(0.005)^{* * *}\end{array}$ & $\begin{array}{c}0.012 \\
(0.001)^{* * *}\end{array}$ & $\begin{array}{c}0.127 \\
(0.004)^{* * *}\end{array}$ & $\begin{array}{c}0.117 \\
(0.004)^{* * *}\end{array}$ & $\begin{array}{c}0.001 \\
(0.001)\end{array}$ \\
\hline TCR & No & No & No & $\mathrm{Si}$ & $\mathrm{Si}$ & $\mathrm{Si}$ \\
\hline IPI e IOE & $\mathrm{Si}$ & $\mathrm{Si}$ & $\mathrm{Si}$ & $\mathrm{Si}$ & $\mathrm{Si}$ & $\mathrm{Si}$ \\
\hline $\begin{array}{l}\text { Observaciones } \\
\text { Pseudo } R^{2}\end{array}$ & $\begin{array}{c}7,641 \\
0.0561\end{array}$ & $\begin{array}{c}7,641 \\
0.0561\end{array}$ & $\begin{array}{c}7,641 \\
0.0561\end{array}$ & $\begin{array}{c}7,641 \\
0.0561\end{array}$ & $\begin{array}{c}7,641 \\
0.0561\end{array}$ & $\begin{array}{c}7,641 \\
0.0561\end{array}$ \\
\hline Nivel educativo & & & & & & \\
\hline $\begin{array}{l}\text { Log. arancel } \\
\text { prom. } \\
\text { Log. arancel } \\
\text { prom*calif }\end{array}$ & $\begin{array}{c}0.120 \\
(0.024)^{* * *} \\
-0.025 \\
(0.075)\end{array}$ & $\begin{array}{c}0.144 \\
(0.052)^{* * *} \\
-0.191 \\
(0.100)^{*}\end{array}$ & $\begin{array}{c}0.028 \\
(0.006)^{* * *} \\
-0.045 \\
(0.017)^{* * *}\end{array}$ & $\begin{array}{c}0.136 \\
(0.023)^{* * *} \\
-0.025 \\
(0.075)\end{array}$ & $\begin{array}{c}0.194 \\
(0.057)^{* * *} \\
-0.191 \\
(0.100)^{*}\end{array}$ & $\begin{array}{c}0.017 \\
(0.007)^{* *} \\
-0.045 \\
(0.017)^{* * *}\end{array}$ \\
\hline $\begin{array}{l}\text { TCR } \\
\text { IPI e IOE }\end{array}$ & $\begin{array}{l}\mathrm{No} \\
\mathrm{Si}\end{array}$ & $\begin{array}{l}\mathrm{No} \\
\mathrm{Si}\end{array}$ & $\begin{array}{l}\mathrm{No} \\
\mathrm{Si}\end{array}$ & $\begin{array}{l}\mathrm{Si} \\
\mathrm{Si}\end{array}$ & $\begin{array}{l}\mathrm{Si} \\
\mathrm{Si}\end{array}$ & $\begin{array}{l}\mathrm{Si} \\
\mathrm{Si}\end{array}$ \\
\hline $\begin{array}{l}\text { Observaciones } \\
\text { Pseudo } R^{2}\end{array}$ & $\begin{array}{c}7,641 \\
0.0570\end{array}$ & $\begin{array}{c}7,641 \\
0.0570\end{array}$ & $\begin{array}{c}7,641 \\
0.0570\end{array}$ & $\begin{array}{c}7,641 \\
0.0570\end{array}$ & $\begin{array}{c}7,641 \\
0.0570\end{array}$ & $\begin{array}{c}7,641 \\
0.0570\end{array}$ \\
\hline
\end{tabular}

Fuente: Elaboración propia en base a EPH y Galiani y Porto (2010).

Notas: Errores estándar agrupados por año entre corchetes. TCR es el tipo de cambio real en $t$; $I P I$ es el índice de penetración de importaciones e $I O E$ el índice de orientación de exportaciones en $t-1$; calif toma valor 1 para individuos calificados.

*** significativo al $1 \%$; ** significativo al $5 \%$; ${ }^{*}$ significativo al $10 \%$. 


\section{Cuadro 4.13: Modelo de transiciones de categoría laboral para desocupados en $t$}

Modelo Multinomial-logit - Sub-periodos 1995-1998 y 1998-2001

\begin{tabular}{|c|c|c|c|c|c|c|}
\hline & \multicolumn{3}{|c|}{$1995-1998$} & \multicolumn{3}{|c|}{$1998-2001$} \\
\hline & \multicolumn{3}{|c|}{$\begin{array}{l}\text { Categoría base: desocupado } \\
\text { en } \mathrm{t}+1\end{array}$} & \multicolumn{3}{|c|}{$\begin{array}{c}\text { Categoría base: desocupado } \\
\text { en } \mathrm{t}+1\end{array}$} \\
\hline & $\begin{array}{l}\text { Informal } \\
\text { SM }\end{array}$ & $\begin{array}{l}\text { Formal } \\
\text { SM }\end{array}$ & $\begin{array}{l}\text { Otro } \\
\text { sector }\end{array}$ & $\begin{array}{l}\text { Informal } \\
\text { SM }\end{array}$ & $\begin{array}{l}\text { Formal } \\
\text { SM }\end{array}$ & $\begin{array}{l}\text { Otro } \\
\text { sector }\end{array}$ \\
\hline Log arancel prom. & $\begin{array}{c}-0.121 \\
(0.004)^{* * *}\end{array}$ & $\begin{array}{c}-0.104 \\
(0.017)^{* * *}\end{array}$ & $\begin{array}{c}-0.018 \\
(0.001) * * *\end{array}$ & $\begin{array}{c}0.290 \\
(0.023)^{* * *}\end{array}$ & $\begin{array}{c}0.176 \\
(0.087)^{* *}\end{array}$ & $\begin{array}{c}0.027 \\
(0.007)^{* * *}\end{array}$ \\
\hline $\begin{array}{l}\text { TCR } \\
\text { IPI IOF }\end{array}$ & $\begin{array}{l}\mathrm{Si} \\
\mathrm{Si}\end{array}$ & $\begin{array}{l}\mathrm{Si} \\
\mathrm{Si}\end{array}$ & $\begin{array}{l}\mathrm{Si} \\
\mathrm{Si}\end{array}$ & $\begin{array}{l}\mathrm{Si} \\
\mathrm{Si}\end{array}$ & $\begin{array}{l}\mathrm{Si} \\
\mathrm{Si}\end{array}$ & $\mathrm{Si}$ \\
\hline $\begin{array}{l}\text { Observaciones } \\
\text { Pseudo } R^{2}\end{array}$ & $\begin{array}{c}4,449 \\
0.0685\end{array}$ & $\begin{array}{c}4,449 \\
0.0685\end{array}$ & $\begin{array}{c}4,449 \\
0.0685\end{array}$ & $\begin{array}{c}3,192 \\
0.0529\end{array}$ & $\begin{array}{c}3,192 \\
0.0529\end{array}$ & $\begin{array}{c}3,192 \\
0.0529\end{array}$ \\
\hline Nivel educativo & & & & & & \\
\hline Log. arancel prom. & $\begin{array}{c}-0.208 \\
(0.027)^{* * *}\end{array}$ & $\begin{array}{c}-0.123 \\
(0.033)^{* * *}\end{array}$ & $\begin{array}{c}0.004 \\
(0.006)\end{array}$ & $\begin{array}{c}0.272 \\
(0.025)^{* * *}\end{array}$ & $\begin{array}{c}0.344 \\
(0.057)^{* * *}\end{array}$ & $\begin{array}{c}0.030 \\
(0.012)^{* *}\end{array}$ \\
\hline $\begin{array}{l}\text { Log. arancel } \\
\text { prom*alif }^{*} \text { cal }\end{array}$ & $\begin{array}{c}0.318 \\
(0.108)^{* * *}\end{array}$ & $\begin{array}{c}0.089 \\
(0.100)\end{array}$ & $\begin{array}{c}-0.063 \\
(0.013)^{* * *}\end{array}$ & $\begin{array}{c}0.055 \\
(0.030)^{*}\end{array}$ & $\begin{array}{l}-0.388 \\
(0.390)\end{array}$ & $\begin{array}{l}-0.007 \\
(0.046)\end{array}$ \\
\hline $\begin{array}{l}\text { TCR } \\
\text { IPI e IOE }\end{array}$ & $\begin{array}{l}\mathrm{Si} \\
\mathrm{Si}\end{array}$ & $\begin{array}{l}\mathrm{Si} \\
\mathrm{Si}\end{array}$ & $\begin{array}{l}\mathrm{Si} \\
\mathrm{Si}\end{array}$ & $\begin{array}{l}\mathrm{Si} \\
\mathrm{Si}\end{array}$ & $\begin{array}{l}\mathrm{Si} \\
\mathrm{Si}\end{array}$ & $\begin{array}{l}\mathrm{Si} \\
\mathrm{Si}\end{array}$ \\
\hline $\begin{array}{l}\text { Observaciones } \\
\text { Pseudo } R^{2}\end{array}$ & $\begin{array}{c}4,449 \\
0.0703\end{array}$ & $\begin{array}{c}4,449 \\
0.0703\end{array}$ & $\begin{array}{c}4,449 \\
0.0703\end{array}$ & $\begin{array}{c}3,192 \\
0.0534\end{array}$ & $\begin{array}{c}3,192 \\
0.0534\end{array}$ & $\begin{array}{c}3,192 \\
0.0534\end{array}$ \\
\hline
\end{tabular}

Fuente: Elaboración propia en base a EPH y Galiani y Porto (2010).

Notas: Errores estándar agrupados por año entre corchetes. $T C R$ es el tipo de cambio real en $t$;

$I P I$ es el índice de penetración de importaciones e $I O E$ el índice de orientación de exportaciones en $t-1$; calif toma el valor 1 para individuos calificados.

El periodo 1995-1998 comprende los paneles 95-96, 96-97 y 97-98; el periodo 1998-2001 abarca los paneles 98-99, 99-00, 00-01.

*** significativo al 1\%; ** significativo al $5 \%$; $*$ significativo al $10 \%$. 


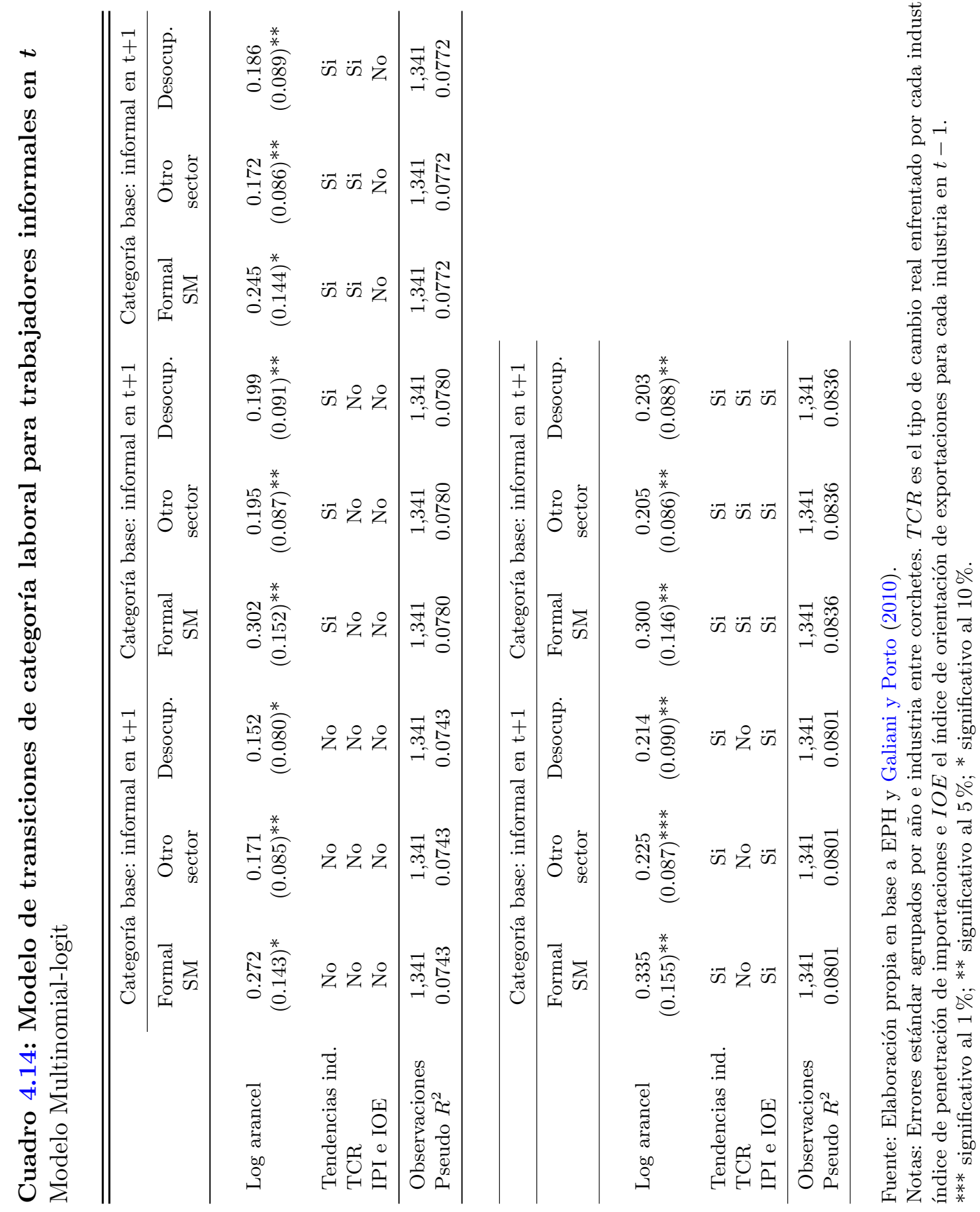




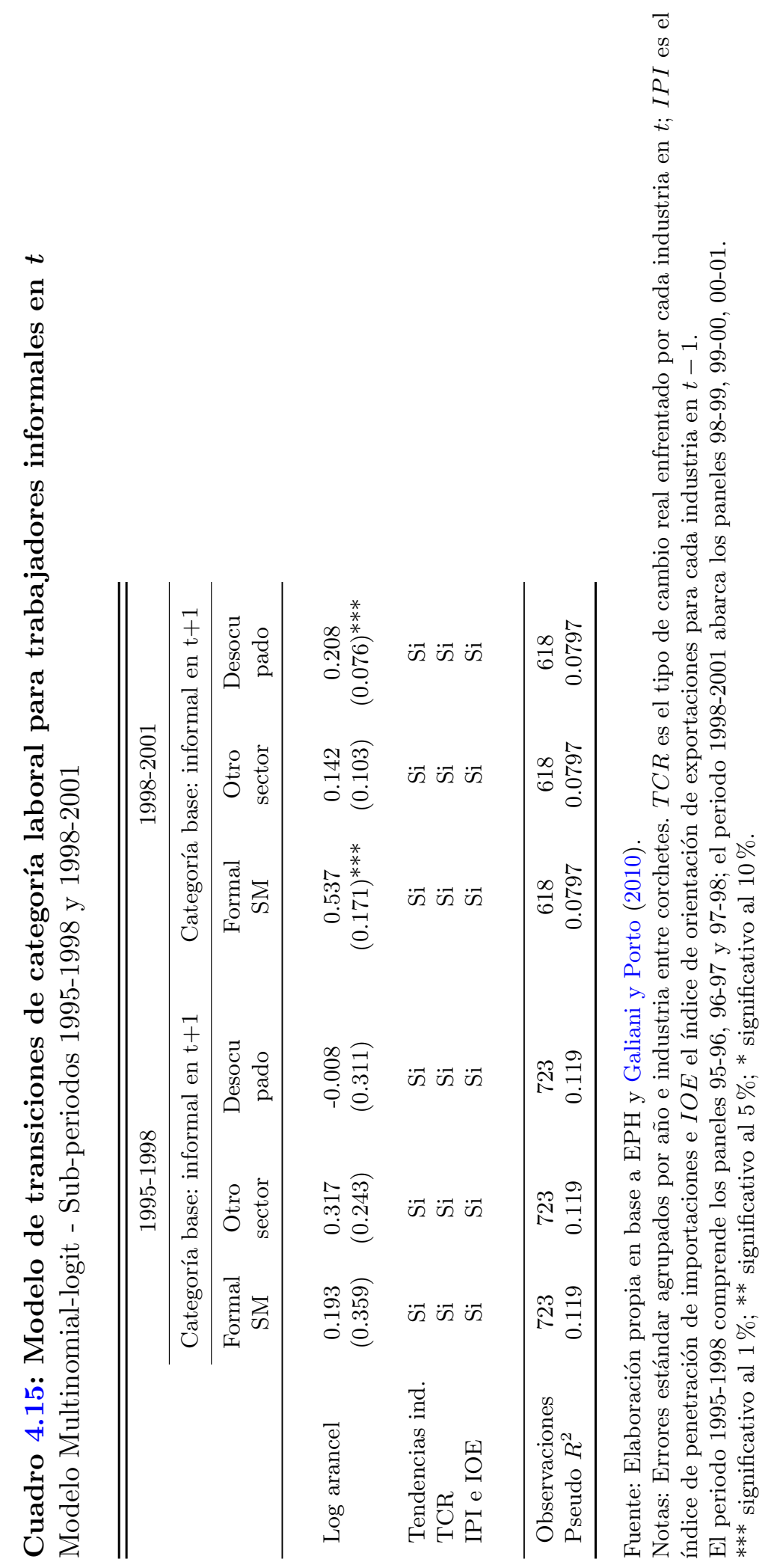




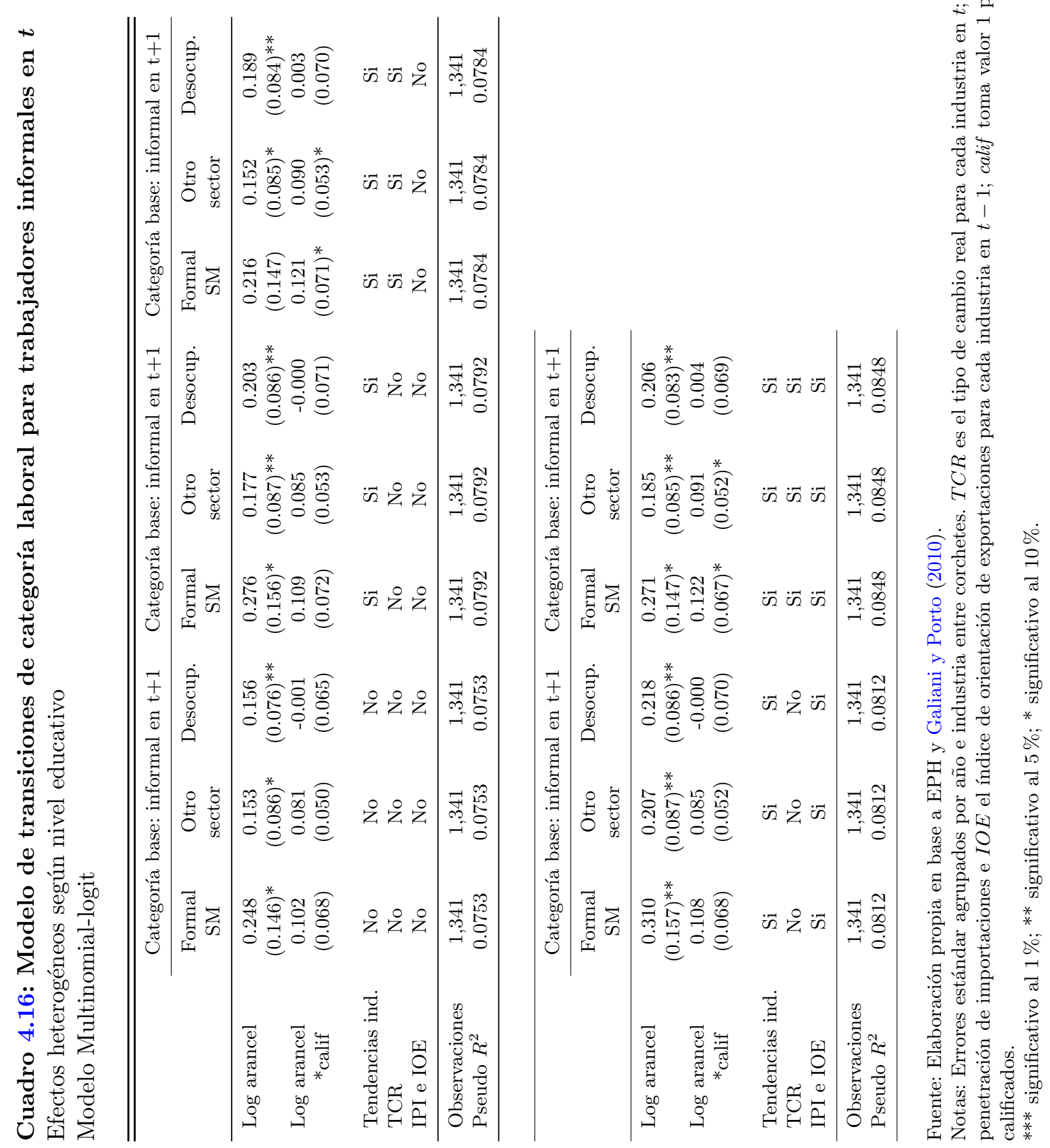




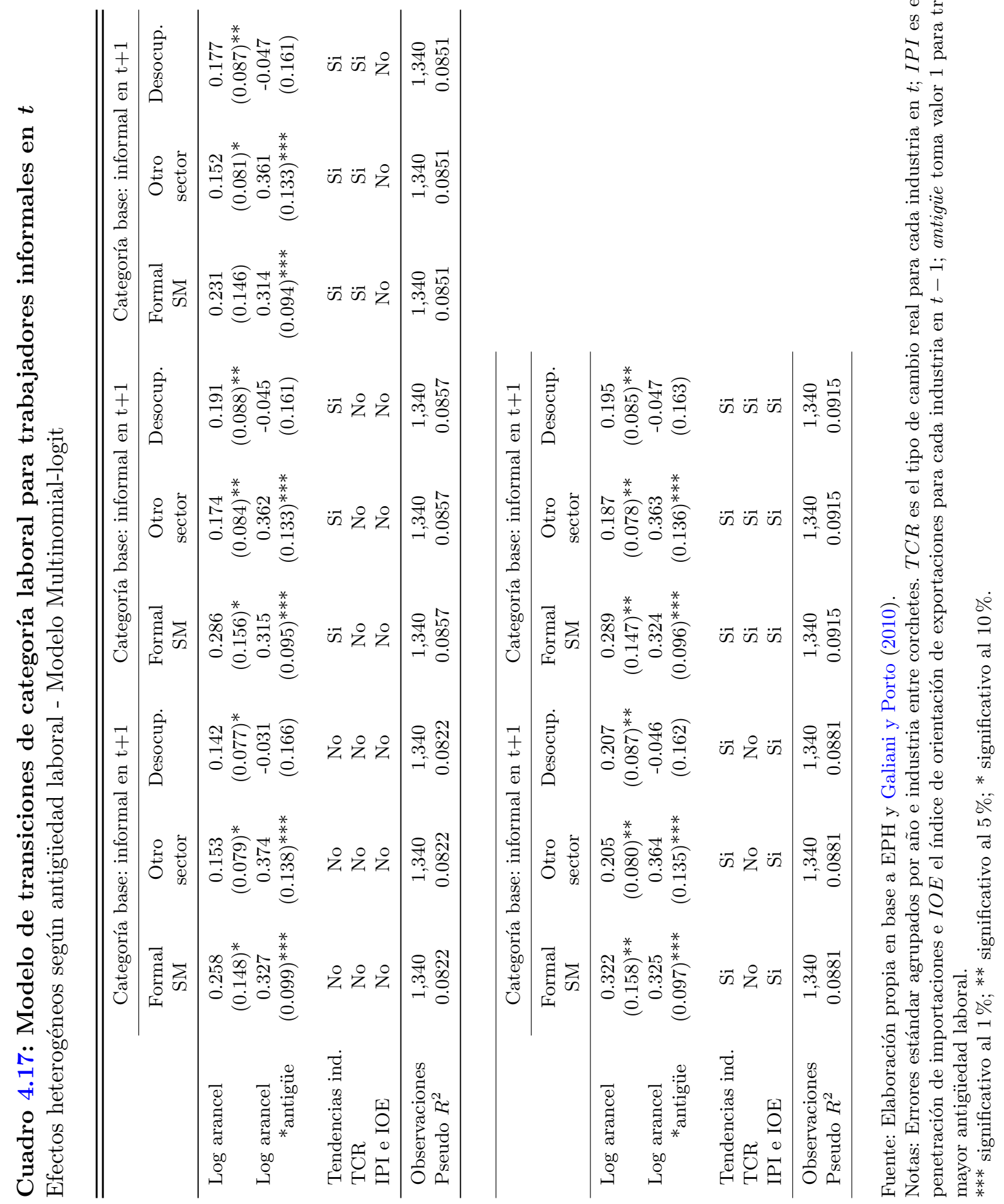




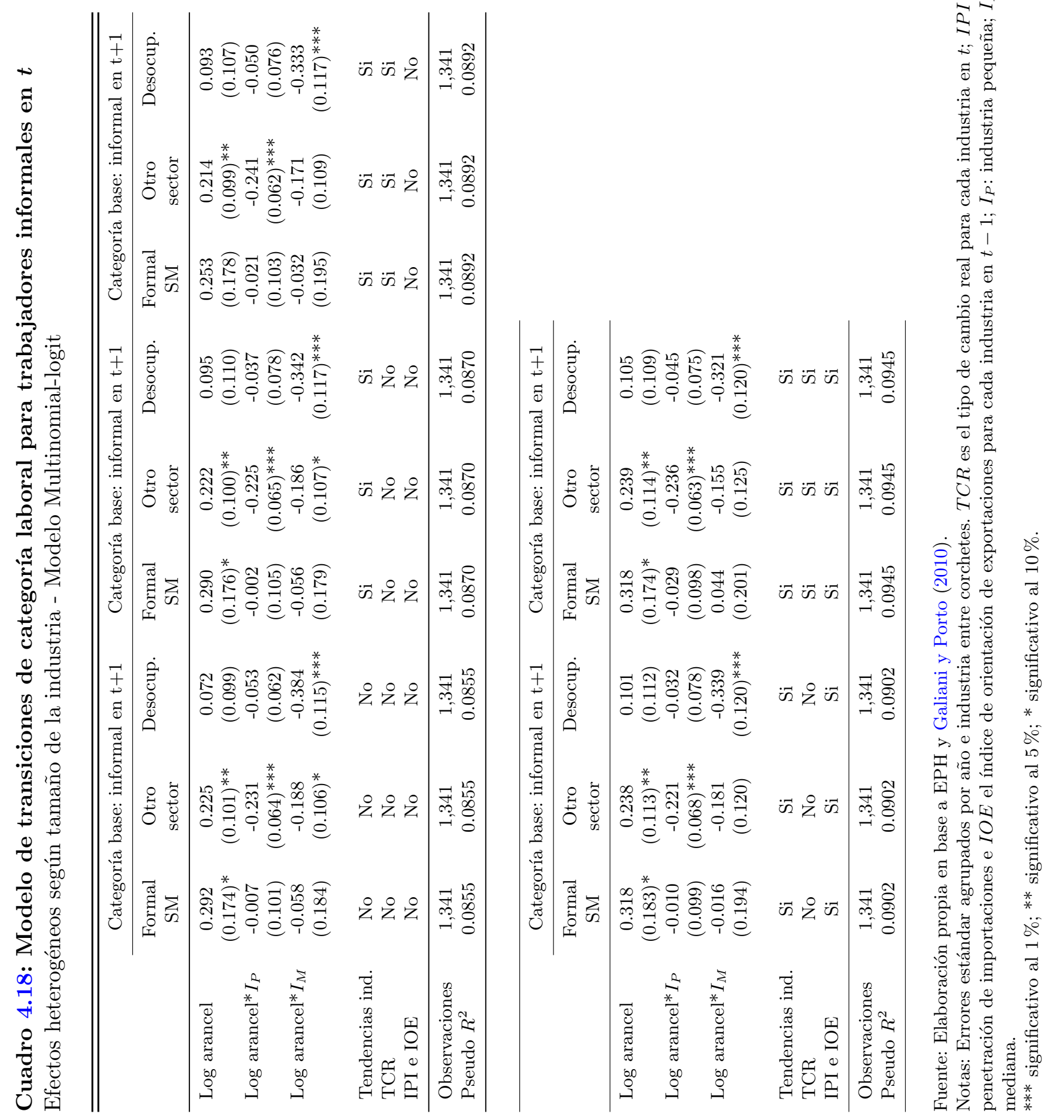




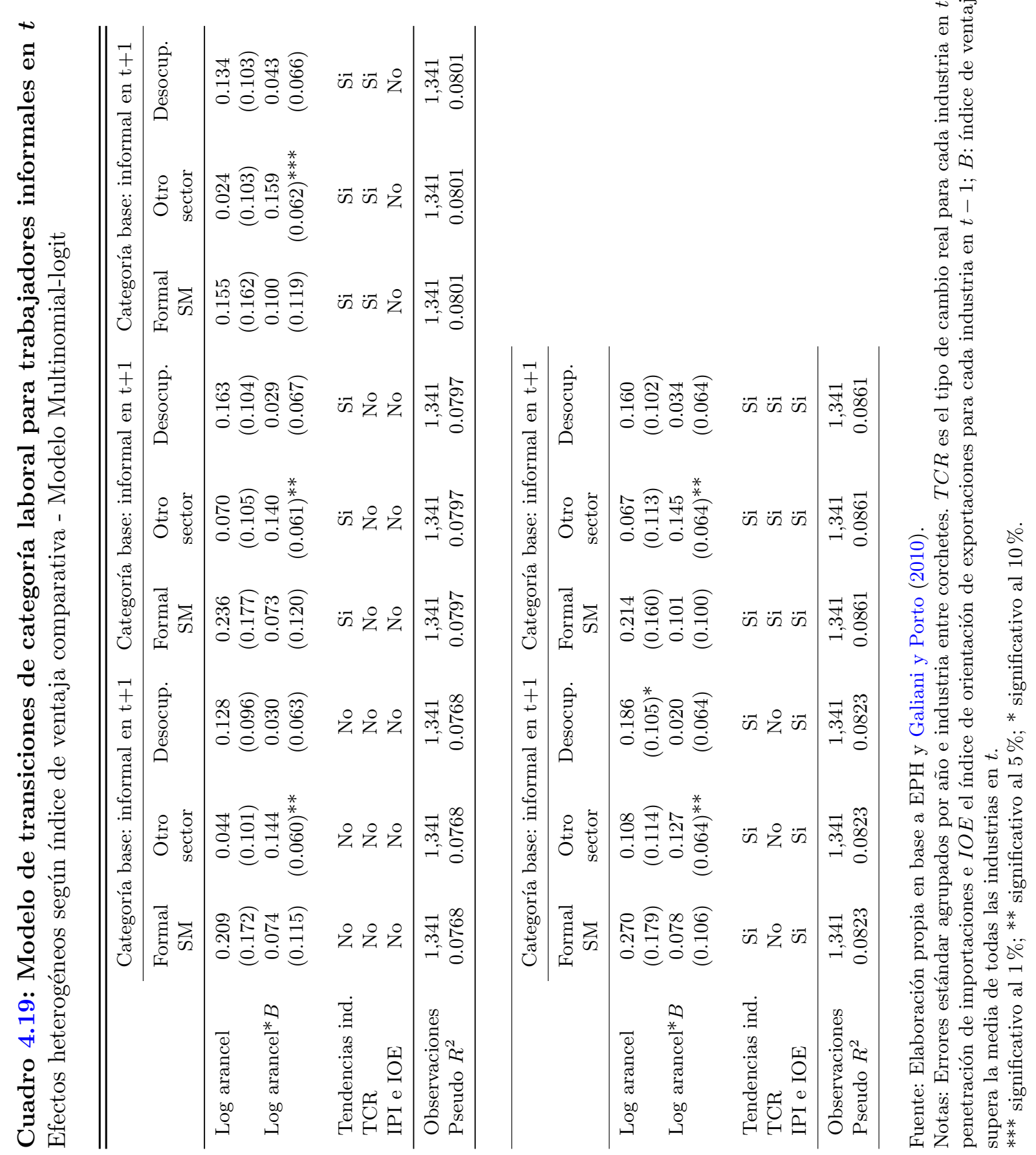



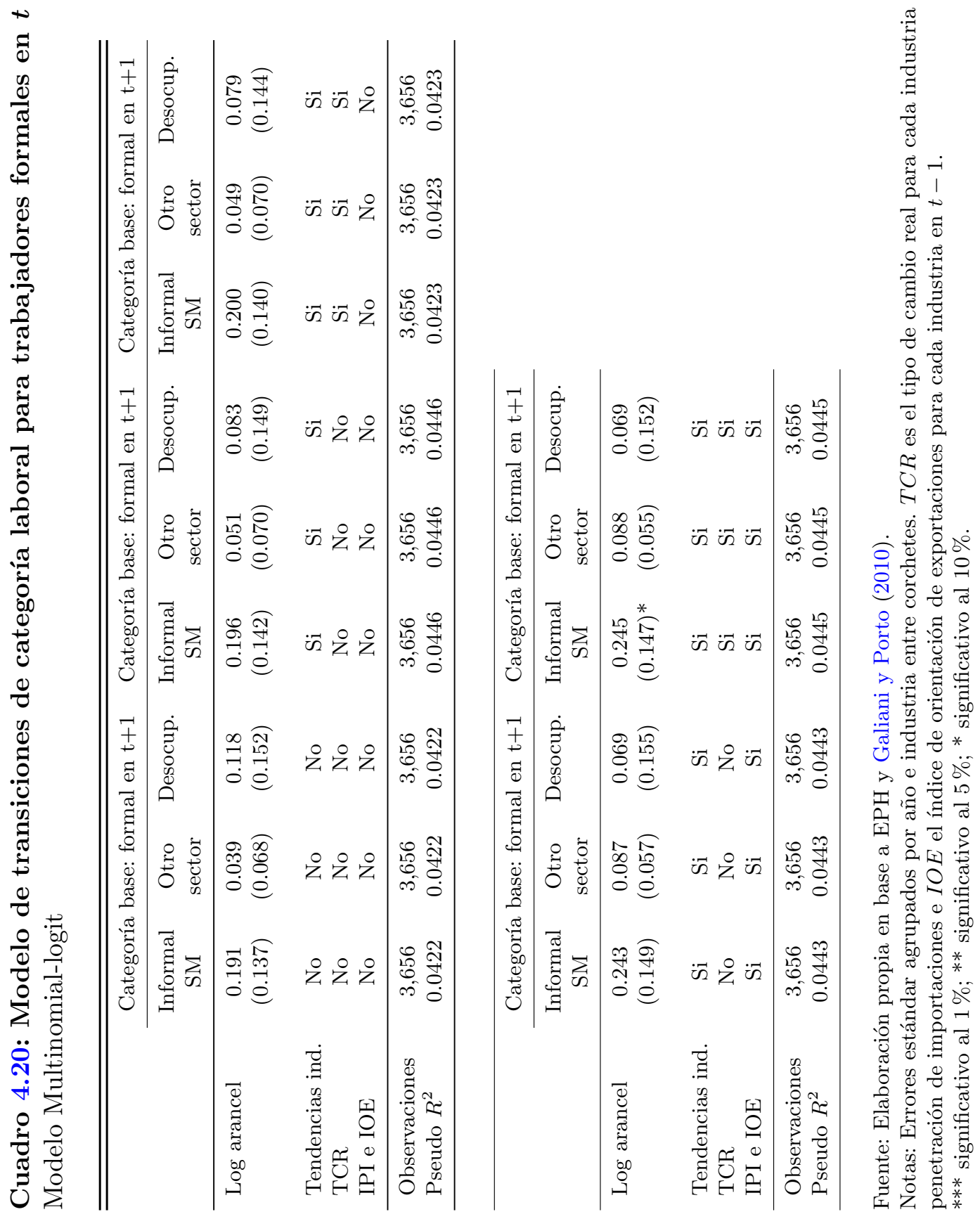


\section{Cuadro 4.21: Modelo de transiciones de categoría laboral para trabajadores formales en $t$}

Modelo Multinomial-logit - Sub-periodos 1995-1998 y 1998-2001

\begin{tabular}{lcccccc}
\hline \hline & \multicolumn{3}{c}{$1995-1998$} & \multicolumn{3}{c}{$1998-2001$} \\
& \multicolumn{1}{c}{ Categoría base: formal en t+1 } & \multicolumn{2}{c}{ Categoría base: formal en t+1 } \\
\cline { 2 - 7 } & $\begin{array}{l}\text { Informal } \\
\mathrm{SM}\end{array}$ & $\begin{array}{c}\text { Otro } \\
\text { sector }\end{array}$ & $\begin{array}{c}\text { Desocu } \\
\text { pado }\end{array}$ & $\begin{array}{c}\text { Informal } \\
\text { SM }\end{array}$ & $\begin{array}{c}\text { Otro } \\
\text { sector }\end{array}$ & $\begin{array}{c}\text { Desocu } \\
\text { pado }\end{array}$ \\
\hline & & & & & & \\
Log arancel & 0.299 & -0.042 & -0.410 & 0.340 & 0.169 & 0.281 \\
& $(0.393)$ & $(0.176)$ & $(0.336)$ & $(0.205)^{*}$ & $(0.064)^{* * *}$ & $(0.289)$ \\
Tendencias ind. & $\mathrm{Si}$ & $\mathrm{Si}$ & $\mathrm{Si}$ & $\mathrm{Si}$ & $\mathrm{Si}$ & $\mathrm{Si}$ \\
TCR & $\mathrm{Si}$ & $\mathrm{Si}$ & $\mathrm{Si}$ & $\mathrm{Si}$ & $\mathrm{Si}$ & $\mathrm{Si}$ \\
IPI e IOE & $\mathrm{Si}$ & $\mathrm{Si}$ & $\mathrm{Si}$ & $\mathrm{Si}$ & $\mathrm{Si}$ & $\mathrm{Si}$ \\
& & & & & & \\
\hline Observaciones & 2,220 & 2,220 & 2,220 & 1,436 & 1,436 & 1,436 \\
Pseudo $R^{2}$ & 0.0593 & 0.0593 & 0.0593 & 0.0745 & 0.0745 & 0.0745 \\
\hline
\end{tabular}

Fuente: Elaboración propia en base a EPH y Galiani y Porto (2010).

Notas: Errores estándar agrupados por año e industria entre corchetes. $T C R$ es el tipo de cambio real para cada industria en $t$; IPI es el índice de penetración de importaciones e $I O E$ el índice de orientación de exportaciones para cada industria en $t-1$.

El periodo 1995-1998 comprende los paneles 95-96, 96-97 y 97-98; el periodo 1998-2001 abarca los paneles 98-99, 99-00, 00-01.

*** significativo al 1\%; ** significativo al $5 \%$; ${ }^{*}$ significativo al $10 \%$. 


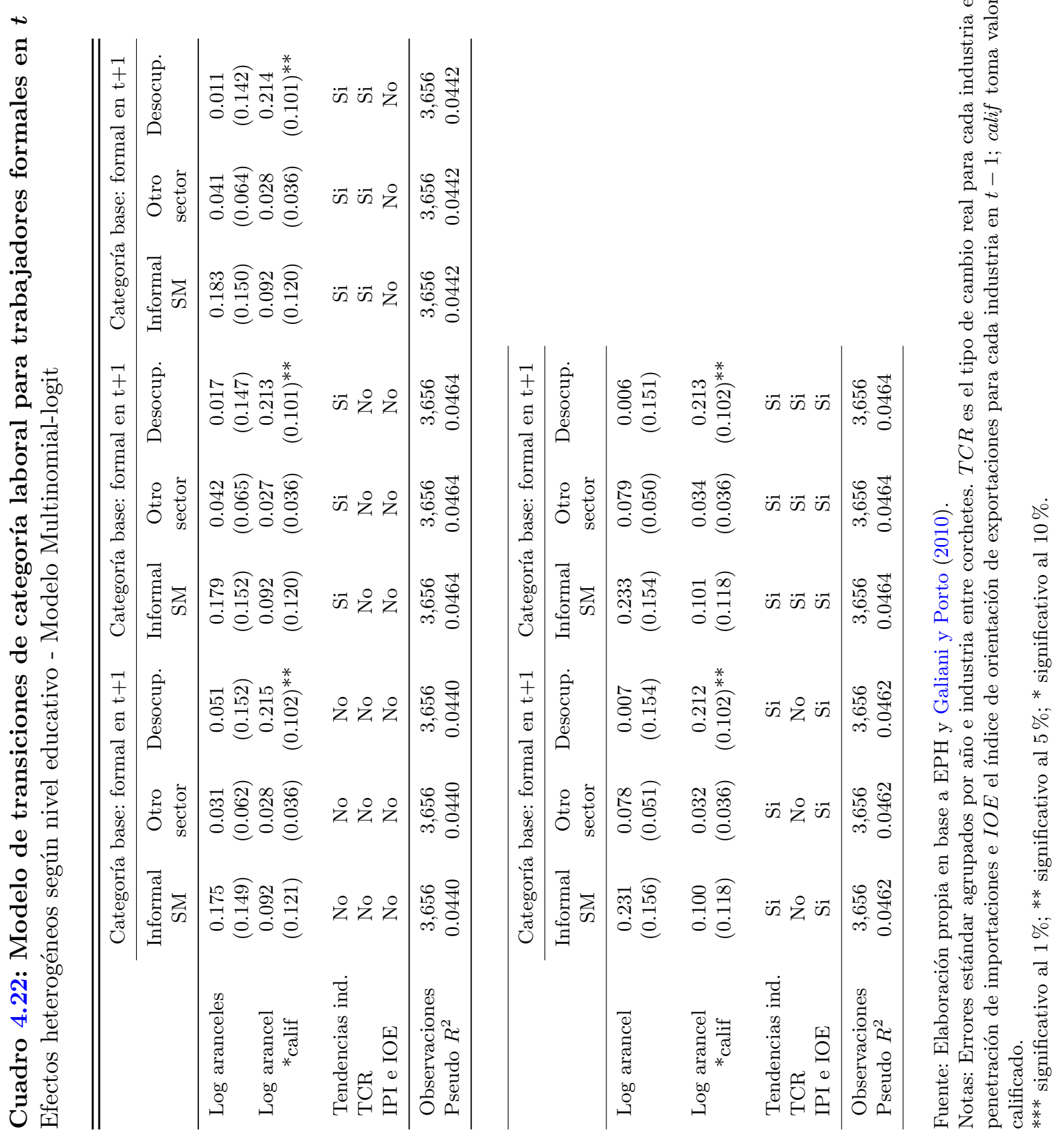




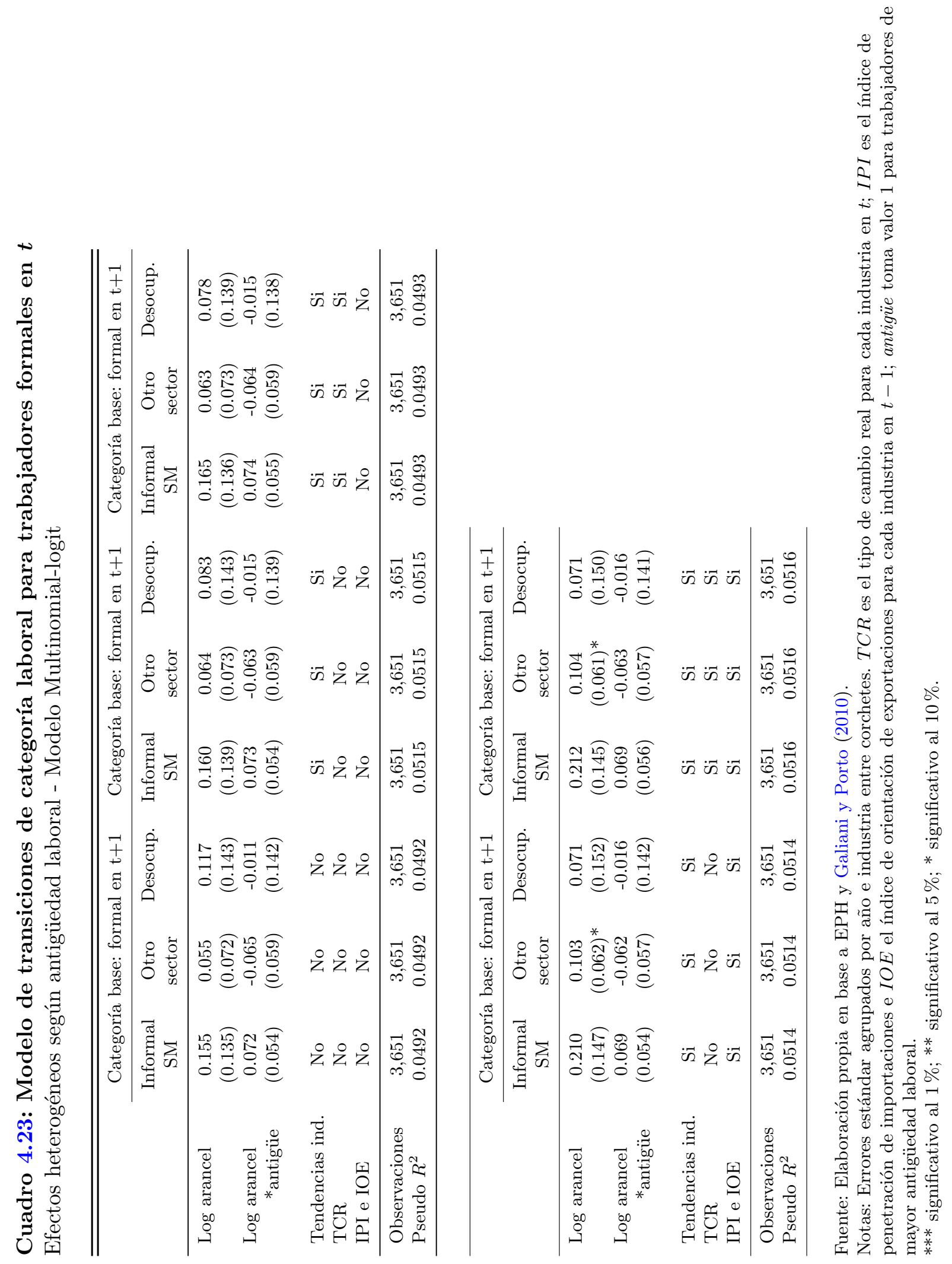




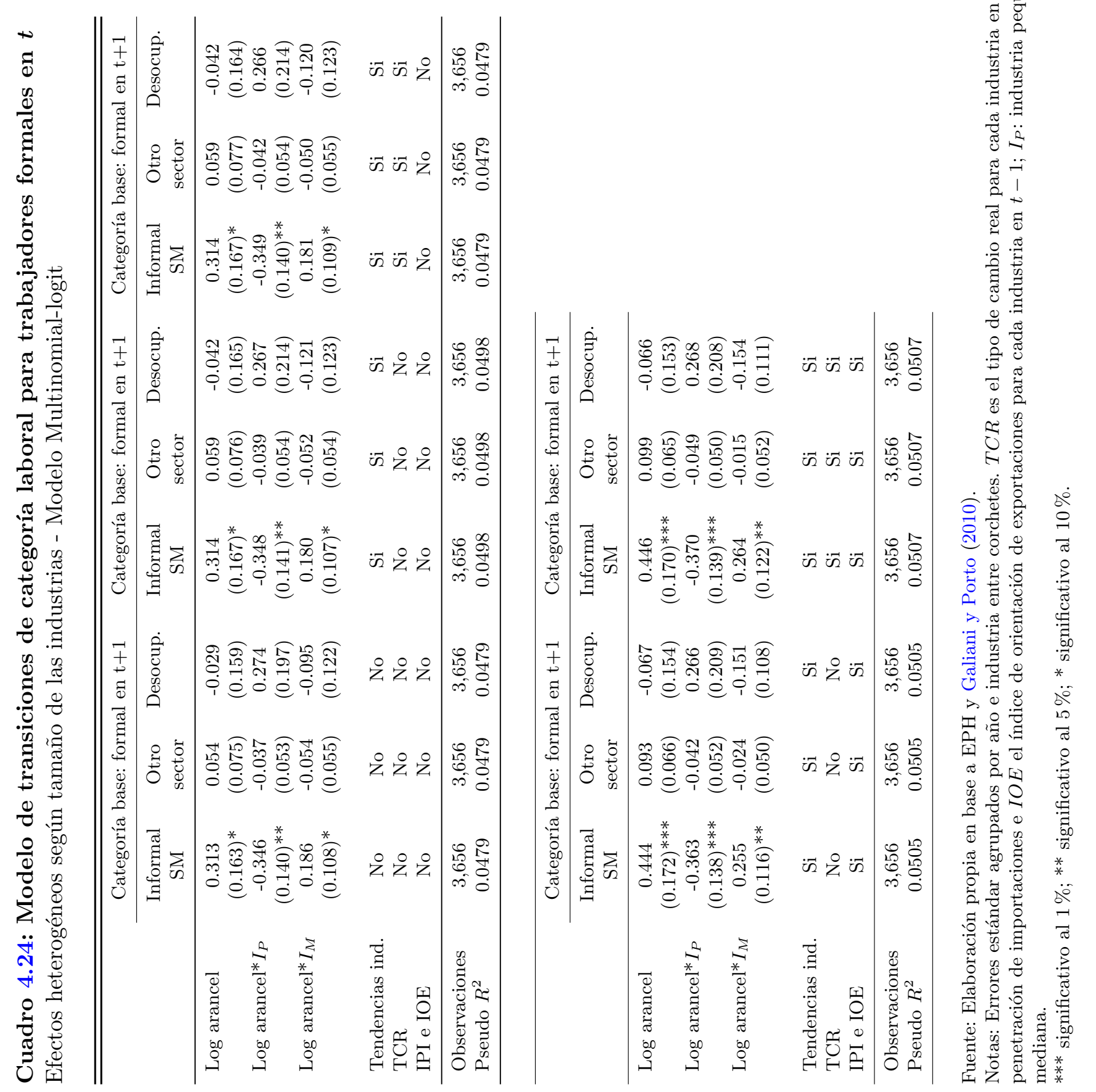




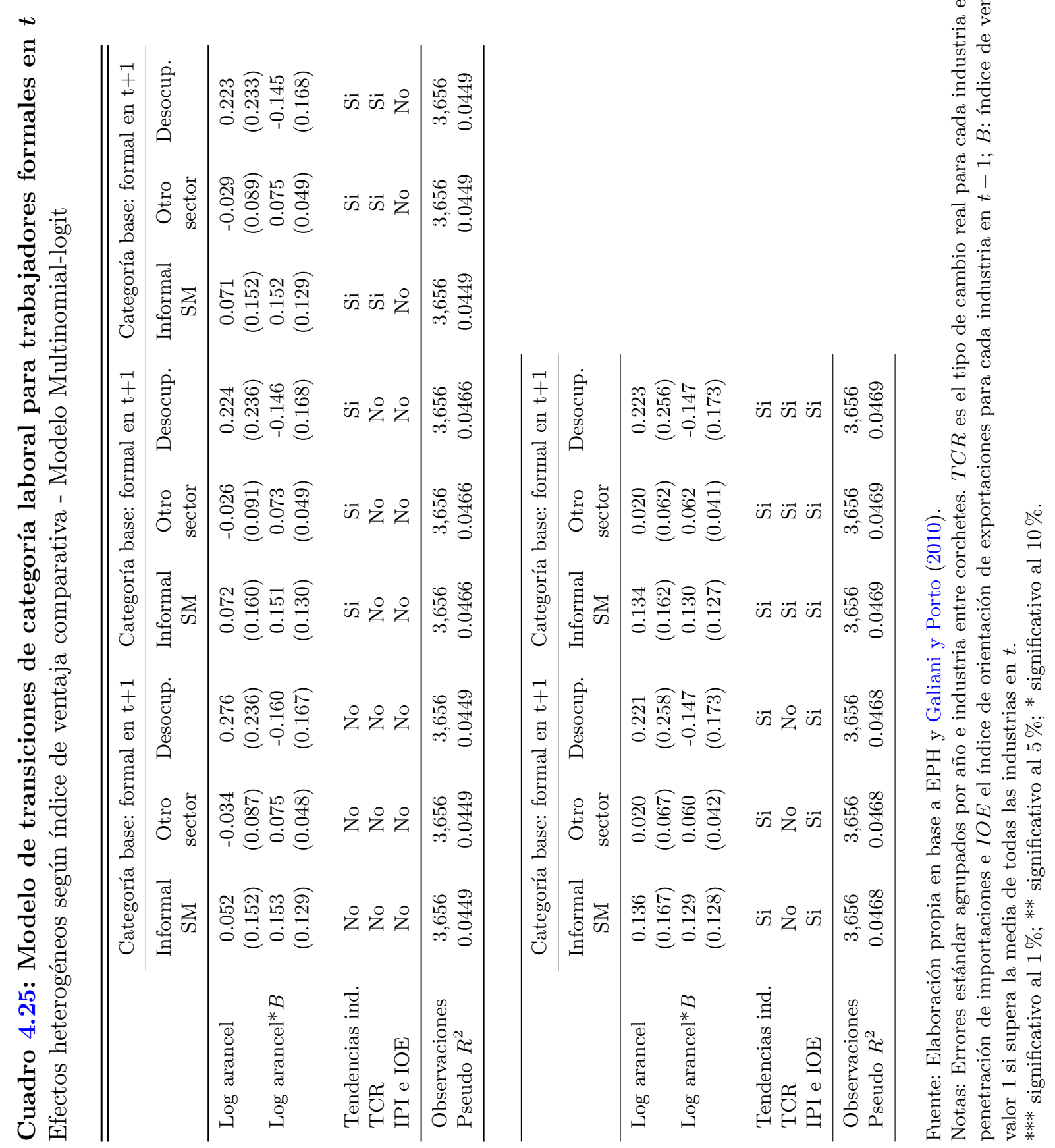


4.6. Gráficos 


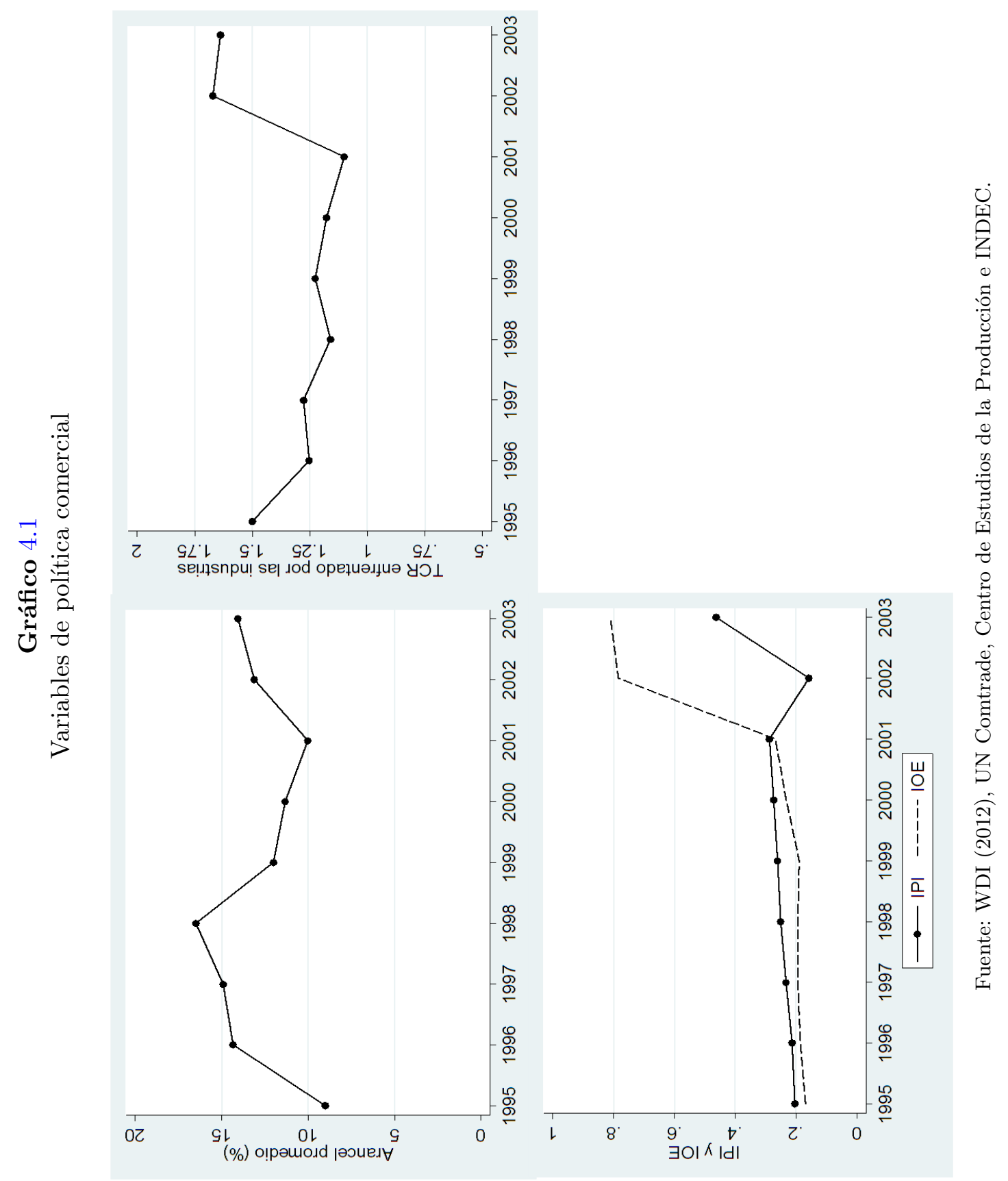




\section{Gráfico 4.2}

Transición del empleo al desempleo en el SM y Arancel promedio en $t$

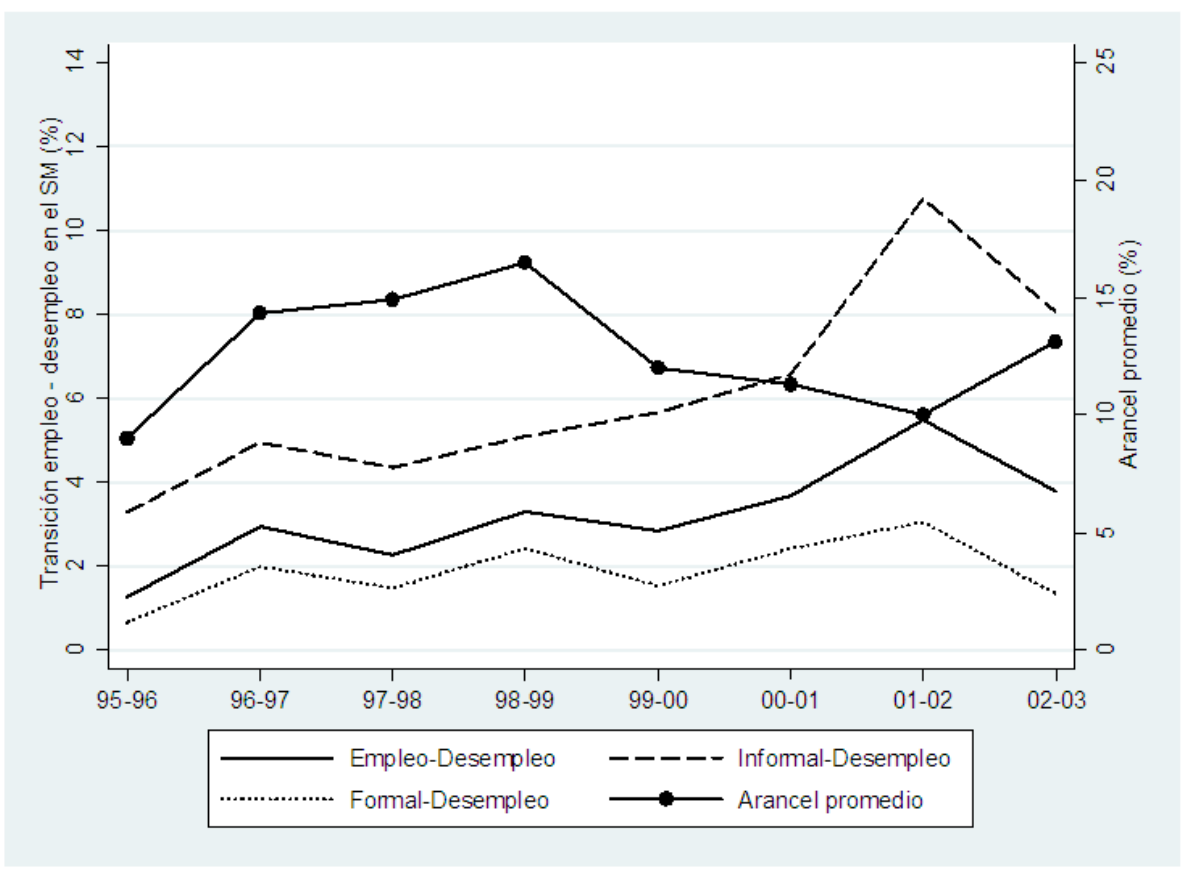

Fuente: Elaboración propia en base a EPH y WDI (2012). 
Gráfico 4.3

Contribución de trabajadores formales e informales del SM en $t$ al desempleo en $t+1$

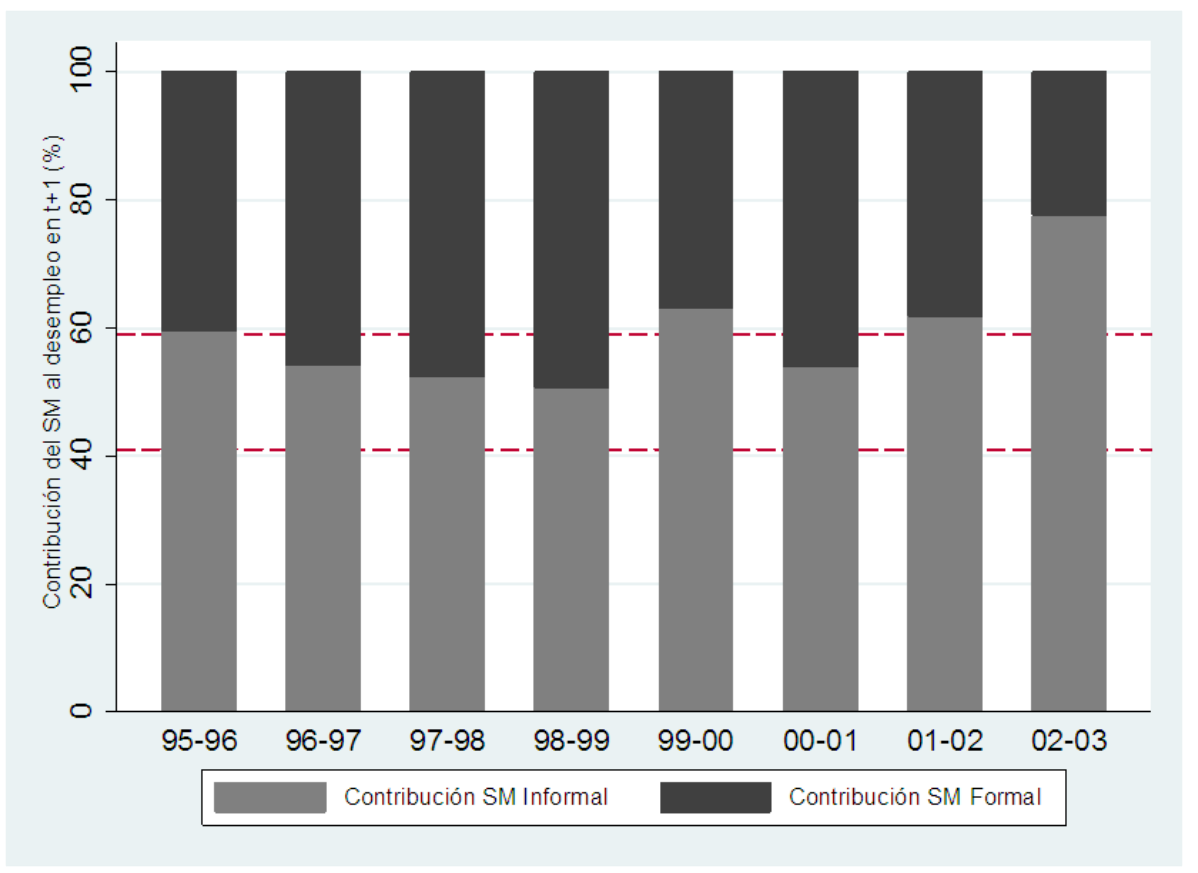

Fuente: Elaboración propia en base a EPH y WDI (2012). 
Gráfico 4.4

Transición de la formalidad a la informalidad en el SM y Arancel promedio en $t$

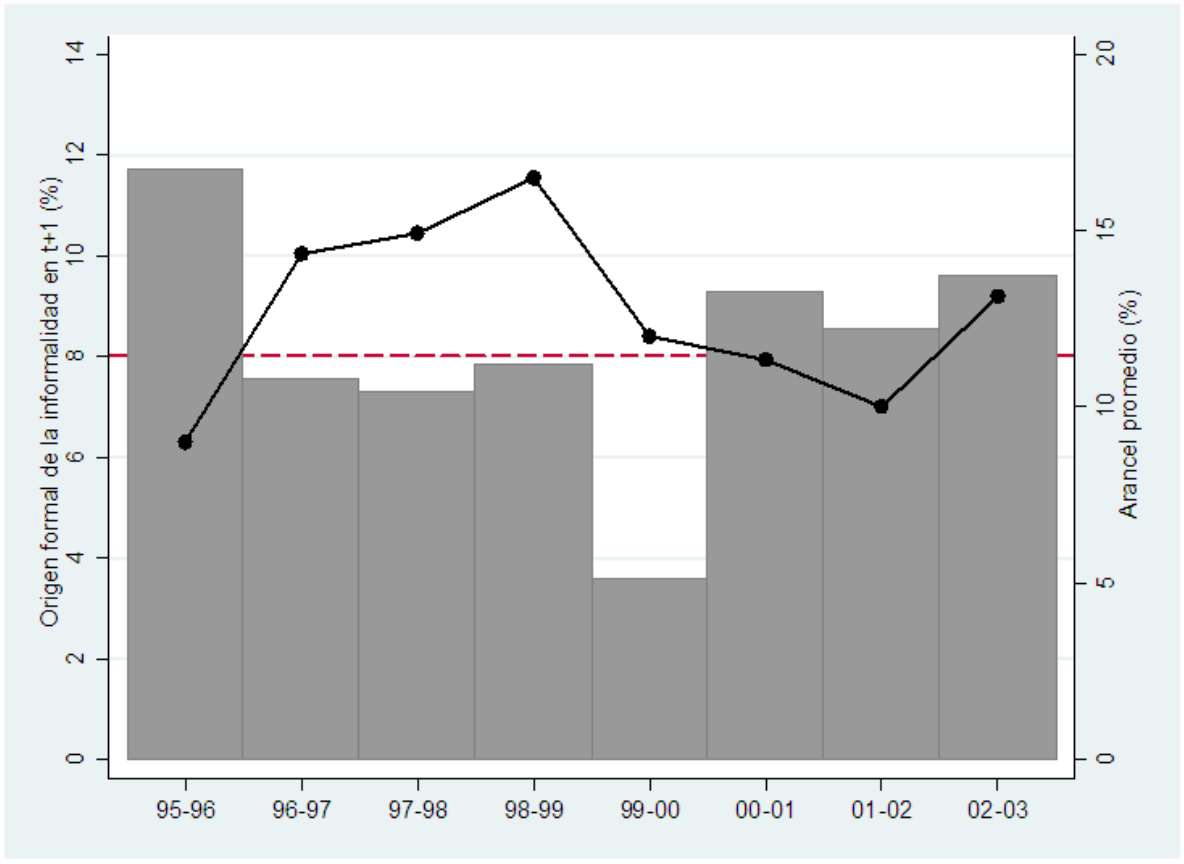

Fuente: Elaboración propia en base a EPH y WDI (2012). 
Gráfico 4.5

Contribución del desempleo en $t$ al empleo formal e informal en $t+1$ en el SM

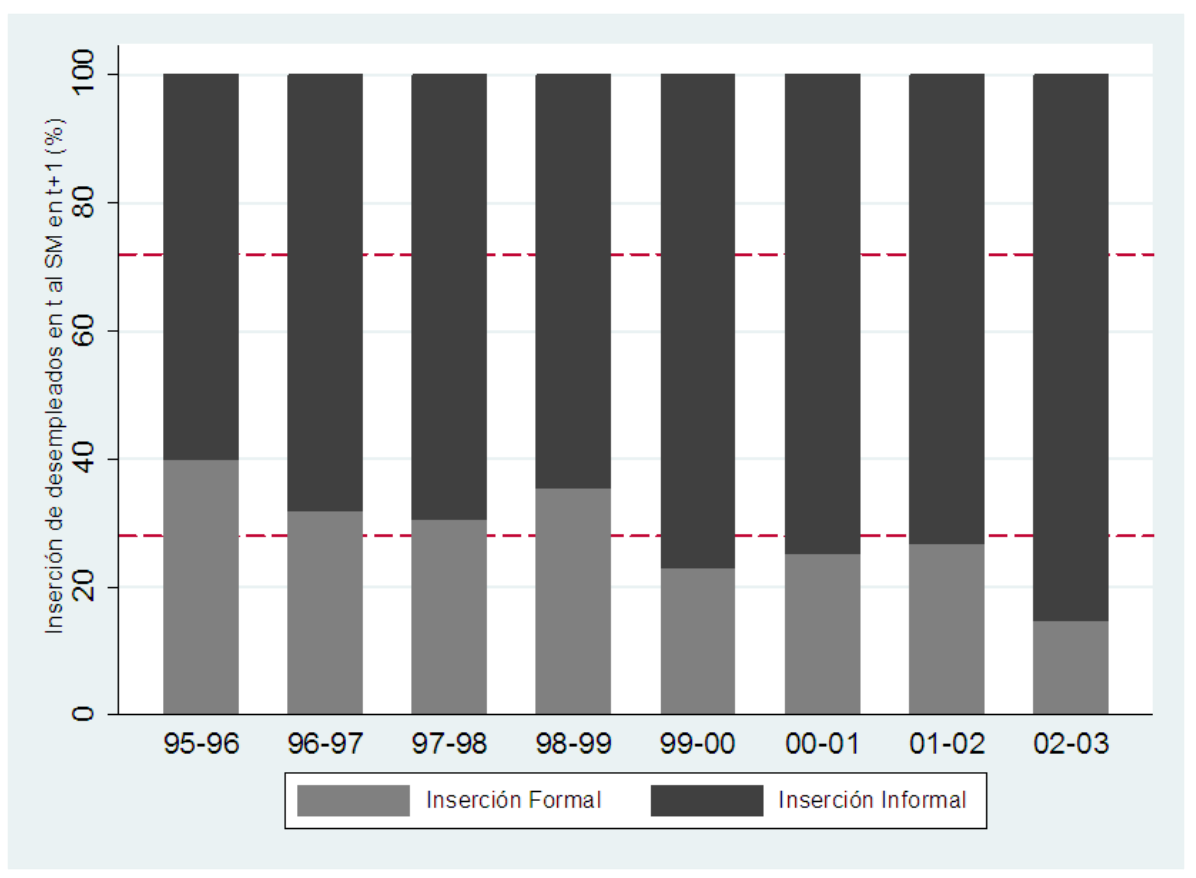

Fuente: Elaboración propia en base a EPH y WDI (2012). 
Gráfico 4.6

Evolución del PBI, exportaciones e inversiones en bienes de capital

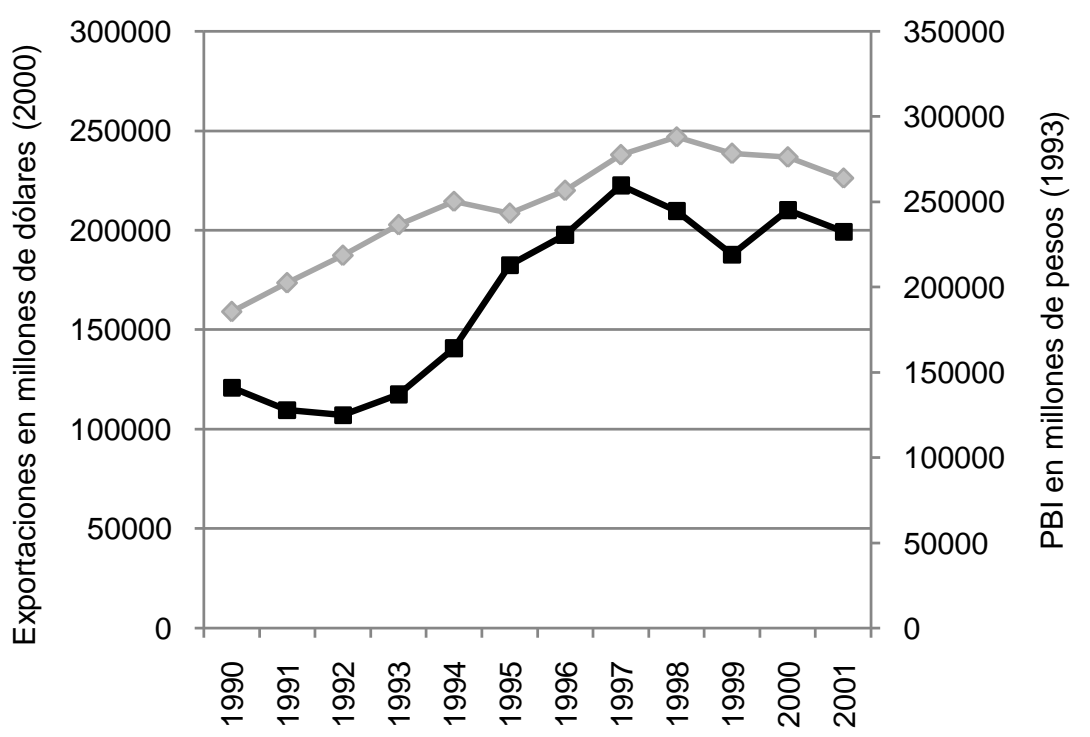

$\rightarrow$ Exportaciones $\multimap \mathrm{PBI}$

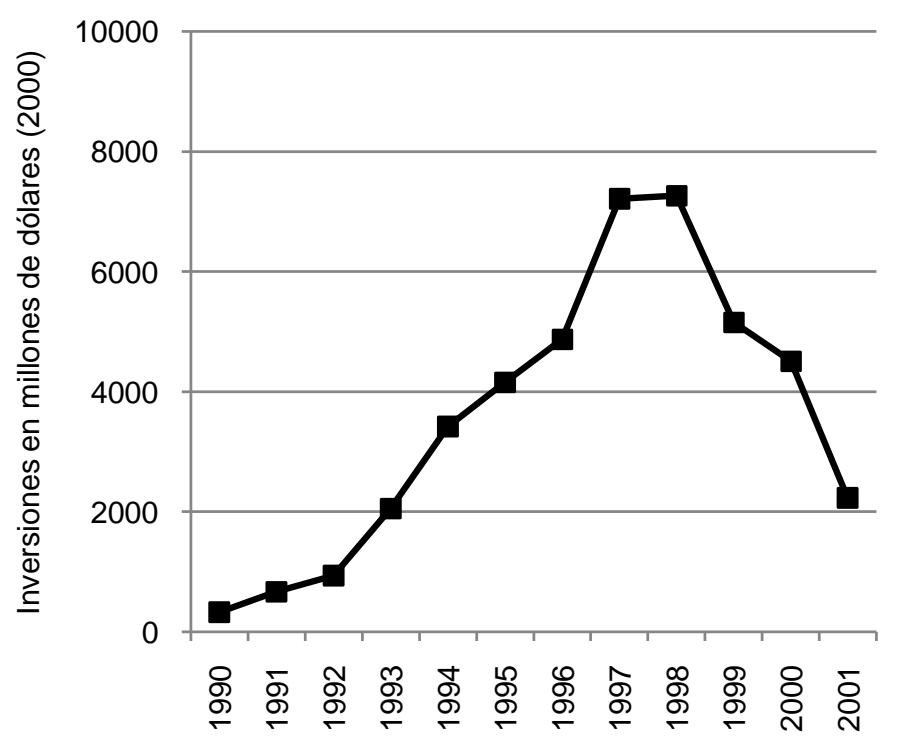

Fuente: Elaboración propia en base a INDEC y Centro de Estudios de la Producción. 


\section{Capítulo 5}

\section{Impacto sobre el diferencial salarial por informalidad}

Los capítulos previos han mostrado evidencia de ausencia de reasignación del empleo entre industrias del sector de manufacturas y entre sectores productivos como consecuencia de la reducción de los aranceles a las importaciones. En coincidencia con la evidencia disponible para países en desarrollo, el ajuste se produjo al interior de las industrias. Más concretamente, la informalidad laboral actuó como un mecanismo de ajuste adicional a los propuestos por la TCI.

En el contexto de ausencia de reasignación del empleo, el ajuste de salarios también cobra relevancia. Si los trabajadores no pueden moverse fácilmente, los modelos de comercio de corto y mediano plazo predicen que aquellos empleados en industrias que enfrentan mayores recortes de aranceles deberían enfrentar una reducción de salarios respecto a los trabajadores que, con idénticas características, se encuentran empleados en industrias que enfrentan una reducción menor en su nivel de protección. Esta reducción de salarios podría impactar de manera diferente en los trabajadores formales e informales. En el capítulo 3 se mostró evidencia indirecta de que los salarios industriales no ajustan ante cambios en los aranceles a las importaciones. ${ }^{1}$ Sin embargo, los cambios en la producción y en la composición de la fuerza laboral puede determinar que el salario formal e informal se vean afectados de manera diferente, aun cuando el salario promedio de la industria no cambie. Por ejemplo, la reducción del tamaño de la fuerza laboral y la existencia de desempleo en el corto plazo puede significar una caída en el salario informal. Si el salario formal tiene un nivel por encima del valor de equilibrio por la existencia de algún mecanismo

\footnotetext{
${ }^{1}$ La inclusión del salario promedio de las industrias como control adicional en la estimación de corto plazo no afectó los resultados.
} 
no competitivo (salario mínimo, por ejemplo) y el salario informal se determina de manera competitiva, los trabajadores formales que perdieron su empleo pasan a engrosar la oferta de trabajo informal generando una caída en su salario. Este tipo de ajuste sería plausible dada la mayor flexibilidad del salario informal respecto de un salario formal determinado por legislación.

La existencia de diferencias salariales entre trabajadores formales e informales igualmente productivos ha sido ampliamente documentada. Distintas teorías explican la existencia del trabajo informal en países en desarrollo con implicancias sobre las disparidades salariales observadas entre trabajadores formales e informales. Para el caso particular de Argentina la evidencia muestra dos resultados claros. En primer lugar, los trabajadores asalariados informales reciben beneficios monetarios y no monetarios inferiores a los recibidos por trabajadores formales igualmente productivos y, en segundo lugar, en los mercados laborales del país prevalece la hipótesis de mercados segmentados, con trabajadores que quisieran ingresar a la formalidad pero encuentran barreras o limitaciones que impiden acceder a este tipo de empleos (Alzúa, 2008; Arias y Khamis, 2008; Waisgrais y Sarabia, 2008). ${ }^{2}$

En este capítulo se analiza cuál fue el cambio en el diferencial salarial por informalidad como consecuencia de los episodios de liberalización del comercio. Los principales resultados del trabajo pueden resumirse en tres puntos. Primero, la estructura industrial de salarios no sufrió cambios asociados a los episodios de liberalización del comercio en el corto plazo, por lo tanto, la predicción de los modelos de corto y mediano plazo de la TCI no es es operativa para explicar los cambios observados en el diferencial salarial entre trabajadores formales e informales. Segundo, tampoco hubo cambios estadísticamente significativos en el diferencial salarial por informalidad en el corto plazo que puedan atribuirse a cambios en la política comercial. Tercero, en el largo plazo los trabajadores informales experimentan una mejora salarial respecto de los formales y esta mejora se produce en el grupo de trabajadores no calificados. Este resultado puede ser explicado a partir de la reasignación del trabajo entre sectores en el largo plazo y de la expansión de un sector de la economía que es más intensivo que el sector importador de manufacturas en el uso de trabajo no calificado donde el informal tiene un mayor peso relativo.

El resto del capítulo se estructura de la siguiente manera. La sección 5.1 introduce

\footnotetext{
${ }^{2}$ Pratap y Quintin (2006) arriban a una conclusión diferente. En la sección siguiente se explica el origen de esa diferencia.
} 
una discusión acerca de la existencia de diferenciales salariales entre trabajadores formales e informales, presentando los resultados encontrados para países de América Latina y enfatizando aquellos disponibles para Argentina. La sección 5.2 discute, en primer lugar, la evidencia disponible sobre la relación entre la penalidad salarial por informalidad y la liberalización del comercio y las diferentes metodologías de estimación. En segundo lugar, presenta la metodología que será aplicada a lo largo de este capítulo. La sección 5.3 presenta evidencia empírica sobre el ajuste de corto plazo en el diferencial salarial por informalidad ante cambios en la política comercial. Para esto se distingue entre el ajuste en la estructura industrial de salarios y el efecto directo sobre la diferencia salarial entre trabajadores formales e informales. La sección 5.4 presenta un modelo sencillo en la línea de los modelos de la TCI para realizar la predicción del cambio en el diferencial salarial por informalidad en el largo plazo. Luego muestra las estimaciones empíricas para este efecto. Por último, la sección 5.5 presenta las conclusiones de este capítulo.

\subsection{Diferencial salarial entre trabajadores formales e informales}

\subsubsection{Aspectos teóricos}

Distintas teorías explican la existencia del trabajo informal en países en desarrollo con implicancias sobre las diferencias salariales observadas entre trabajadores formales e informales. La teoría de mercados duales, introducida por Lewis (1954) y Harris y Todaro (1970), concibe al trabajo informal como un segmento del mercado laboral que se encuentra en desventaja. Bajo esta visión los trabajadores informales reciben beneficios monetarios y no monetarios inferiores a los recibidos por trabajadores formales igualmente productivos. Los trabajadores de este segmento o sector "secundario" eligen involuntariamente el empleo informal y desean pasar a la formalidad o sector "primario" pero existen rigideces de mercado que lo impiden. Son ejemplo de esas rigideces la existencia de sindicatos, la determinación de salarios por encima del nivel de equilibrio por motivos de eficiencia o por regulaciones como el salario mínimo. Los trabajadores que no pueden acceder a un trabajo formal tienen opciones limitadas y aceptan trabajos con menores salarios y peores condiciones laborales y/o sin acceso a la seguridad social. Las barreras al empleo formal son para esta teoría la razón de la existencia de diferencias salariales entre trabajadores 
formales e informales con características comparables. Fields (1975) formalizó esta visión en un modelo de equilibrio parcial donde los agentes trabajan en el sector informal o destinan su tiempo a buscar un trabajo formal mejor pago. En un trabajo más reciente, Rauch (1991) describe un modelo de equilibrio general donde las firmas pueden elegir incumplir la regulación de salarios mínimos dado que su escala es inferior al límite de detección de la autoridad tributaria. En este modelo algunos trabajadores encuentran trabajo en firmas grandes que son formales mientras que una fracción de la fuerza laboral debe aceptar trabajos informales con un menor pago. Fortin et al. (1997) extienden el desarrollo de Rauch (1991) introduciendo obligaciones tributarias que las firmas deben pagar cuando operan formalmente, como la contribuciones a la seguridad social. En equilibrio, las firmas pequeñas operan informalmente, evadiendo impuestos y pagando menores salarios en comparación a las firmas formales.

En otro extremo, la teoría de mercados de trabajo integrados predice que no existen barreras que impidan la entrada a la formalidad. La informalidad surge a partir de trabajadores y firmas que evalúan los costos y beneficios privados de operar informalmente (de Soto, 1989; Loayza, 1996; Maloney, 1999). Muchos trabajadores asalariados y auto-empleados, por ejemplo, trabajadores jóvenes, mujeres casadas y trabajadores poco calificados, elegirían voluntariamente la informalidad. Las razones se encuentran en la posibilidad de entrada al mercado laboral, la posibilidad de obtener beneficios no monetarios, como por ejemplo, la flexibilidad horaria, la oportunidad de recibir entrenamiento en el puesto de trabajo o de escapar de un sistema de protección social que funciona inadecuadamente. Esta visión extrema se construye a partir de la teoría de diferencias salariales compensadoras (Rosen, 1986) y elección del empleo en base a las ventajas comparativas de cada trabajador (Carneiro y Heckman, 2002). La idea central es que un mercado laboral competitivo determina un salario implícito para cada tipo de empleo. En equilibrio, la movilidad del trabajo establece un salario relativo que hace que los trabajadores estén indiferentes entre los distintos tipos de empleo. Por ejemplo, trabajos más deseables en términos de amenidades como beneficios no monetarios, flexibilidad, estabilidad, pueden pagar salarios por debajo del promedio, mientras que trabajos menos deseables en términos de estas características pagarán salarios mayores. Bajo esta visión es posible que existan diferencias de salario monetario entre trabajadores formales e informales aun cuando los mercados no estén segmentados. En este campo han 
surgido planteos teóricos con modelos donde los trabajadores eligen el sector en el cual trabajan, por ejemplo Boeri y Garibaldi (2006); Loayza y Rigolini (2006) y de Paula y Scheinkman (2011). Amaral y Quintin (2006) modelan un mercado laboral competitivo donde las firmas del sector formal pagan impuestos y tienen acceso al mercado de crédito y lo contrario ocurre con las firmas informales. En este caso, los trabajadores solo derivan utilidad del salario recibido. Como consecuencia, trabajadores similares obtienen el mismo salario en el sector formal e informal. Galiani y Weinschelbaum (2011) modelan una economía donde el tamaño de las firmas y el salario formal e informal se determinan endógenamente. En equilibrio, las firmas de menor (mayor) tamaño y menor (mayor) capacidad de gestión son informales (formales), mientras que los trabajadores de menor (mayor) nivel educativo son informales (formales). En este modelo el salario informal puede ser menor, igual o mayor al salario formal. Fiess et al. (2010) desarrollan un modelo que incorpora un componente voluntario en el segmento de auto-empleados y que es lo suficientemente general para admitir el empleo informal no voluntario por segmentación de mercado.

Estas dos visiones extremas suponen que el sector informal es homogéneo. Este supuesto a sido levantado recientemente por diversos autores (Cunningham y Maloney, 2001; Fields, 2005; Paulson y Townsend, 2005; Guha-Khasnobis et al., 2006). La hipótesis alternativa postula una estructura más compleja para el sector informal. Cunningham y Maloney (2001) limitan el análisis a trabajadores auto-empleados y representan al sector de auto-empleados informales como una combinación de distintos segmentos. Fields (2005) argumenta que el sector informal está formado por dos niveles, uno superior y otro inferior. El nivel superior representa la parte competitiva al cual los individuos ingresan voluntariamente porque esperan obtener un mayor ingreso siendo informales. El nivel inferior está formado por individuos segmentados del mercado laboral formal. Con una perspectiva dinámica, Paulson y Townsend (2005) muestran que los individuos que iniciaron actividades informales como auto-empleados durante un periodo de crisis (para escapar del desempleo) obtienen un ingreso inferior respecto a los auto-empleados informales que comenzaron su actividad en tiempos de estabilidad, probablemente con una mayor inversión inicial.

Los estudios que han analizado la relevancia de estas hipótesis para el mercado de trabajo argentino encuentran que prevalece la hipótesis de mercados segmentados, con trabajadores que quisieran ingresar a la formalidad pero encuentran barreras o 
limitaciones que impiden acceder a este tipo de empleos. A partir de un modelo que admite mecanismos de determinación de salarios diferentes entre sectores y que no impone ex-ante cuáles son los trabajadores que están en el sector primario y secundario, Alzúa (2008) encuentra evidencia de mercados duales para los trabajadores asalariados en el periodo 1975-2001 y de cambios en el tamaño del sector "secundario" a lo largo del tiempo. Los resultados obtenidos por este trabajo no permiten concluir que el sector secundario se corresponda con el empleo informal definido como la ausencia de la protección de la seguridad social en el puesto de trabajo. Arias y Khamis (2008) también confirman la hipótesis de mercados segmentados entre los trabajadores asalariados para el año 2005 utilizando técnicas econométricas de evaluación de impacto para corregir por sesgos de selección y endogeneidad en la condición de informalidad de los trabajadores y obteniendo evidencia de diferenciales salariales que favorecen a los trabajadores formales. Utilizando el módulo especial sobre informalidad laboral de la EPH del año 2005, Waisgrais y Sarabia (2008) muestran que la mayor parte de los trabajadores informales está en dicha situación porque tiene restricciones para acceder a un trabajo formal. De acuerdo a sus hallazgos, estos trabajadores están, en líneas generales, insatisfechos con sus empleos independientemente de la categoría ocupacional a la que pertenezcan. De aquí se desprende que los trabajadores informales desearían ingresar a la formalidad pero encuentran limitaciones para hacerlo.

\subsubsection{Evidencia empírica}

La evidencia empírica sobre la existencia de diferencias salariales entre trabajadores formales e informales en países en desarrollo es mixta. La disparidad de resultados puede ser en parte explicada por las diferentes definiciones de informalidad laboral utilizada en cada estudio, por las categorías laborales analizadas (asalariados, auto-empleados o ambas), y por la existencia de distintas regulaciones laborales en cada país. Por otro lado, la mayor parte de la literatura tiene por objetivo evaluar la hipótesis de mercados segmentados versus mercados integrados, siendo el diferencial salarial entre trabajadores formales e informales un elemento de este test empírico. Así es que buena parte de la literatura empírica postula diferentes mecanismos de determinación de salarios para cada tipo de trabajador (switching earnings models). Restringiendo la atención a los estudios que analizan el mercado de trabajo de países de América Latina, Pradhan y Van Soest (1995) para Bolivia, 
Gong y Van Soest (2001) para México, Arias y Khamis (2008) para Argentina proveen evidencia empírica en favor de la hipótesis de mercados segmentados a partir de la existencia de diferenciales salariales que favorecen a los trabajadores formales, en este último caso solo para la muestra de asalariados, pero no así para la muestra de auto-empleados. En cambio, Marcouiller et al. (1997) encuentran una prima salarial para los trabajadores informales en México, al igual que Juarez (2008), aunque no para El Salvador y Perú. Maloney (1999), usando datos para México, argumenta que buena parte del empleo informal es el resultado de la elección voluntaria de los trabajadores y encuentra diferencias salariales que favorecen a los formales en algunos casos y a los informales en otros, dependiendo de las categorías laborales analizadas. Otros trabajos encuentran que existe una penalidad salarial para los trabajadores informales pero dicha penalidad depende de otras características. Por ejemplo, del sexo (Tansel, 1999), del nivel educativo (Gong y Van Soest, 2001), del tamaño de las firmas (El Badaoui et al., 2008; Falco et al., 2011) o del punto de la distribución de salarios (Tannuri-Pianto y Pianto, 2002; Bargain y Kwenda, 2011). En otros estudios la existencia de diferenciales salariales se explica enteramente por heterogeneidades no observadas (Pratap y Quintin, 2006). Esta disparidad de evidencia conduce a concluir que existe heterogeneidad en el tamaño y penalidad salarial del sector informal dependiendo del grupo de trabajadores considerado.

Para el caso particular de Argentina la evidencia también es mixta. Pratap y Quintin (2006) encuentran que, a diferencia de la mayor parte de la evidencia empírica para países en desarrollo, no hay diferencias salariales entre formales e informales. Los autores argumentan que su hallazgo descansa en dos aspectos técnicos. En primer lugar, los estudios previos usan técnicas paramétricas y las funciones de ingreso pueden estar mal especificadas, especialmente si la distribución de las características de los empleos y los trabajadores difiere entre los sectores formal e informal. En segundo lugar, las estimaciones por MCO pueden estar sesgadas si existe endogeneidad en la elección del sector. Ante estas limitaciones, utilizan técnicas semiparamétricas (estimadores de matching) que no requieren ningún supuesto sobre la forma funcional de la ecuación de ingresos y limitan la comparación de salarios a trabajadores observacionalmente iguales. Sin embargo, este método no controla por la existencia de factores no observables que afectan los salarios y pueden incidir en la condición de informalidad de un trabajador. Para aislar las heterogeneidades no observadas los autores combinan el estimador semiparamétrico con un estimador de diferencias 
en diferencias. El supuesto de identificación de la estrategia de identificación utilizada por los autores indica que en ausencia de movimientos hacia la formalidad, el salario del grupo tratado (aquellos que pasaron de la informalidad a la formalidad) hubiese evolucionado de la misma manera que el del grupo de control (trabajadores que permanecieron en la informalidad). Los autores argumentan que el movimiento entre sectores es endógeno (por ejemplo, el movimiento puede ser voluntario) y que la dirección del sesgo resultante es difícil de precisar. Asimismo, el periodo de tiempo analizado, 1993-1995, abarca importantes cambios en las regulaciones laborales que pueden haber afectado de manera diferente al grupo tratado y de control, invalidando la estrategia. Otro punto a destacar es que, si bien los autores indican que los datos corresponden al salario bruto de los trabajadores (salario antes de impuestos), la EPH de Argentina, fuente de datos utilizada en este trabajo, no es precisa respecto a si el individuo encuestado debe indicar su ingreso antes o después de impuestos. En el caso de trabajadores asalariados se espera que reporten su salario "de bolsillo" o neto. Bajo esas condiciones, la ausencia de diferencia estadísticamente significativa entre el salario formal e informal se traduce en una mayor remuneración para los formales, dado que además del salario monetario reciben el paquete de beneficios de la seguridad social. En la sección siguiente se aportan más detalles sobre este punto.

Arias y Khamis (2008) estiman regresiones paramétricas y semiparamétricas con variables instrumentales locales. Sus resultados muestran que no existen diferencias salariales entre los trabajadores formales asalariados y los auto-empleados (informales), pero sí existe una penalidad salarial para los trabajadores informales cuando solo analizan el grupo de asalariados. Sus estimaciones que corrigen por sesgo de selección y por el sesgo que atribuyen a la ventaja comparativa de cada trabajador muestran que los trabajadores informales son penalizados entre dos y cuatro veces más respecto a las estimaciones por MCO.

\subsection{Política comercial y diferencias salariales por infor- malidad: evidencia preliminar}

El periodo comprendido entre los años 1980 y 2001 se caracterizó por una profundización en la penalidad salarial por informalidad. El gráfico 5.1 muestra que en 1980 un trabajador informal ganaba, en promedio, un $15 \%$ menos que un trabajador formal con idénticas características, mientras que esa diferencia alcanzó el $28 \%$ en el año 2001. Esa tendencia general mostró un claro patrón de recuperación entre los 
años 1990 y 1994 posiblemente explicado por el crecimiento de la economía en los primeros años de la década del noventa y el hecho de que el salario informal puede responder en mayor medida a las condiciones competitivas y es más flexibles que el salario formal. Este proceso de crecimiento comenzó a verse interrumpido a partir de una serie de crisis externas a mediados de la misma década. Asimismo, en el año 1994 se destrabó la marcha de la flexibilización del mercado de trabajo que no había sido exitosa hasta ese momento (Torre y Gerchunoff, 1999). A lo largo de todo el periodo la tasa de informalidad creció a medida que la tasa arancelaria (promedio nacional) se reducía. De acuerdo a la evidencia presentada en el capítulo 3, el proceso de liberalización del comercio afectó la tasa de informalidad de las industrias del sector de manufacturas. En este capítulo se buscará precisar si la evolución del diferencial salarial por informalidad también puede ser explicado por los shocks de política comercial.

El modelo de factores específicos, modelo de corto plazo por naturaleza que asume inmovilidad de factores productivos entre sectores, predice una asociación positiva entre los salarios industriales y la protección arancelaria. De acuerdo a este modelo las industrias que enfrentaron un recorte proporcionalmente mayor en su tasa arancelaria deberían experimentar una reducción en su prima salarial. Esto podría afectar de manera diferente el salario de los trabajadores formales e informales por los cambios en la producción y en la composición de la fuerza laboral reportados en el capítulo 3. Aun cuando el salario promedio de la industria no se modifique los ajustes de producción y composición podrían estar detrás del cambio en el diferencial de salarios entre formales e informales. Por ejemplo, la reducción del tamaño de la fuerza laboral y la existencia de desempleo en el corto plazo puede significar una caída en el salario informal. Si el salario formal tiene un nivel por encima del valor de equilibrio por la existencia de algún mecanismo no competitivo (salario mínimo, por ejemplo) y el salario informal se determina de manera competitiva, los trabajadores formales que pierden su empleo pasan a engrosar la oferta de trabajo informal generando una caída en su salario. Este tipo de ajuste sería plausible dada la mayor flexibilidad del salario informal respecto de un salario formal determinado por legislación.

La literatura que vincula la informalidad con cambios de política comercial es escasa y los trabajos que han analizado el impacto de este tipo de shocks sobre el salario de los trabajadores formales e informales se limita a dos estudios. En el primero de ellos, Alemán-Castilla (2006) procede en dos etapas estimando en pri- 
mer lugar un modelo para el logaritmo del salario, donde la variable explicativa de interés es la interacción entre las indicadoras de industria y la variable indicadora de informalidad. Este modelo es estimado para cada año de la muestra. En la segunda etapa se agrupan los estimadores de la variable explicativa de interés de la primera etapa y se regresan contra las variables de política comercial. Siguiendo este procedimiento no encuentra ningún efecto estadísticamente significativo de los aranceles a las importaciones aplicados en México sobre el diferencial salarial entre trabajadores formales e informales. Esta estrategia de estimación presenta al menos dos limitaciones. En primer lugar, considera la variable indicadora de la condición de informalidad de los trabajadores como una variable exógena en el modelo de salarios y, en segundo lugar, no captura el efecto de los aranceles sobre la probabilidad de empleo informal.

Paz (2013) procede con una estrategia de estimación diferente al implementar un modelo del tipo switching regression. En una primera etapa estima la probabilidad de empleo informal controlando por las variables de política comercial. La segunda etapa consiste en estimar modelos separados para el logaritmo del salario de trabajadores formales e informales, controlando nuevamente por las variables de política comercial y por la selección en la informalidad o formalidad mediante la inversa del ratio de Mills. Siguiendo la lógica de los modelos de selección, la primera etapa incluye una variable excluida en el modelo de salarios que es el instrumento para la variable de informalidad, de este modo se controla por la posible selección en inobservables. Este procedimiento es aplicado utilizando MCO y VI en ambas etapas. En este último caso se instrumenta la variable de aranceles. Sus resultados muestran una reducción en el salario formal del sector de manufacturas de Brasil como resultado de la reducción en los aranceles a las importaciones, y cambios ambiguos en el salario informal. Esta estrategia de estimación parece adecuada en términos de postular en primer lugar un modelo para la probabilidad de empleo informal capturando allí el efecto de las variables de política comercial y, en segundo lugar, instrumentando tanto la variable de informalidad como la variable de aranceles. Sin embargo, la estimación de modelos separados para el logaritmo del salario de trabajadores formales e informales introduce la necesidad de corregir por el sesgo de selección. Esto implica imponer supuestos distributivos y complica el cómputo de los efectos marginales. Además de ello, el método requiere conocer el modelo subyacente de cómo los trabajadores se seleccionan en la formalidad o informalidad. 
Una mala especificación para el modelo de la primera etapa puede generar un sesgo en lugar de mejorar las estimaciones por MCO (Heckman, 1979).

Es importante mencionar que ninguno de los trabajos que vincula los cambios en la política comercial con la penalidad salarial por informalidad analiza cuáles son los canales a través de los cuales pudo haber operado dicho efecto. Tampoco se evalúa si el ajuste estimado empíricamente es compatible con las predicciones de la TCI o si es posible que otro mecanismo de ajuste de precios sea la explicación detrás de los cambios observados. En la sección siguiente se analizan en detalles estos puntos.

El objetivo de este capítulo es evaluar el efecto que tuvieron los shocks de política comercial sobre el diferencial salarial entre trabajadores formales e informales asalariados. Para ello se procederá de manera simple, estimando el efecto del cambio en las tasas arancelarias sobre el diferencial salarial entre trabajadores formales e informales utilizando MCO y VI como métodos de estimación. En el último caso se corregirán, en caso de existir, los sesgos por factores inobservables relevantes en la ecuación de salarios que también inciden en la condición de informalidad de un trabajador -perspectivas laborales, actitud frente al trabajo- y la posible determinación simultánea entre salarios e informalidad -un salario formal bajo puede llevar a que el empleo informal sea una opción preferida a ser un asalariado formal-. Con la primera etapa de este método también se estará capturando la incidencia de los observables en la probabilidad de empleo informal, incluyendo el efecto de los aranceles.

En este punto es relevante mencionar la definición de salarios utilizada. La EPH de Argentina pregunta acerca de los ingresos laborales recibidos en el mes de referencia de la encuesta, aunque no especifica claramente si ese ingreso es antes o después de impuestos. Con esta información se presume que los trabajadores asalariados reportan su ingreso luego de los descuentos por contribuciones e impuestos. Esto significa que para los trabajadores formales se conoce su salario neto, mientras que para los informales el salario neto coincide con el bruto ya que no realizan contribuciones ni pagan impuestos. Idealmente debería compararse el salario bruto de los trabajadores formales (salario monetario más los beneficios de la seguridad social que recibe a cambio de los impuestos pagados) con el salario percibido por los informales, con el cual deberán enfrentar (o no) el pago de esos servicios de manera privada. Ante la imposibilidad de observar el salario bruto de los trabajadores formales se trabajará con la serie de salario neto, ajustada por cambios en el índice de precios. Si las estimaciones indican que los trabajadores formales reciben 
una remuneración mayor o igual en términos netos, esto implicará que el diferencial salarial es aún mayor. Mientras que la estimación de un diferencial salarial en favor de los trabajadores informales no permitirá extraer ninguna conclusión. Si el valor del paquete de beneficios de la seguridad social es lo suficientemente alto para los trabajadores formales, la remuneración bruta podría ser superior para ellos. Otro punto a destacar es que a largo del capítulo se estarán considerando diferencias de remuneración pecuniarias (suponiendo que los impuestos pagados por el trabajador formal se traducen exactamente en el paquete de beneficios de la seguridad social). Pero es posible que cada tipo de empleo tenga asociada una remuneración no pecuniaria como, por ejemplo, mayor estabilidad laboral en el caso de un trabajo formal, o mayor flexibilidad horaria en el caso de un trabajo informal. Este tipo de valoraciones no estarán siendo capturadas.

\subsubsection{Estimación del diferencial salarial por informalidad}

Antes de avanzar en el análisis del efecto del cambio en los aranceles a las importaciones sobre el salario recibido por trabajadores formales e informales, se evalúa la existencia de una penalidad salarial por informalidad en el mercado laboral argentino durante el periodo 1980-2001. Las estimaciones se realizaron por MCO y por VI. El instrumento utilizado es una función de la condición de informalidad de los restantes miembros del hogar (Roberts, 1989; Olson, 2002; Pratap y Quintin, 2006):

$z_{\text {iht }}^{3}= \begin{cases}d_{\text {jefe,h }} & \text { si } i \neq \text { jefe } \\ d_{\text {otros }, h} & \text { si } i=\text { jefe. }\end{cases}$

Para construir la variable instrumental se asignó status de informalidad a los individuos del hogar que estuviesen desocupados o fuera de la fuerza laboral sin recibir ingresos jubilatorios. La lógica detrás de este procedimiento es que estos individuos carecen de la protección de la seguridad social de manera directa.

Si el individuo $i$ perteneciente al hogar $h$ no es jefe se asigna la situación de informalidad del jefe de hogar $\left(d_{j e f e, h}\right)$, mientras que para los individuos de la muestra que son jefes, se asigna como valor para el instrumento el promedio de la condición de informalidad de los restantes miembros del hogar $\left(d_{\text {otros }, h}\right)$.

Esta dependencia entre las decisiones laborales al interior del hogar -la decisión del jefe depende de la de los otros miembros, y la de los restantes miembros depende de la del jefe- se ubica en el marco de los joint utility models donde los miembros del hogar toman decisiones de manera conjunta para maximizar la utilidad de la 
familia (Lundberg, 1988). La validez del instrumento se sustenta en la extensión de algunos de los componentes de la seguridad social a otros miembros del hogar, como por ejemplo el seguro de salud. ${ }^{3} \mathrm{Si}$ un individuo ya está cubierto a través de otro miembro del hogar entonces puede optar por la informalidad para acceder a ciertos beneficios no monetarios sin que esto implique la pérdida de cobertura social. Un ejemplo de esto puede encontrarse en Galiani y Weinschelbaum (2011) quienes muestran que, condicional en el nivel educativo, la tasa de formalización de los jefes de hogar es superior a la de los cónyuges en países de América Latina.

La validez del instrumento también requiere que se verifique la restricción de exclusión. Ella no se cumpliría si la condición de informalidad de otro miembro del hogar tuviese algún efecto independiente sobre el salario de los individuos. Resulta difícil pensar en una situación en la que la condición laboral de otro miembro del hogar -formal o informal- pueda afectar la productividad y salario que recibe cada individuo en el mercado de trabajo. Esto solo ocurriría a través de la selección en la formalidad o informalidad. Por ejemplo, si la condición de informalidad del jefe refleja un conjunto de observables e inobservables a nivel de hogar -nivel educativo o preferencias del hogar-, ellas no tendrán un efecto directo en la productividad de los otros miembros, si no que, al igual que en el caso del jefe, impactarán en su condición de informalidad. En este ejemplo, el nivel educativo del hogar o las preferencias del hogar -su valoración de los beneficios de la seguridad social- no tendrían un efecto directo sobre el salario si no que lo afectarían indirectamente a través de observables como la condición de informalidad o los años de educación del individuo.

Los resultados de la primera etapa aparecen en el cuadro 5.1. La primera columna muestra que existe una relación positiva y significativa estadísticamente entre el instrumento propuesto y la condición de informalidad de los individuos, es decir, que las preferencias por la formalidad o informalidad se comparten al interior del hogar. Esto indicaría que la seguridad social no es altamente valorada ya que los individuos no están dispuestos a perder una fracción del salario para realizar las contribuciones a la seguridad social que podrían extenderse a los otros miembros del hogar. La informalidad al interior del hogar también es factible en presencia de planes sociales condicionales en la informalidad o desempleo. Por ejemplo, los Planes

\footnotetext{
${ }^{3} \mathrm{Si}$ bien la variable indicadora de informalidad se construye a partir de información sobre el beneficio jubilatorio al momento de retiro, este representa una aproximación de los otros beneficios de la seguridad social. La correlación entre el derecho a recibir jubilación y el seguro de salud vinculado al empleo es de 0.9 para todos los años de la muestra.
} 
Trabajar fueron programas de empleo transitorio entregados a personas en situación de desempleo. En otras palabras, este tipo de programas solo era compatible con un empleo informal (no registrado). De manera equivalente, si el jefe es formal, los restantes individuos del hogar tienen mayores chances de ser formales. En este caso, los individuos optan por el mayor salario formal a pesar de duplicar las contribuciones al seguro social. La correlación positiva entre la condición de informalidad de los miembros del hogar refleja que las preferencias sobre la seguridad social se comparten (o se transmiten) dentro del hogar. Es importante considerar que la relación es fuerte estadísticamente pero la magnitud de la correlación parcial entre el instrumento y la variable a instrumentar es pequeña, especialmente cuando se controla por el tamaño de las firmas. Por ejemplo, un aumento de un puntos porcentual en el promedio de la condición de informalidad de los miembros del hogar (el promedio pasa, por ejemplo, de 0.50 a 0.51 ), aumenta la probabilidad de informalidad en 0.00092 puntos porcentuales. En la sección siguiente se amplía sobre este punto.

Los resultados de la estimación del modelo de ingresos se muestran en el cuadro 5.2. La variable dependiente es el logaritmo del salario horario y los modelos controlan por sexo, edad y su cuadrado, estado civil, variable indicadora de jefatura del hogar, y variables indicadoras de nivel educativo, de industria y de periodo de tiempo. La primera especificación (columna 1) no incluye al tamaño de las firmas como control mientras que la segunda sí lo incluye (columna 2). En el primer modelo se observa un diferencial salarial que favorece a los trabajadores formales o, en otras palabras, una penalidad salarial por informalidad. Mientras que en la estimación por MCO un trabajador informal obtiene un salario $16 \%$ inferior al de un trabajador formal con idénticas características, esta diferencia es del $18 \%$ cuando la estimación se realiza por VI. Dado que los trabajadores formales pueden estar empleados en firmas más grandes y más productivas, parte de la penalidad salarial estimada con la primera especificación estará captando ese efecto. En la columna 2 se controla por el tamaño de la firma en la que cada trabajador está empleado. En la estimación por MCO la penalidad salarial por informalidad reduce su magnitud. En este caso un trabajador informal recibe un salario $11 \%$ inferior respecto a un trabajador formal. La estimación por VI muestra que esta diferencia de salarios desaparece al comparar trabajadores formales e informales empleados en firmas de igual tamaño. Volviendo a la definición de salarios, la variable utilizada es el salario neto o salario monetario recibido por los trabajadores. El trabajador formal recibe 
adicionalmente el paquete de beneficios de la seguridad social. Esto significa que si bien no hay diferencia estadística entre el salario monetario recibido por cada tipo de trabajador, la remuneración total es superior para los formales. ${ }^{4}$

Retomando el punto del instrumento débil para la condición de informalidad, cuando el instrumento es marginalmente inválido una correlación baja en la primera etapa puede resultar en una estimación con un sesgo superior al de MCO. Del análisis del cuadro 5.2 surge que ese no sería el caso. Si la verdadera diferencia salarial en favor de los formales fuese menor a la reportada por MCO, VI podría sobreestimar la pérdida de los informales, pero eso es incompatible con el resultado de la columna 2. En la situación opuesta, si la verdadera diferencia salarial favorece aun más a los formales, VI podría subestimar la pérdida de los informales en mayor medida que MCO. El resultado de la columna 1 contradice esa posibilidad.

En conclusión, los trabajadores informales asalariados enfrentan penalidades salariales respecto a los asalariados formales, incluso después de controlar por la posible endogeneidad de la variable que indica la condición de informalidad. El tamaño de la firma es un factor relevante. Al comparar trabajadores formales e informales empleados en firmas de igual tamaño, la diferencia de remuneración solo se explica por los impuestos pagados que se traducen en la protección de la seguridad social. En otras palabras, no hay diferencias de salario monetario. Lógicamente, estos resultados no permiten extraer una conclusión acerca del bienestar de los trabajadores, quienes pueden valorar características del empleo que no son medibles. Lo que estarían indicando es que la remuneración del mercado es superior para los trabajadores formales.

\subsection{Efectos de la política comercial sobre los salarios: evidencia de corto plazo}

\subsubsection{Efectos sobre la estructura industrial de salarios}

Con el objetivo de evaluar el efecto de los cambios en la política comercial sobre el diferencial salarial entre trabajadores formales e informales se propone como primer ejercicio la estimación del efecto de los aranceles sobre los salarios industriales. De acuerdo a los modelos de corto y mediano plazo de la TCI existiría una relación

\footnotetext{
${ }^{4}$ Desde el punto de vista de la firma, el costo del empleo formal es superior al del empleo informal antes de considerar la probabilidad de detección y multa por parte de la autoridad tributaria. En el modelo del capítulo 3 esto implica que $w_{f}=w_{i}$ y entonces $w_{f}(1+s)>w_{i}$.
} 
positiva entre el nivel de protección recibido por cada industria y su nivel de salarios. Esto implica que las industrias que sufrieron recortes de aranceles proporcionalmente mayores deberían sufrir una pérdida salarial mayor. El ajuste en la composición de la fuerza laboral reportado en el capítulo 3 implicaría que esta reducción de salarios podría impactar de manera diferente en los trabajadores formales e informales.

El modelo propuesto regresa el logaritmo del salario del individuo $i$ empleado en la industria $j$ en el momento $t\left(l_{n} w_{i j t}\right)$ en el logaritmo de la tasa arancelaria de la industria $j$ en el momento $t\left(l n \tau_{j t}\right)$ y en características individuales incluidas en el vector $\mathrm{x}$ tales como sexo, edad y su cuadrado, estado civil, variables indicadoras de nivel educativo y jefatura del hogar. El modelo también incluye efectos fijos por industria y periodo de tiempo:

$\ln w_{i j t}=\mathbf{x}_{i j t} \beta_{x}+\beta_{\tau} \ln \tau_{j t}+I_{j}+T_{t}+\varepsilon_{i j t}$.

Este modelo fue estimado por MCO y por VI. Las variables utilizadas para instrumentar el logaritmo de los aranceles son las introducidas en el capítulo 3. La primera de ellas $\left(z_{j t}^{1}\right)$ es una medida del tipo de cambio promedio de los principales socios comerciales ponderado por la participación del socio comercial en las importaciones argentinas del producto $j$ en 1980. El segundo instrumento $\left(z_{j t}^{2}\right)$ interactúa los aranceles industriales del momento inicial (1980) con una variable que contiene tres categorías que se corresponden con cada una de las tres etapas en la evolución de la política comercial argentina. En el capítulo 3 se discutieron los detalles acerca de la validez de estos instrumentos.

Los resultados del modelo (5.2) se presentan en la parte superior del cuadro 5.3. La estimación por MCO indica que, ceteris paribus, las tasas arancelarias protegen los salarios industriales o, equivalentemente, existen rentas industriales que se reducen con la liberalización del comercio. Este efecto desaparece al instrumentar los aranceles, resultado que se confirma utilizando $z_{j t}^{1}$ como instrumento para $\ln \tau_{j t}$ (columna 1 en la tabla 5.3), $z_{j t}^{2}$ (columna 2) y ambas variables instrumentales (columna 3). Esto estaría indicando que la omisión de variables correlacionadas con los aranceles genera un sesgo positivo en la estimación por MCO. Por ejemplo, si las industrias con mayor poder sindical son las que obtienen mayor protección arancelaria, el coeficiente positivo obtenido por MCO estaría reflejando este factor de política económica. Al aislar esos efectos en la estimación por VI, el impacto positivo desaparece. La ausencia de cambios en la estructura industrial de salarios coincide 
con los resultados encontrados por Currie y Harrison (1997) para Marruecos, Feliciano (2001) para México, Pavcnik et al. (2003) para Brasil, y Galiani y Sanguinetti (2003) para Argentina. Pero la literatura no es concluyente al respecto. Revenga (1997) encuentra una relación positiva entre los salarios reales y los aranceles en México, Attanasio et al. (2004) encuentran un efecto significativo para Colombia, mientras que Topalova (2010) y Galiani y Porto (2010) confirman este resultado para India y Argentina, respectivamente, en el último caso mediante estimaciones por MCO. Estos resultados permiten concluir que el ajuste de la prima salarial de las industrias no estuvo detrás de la profundización de la penalidad salarial por informalidad observada a lo largo del periodo analizado. Esta ausencia de ajuste también permite confirmar el resultado del capítulo 3 donde se encontró que el efecto de los aranceles sobre la informalidad laboral no difiere al incluir el salario industrial como control adicional.

\subsubsection{Efectos sobre el diferencial salarial por informalidad}

Aun cuando la evidencia indica que no existe relación entre la estructura industrial de salarios y los cambios en la exposición de cada industria al comercio internacional, es posible que la reducción de aranceles haya afectado de manera diferencial el salario de trabajadores formales e informales. De acuerdo a lo discutido en la sección previa estos efectos dependerán de los cambios en el nivel de producción de las firmas y del ajuste en la composición de su fuerza laboral.

En este apartado se estima el efecto de los aranceles a las importaciones sobre el diferencial salarial entre trabajadores formales e informales. El primer modelo a estimar es el siguiente:

$\ln w_{i j t}=\mathbf{x}_{i j t} \beta_{x}+\beta_{d} d_{i j t}+\beta_{\tau} \ln \tau_{j t}+\beta_{d \tau} d_{i j t} \ln \tau_{j t}+I_{j}+T_{t}+\varepsilon_{i j t}$.

La variable $d_{i j t}$ indica la condición de informalidad del trabajador $i$ empleado en la industria $j$ en el momento $t$. El parámetro de interés $\beta_{d \tau}$ indica el impacto diferencial de un cambio en el logaritmo del arancel $\left(\ln \tau_{j t}\right)$ sobre el salario de un trabajador informal respecto de uno que es formal.

Volviendo a los resultados presentados en el capítulo 3, la liberalización del comercio generó un aumento en la tasa de informalidad de las industrias inicialmente pequeñas y medianas mientras que el efecto en industrias grandes fue nulo, al igual que el efecto promedio para todas las industrias. Este heterogeneidad de resulta- 
dos según el tamaño inicial de las industrias conduce a expandir el modelo (5.3) para aislar correctamente el efecto sobre los salarios. El modelo (5.3) estará mostrando el efecto promedio para todas las industrias y este podría esconder patrones diferenciados dependiendo de su tamaño y del cambio en la tasa de informalidad experimentado por cada una de ellas.

El modelo expandido incluye la interacción entre la variable de interés $\left(d_{i j t} l n \tau_{j t}\right)$ y variables indicadoras del tamaño inicial de las industrias:

$$
\begin{aligned}
\ln w_{i j t}=\mathbf{x}_{i j t} \beta_{x}+\beta_{d} d_{i j t}+ & \beta_{\tau} \ln \tau_{j t}+\beta_{d \tau} d_{i j t} \ln \tau_{j t} \\
& +\sum_{g} \beta_{g d \tau} d_{i j t} \ln \tau_{j t} S_{g j}+\sum_{g} \beta_{g} S_{g j}+I_{j}+T_{t}+\varepsilon_{i j t},
\end{aligned}
$$

donde $g$ indexa el tamaño inicial de las industrias. El parámetro $\beta_{g d \tau}$ captura el efecto diferencial de la apertura sobre el diferencial salarial por informalidad en industrias que difieren en su tamaño inicial. Teniendo en cuenta la evidencia presentada en los capítulos 3 y 4 , en las industrias inicialmente grandes la tasa de informalidad laboral no sufrió ningún cambio estadísticamente significativo. Las firmas pertenecientes a estas industrias -firmas que enfrentan una probabilidad de detección alta y entre las que se encuentran las firmas exportadoras y las que lograron mejoras de productividad- se habrían expandido empleando a más trabajadores formales. Esto podría traducirse en una mejora salarial para ellos, pero dicho ajuste dependerá de la posibilidad de legislar un nuevo nivel salarial en el corto plazo. En industrias pequeñas y medianas la tasa de informalidad ajustó a través de mecanismos diferentes. En industrias pequeñas prevaleció el cambio en las características de relaciones laborales existentes, con trabajadores formales que perdieron la protección de la seguridad social. En industrias medianas se dio un proceso de rotación laboral, con trabajadores formales e informales que perdieron su empleo en diferente medida. La dirección del cambio en el diferencial salarial es difícil de predecir en estos casos. Las firmas de estas industrias habrían reducido el tamaño de su fuerza laboral y el efecto sobre el salario formal e informal dependerá de la magnitud del cambio en la demanda de cada tipo de trabajo, de su elasticidad y de la flexibilidad de los salarios.

Los dos modelos propuestos fueron estimados por MCO y por VI. Los instrumentos utilizados para la variable de aranceles son $z_{j t}^{1}$ y $z_{j t}^{2}$. En la sección 5.2 se presentaron diversas razones para creer que la variable indicadora de la condición de 
informalidad de los trabajadores $\left(d_{i j t}\right)$ se determina simultáneamente con el salario y que existen variables no observables que pueden incidir en el status de informalidad de un trabajador. Asimismo, el tipo de relación laboral entre el trabajador y la firma -formal o informal- puede verse alterado como resultado de los shocks de política comercial. Con el fin de incluir estas consideraciones en las estimaciones econométricas, los modelos previos también instrumentan la variable de informalidad mediante $z_{i h t}^{3}$. La estimación por VI permite, en primer lugar, asegurar la consistencia del efecto estimado. En segundo lugar, la primera etapa captura el impacto de los aranceles, más exactamente de los instrumentos $z_{j t}^{1}$ y $z_{j t}^{2}$, sobre el empleo informal.

Los resultados se presentan instrumentando solo la variable de aranceles, e instrumentando la variable de aranceles y la indicadora de la condición de informalidad de los trabajadores conjuntamente. Esta diferenciación se realiza por dos motivos: (i) los errores estándar de las estimaciones por VI tienden a ser grandes. Esto puede significar que ningún efecto sea estadísticamente significativo. La comparación con MCO permitirá contrastar estimaciones posiblemente inconsistentes pero más precisas con estimadores consistentes que poseen menor precisión; (ii) al instrumentar la variable de aranceles y la indicadora de la condición de informalidad de los trabajadores se estarán imponiendo muchas restricciones de sobreidentificación, especialmente en el modelo 5.4 que introduce interacciones por tamaño de industria. Incluso cuando los instrumentos son válidos y el tamaño de la muestra es grande, esto puede generar un sesgo muy grande en las estimaciones por VI cuando los instrumentos son débiles (Bound et al., 1995; Staiger y Stock, 1997). El cuadro 5.4 muestra los resultados de la primera etapa cuando se instrumentan el logaritmo de los aranceles y la indicadora de informalidad en los modelos 5.3 y 5.4. Los resultados no son alentadores. El p-valor del test $\mathrm{F}$ de significatividad conjunta de los instrumentos permite rechazar la hipótesis nula, sin embargo, en muy pocos casos las variables son significativas estadísticamente a nivel individual.

Los resultados se presentan en el cuadro 5.5. La columna 1 muestra la estimación correspondiente al modelo (5.3). El cambio en el nivel de protección no afectó de manera estadísticamente significativa al diferencial salarial por informalidad. Más allá de esta ausencia de significatividad estadística, es interesante notar el cambio en el signo del coeficiente asociado a la variable de política comercial. Al igual que en la estimación del efecto del cambio en los aranceles sobre la estructura industrial 
de salarios, la omisión de factores de política económica estaría generando un sesgo positivo en la estimación por MCO, por ejemplo, por la acción y presión de sindicatos por mayores salarios y mayor protección arancelaria. El coeficiente asociado a la interacción $d_{i j t} l n \tau_{j t}$ también modifica su signo al pasar de la estimación por MCO al panel VI-1 y VI-2. La comparación más interesante es entre MCO y VI-1, ya que el panel VI-2 probablemente presente un sesgo mayor. Mientras que MCO indica que la reducción de aranceles se asocia a una mejora salarial para los informales respecto de los formales, el efecto es el opuesto en el panel VI-1. Esta diferencia podría se explicada a través del mismo argumento. La caída de aranceles redujo la renta tarifaria de los sindicatos y que era distribuida entre los trabajadores protegidos (formales).

Este efecto nulo podría estar reflejando la ausencia de ajuste en la tasa de informalidad para el promedio de todas las industrias. La columna 2 incluye la posibilidad de efectos diferenciados según su tamaño. Las estimaciones por MCO no muestran ningún efecto estadísticamente significativo. El signo de los coeficientes indica que la dirección del ajuste sería la de una mejora en el salario de los informales respecto de los formales con un efecto más pronunciado en industrias grandes. Las estimaciones por VI tampoco son significativas en términos estadísticos para ningún tamaño de industria. El signo de los coeficientes en el panel VI-1 indica que la diferencia salarial por informalidad se habría ajustado en favor de los formales -los informales habrían tenido una pérdida salarial en relación a los formales- con un efecto más fuerte en industrias pequeñas y medianas.

Las estimaciones presentadas en el panel VI-1 estarían mostrando estimadores que se comportan mejor que MCO en términos de consistencia pero que son menos precisos. Sin embargo, el tamaño de los errores estándar no aumenta sustancialmente para las variables que capturan el efecto sobre el diferencial salarial por informalidad. Por otro lado, estas estimaciones están suponiendo que la condición de informalidad es una variable exógena en el modelo de salarios. La sección previa mostró que MCO tiende a sobreestimar la diferencia salarial en favor de los formales cuando se controla por tamaño de firma, pero no modifica la dirección del efecto. Con esto se concluye que la reducción de aranceles no afectó el salario de los trabajadores informales en relación a los formales en el corto plazo.

Estos resultados indican no solo que los salarios industriales no sufrieron variaciones como consecuencia de la reducción de aranceles, si no que al interior de 
las industrias tampoco hubo un ajuste diferencial del salario formal e informal. Esta evidencia es compatible con el supuesto aplicado en el capítulo 3 donde se definió al corto plazo como un escenario en el que el trabajo no se reasigna entre industrias/sectores y los salarios no ajustan. La rigidez del salario formal en el corto plazo puede explicarse por su determinación institucional, a través de la legislación de salario mínimo o mediante convenios colectivos de trabajo cuya modificación no puede realizarse rápidamente. En el caso del salario informal, la predicción indicaba que este precio sería más flexible, pudiendo caer, especialmente en industrias pequeñas y medianas donde las firmas habrían reducido el tamaño de su planta de empleados. La ausencia de ajuste podría estar indicando que el salario informal sigue la evolución del salario formal. Cuando el salario formal aumenta, por ejemplo, por el establecimiento de un nuevo salario mínimo, el salario informal también aumenta hasta lograr igualar el componente monetario.

\subsubsection{Ejercicios adicionales}

La ausencia de ajuste en el salario del trabajo informal respecto del formal es compatible tanto con salarios (formal e informal) constantes como con variaciones en la misma dirección y en magnitudes similares. El primer ejercicio consiste en evaluar estas alternativas analizando el efecto de los aranceles sobre el salario formal e informal de manera separada. Para esto se implementó la metodología de switching regression models aplicada por Paz (2013). De este modo, el ejercicio también constituye una evaluación de la robustez del método de estimación aplicado en este trabajo. La metodología se detalla en el Apéndice 1 y el cuadro 5.6 presenta los resultados. El panel 1 muestra las estimaciones obtenidas cuando se instrumenta la variable de aranceles tanto en la ecuación de selección como en la ecuación de regresión y la identificación descansa en la no linealidad del ratio de Mills. En el panel 2, la ecuación de selección incluye un regresor adicional que es el instrumento $z_{i h t}^{3}$. En ambos paneles se encuentra que los salarios formal e informal no experimentaron cambios estadísticamente significativos vinculados a la variación en los aranceles a las importaciones. Esto se verifica en la especificación de la columna 1 y en la de la columna 2 que incluye interacciones por tamaño de industrias. Ambas metodologías proveen resultados equivalente que indican que los episodios de liberalización del comercio no impactaron sobre la penalidad salarial por informalidad y eso se explica por la ausencia de cambios en el salario formal e informal. 
El segundo ejercicio consiste en separar las estimaciones previas para el periodo 1980-1989 y 1990-2001. Como se vio en la sección 3, a lo largo de todo el periodo existió una tendencia hacia la ampliación del diferencial salarial en favor de los trabajadores formales, aunque se registró una mejora en el salario de los informales respecto de los formales a principio de la década de los noventa. Los resultados obtenidos se presentan en el cuadro 5.7. Para el sub-periodo 1980-1989 las estimaciones por MCO no muestran ningún cambio estadísticamente significativo. Al instrumentar la variable de aranceles (panel VI-1) el signo de los coeficientes se mantiene y su magnitud no difiere sustancialmente. En el último panel (VI-2) se produce una reversión en el signo de la variable $d_{i j t} l n \tau_{j t}$ mientras que la magnitud de los coeficientes aumenta drásticamente, reflejando el sesgo de las estimaciones por VI en presencia de muchas restricciones de sobreidentificación junto a un instrumento débil. De la comparación de los primeros dos paneles del cuadro y recurriendo nuevamente a hecho de que MCO predice correctamente la dirección del diferencial salarial por informalidad pero sobreestima el efecto cuando se controla por tamaño de firma, se concluye que en este periodo no hubo un efecto significativo de la política comercial sobre la variable de interés.

Para el sub-periodo 1990-2001 las estimaciones por MCO muestran una caída en los salarios asociada a la reducción de aranceles (significativa al 10\%) y ningún efecto sobre el diferencial salarial por informalidad. Las estimaciones que instrumentan la variable de aranceles, en cambio, muestran una mejora salarial para los informales en relación a los formales que se reduce con el tamaño de las industrias. El periodo 19902001 se caracterizó por la introducción de importantes reformas en el ámbito laboral pudiendo afectar los incentivos a la informalidad. La intuición es que en momentos donde la protección laboral es baja la informalidad puede ser más atractiva. Estos resultados podrían estar explicados por la variación endógena de la informalidad durante este periodo dificultando la obtención de una conclusión en este caso.

En el cuadro 5.8 se presentan los resultados obtenidos al incluir tendencias específicas para cada industria como controles adicionales en los modelos (5.3) y (5.4). Con esto se busca investigar la posibilidad de que existan variables omitidas en el modelo que puedan estar sesgando los resultados. Por ejemplo, la evolución del salario formal puede ser diferente en cada industria dependiendo del poder de sus sindicatos que a su vez pueden lograr mayor protección arancelaria para su sector. Cada industria puede acordar diferentes condiciones de trabajo en las negociacio- 
nes colectivas lo que puede afectar las relación laboral entre empleador y empleado modificando los incentivos a la informalidad. Otra posible tendencia omitida podría ser el cambio en las contribuciones a la seguridad social. Luego de la reforma al sistema de seguridad social en 1994, Argentina implementó una serie de cambios en los impuestos al trabajo. Las contribuciones a la seguridad social pasaron de ser uniformes en todo el país a presentar variabilidad por zonas geográficas (Cruces et al., 2010). Como los datos de este capítulo se restringen al área del Gran Buenos Aires, este cambio de política solo estará introduciendo un quiebre a lo largo del tiempo que puede ser capturado por los efectos fijos de periodo de tiempo. Al igual que en el capítulo 3, las tendencias específicas para cada industria se construyen como la interacción entre algunas características iniciales de cada industria -nivel inicial de empleo y proporción de trabajadores calificados- y la variable categórica que indica las distintas etapas en la evolución de la política comercial $\left(\right.$ Post $\left._{t}\right)$. Los resultados coinciden con las estimaciones previas y no muestran cambios significativos en el diferencial salarial por informalidad como consecuencia de la reducción en los aranceles a las importaciones.

En conclusión, la evidencia de corto plazo puede resumirse en dos puntos: (i) es difícil extraer conclusiones acerca del efecto de la liberalización del comercio sobre el diferencial salarial por informalidad en el corto plazo por la presencia de endogeneidades provenientes de dos fuentes y la dificultad de corregir por ambas; (ii) la evidencia obtenida indica que no habría un efecto estadísticamente significativo para la totalidad de las industrias y tampoco al distinguir por su tamaño. Esto aparece más claramente en el sub-periodo 1980-1989, mientras que en 1990-2001 el movimiento endógeno hacia la informalidad es más evidente.

\subsection{Efectos de la política comercial sobre los salarios: evidencia de largo plazo}

\subsubsection{Predicción}

Las predicciones de los modelos de largo plazo de la TCI se desprenden fundamentalmente de dos supuestos. El primero de ellos es el de movilidad de factores productivos entre sectores. Bajo esta condición, una reforma comercial afectará el retorno de los factores productivos en toda la economía, ya que no habrá retornos específicos a nivel de industria. El segundo de los supuestos es el de intensidad de uso 
de los factores productivos en los distintos sectores. Este supuesto es el que genera cambios en el precio relativo de los factores dependiendo de cuál es el sector que reduce su tamaño y cuál es el que se expande como resultado del shock de política comercial. Para poder realizar una predicción del cambio en el diferencial salarial por informalidad en el largo plazo será necesario expandir el análisis incluyendo a otros sectores de la economía y a otro factor productivo, y realizar supuestos acerca de la intensidad de uso de dichos factores en cada sector. El apartado siguiente desarrolla un modelo que se encuentra en línea con los modelos de largo plazo de la TCI, distinguiendo entre el sector importador de la economía y el sector exportador, y entre trabajo calificado y no calificado. Ambos factores productivos pueden ser empleados formal o informalmente, pero la modalidad informal tiene un mayor peso relativo entre los trabajadores no calificados y lo contrario ocurre con el empleo formal.

Los estudios teóricos que vinculan las políticas de liberalización del comercio con el salario informal modelan el trabajo formal e informal como dos sectores diferentes de la economía. En estos modelos el sector informal es el segmento pobre formado principalmente por trabajadores por cuenta propia. En este marco, una reforma como la apertura del comercio contrae al sector formal (productor de manufacturas que compiten con las importaciones) liberando trabajo hacia el sector informal. A partir de un análisis de equilibrio general se concluye que si el capital puede moverse libremente hacia el sector informal, la mayor oferta de trabajo no necesariamente reducirá su salario (Marjit, 2003; Marjit et al., 2003).

Marjit y Kar (2007) analizan el impacto de una de las consecuencias de la liberalización del comercio en una economía en desarrollo, como es el aumento en la productividad del trabajo en el sector formal, sobre el salario informal. También concluyen que el grado de movilidad del capital entre el sector formal e informal es clave para determinar si los beneficios del aumento de productividad alcanzan a los trabajadores informales. Chaudhuri y Banerjee (2007) evalúan las consecuencias de diversas reformas económicas sobre el bienestar del sector informal capturado mediante el salario. Los autores encuentran que diferentes políticas de liberalización producen efectos diversos sobre el salario informal y, a diferencias de los trabajos previos, los resultados son independientes de la movilidad del capital entre el sector formal e informal. La liberalización del comercio reduce el salario informal, excepto en un caso muy particular, mientras que la entrada de capitales extranjeros y re- 
formas del mercado de trabajo lo incrementan. ${ }^{5}$ Marjit et al. (2007), en un trabajo más reciente, encuentran que con la liberalización del comercio el salario informal puede aumentar incluso cuando no se permite que exista movilidad del capital entre el sector formal e informal. Concluyen que la movilidad del capital entre sectores es clave cuando se modelan solo dos sectores de la economía. En presencia de más sectores informales es posible que el salario informal aumenta bajo el supuesto de que uno de estos sectores sea más capital intensivo respecto del otro.

\subsubsection{Modelo}

El modelo de este apartado combina una hipótesis de abundancia factorial siguiendo la lógica de los modelos tradicionales de comercio internacional- junto con una hipótesis de intensidad de uso del trabajo formal e informal en cada grupo de nivel educativo. A diferencia de los trabajos mencionados en la sub-sección previa, se incorpora la distinción entre trabajo formal e informal en cada grupo de nivel educativo y se incluye un mecanismo de determinación de salarios competitivo luego de que el propietario de la firma capturó parte de la renta tarifaria.

La economía está compuesta por dos sectores transables, el primero de ellos es el sector que compite con las importaciones y el segundo es el sector exportador. Existe un sector de bienes no transables cuyo precio se determina endógenamente. Existen dos factores productivos con oferta fija, trabajo calificado $(s)$ y trabajo no calificado $(u)$. Cada tipo de trabajador puede ser contratado de manera formal o informal. El costo del trabajo formal es $w_{f}^{j}$ y el del informal $w_{i}^{j}$ con $w_{f}^{j}>w_{i}^{j}$ para $j=s, u .^{6}$

El sector que compite con las importaciones es intensivo en trabajo calificado:

$$
\frac{a_{1}^{s}}{a_{1}^{u}}>\frac{a_{2}^{s}}{a_{2}^{u}}
$$

donde $a_{h}^{s}$ y $a_{h}^{u}$ son los requerimientos tecnológicos de trabajo calificado y no calificado en el sector $h$. Un país relativamente abundante en trabajo no calificado exportará el bien cuya producción utiliza intensivamente ese factor -bien producido por el sector 2-, mientras que el bien producido por el sector que utiliza intensivamente trabajo

\footnotetext{
${ }^{5}$ Cuando el sector no transable produce un insumo agrícola los autores encuentras que la reducción de aranceles a las importaciones aumenta el salario informal.

${ }^{6}$ En términos del modelo del capítulo $3, w_{f}^{j}$ es el costo del trabajo para la firma. Esto incluye el pago de las contribuciones a la seguridad social.
} 
calificado se importa -bien producido por el sector 1-. ${ }^{7}$ Respecto al uso de trabajo formal e informal se supone que entre los trabajadores calificados la participación de formales es superior en relación a lo que ocurre entre los no calificados. Como consecuencia, la participación de trabajadores informales será superior entre los trabajadores no calificados, respecto de los calificados.

El trabajo es perfectamente móvil entre sectores. Los salarios de equilibrio son $w_{f}^{s}$ para el trabajo calificado formal, $w_{f}^{u}$ para el trabajo no calificado formal, $w_{i}^{s}$ para el calificado informal y $w_{i}^{u}$ para el no calificado informal. Tanto para los trabajadores formales como para los informales existe una prima salarial por calificación. La siguiente regla representa de manera simple estos diferenciales:

$w_{f}^{s}=\gamma w_{f}^{u}$

$w_{i}^{s}=\gamma w_{i}^{u}$,

con $\gamma>1$. Este parámetro determina la existencia de una prima salarial por calificación en el grupo de trabajadores formales e informales.

Los mercados de bienes son competitivos. La condición de equilibrio en el sector no transable (sector 0) es:

$p_{0}=a_{0}^{s}\left[\theta_{0 f}^{s} w_{f}^{s}+\theta_{0 i}^{s} w_{i}^{s}\right]+a_{0}^{u}\left[\theta_{0 f}^{u} w_{f}^{u}+\theta_{0 i}^{u} w_{i}^{u}\right]$,

donde $\theta_{h f}^{j}$ y $\theta_{h i}^{j}$ representan la proporción de trabajo formal e informal, respectivamente, que posee nivel educativo $j$ en el sector $h . \theta_{h f}^{j}+\theta_{h i}^{j}=1$ y $p_{0}$ es el precio expresado en moneda local. El supuesto de participación del trabajo formal e informal en cada grupo de nivel educativo implica que $\theta_{f}^{s}>\theta_{f}^{u}$ y, entonces, $\theta_{i}^{s}<\theta_{i}^{u}$.

El sector transable importador (sector 1) es protegido mediante aranceles a las importaciones $t$. El precio que enfrentan las firmas es $p_{1}=p_{1}^{*}(1+t)$, siendo $p_{1}^{*}$ el precio internacional del bien. Las firmas incumbentes capturan una fracción $\delta$ de la renta tarifaria $p^{*} t,{ }^{8}$ mientras que la fracción $1-\delta=\tilde{\delta}$ atrae nuevas firmas al sector

\footnotetext{
${ }^{7}$ La evidencia indica que Argentina es relativamente abundante en trabajo no calificado. Lo es en relación a socios comerciales como la Unión Europea y Estados Unidos (Galiani y Sanguinetti, 2003). En comparación a otros países latinoamericanos, Argentina está mejor dotada de trabajo calificado. Sin embargo, en comparación a Brasil, principal socio comercial de la región, Argentina es relativamente abundante en recursos naturales y trabajo no calificado (Berlinski, 1994).

${ }^{8}$ Esta es la renta tarifaria antes del ajuste en el precio de los factores. La absorción de parte de la renta tarifaria por parte de las firmas busca incluir un componente de competencia imperfecta, aunque la evidencia de ausencia de rentas industriales en el corto plazo impone la restricción de que la fracción $\delta$ no altere la estructura industrial de salarios.
} 
importador que se expande demandando trabajo calificado y no calificado hasta que dicha renta desaparece. La condición de equilibrio para este sector es:

$p_{1}=p_{1}^{*}(1+t \tilde{\delta})=a_{1}^{s}\left[\theta_{1 f}^{s} w_{f}^{s}+\theta_{1 i}^{s} w_{i}^{s}\right]+a_{1}^{u}\left[\theta_{1 f}^{u} w_{f}^{u}+\theta_{1 i}^{u} w_{i}^{u}\right]$

Cuanto mayor sea la fracción de la renta capturada por las firmas $(\delta)$, menor será el margen de ajuste de salarios por la expansión del sector y la mayor demanda de factores.

La condición de equilibrio del sector transable exportador (sector 2) es:

$p_{2}=a_{2}^{s}\left[\theta_{2 f}^{s} w_{f}^{s}+\theta_{2 i}^{s} w_{i}^{s}\right]+a_{2}^{u}\left[\theta_{2 f}^{u} w_{f}^{u}+\theta_{2 i}^{u} w_{i}^{u}\right]$,

donde $p_{2}$ es el precio del bien exportable expresado en moneda doméstica.

Por último, las condiciones de equilibrio en el mercado de factores son:

$a_{0}^{s} Y_{0}+a_{1}^{s} Y_{1}+a_{2}^{s} Y_{2}=L^{s}$

$a_{0}^{u} Y_{0}+a_{1}^{u} Y_{1}+a_{2}^{u} Y_{2}=L^{u}$

donde $Y_{h}$ es el nivel de producción del sector $h$ y $L^{s}$ y $L^{u}$ la oferta fija de trabajo calificado y no calificado.

Para estudiar como la estructura de salarios depende de la estructura de protección, se diferencian totalmente las expresiones (5.5), (5.6), (5.7) y (5.8). Por el momento se asume que la prima salarial por calificación $(\gamma)$ no cambia con la apertura comercial:

$d t \tilde{\delta}=\left(\alpha_{1 f}^{s} \gamma+\alpha_{1 f}^{u}\right) d w_{f}^{u}+\left(\alpha_{1 i}^{s} \gamma+\alpha_{1 i}^{u}\right) d w_{i}^{u}$,

$d w_{i}^{u}=-\frac{\left(\alpha_{2 f}^{s} \gamma+\alpha_{2 f}^{u}\right)}{\left(\alpha_{2 i}^{s} \gamma+\alpha_{2 i}^{u}\right)} d w_{f}^{u}=-\varphi_{2} d w_{f}^{u}$

$d w_{f}^{s}=\gamma d w_{f}^{u}$,

$d w_{i}^{s}=\gamma d w_{i}^{u}$,

donde $\alpha_{h g}^{j}=\frac{a_{h g}^{j} \theta_{h g}^{j}}{p_{h}} \operatorname{con} j=s, u, h=1,2$ y $g=f, i$.

Un cambio en el arancel $t$ genera en el sector que compite con las importaciones un ajuste en la composición de su fuerza laboral. La reducción del arancel incrementa la participación del trabajo informal y genera desempleo, mientras que un aumento en la protección arancelaria se traduce en una reducción en la informalidad en el corto plazo. La expresión de los cambios en los salarios ante cambios en el arancel 
a las importaciones $t$ una vez que el ajuste en la composición de la fuerza laboral se produjo -i.e. $\theta_{h f}^{j}$ y $\theta_{h i}^{j}$ representan la participación del empleo formal e informal $e x$ post- y los factores pueden moverse entre sectores es:

$\frac{\hat{w}_{f}^{u}}{\hat{t}}=\frac{t \tilde{\delta}}{w_{f}^{u} \varphi_{1}}>0$

$\frac{\hat{w}_{f}^{s}}{\hat{t}}=\frac{\gamma t \tilde{\delta}}{w_{f}^{s} \varphi_{1}}>0$

$\frac{\hat{w}_{i}^{u}}{\hat{t}}=-\frac{t \tilde{\delta} \varphi_{2}}{w_{i}^{u} \varphi_{1}}<0$

$\frac{\hat{w}_{i}^{s}}{\hat{t}}=-\frac{\gamma t \tilde{\delta} \varphi_{2}}{w_{i}^{s} \varphi_{1}}<0$,

donde $\varphi_{1}=\left(\alpha_{1 f}^{s} \gamma+\alpha_{1 f}^{u}\right)-\varphi_{2}\left(\gamma \alpha_{1 i}^{s}+\alpha_{1 i}^{u}\right)>0^{9}$ y $\hat{x}=\frac{d x}{x}$.

Dados el supuesto de abundancia factorial que define el patrón de comercio y de participación del trabajo formal e informal en cada grupo de nivel educativo, el modelo predice que un aumento de aranceles generará una expansión del sector protegido (sector 1). Este sector demandará más trabajo calificado en relación al no calificado, entre los cuales el trabajo formal tiene mayor peso relativo. Esto afectará el precio de los factores: aumentará el salario de los trabajadores formales (ecuaciones (5.13) y (5.14)), mientras que el salario informal caerá (ecuaciones (5.15) y (5.16)). De manera equivalente, la liberalización del comercio conduce a que el diferencial salarial por informalidad se reduzca, i.e. los informales mejoran respecto de los formales. En todos los casos un menor valor del parámetro $\tilde{\delta}$, fracción de la renta tarifaria no apropiada por las firmas incumbentes, determinará un menor ajuste de salarios.

Un resultado importante es que en ausencia de cambio en la prima salarial por calificación, el cambio en el salario de los trabajadores formales calificados y no calificados es idéntico ((5.13) es igual a (5.14)) y lo mismo sucede entre los informales $((5.15)$ es igual a (5.16)). Es decir, en ausencia de cambios en el parámetro $\gamma$, la penalidad salarial por informalidad no muestra un patrón de cambio diferente al interior de cada grupo de nivel educativo. Un resultado habitual en la literatura empírica que vincula la liberalización del comercio con la desigualdad salarial en países en desarrollo es el cambio en la prima salarial por calificación. Numerosos

\footnotetext{
${ }^{9}$ En el Apéndice 2 se prueba el signo positivo de $\varphi_{1}$.
} 
trabajos han encontrado que la prima salarial por calificación aumenta en el corto plazo como consecuencia de la liberalización del comercio. Algunos trabajos que confirman este resultado son Revenga (1997), Harrison y Hanson (1999) y Feliciano (2001) para México, Goldberg y Pavcnik (2005) para Colombia, Galiani y Sanguinetti (2003) y Galiani y Porto (2010) para Argentina. En el largo plazo, en cambio, este resultado puede revertirse. Esos son los resultados presentados por Galiani y Porto (2010) para Argentina y por Atolia (2007) en una simulación de un modelo de equilibrio general para una economía en desarrollo.

Si se incorpora la posibilidad de que esta prima varíe junto con los aranceles, las expresiones de los diferenciales totales de (5.5), (5.6), (5.7) y (5.8) son las siguientes:

$$
\begin{aligned}
& d t \tilde{\delta}=\left(\alpha_{1 f}^{s} \gamma+\alpha_{1 f}^{u}\right) d w_{f}^{u}+\left(\alpha_{1 i}^{s} \gamma+\alpha_{1 i}^{u}\right) d w_{i}^{u}+\left(\alpha_{1 f}^{s} w_{f}^{u}+\alpha_{1 i}^{s} w_{i}^{u}\right) d \gamma \\
& d w_{i}^{u}=-\frac{\left(\alpha_{2 f}^{s} \gamma+\alpha_{2 f}^{u}\right)}{\left(\alpha_{2 i}^{s} \gamma+\alpha_{2 i}^{u}\right)} d w_{f}^{u}-\frac{\left(\alpha_{2 f}^{s} w_{f}^{u}+\alpha_{2 i}^{s} w_{i}^{u}\right)}{\left(\alpha_{2 i}^{s} \gamma+\alpha_{2 i}^{u}\right)} d \gamma=-\varphi_{2} d w_{f}^{u}-\tilde{\varphi}_{2} d \gamma \\
& d w_{f}^{s}=\gamma d w_{f}^{u}+d \gamma w_{f}^{u}, \\
& d w_{i}^{s}=\gamma d w_{i}^{u}+d \gamma w_{i}^{u} .
\end{aligned}
$$

La expresión de los cambios en los salarios ante cambios en el arancel a las importaciones $t$ cuando se permite que la prima salarial por calificación también varíe es:

$$
\begin{aligned}
& \frac{\hat{w}_{f}^{u}}{\hat{t}}=\frac{t \tilde{\delta}}{\varphi_{1} w_{f}^{u}}-\frac{\hat{\gamma}}{\hat{t}} \frac{\gamma \tilde{\varphi}_{1}}{\varphi_{1} w_{f}^{u}} \gtrless 0, \\
& \frac{\hat{w}_{f}^{s}}{\hat{t}}=\frac{\gamma t \tilde{\delta}}{\varphi_{1} w_{f}^{s}}+\frac{\hat{\gamma}}{\hat{t}}\left[1-\frac{\tilde{\varphi}_{1} \gamma}{\varphi_{1} w_{f}^{u}}\right] \gtrless 0, \\
& \frac{\hat{w}_{i}^{u}}{\hat{t}}=-\frac{t \tilde{\delta} \varphi_{2}}{w_{i}^{u} \varphi_{1}}+\frac{\hat{\gamma}}{\hat{t}} \frac{\gamma}{w_{i}^{u}}\left[\frac{\tilde{\varphi}_{1} \varphi_{2}}{\varphi_{1}}-\tilde{\varphi}_{2}\right] \gtrless 0, \\
& \frac{\hat{w}_{i}^{s}}{\hat{t}}=-\frac{t \tilde{\delta} \varphi_{2} \gamma}{w_{i}^{s} \varphi_{1}}+\frac{\hat{\gamma}}{\hat{t}}\left[\frac{\gamma^{2}}{w_{i}^{s}}\left(\frac{\tilde{\varphi}_{1} \varphi_{2}}{\varphi_{1}}-\tilde{\varphi}_{2}\right)+1\right] \gtrless 0,
\end{aligned}
$$

donde $\tilde{\varphi}_{1}=\left(\alpha_{1 f}^{s} w_{f}^{u}+\alpha_{1 i}^{s} w_{i}^{u}\right)-\tilde{\varphi}_{2}\left(\alpha_{1 i}^{s} \gamma+\alpha_{1 i}^{u}\right)>0 .{ }^{10}$

Cuando el diferencial salarial por calificación también ajusta ante un cambio en el arancel, el cambio en los salarios tendrá dos componentes, uno directo cuyo signo depende de los supuestos de intensidad de uso de los factores y otro que depende

\footnotetext{
${ }^{10}$ En el Apéndice 2 se presenta la prueba de que $\tilde{\varphi}_{1}>0,\left[1-\frac{\tilde{\varphi}_{1} \gamma}{\varphi_{1} w_{f}^{u}}\right]<0$ y $\left[\frac{\tilde{\varphi}_{1} \varphi_{2}}{\varphi_{1}}-\tilde{\varphi}_{2}\right]>0$.
} 
del signo del cambio en el parámetro $\gamma$. Si la liberalización del comercio genera una mejora relativa para los trabajadores calificados $(\hat{\gamma} / \hat{t}<0)$, la ganancia relativa de los informales persiste $\left(\hat{w_{i}^{s}} / \hat{t}<0\right.$ y $\left.\hat{w}_{i}^{u} / \hat{t}<0\right)$ pero la mejora salarial es superior para los calificados, respecto de los no calificados. De la misma manera, los trabajadores formales empeoran $\left(\hat{w_{f}^{s}} / \hat{t}>0\right.$ y $\left.\hat{w}_{f}^{u} / \hat{t}>0\right)$ pero la pérdida de los formales calificados es menor a la pérdida de los formales no calificados:

$\frac{\hat{w}_{i}^{s}}{\hat{t}}-\frac{\hat{w}_{i}^{u}}{\hat{t}}=\frac{\hat{w}_{f}^{s}}{\hat{t}}-\frac{\hat{w}_{f}^{u}}{\hat{t}}=\frac{\hat{\gamma}}{\hat{t}}<0$.

Si la liberalización del comercio reduce la prima salarial por calificación $(\hat{\gamma} / \hat{t}>0)$, el signo de las expresiones 5.22, 5.24, 5.21 y 5.23 dependerá de la magnitud de ese cambio. En presencia de una caída en la prima por calificación no es posible extraer una conclusión acerca de la dirección del ajuste en el diferencial salarial por informalidad. Si $\frac{\hat{\gamma}}{\hat{t}}<\frac{t \tilde{\delta}_{\varphi_{2}}}{\left[\gamma\left(\tilde{\varphi}_{1} \varphi_{2}-\tilde{\varphi}_{2} \varphi_{1}\right)+w_{i}^{u} \varphi_{1}\right]}$, los informales mejoran su salario (con una mejora mayor para los no calificados) y los formales sufren una reducción de salario (con una pérdida mayor para los calificados).

Este resultado es perfectamente compatible con las predicciones de los modelos de largo plazo de la TCI. Aun cuando los mayores recortes de aranceles hayan tenido lugar en industrias que utilizaban intensivamente trabajo no calificado (donde el informal tiene mayor peso relativo), en la economía puede haber otro sector más intensivo en trabajo no calificado respecto a la totalidad del sector de manufacturas (Atolia, 2007), por ejemplo, el sector agrícola exportador. ${ }^{11}$ Considerando que en el largo plazo los factores pueden reasignarse no solo entre industrias del sector de manufacturas si no entre los distintos sectores de la economía, el trabajo no calificado, donde el informal tiene un mayor peso relativo, migrará al sector exportador en expansión. Esto determina una mejora salarial para los trabajadores informales respecto de los formales.

\subsubsection{Evidencia empírica}

La evidencia encontrada a partir de la variabilidad de corte transversal de los datos indicó que la liberalización del comercio no afectó el diferencial salarial por informalidad. Esta evidencia puede ser interpretada como el efecto de corto plazo, cuando los factores no pueden reasignarse entre sectores y, por lo tanto, pueden

\footnotetext{
${ }^{11}$ Aun cuando el sector productor de manufacturas que compite con las importaciones es relativamente intensivo en trabajo no calificado en relación al sector exportador de manufacturas.
} 
existir efectos diferenciales de la apertura comercial en las distintas industrias. Para estimar el impacto en el largo plazo se procederá utilizando la variabilidad de los datos en el tiempo e identificando el efecto para toda la economía en conjunto. La intuición en este caso es que en el largo plazo la afiliación industrial o el sector de la economía no es relevante porque los factores pueden desplazarse libremente.

La estrategia de estimación es similar a la implementada en el capítulo 3. En una primera etapa se estima el modelo (5.3) incluyendo como controles adicionales la interacción entre la variable indicadora de la condición de informalidad de los trabajadores $d_{i j t}$ y las variables indicadoras de periodo de tiempo. Los coeficientes asociados a estas variables indican el efecto diferencial en la brecha salarial por informalidad que se puede atribuir a cada periodo de tiempo. En esta primera etapa se controla por la estructura sectorial de aranceles, por lo tanto, las interacciones entre $d_{i j t}$ y las variables de periodo de tiempo estarán capturando un efecto dado el impacto de los aranceles industriales sobre los salarios en el corto plazo. La primera etapa se estimó de manera separada para el sector de manufacturas y para el resto de la economía. En este último caso, el modelo no controla por variables de política comercial.

En la segunda etapa se utiliza la dimensión temporal de los datos y se especifica un modelo para el diferencial salarial por informalidad en cada periodo de tiempo -variable estimada en la primera etapa- controlando por el arancel promedio de la economía (Galiani y Porto, 2010):

$\hat{\beta}_{d t}=\mathbf{x}_{t}^{\prime} \alpha_{x}+\alpha_{\tau} \ln \tau_{t}+\nu_{t}$.

En esta segunda etapa se agrupan los coeficientes estimados para el sector de manufacturas y para el resto de la economía. El vector $\mathbf{x}_{t}$ incluye la relación de fuerza laboral entre el sector de manufacturas y el no transable (para captar los cambios en la estructura productiva de la economía), la relación entre la fuerza laboral formal e informal (para controlar por cambios en la composición de la fuerza laboral a lo largo del tiempo) y por la composición por nivel de educativo de la fuerza laboral formal e informal (para captar el hecho de que la movilidad de trabajadores depende de su nivel educativo). Como la variable dependiente en la segunda etapa es una variable estimada, se utiliza el método de Mínimos Cuadrados Ponderados con la inversa de la varianza de los efectos estimados en la primera etapa como ponderador.

Los resultados de las estimaciones de la segunda etapa por MCO se muestran 
en el cuadro 5.9 e indican una mejora salarial en el tiempo para los trabajadores informales respecto de los formales. Por cada reducción del $10 \%$ en el arancel promedio nacional, el salario de los trabajadores informales mejora entre 1.2 y $1.7 \%$ en relación a los formales dependiendo de la especificación del modelo. El término de interacción entre el logaritmo del arancel promedio nacional y la variable indicadora del sector no transable de la economía no es estadísticamente significativo en ningún caso. Esto es consistente con el resultado esperado: en el largo plazo, cuando los trabajadores pueden desplazarse entre industrias y sectores, no hay ajustes diferenciales de salarios. El signo positivo de la variable que capta el tamaño relativo de la oferta laboral en el sector de manufacturas indica que cuando este sector reduce su tamaño (en relación al sector no transable) dicho ajuste impacta negativamente sobre el diferencial salarial de los trabajadores informales.

Los paneles siguientes muestran las estimaciones separando a los trabajadores de acuerdo a su nivel educativo. En este caso, la primera etapa se restringe a las observaciones de trabajadores calificados o no calificados. La segunda etapa procede utilizando las estimaciones del diferencial salarial por informalidad en cada año correspondientes a cada grupo de calificación. De acuerdo a las predicciones del modelo de la sub-sección anterior, en ausencia de cambios en el diferencial salarial por calificación, el ajuste de la brecha salarial por informalidad sería idéntico al interior de cada grupo de nivel educativo. Si el diferencial salarial por calificación también ajusta, no es posible concluir en qué dirección se moverá la brecha de salarios entre trabajadores formales e informales con igual nivel educativo. Lo que indica la evidencia de MCO es que para el grupo de trabajadores calificados no se produjo ningún ajuste en el diferencial salarial por informalidad. El coeficiente asociado al logaritmo del arancel promedio nacional es negativo pero no significativo estadísticamente. En cambio, entre los no calificados la reducción de aranceles produce una mejora en el salario de los trabajadores informales en relación a los formales en el sector no transable de la economía. Este resultado es significativo al $10 \%$.

En las estimaciones por MCO el arancel promedio nacional captura, además del impacto sobre el diferencial salarial por informalidad, otros efectos como la incidencia de factores de política económica y los cambios en la prima salarial por calificación. Los diferentes resultados encontrados para cada grupo de nivel educativo confirman esto último. Para lograr aislar estos efectos se aplicó el mismo procedimiento en dos etapas utilizando VI como método de estimación. Dadas las 
dificultades mencionadas previamente para obtener estimadores confiables cuando se instrumenta la variable indicadora de informalidad laboral junto con la variable de aranceles, en la primera etapa se instrumentó únicamente la variable de política comercial mediante $z_{j t}^{1}$ y $z_{j t}^{2}$. En la segunda etapa se utilizó el promedio del tipo de cambio real de los principales socios comerciales como instrumento para cada periodo de tiempo. Los resultados se muestran en el cuadro 5.10 e indican que la reducción del arancel promedio nacional generó una mejora en el salario de los informales respecto de los formales que es superior en magnitud respecto a las estimaciones por MCO. Una reducción del $10 \%$ en el arancel promedio se traduce en una mejora de entre $2.8 \%$ y $3.5 \%$ en el salario de un informal respecto de un trabajador formal y este efecto es válido para toda la economía (la interacción con la variable indicadora de sector no transable no estadísticamente significativa). La distinción por grupos de nivel educativo muestra que esta mejora se produjo entre los trabajadores no calificados, mientras que entre los calificados no se observa ningún efecto. Al aislar el impacto del cambio en la prima por calificación (al menos parcialmente), el efecto estadísticamente nulo estimado por MCO para los no calificados se transforma en una mejora para los informales respecto de los formales.

En conclusión, la liberalización del comercio afectó la evolución del diferencial salarial por informalidad en el largo plazo permitiendo una mejora del salario de los trabajadores informales respecto de los formales en toda la economía. Este efecto parece estar correlacionado con los cambios en la prima salarial por calificación. Al aislar el impacto de ese factor la mejora del salario informal (respecto del formal) es superior y también se encuentra un patrón de ajuste diferente por grupos de nivel educativo. Más precisamente, la mejora relativa de los informales se explica totalmente por el ajuste del diferencial salarial por informalidad en el grupo de trabajadores no calificados.

\subsection{Conclusiones}

En un contexto de ausencia de reasignación del empleo en respuesta a cambios en la política comercial el ajuste de salarios cobra relevancia. En los capítulos previos se mostró evidencia de que el trabajo no se movió entre industria ni entre sectores productivos como consecuencia de la reducción de los aranceles a las importaciones y, en cambio, el ajuste tuvo lugar al interior de las industrias a través del aumento en la tasa de informalidad laboral. En este capítulo se analizó cuál fue el cambio 
en el diferencial salarial por informalidad como consecuencia de los episodios de liberalización del comercio.

Los principales resultados del trabajo pueden resumirse en tres puntos. En primer lugar, se evaluó la predicción de los modelos de corto y mediano plazo de la TCI. Estos modelos predicen que los trabajadores en industrias que enfrentan mayores recortes de aranceles deberían enfrentar una reducción de salarios respecto a los trabajadores que, con idénticas características, se encuentran empleados en industrias que enfrentan una reducción menor en su nivel de protección. Los resultados indicaron que la estructura industrial de salarios no sufrió cambios asociados a los episodios de liberalización del comercio en el corto plazo. Aun cuando el salario promedio de la industria no cambia, el ajuste en la composición de la fuerza laboral entre trabajadores formales e informales, evidencia presentada en el capítulo 3 , puede determinar que el salario formal e informal se vean afectados de manera diferente. La evaluación empírica de esta posibilidad constituye el segundo resultado de este capítulo. La presencia de endogeneidades provenientes de dos fuentes (condición ed informalidad de los trabajadores y variable de aranceles) y la dificultad de corregir por ambas dificulta la obtención de una conclusión acerca del efecto de la liberalización del comercio sobre el diferencial salarial por informalidad en el corto plazo. La evidencia obtenida indicó que no habría un efecto estadísticamente significativo para la totalidad de las industrias y tampoco al distinguir por su tamaño. Esto apareció más claramente en el sub-periodo 1980-1989, mientras que en 1990-2001 el movimiento endógeno hacia la informalidad fue más evidente. Por último, se estimó el efecto de largo plazo del cambio en el arancel promedio nacional sobre el diferencial salarial por informalidad de toda la economía. Los resultados indicaron que las reducciones en el arancel promedio permitieron una mejora en el salario de los trabajadores informales respecto de los formales en toda la economía y ese cambio se explica totalmente por la mejora entre los trabajadores no calificados.

El último resultado pudo ser racionalizado mediante un modelo de largo plazo dentro de la lógica de los modelos de la TCI. Este modelo combinó una hipótesis de abundancia factorial junto con una hipótesis de intensidad de uso del trabajo formal e informal en cada grupo de nivel educativo, e incorporó un mecanismo de determinación de salarios competitivo luego de que los propietarios de las firmas capturan parte de la renta tarifaria. Las predicciones mostraron que cuando la prima salarial por calificación no ajusta el salario informal aumenta mientras que el formal cae, y el 
ajuste es idéntico al interior de cada grupo de nivel educativo. Cuando la prima por calificación ajusta no es posible determinar en qué dirección se moverá el diferencial salarial por informalidad. En particular, si la prima por calificación se reduce (resultado documentado como efecto de largo plazo para economías en desarrollo por Galiani y Porto (2010) y Atolia (2007)) no es posible determinar en qué dirección se moverá cada uno de los salarios sin imponer una restricción sobre el tamaño del cambio de dicha prima. El modelo muestra que aun cuando los mayores recortes de aranceles hayan tenido lugar en industrias que utilizaban intensivamente trabajo no calificado (donde el informal tiene mayor peso relativo), en la economía puede haber otro sector más intensivo en trabajo no calificado respecto a la totalidad del sector de manufacturas. Considerando que en el largo plazo los factores pueden reasignarse no solo entre industrias del sector de manufacturas si no entre los distintos sectores de la economía, el trabajo no calificado, donde el informal tiene un mayor peso relativo, migrará al sector exportador en expansión. Esto determina una mejora salarial para los trabajadores informales respecto de los formales. 


\subsection{Apéndice 1}

\section{Switching regression model o Tobit type 5}

$y_{1}$ representa la condición de informalidad de los individuos. Es posible observar $y_{1}=1$ o $y_{1}=0$ de acuerdo a:

$y_{1}= \begin{cases}1 & \text { si } y_{1}^{*}>0 \\ 0 & \text { si } y_{1}^{*} \leq 0 .\end{cases}$

La variable de resultado y (el logaritmo del salario horario) es:

$y= \begin{cases}y_{2}^{*} & \text { si } y_{1}^{*}>0 \\ y_{3}^{*} & \text { si } y_{1}^{*} \leq 0\end{cases}$

El modelo queda expresados por las siguientes tres ecuaciones:

$$
\begin{aligned}
& y_{1}^{*}=x_{1}^{\prime} \beta_{1}+\varepsilon_{1} \\
& y_{2}^{*}=x_{2}^{\prime} \beta_{2}+\varepsilon_{2} \\
& y_{3}^{*}=x_{3}^{\prime} \beta_{3}+\varepsilon_{3}
\end{aligned}
$$

Los errores tienen distribución conjunta normal con media 0 y varianza normalizada a $\sigma_{1}^{2}=1$. El método de estimación es el de Heckman en dos etapas con:

$E\left[y \mid x, y_{1}^{*}>0\right]=x_{2}^{\prime} \beta_{2}+\sigma_{12} \lambda\left(x_{1}^{\prime} \beta_{1}\right)$

$E\left[y \mid x, y_{1}^{*} \leq 0\right]=x_{3}^{\prime} \beta_{3}-\sigma_{13} \lambda\left(-x_{1}^{\prime} \beta_{1}\right)$

donde $\lambda(z)=\frac{\phi(z)}{\varphi(z)}$ y $\phi($.$) es la función de densidad normal estándar y \varphi($.$) es la$ función de distribución acumulada normal.

En la primera etapa se estimó la probabilidad de empleo informal controlando por sexo, edad y su cuadrado, estado civil, variables indicadoras de nivel educativo y jefatura del hogar, variables indicadoras de industria y periodo de tiempo, y aranceles a las importaciones. En la segunda etapa se estimaron dos modelos, uno para el logaritmo del salario horario de los trabajadores formales y otro para el logaritmo del salario horario de los trabajadores informales, incluyendo la inversa del ratio de Mills como control $(\lambda(z))$. Los errores estándar en la segunda etapa se obtuvieron por bootstrap con 500 repeticiones. 


\subsection{Apéndice 2}

Prueba $\varphi_{1}>0$

Sin pérdida de generalidad se supone que $\theta_{1 g}^{j}=\theta_{2 g}^{j}$ con $j=s, u$ y $g=f, i$. Es decir, el peso del trabajo formal e informal al interior de cada grupo de nivel educativo es idéntico en los sectores 1 y 2 .

$$
\begin{aligned}
& \varphi_{1}=\left(\alpha_{1 f}^{s} \gamma+\alpha_{1 f}^{u}\right)-\varphi_{2}\left(\alpha_{1 i}^{s} \gamma+\alpha_{1 i}^{u}\right) \\
& =\frac{\gamma a_{1}^{s} \theta_{f}^{s}+a_{1}^{u} \theta_{f}^{u}}{\gamma a_{1}^{s} \theta_{i}^{s}+a_{1}^{u} \theta_{i}^{u}}-\frac{\gamma a_{2}^{s} \theta_{f}^{s}+a_{2}^{u} \theta_{f}^{u}}{\gamma a_{2}^{s} \theta_{i}^{s}+a_{2}^{u} \theta_{i}^{u}} \\
& \varphi_{1}>0 \mathrm{si}: \\
& \frac{\gamma\left(\frac{a_{1}^{s}}{a_{1}^{u}}\right) \theta_{f}^{s}+\theta_{f}^{u}}{\gamma\left(\frac{a_{1}^{s}}{a_{1}^{u}}\right) \theta_{i}^{s}+\theta_{i}^{u}}>\frac{\gamma\left(\frac{a_{2}^{s}}{a_{2}^{u}}\right) \theta_{f}^{s}+\theta_{f}^{u}}{\gamma\left(\frac{a_{2}^{s}}{a_{2}^{u}}\right) \theta_{i}^{s}+\theta_{i}^{u}} \\
& \theta_{f}^{s} \theta_{i}^{u}\left[\frac{a_{1}^{s}}{a_{1}^{u}}-\frac{a_{2}^{s}}{a_{2}^{u}}\right]>\theta_{f}^{u} \theta_{i}^{s}\left[\frac{a_{1}^{s}}{a_{1}^{u}}-\frac{a_{2}^{s}}{a_{2}^{u}}\right] \\
& \frac{\theta_{f}^{s}}{\theta_{i}^{s}}>\frac{\theta_{f}^{u}}{\theta_{i}^{u}}
\end{aligned}
$$

Esta condición se cumple por los supuestos de intensidad de uso del trabajo formal e informal en cada grupo de nivel educativo. 


\section{Prueba $\tilde{\varphi}_{1}>0$}

Nuevamente se supone, sin pérdida de generalidad, que $\theta_{1 g}^{j}=\theta_{2 g}^{j}$ con $j=s, u \mathrm{y}$ $g=f, i$.

$$
\begin{aligned}
\tilde{\varphi}_{1} & =\left(\alpha_{1 f}^{s} w_{f}^{u}+\alpha_{1 i}^{s} w_{i}^{u}\right)-\tilde{\varphi}_{2}\left(\alpha_{1 i}^{s} \gamma+\alpha_{1 i}^{u}\right) \\
& =\left(\alpha_{1 f}^{s} w_{f}^{u}+\alpha_{1 i}^{s} w_{i}^{u}\right)-\frac{\left(\alpha_{2 f}^{s} w_{f}^{u}+\alpha_{2 i}^{s} w_{i}^{u}\right)}{\left(\alpha_{2 i}^{s} \gamma+\alpha_{2 i}^{u}\right)}\left(\alpha_{1 i}^{s} \gamma+\alpha_{1 i}^{u}\right) \\
& =w_{f}^{u}\left[\alpha_{1 f}^{s}-\alpha_{2 f}^{s} \frac{\left(\alpha_{1 i}^{s} \gamma+\alpha_{1 i}^{u}\right)}{\left(\alpha_{2 i}^{s} \gamma+\alpha_{2 i}^{u}\right)}\right]+w_{i}^{u}\left[\alpha_{1 i}^{s}-\alpha_{2 i}^{s} \frac{\left(\alpha_{1 i}^{s} \gamma+\alpha_{1 i}^{u}\right)}{\left(\alpha_{2 i}^{s} \gamma+\alpha_{2 i}^{u}\right)}\right]
\end{aligned}
$$

$\tilde{\varphi}_{1}>0$ si:

$$
w_{f}^{u} \theta_{i}^{u}\left(a_{1}^{s} a_{2}^{u}-a_{2}^{s} a_{1}^{u}\right)+w_{i}^{u} \theta_{i}^{u}\left(a_{1}^{s} a_{2}^{u}-a_{2}^{s} a_{1}^{u}\right)>0
$$

Esta condición se cumple por el supuesto de intensidad de uso del trabajo calificado y no calificado en cada sector. 
Prueba $\tilde{\varphi}_{1} \frac{\varphi_{2}}{\varphi_{1}}-\tilde{\varphi}_{2}>0$

$$
\begin{aligned}
& \frac{\tilde{\varphi}_{1} \varphi_{2}}{\varphi_{1}}-\tilde{\varphi}_{2}>0 \\
& {\left[\left(\alpha_{1 f}^{s} w_{f}^{u}+\alpha_{1 i}^{s} w_{i}^{u}\right)-\tilde{\varphi}_{2}\left(\alpha_{1 i}^{s} \gamma+\alpha_{1 i}^{u}\right)\right] \varphi_{2}-\left[\left(\alpha_{1 f}^{s} \gamma+\alpha_{1 f}^{u}\right)-\varphi_{2}\left(\alpha_{1 i}^{s} \gamma+\alpha_{1 i}^{u}\right)\right] \tilde{\varphi}_{2}>0} \\
& \varphi_{2}\left(\alpha_{1 f}^{s} w_{f}^{u}+\alpha_{1 i}^{s} w_{i}^{u}\right)-\tilde{\varphi}_{2}\left(\alpha_{1 f}^{s} \gamma+\alpha_{1 f}^{u}\right)>0 \\
& w_{f}^{u} \theta_{f}^{s} \theta_{f}^{u}\left[a_{1}^{s} a_{2}^{u}-a_{2}^{s} a_{1}^{u}\right]+w_{i}^{u} \theta_{i}^{s} \theta_{f}^{u}\left[a_{1}^{s} a_{2}^{u}-a_{2}^{s} a_{1}^{u}\right]>0
\end{aligned}
$$

Esta condición se cumple por el supuesto de intensidad de uso del trabajo calificado y no calificado en cada sector. 
Prueba $1-\frac{\tilde{\varphi}_{1}}{\varphi_{1}} \frac{\gamma}{w_{f}^{u}}<0$

$\varphi_{1} w_{f}^{u}-\tilde{\varphi}_{1} \gamma<0$

$\left[\left(\alpha_{1 f}^{s} \gamma+\alpha_{1 f}^{u}\right)-\frac{\left(\alpha_{2 f}^{s} \gamma+\alpha_{2 f}^{u}\right)}{\left(\alpha_{2 i}^{s} \gamma+\alpha_{2 i}^{u}\right)}\left(\left(\alpha_{1 i}^{s} \gamma+\alpha_{1 i}^{u}\right)\right)\right] w_{f}^{u}-\left[\left(\alpha_{1 f}^{s} w_{f}^{u}+\alpha_{1 i}^{s} w_{i}^{u}\right)-\frac{\left(\alpha_{2 f}^{s} w_{f}^{u}+\alpha_{2 i}^{s} w_{i}^{u}\right)}{\left(\alpha_{2 i}^{s} \gamma+\alpha_{2 i}^{u}\right)}\left(\left(\alpha_{1 i}^{s} \gamma+\alpha_{1 i}^{u}\right)\right)\right] \gamma<0$

$w_{f}^{u} a_{1}^{s} a_{2}^{u} \gamma\left(\theta_{f}^{s} \theta_{i}^{u}-\theta_{f}^{u} \theta_{i}^{s}\right)-\gamma\left(a_{1}^{s} a_{2}^{u}-a_{2}^{s} a_{1}^{u}\right)\left[w_{f}^{u} \theta_{f}^{s} \theta_{i}^{u}+w_{i}^{u} \theta_{i}^{s} \theta_{i}^{u}\right]<0$

$w_{i}^{u} \gamma \theta_{i}^{s} \theta_{i}^{u}\left(a_{2}^{s} a_{1}^{u}-a_{1}^{s} a_{2}^{u}\right)<0$

Esta condición se cumple por el supuesto de intensidad de uso del trabajo calificado y no calificado en cada sector. 


\subsection{Cuadros}

Cuadro 5.1: Diferencial salarial por informalidad

Estimación por VI - Resultados de la primera etapa

\begin{tabular}{lcc}
\hline \hline & $=1$ si informal & $=1$ si informal \\
\hline$z_{\text {iht }}^{3}$ & 0.127 & 0.092 \\
& {$[0.010]^{* * *}$} & {$[0.009]^{* * *}$} \\
Controla por tamaño de firma & No & Si \\
& & \\
\hline Observaciones & 20661 & 20661 \\
$R^{2}$ & 0.19 & 0.28 \\
\hline
\end{tabular}

Fuente: Elaboración propia en base a EPH

Notas: Errores estándar robustos entre corchetes.

*** significativo al 1\%; ** significativo al $5 \%$; $*$ significativo al $10 \%$. 
Cuadro 5.2: Diferencial salarial por informalidad Estimación por MCO y VI

\begin{tabular}{|c|c|c|c|c|}
\hline & \multicolumn{2}{|c|}{$\mathrm{MCO}$} & \multicolumn{2}{|c|}{ VI } \\
\hline & (1) & (2) & (1) & (2) \\
\hline$=1$ si informal & $\begin{array}{c}-0.175 \\
{[0.010]^{* * *}}\end{array}$ & $\begin{array}{c}-0.114 \\
{[0.011]^{* * *}}\end{array}$ & $\begin{array}{c}-0.202 \\
{[0.094]^{* *}}\end{array}$ & $\begin{array}{c}-0.034 \\
{[0.129]}\end{array}$ \\
\hline Controla por tamaño de firma & No & $\mathrm{Si}$ & No & $\mathrm{Si}$ \\
\hline $\begin{array}{l}\text { Observaciones } \\
R^{2}\end{array}$ & $\begin{array}{c}20661 \\
0.38\end{array}$ & $\begin{array}{c}20661 \\
0.39\end{array}$ & 20661 & 20661 \\
\hline
\end{tabular}

Fuente: Elaboración propia en base a EPH

Notas: Errores estándar robustos entre corchetes.

*** significativo al $1 \%$; ** significativo al $5 \%$; ${ }^{*}$ significativo al $10 \%$. 
Cuadro 5.3: Aranceles a las importaciones y Estructura industrial de salarios

Estimación por MCO y VI

\begin{tabular}{lcccc}
\hline \hline & MCO & \multicolumn{3}{c}{ VI } \\
\cline { 3 - 5 } & & $(1)$ & $(2)$ & $(3)$ \\
\hline Log aranceles & 0.039 & -0.208 & -0.162 & -0.190 \\
& {$[0.022]^{*}$} & {$[0.290]$} & {$[0.317]$} & {$[0.230]$} \\
Observaciones & & & & 20661 \\
$R^{2}$ & 20661 & 20661 & 20661 & 0.91 \\
Test de sobreidentificación & 0.38 & & & \\
(p-valor) & & & & \\
& & & & \\
\hline Resultados de la primera etapa & & & & -0.148 \\
$z_{j t}^{1}$ & & -0.165 & & -0.059 \\
$z_{j t}^{2}$ & & {$[0.017]^{* * *}$} & & \\
& & & -0.070 & \\
$R^{2}$ & & & $0.007]^{* * *}$ & {$[0.007]^{* * *}$} \\
Test F (p-valor) & & 0.73 & 0.73 & 0.73 \\
\hline
\end{tabular}

Fuente: Elaboración propia en base a EPH y Galiani y Porto (2010).

Notas: Errores estándar agrupados por año e industria entre corchetes.

*** significativo al 1\%; ** significativo al $5 \%$; ${ }^{*}$ significativo al $10 \%$. 
Cuadro 5.4: Aranceles a las importaciones y Diferencial salarial por informalidad

Estimación por VI - Resultados de la primera etapa

\begin{tabular}{|c|c|c|c|c|}
\hline & $\begin{array}{l}=1 \mathrm{si} \\
\text { informal }\end{array}$ & $\begin{array}{c}\text { Log de } \\
\text { aranceles }\end{array}$ & $\begin{array}{c}=1 \mathrm{si} \\
\text { informal }\end{array}$ & $\begin{array}{c}\log \text { de } \\
\text { aranceles }\end{array}$ \\
\hline \multirow[t]{2}{*}{$z_{i h t}^{3}$} & 0.012 & 0.023 & 0.023 & 0.092 \\
\hline & {$[0.043]$} & {$[0.045]$} & {$[0.045]$} & {$[0.022]^{* * *}$} \\
\hline \multirow[t]{2}{*}{$z_{j t}^{1}$} & -0.013 & -0.012 & -0.012 & -0.175 \\
\hline & {$[0.028]$} & {$[0.029]$} & {$[0.029]$} & {$[0.018]^{* * *}$} \\
\hline \multirow[t]{2}{*}{$z_{j t}^{2}$} & 0.025 & 0.018 & 0.018 & -0.072 \\
\hline & {$[0.014]^{*}$} & {$[0.014]$} & {$[0.014]$} & {$[0.007]^{* * *}$} \\
\hline \multirow[t]{2}{*}{$z_{i h t}^{3} * z_{j t}^{1}$} & 0.021 & 0.035 & 0.035 & -0.021 \\
\hline & {$[0.024]$} & {$[0.028]$} & {$[0.028]$} & {$[0.016]$} \\
\hline \multirow{2}{*}{$z_{i h t}^{3} * z_{j t}^{2}$} & 0.006 & 0.003 & 0.003 & -0.010 \\
\hline & {$[0.004]^{*}$} & {$[0.004]$} & {$[0.004]$} & {$[0.002]^{* * *}$} \\
\hline \multirow[t]{2}{*}{$z_{i h t}^{3} * z_{j t}^{1} * I_{P}$} & & & -0.085 & -0.420 \\
\hline & & & {$[0.093]$} & {$[0.030]^{* * *}$} \\
\hline \multirow{2}{*}{$z_{i h t}^{3} * z_{j t}^{1} * I_{M}$} & & & -0.047 & 0.023 \\
\hline & & & {$[0.029]$} & {$[0.015]$} \\
\hline \multirow[t]{2}{*}{$z_{i h t}^{3} * z_{j t}^{2} * I_{P}$} & & & 0.005 & 0.023 \\
\hline & & & {$[0.005]$} & {$[0.002]^{* * *}$} \\
\hline \multirow[t]{2}{*}{$z_{i h t}^{3} * z_{j t}^{2} * I_{M}$} & & & 0.007 & 0.005 \\
\hline & & & {$[0.003]^{* *}$} & {$[0.002]^{* * *}$} \\
\hline Observaciones & 20661 & 20661 & 20661 & 20661 \\
\hline$R^{2}$ & 0.28 & 0.28 & 0.28 & 0.73 \\
\hline Test F & 20.26 & 33.14 & 11.85 & 39.94 \\
\hline p-valor & 0.000 & 0.000 & 0.000 & 0.000 \\
\hline
\end{tabular}

Fuente: Elaboración propia en base a EPH y Galiani y Porto (2010).

Notas: Errores estándar agrupados por año e industria entre corchetes.

*** significativo al $1 \%$; ** significativo al $5 \%$; ${ }^{*}$ significativo al $10 \%$. 


\section{Cuadro 5.5: Aranceles a las importaciones y Diferencial salarial por informalidad}

Estimación por MCO y VI

\begin{tabular}{|c|c|c|c|c|c|c|}
\hline & \multicolumn{2}{|c|}{$\mathrm{MCO}$} & \multicolumn{2}{|c|}{ VI-1 } & \multicolumn{2}{|c|}{ VI-2 } \\
\hline & $(1)$ & $(2)$ & $(1)$ & $(2)$ & (1) & $(2)$ \\
\hline$=1$ si informal & $\begin{array}{l}-0.111 \\
{[0.098]}\end{array}$ & $\begin{array}{l}-0.081 \\
{[0.101]}\end{array}$ & $\begin{array}{c}-0.384 \\
{[0.224]^{*}}\end{array}$ & $\begin{array}{l}-0.233 \\
{[0.213]}\end{array}$ & $\begin{array}{l}1.223 \\
{[1.970]}\end{array}$ & $\begin{array}{c}0.560 \\
{[1.360]}\end{array}$ \\
\hline Log de aranceles & $\begin{array}{c}0.024 \\
{[0.022]}\end{array}$ & $\begin{array}{c}0.027 \\
{[0.022]}\end{array}$ & $\begin{array}{l}-0.076 \\
{[0.229]}\end{array}$ & $\begin{array}{l}-0.092 \\
{[0.211]}\end{array}$ & $\begin{array}{l}-0.045 \\
{[0.245]}\end{array}$ & $\begin{array}{l}-0.015 \\
{[0.183]}\end{array}$ \\
\hline$=1$ si informal $*$ Log aranceles & $\begin{array}{l}-0.001 \\
{[0.030]}\end{array}$ & $\begin{array}{l}-0.014 \\
{[0.033]}\end{array}$ & $\begin{array}{l}0.088 \\
{[0.073]}\end{array}$ & $\begin{array}{l}0.037 \\
{[0.072]}\end{array}$ & $\begin{array}{l}-0.433 \\
{[0.682]}\end{array}$ & $\begin{array}{l}-0.238 \\
{[0.467]}\end{array}$ \\
\hline$=1$ si informal ${ }^{*} \log$ aranceles ${ }^{*} I_{P}$ & & $\begin{array}{c}0.008 \\
{[0.012]}\end{array}$ & & $\begin{array}{l}0.003 \\
{[0.015]}\end{array}$ & & $\begin{array}{l}-0.172 \\
{[0.106]}\end{array}$ \\
\hline$=1$ si informal ${ }^{*} \log$ aranceles* $I_{M}$ & & $\begin{array}{c}0.004 \\
{[0.009]}\end{array}$ & & $\begin{array}{c}0.004 \\
{[0.010]}\end{array}$ & & $\begin{array}{c}0.102 \\
{[0.066]}\end{array}$ \\
\hline Observaciones & 20661 & 20661 & 20661 & 20661 & 20661 & 20661 \\
\hline$R^{2}$ & 0.38 & 0.38 & & & & \\
\hline $\begin{array}{l}\text { Test de sobreidentificación } \\
\text { (p-valor) }\end{array}$ & & & 0.49 & 0.25 & 0.05 & 0.37 \\
\hline
\end{tabular}

Fuente: Elaboración propia en base a EPH y Galiani y Porto (2010).

Notas: Errores estándar agrupados por año e industria entre corchetes.

*** significativo al $1 \%$; ** significativo al $5 \%$; ${ }^{*}$ significativo al $10 \%$. 


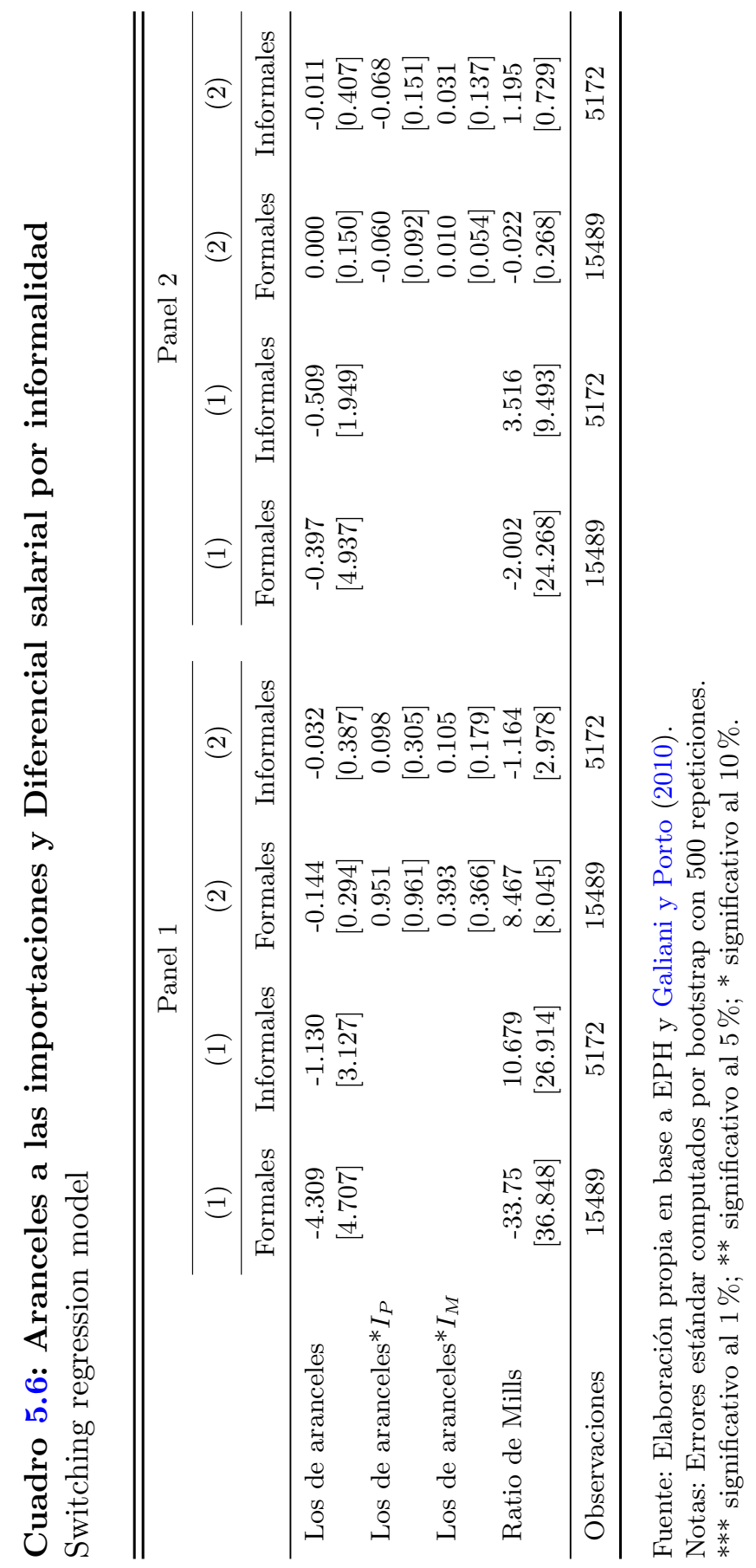




\section{Cuadro 5.7: Aranceles a las importaciones y Diferencial salarial por informalidad}

Sub-periodos 1980-1989 y 1990-2001

Estimación por MCO y VI

\begin{tabular}{|c|c|c|c|c|c|c|}
\hline & \multicolumn{2}{|c|}{$\mathrm{MCO}$} & \multicolumn{2}{|c|}{ VI-1 } & \multicolumn{2}{|c|}{ VI-2 } \\
\hline & (1) & $(2)$ & (1) & $(2)$ & (1) & $(2)$ \\
\hline \multicolumn{7}{|l|}{ Periodo 1980-1989 } \\
\hline$=1$ si informal & $\begin{array}{l}-0.035 \\
{[0.104]}\end{array}$ & $\begin{array}{c}0.013 \\
{[0.116]}\end{array}$ & $\begin{array}{c}0.032 \\
{[0.189]}\end{array}$ & $\begin{array}{c}0.004 \\
{[0.194]}\end{array}$ & $\begin{array}{l}-0.561 \\
{[2.194]}\end{array}$ & $\begin{array}{l}-0.785 \\
1.435]\end{array}$ \\
\hline Log de aranceles & $\begin{array}{c}0.020 \\
{[0.032]}\end{array}$ & $\begin{array}{c}0.030 \\
{[0.032]}\end{array}$ & $\begin{array}{c}0.020 \\
{[0.146]}\end{array}$ & $\begin{array}{c}0.010 \\
{[0.143]}\end{array}$ & $\begin{array}{c}0.012 \\
{[0.162]}\end{array}$ & $\begin{array}{c}0.108 \\
{[0.162]}\end{array}$ \\
\hline$=1$ si informal ${ }^{*} \log$ de aranceles & $\begin{array}{l}-0.020 \\
{[0.032]}\end{array}$ & $\begin{array}{l}-0.050 \\
{[0.038]}\end{array}$ & $\begin{array}{l}-0.060 \\
{[0.064]}\end{array}$ & $\begin{array}{l}-0.070 \\
{[0.069]}\end{array}$ & $\begin{array}{l}0.203 \\
{[0.724]}\end{array}$ & $\begin{array}{c}0.198 \\
{[0.419]}\end{array}$ \\
\hline$=1$ si informal ${ }^{*} \log$ de aranceles$* I_{P}$ & & $\begin{array}{c}0.020 \\
{[0.013]}\end{array}$ & & $\begin{array}{c}0.030 \\
{[0.019]}\end{array}$ & & $\begin{array}{c}0.279 \\
{[0.239]}\end{array}$ \\
\hline$=1$ si informal ${ }^{*} \log$ de aranceles ${ }^{*} I_{M}$ & & $\begin{array}{c}0.010 \\
{[0.010]}\end{array}$ & & $\begin{array}{c}0.020 \\
{[0.011]}\end{array}$ & & $\begin{array}{c}0.139 \\
{[0.134]}\end{array}$ \\
\hline $\begin{array}{l}\text { Observaciones } \\
R^{2}\end{array}$ & $\begin{array}{c}10534 \\
0.40\end{array}$ & $\begin{array}{c}10534 \\
0.40\end{array}$ & 10534 & 10534 & 10534 & 10534 \\
\hline $\begin{array}{l}\text { Test de sobreidentificación } \\
\text { (p-valor) }\end{array}$ & & & 0.62 & 0.43 & 0.36 & 0.55 \\
\hline Periodo 1990-2001 & & & & & & \\
\hline$=1$ si informal & $\begin{array}{l}-0.127 \\
{[0.191]}\end{array}$ & $\begin{array}{l}-0.103 \\
{[0.192]}\end{array}$ & $\begin{array}{c}0.000 \\
{[0.750]}\end{array}$ & $\begin{array}{c}1.128 \\
{[0.570]^{* *}}\end{array}$ & $\begin{array}{c}7.749 \\
{[4.163]^{*}}\end{array}$ & $\begin{array}{c}0.295 \\
{[6.494]}\end{array}$ \\
\hline Log de aranceles & $\begin{array}{c}0.073 \\
{[0.043]^{*}}\end{array}$ & $\begin{array}{c}0.075 \\
{[0.043]^{*}}\end{array}$ & $\begin{array}{l}-1.683 \\
{[3.240]}\end{array}$ & $\begin{array}{c}0.539 \\
{[0.667]}\end{array}$ & $\begin{array}{l}-0.354 \\
{[2.080]}\end{array}$ & $\begin{array}{l}-0.010 \\
{[1.220]}\end{array}$ \\
\hline$=1$ si informal ${ }^{*} \log$ de aranceles & $\begin{array}{c}0.003 \\
{[0.062]}\end{array}$ & $\begin{array}{l}-0.007 \\
{[0.063]}\end{array}$ & -0.063 & $\begin{array}{c}-0.458 \\
{[0.198]^{* *}}\end{array}$ & $\begin{array}{l}-2.602 \\
{[1.825]}\end{array}$ & $\begin{array}{l}-0.067 \\
{[3.572]}\end{array}$ \\
\hline$=1$ si informal ${ }^{*} \log$ de aranceles ${ }^{*} I_{P}$ & & $\begin{array}{c}0.004 \\
{[0.018]}\end{array}$ & & $\begin{array}{c}0.055 \\
{[0.030]^{*}}\end{array}$ & & $\begin{array}{l}-0.368 \\
{[0.364]}\end{array}$ \\
\hline$=1$ si informal ${ }^{*} \log$ de aranceles ${ }^{*} I_{M}$ & & $\begin{array}{c}0.004 \\
{[0.014]}\end{array}$ & & $\begin{array}{c}0.033 \\
{[0.020]^{*}}\end{array}$ & & $\begin{array}{c}0.070 \\
{[0.097]}\end{array}$ \\
\hline Observaciones & 10127 & 10127 & 10127 & 10127 & 10127 & 10127 \\
\hline$R^{2}$ & 0.39 & 0.39 & & & & \\
\hline $\begin{array}{l}\text { Test de sobreidentificación } \\
\text { (p-valor) }\end{array}$ & & & 0.02 & 0.01 & 0.15 & 0.42 \\
\hline
\end{tabular}

Fuente: Elaboración propia en base a EPH y Galiani y Porto (2010).

Notas: Errores estándar agrupados por año e industria entre corchetes.

*** significativo al $1 \%$; ** significativo al $5 \%$; * significativo al $10 \%$. 


\section{Cuadro 5.8: Aranceles a las importaciones y Diferencial salarial por informalidad}

Control por tendencias industriales

Estimación por MCO y VI

\begin{tabular}{|c|c|c|c|c|c|c|}
\hline & \multicolumn{2}{|c|}{$\mathrm{MCO}$} & \multicolumn{2}{|c|}{ VI-1 } & \multicolumn{2}{|c|}{ VI-2 } \\
\hline & (1) & $(2)$ & $(1)$ & $(2)$ & $(1)$ & $(2)$ \\
\hline \multirow[t]{2}{*}{$=1$ si informal } & -0.159 & -0.112 & -0.376 & -0.247 & 0.461 & -0.261 \\
\hline & {$[0.095]^{*}$} & {$[0.101]$} & {$[0.229]^{*}$} & {$[0.217]$} & {$[2.424]$} & [2.111] \\
\hline \multirow[t]{2}{*}{ Log de aranceles } & 0.03 & 0.033 & -0.106 & -0.081 & -0.149 & -0.015 \\
\hline & {$[0.022]$} & {$[0.022]$} & {$[0.191]$} & {$[0.170]$} & {$[0.208]$} & {$[0.148]$} \\
\hline \multirow[t]{2}{*}{$=1$ si informal ${ }^{*} \log$ de aranceles } & -0.005 & -0.027 & 0.066 & 0.019 & -0.265 & -0.046 \\
\hline & {$[0.030]$} & {$[0.033]$} & {$[0.070]$} & {$[0.067]$} & {$[0.715]$} & {$[0.612]$} \\
\hline \multirow{2}{*}{$=1$ si informal ${ }^{*} \log$ de aranceles* $I_{P}$} & & 0.012 & & 0.008 & & -0.108 \\
\hline & & {$[0.012]$} & & {$[0.017]$} & & {$[0.122]$} \\
\hline \multirow{2}{*}{$=1$ si informal ${ }^{*} \log$ de aranceles ${ }^{*} I_{M}$} & & 0.010 & & 0.010 & & 0.094 \\
\hline & & {$[0.009]$} & & {$[0.011]$} & & {$[0.071]$} \\
\hline Observaciones & 20661 & 20661 & 20661 & 20661 & 20661 & 20661 \\
\hline$R^{2}$ & 0.62 & 0.62 & & & & \\
\hline $\begin{array}{l}\text { Test de sobreidentificación } \\
\text { (p-valor) }\end{array}$ & & & 0.50 & 0.22 & 0.15 & 0.35 \\
\hline
\end{tabular}

Fuente: Elaboración propia en base a EPH y Galiani y Porto (2010).

Notas: Errores estándar agrupados por año e industria entre corchetes.

$* * *$ significativo al $1 \%$; $* *$ significativo al $5 \%$; ${ }^{*}$ significativo al $10 \%$. 


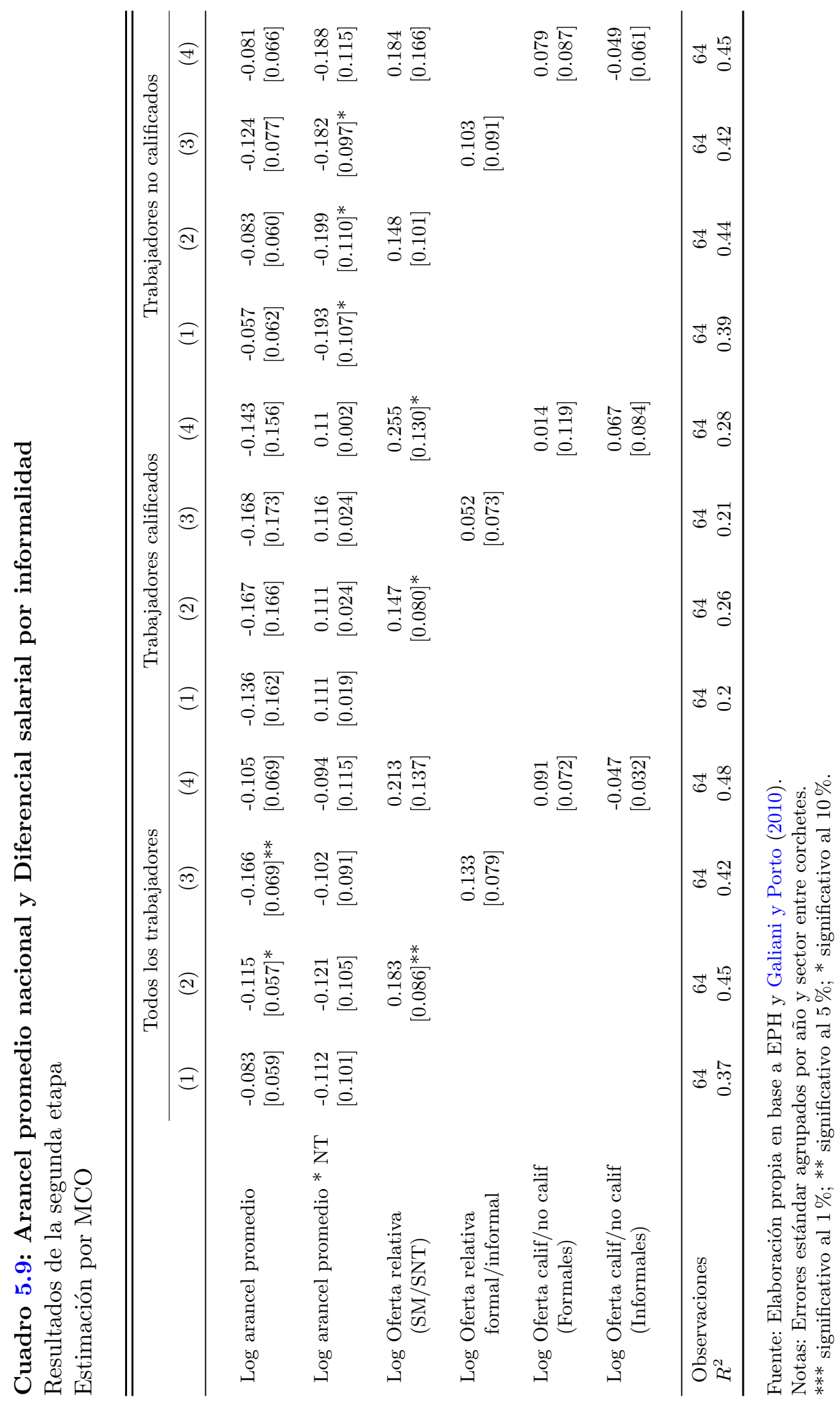




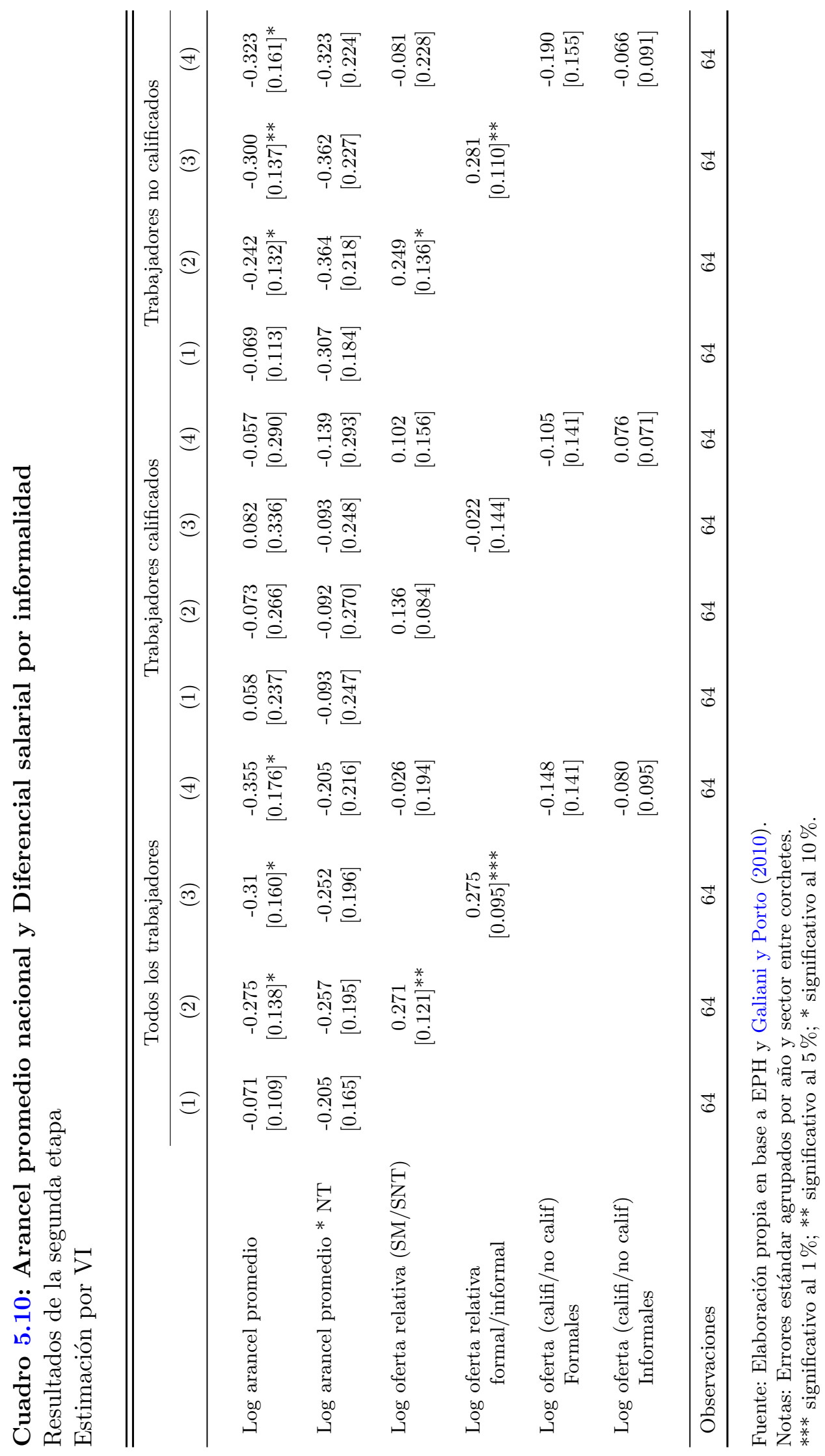




\subsection{Gráficos}

\section{Gráfico 5.1}

Aranceles a las importaciones y Diferencial salarial por informalidad

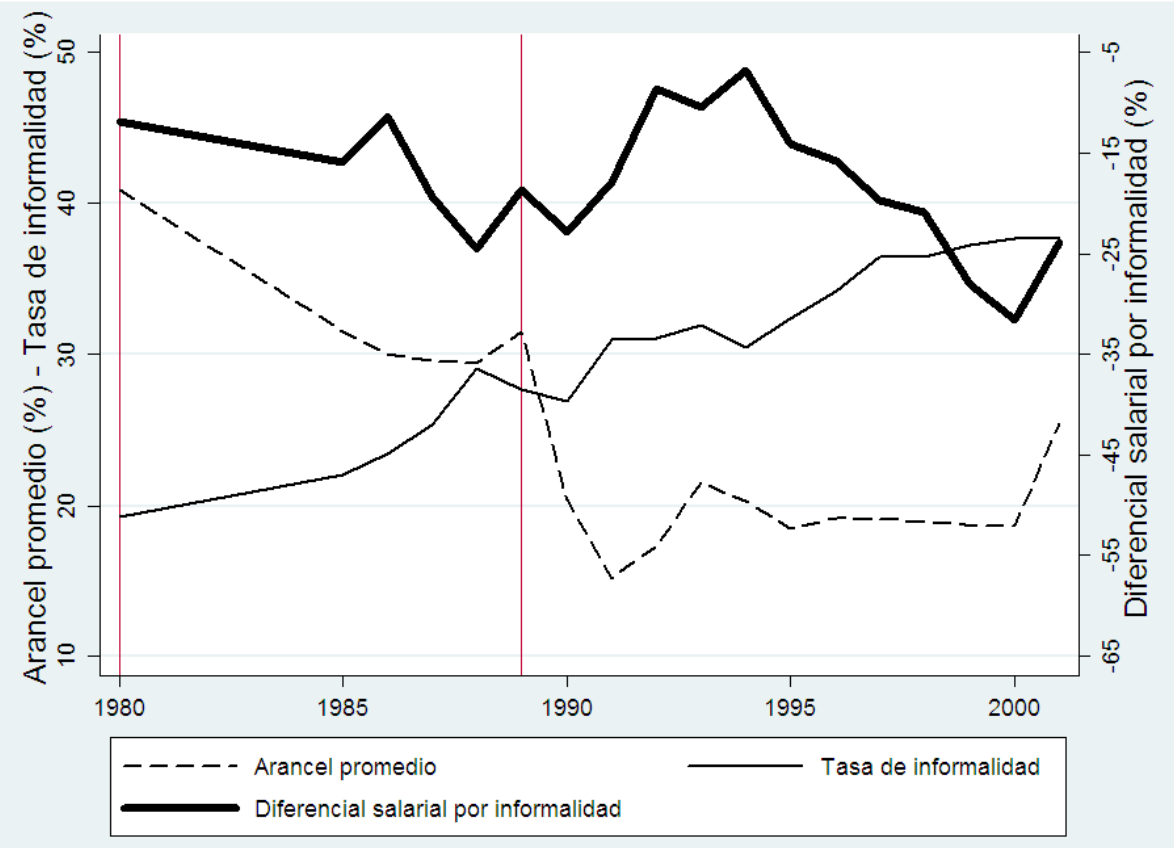

Fuente: Elaboración propia en base a EPH y Galiani y Porto (2010). Arancel: Arancel promedio entre sectores a 3-dígitos ISIC ponderado por nivel de empleo. Diferencial salarial por informalidad: coeficientes de variable indicadora de la condición de informalidad en una regresión de ingresos para cada año. 


\section{Capítulo 6}

\section{Conclusiones}

La teoría del comercio internacional predice que cuando las barreras al comercio son removidas los factores se reasignan hacia los sectores que poseen ventajas comparativas (modelo Ricardiano) o utilizan de manera intensiva el factor relativamente abundante en el país (modelo de Hecksher-Ohlin). La evidencia disponible para países en desarrollo indica que existe una respuesta del mercado de trabajo luego de un shock de política comercial, pero la transición hacia el equilibrio de largo plazo puede tomar varios años. El patrón de ajuste del mercado de trabajo en estos países se caracteriza por un proceso de creación y destrucción simultánea de empleos al interior de cada industria y una reasignación muy lenta de trabajo hacia las industrias con ventajas comparativas. Este trabajo planteó como hipótesis que en economías en desarrollo las firmas pertenecientes a los sectores que pierden protección disponen de un margen de ajuste adicional al poder sustituir trabajadores formales por informales. La evasión de impuestos, en la forma de no registración de trabajadores, actuaría como un mecanismo para absorber parte del shock generado por la reforma.

El objetivo de este trabajo fue analizar el impacto de las reformas comerciales sobre la informalidad laboral, la transición de trabajadores entre la formalidad y la informalidad y sobre el diferencial salarial entre trabajadores formales e informales en las industrias del sector de manufacturas de Argentina durante el periodo 19802001, buscando identificar mecanismos de ajuste adicionales a los propuestos por la teoría del comercio internacional. Para esto se diferenció entre un efecto de corto plazo, definido como un escenario donde el trabajo no se reasigna entre sectores y los salarios no ajustan, y un efecto de largo plazo, escenario donde el sector de bienes no transables también puede resultar afectado a través de efectos de equilibrio general. 
Los principales hallazgos del estudio permitieron entender los cambios en la tasa de informalidad en el contexto del proceso de ajuste del mercado de trabajo argentino ante shocks de política comercial. Los resultados pueden resumirse de la siguiente manera:

(i) La tasa de informalidad de las industrias aumentó en el corto plazo (cuando los trabajadores no se reasignan entre sectores y los salarios no ajustan) como consecuencia de la reducción en el nivel de protección arancelaria. Las firmas del sector de manufacturas que enfrentaron episodios de liberalización del comercio ajustaron el tamaño de su fuerza laboral y modificaron la composición de su fuerza de trabajo sustituyendo trabajadores formales por informales. La evasión de impuestos actuó como un mecanismo de ajuste adicional a los propuestos por la teoría del comercio internacional permitiendo a las firmas suavizar el impacto del shock negativo.

(ii) La magnitud de este efecto fue diferente de acuerdo al tamaño de las firmas en cada industria. Cuando las firmas pequeñas prevalecen, la sustitución entre trabajadores formales e informales actúa como mecanismo de ajuste, pero este efecto se diluye al considerar firmas de mayor tamaño. Esto pudo racionalizarse a partir de los argumentos de la literatura de evasión de impuestos (la probabilidad de detección es más alta en firmas de mayor tamaño y la informalidad laboral no sería un mecanismo de ajuste en ese caso), el diferente comportamiento de las firmas según su exposición al comercio internacional (las firmas exportadoras que pueden acceder a nuevos mercados con la apertura tienden a ser grandes), y la incorporación de bienes de capital que permiten lograr mejoras de productividad (la evidencia muestra un patrón de mejoras de productividad creciente en el tamaño de las firmas).

(iii) El análisis de transiciones laborales permitió caracterizar el proceso de ajuste del mercado de trabajo. Los resultados mostraron un patrón de ajuste diferente de acuerdo al tamaño de las firmas en cada industria, reforzando la evidencia previa de reacciones heterogéneas en función de esta característica. En industrias con firmas pequeñas se produjo un cambio en la naturaleza de las relaciones laborales, con trabajadores formales que perdieron los beneficios de la seguridad social, y en industrias con firmas medianas el ajuste se dio a través de la rotación laboral y el despido de trabajadores formales e informales en diferente medida. En industrias con firmas grandes los trabajadores conservaron su categoría. La evidencia encontrada también confirmó el resultado habitual de ausencia de reasignación del empleo entre 
industrias y sectores como consecuencia de la liberalización del comercio. Con este resultado, compatible con la definición de corto plazo, fue posible entender a través de qué mecanismo se produjo el aumento en la tasa de informalidad en industrias pequeñas y medianas reportado previamente.

(iv) Utilizando la variabilidad de los datos en el tiempo se encontró que el efecto identificado para las industrias del sector de manufacturas en el corto plazo se revirtió en el largo plazo y el sector de bienes no transables también resultó afectado por los episodios de liberalización del comercio a través de efectos de equilibrio general. La tasa de informalidad creció en este sector cuando el arancel promedio de la economía se reducía. Estos resultados fueron racionalizados a partir de la movilidad del trabajo desde el sector de manufacturas hacia el de bienes no transables, el ajuste de salarios, la salida de las firmas pequeñas e informales que no pudieron competir en el sector de manufacturas y el ingreso de nuevas firmas pequeñas al sector de bienes no transables.

(v) En un contexto de ausencia de reasignación del empleo en respuesta a cambios en la política comercial el ajuste de salarios cobra relevancia. El análisis del ajuste del diferencial salarial entre trabajadores formales e informales ante la caída en el nivel de protección mostró que no existió ningún ajuste. Para arribar a esta conclusión se evaluó la predicción de los modelos de corto y mediano plazo de la TCI. Estos modelos predicen que los trabajadores en industrias que enfrentan mayores recortes de aranceles deberían enfrentar una reducción de salarios respecto a los trabajadores que, con idénticas características, se encuentran empleados en industrias que enfrentan una reducción menor en su nivel de protección. Los resultados indicaron que la estructura industrial de salarios no sufrió cambios asociados a los episodios de liberalización del comercio en el corto plazo. Aun cuando el salario promedio de la industria no cambia, el ajuste en la composición de la fuerza laboral entre trabajadores formales e informales puede determinar que el salario formal e informal se vean afectados de manera diferente. La evaluación empírica de esta posibilidad indicó que no habría un efecto estadísticamente significativo para la totalidad de las industrias y tampoco al distinguir por su tamaño.

(vi) La evidencia de largo plazo mostró que los trabajadores informales mejoraron su salario en términos relativos y esa mejora se produjo entre los no calificados. Este efecto pudo ser explicado a partir de la movilidad del trabajo entre los distintos sectores de la economía en el largo plazo, y no solo entre las industrias del sector de 
manufacturas, y en la existencia de un sector -sector exportador- que es intensivo en el uso de trabajo no calificado (donde el empleo informal tiene un mayor peso relativo) respecto al sector de manufacturas.

Estos resultados significan una contribución a la literatura en varios aspectos. En primer lugar, realizan un aporte a la literatura que analiza el ajuste del mercado laboral ante reformas comerciales en el corto plazo. El vínculo entre la informalidad laboral y la liberalización del comercio ha sido analizado pero raramente interpretado como un efecto de corto plazo de las reformas que se puede revertir o intensificar con el transcurso del tiempo. El análisis en esta dimensión temporal innovó al permitir que existan efectos heterogéneos de acuerdo al tamaño promedio de las firmas en cada industria, resultado que es compatible con los argumentos de la literatura de evasión de impuestos, con los modelos de comercio con firmas heterogéneas y con el proceso de incorporación de bienes de capital.

La segunda innovación es la estimación de un efecto de largo plazo. No existen antecedentes en la literatura teórica y empírica que vinculen episodios de liberalización del comercio con cambios en la informalidad laboral distinguiendo entre el efecto que opera en el corto plazo y el efecto de largo plazo. Los resultados indicaron que cuando el trabajo puede moverse entre sectores, los salarios ajustan y se produce la salida y entrada de firmas al mercado, la tasa de informalidad se reduce en el sector de manufacturas junto con el arancel promedio nacional y el sector de bienes no transables también es afectado a través de efectos de equilibrio general. En este caso, el efecto es el opuesto indicando que la tasa de informalidad aumentó en este sector. Esta reversión en el efecto identificado para el sector de manufacturas permite interpretar la evidencia empírica en conflicto. Parte de los trabajos disponibles encuentran un aumento en la informalidad laboral en respuesta a episodios de liberalización del comercio, otros encuentran una caída y otros concluyen que no existió ningún efecto. Los diferentes mecanismos que operan en el corto y largo plazo estarían detrás de estos resultados contrapuestos. Esta distinción en la dimensión temporal del análisis también resulta clave desde el punto de vista de la política económica. Comprender cómo reacciona la economía en el corto y mediano plazo luego de un episodio de liberalización del comercio es un insumo necesario para conocer cuánto tiempo demandará la transición hacia el equilibrio de largo plazo, quiénes son los ganadores y perdedores y, entonces, poder diseñar políticas orientadas a reducir costos de ajuste y compensar a los perdedores. 
Otra contribución del trabajo es la presentación de un modelo sencillo que muestra el ajuste en la demanda de trabajo de las firmas de una industria que compite con las importaciones sin imponer ex-ante una segmentación por sector, con firmas totalmente formales o informales. En este caso se propuso un escenario más parsimonioso y realista donde los trabajadores son homogéneos y su condición de informalidad depende de la decisión (óptima) de la firma de pagar o evadir las contribuciones a la seguridad social de sus trabajadores lo cual es función de los costos asociados a dicha decisión. Como consecuencia, las firmas pueden emplear simultáneamente a trabajadores registrados y no registrados. El modelo innova al permitir que exista tanto un margen extensivo de evasión (las firmas deciden si registrar trabajadores o no) como un margen intensivo (las firmas deciden que proporción de su fuerza laboral no está registrada). Estas característica del modelo se ajustan al hecho estilizado que muestra una correlación negativa entre la informalidad laboral y el tamaño de las firmas, y permite racionalizar el impacto heterogéneo de las reformas comerciales que se encuentra en el análisis empírico.

Una última contribución del trabajo es el análisis del ajuste en el diferencial salarial por informalidad en el corto y largo plazo. Los resultados encontrados son compatibles con el supuesto de ausencia de ajuste de salarios en el corto plazo, mientras que la evidencia de largo plazo es un factor que ayuda a interpretar la reversión en el impacto de la apertura sobre la tasa de informalidad en el sector de manufacturas.

Los hallazgos empíricos y modelos teóricos de este trabajo permitieron racionalizar algunos de los ajustes de corto y largo plazo observados en países en desarrollo luego de episodios de liberalización del comercio. También se validó empíricamente la intuición de que el canal de evasión-informalidad es relevante como mecanismo de ajuste de la demanda de trabajo de las firmas, permitiendo suavizar el impacto del shock. Esta puede ser una de las razones detrás de la resistencia de los gobiernos en países en desarrollo a aumentar los esfuerzos para mejorar el cumplimiento de las regulaciones, al menos en momentos de reforma. Si bien los trabajadores sufren un costo en términos de trabajos de menor calidad, este margen de ajuste adicional permite mantener el nivel de empleo, siendo este uno de los trade-offs que enfrentan los policy makers. La distinción entre el ajuste de corto y largo plazo mostró otra dimensión de este trade-off. Para el caso particular de Argentina, la tasa de informalidad se reduce en el largo plazo en el sector de manufacturas, pero aumenta en 
el sector de bienes no transables.

La movilidad del trabajo entre sectores es usualmente evaluada como deseable, y este trabajo indicó que existe una dimensión adicional en la que sería beneficiosa para permitir el ajuste hacia el equilibrio de largo plazo a un menor costo. En este caso, permitiría una transición más suave hacia el equilibrio final, evitando aumentos transitorios en la informalidad laboral y la aparición de desempleo. Una red de protección social más amplia no asociada al empleo (como es el caso de la mayoría de los sistema de seguro social en América Latina) ayudaría a mitigar los costos para aquellos trabajadores que pierden los beneficios de la seguridad social durante el proceso de ajuste. 



\section{Bibliografía}

Acosta, P. y Gasparini. L. (2007): "Capital Accumulation, Trade Liberalization, and Rising Wage Inequality: The Case of Argentina". Economic Development and Cultural Change, 55, pp. 793-812.

Acosta, P. y Montes-Rojas, G. (2010): "Informal Jobs and Trade Liberalization in Argentina". Working Paper.

Alemán-Castilla, B. (2006): "The Effect of Trade Liberalization on Informality and Wages: Evidence from Mexico". CEP Discussion Paper 763.

Almeida, R. y Poole, J. (2013): "Trade and Labor Reallocation with Heterogeneous Enforcement of Labor Regulations". IZA Discussion Papers 7358, Institute for the Study of Labor (IZA).

Alzúa, M.L. (2008): "Are Informal Workers Secondary Workers?: Evidence for Argentina". Documento de Trabajo del CEDLAS Nro. 73.

Amaral, P. y Quintin, E. (2006): "A competitive model of the informal sector". Journal of Monetary Economics, 53, pp. 1541-1553.

Angrist, J. y Pishke, J. (2008): Mostly Harmless Econometrics: An Empiricist's Companion. Princeton University Press. Capítulo 3.

Arias, O. y Khamis, M. (2008): "Comparative Advantage, Segmentation and Informal Earnings: A Marginal Treatment Effects Approach". IZA Discussion Paper 3916.

Artuç, E., Chaudhuri, S. y McLaren, J. (2010): "Trade Shocks and Labor Adjustment: A Structural Empirical Approach". The American Economic Review, 100(3), pp. 1008-1045. 
Atolia, M. (2007): "Trade liberalization and rising wage inequality in Latin America: Reconciliation with HOS theory". Journal of International Economics, 71(2), pp. 467-494.

Attanasio, O., Goldberg, P. y Pavcnik, N. (2004): "Trade Reforms and Wage Inequality in Colombia". Journal of Development Economics, 74(2), pp. 331-366.

Auriol, E. y Warlters, M. (2005): "Taxation base in developing countries". Journal of Public Economics, 89(4), pp. 625-646.

Autor, D., Dorn, D., Hanson, G. y Song, J. (2013): "Trade Adjustment: Worker Level Evidence". NBER Working Papers 19226, National Bureau of Economic Research.

Balassa, B. (1965): "Trade Liberalization and Revealed Comparative Advantage". Manchester School of Economic and Social Studies, 33, pp. 99-123.

Bargain, O. y Kwenda, P. (2011): "Earnings Structures, Informal Employment, and Self-Employment: New Evidence from Brazil, Mexico, and South Africa". Review of Income and Wealth, 57, S100-S122.

Becker D. (2013): "Heterogeneous firms and informality: the effects of trade liberalization on labor markets". Charles H. Dyson School of Applied Economics and Management, Cornell University.

Bérgolo, M. y Cruces, G. (2013): "Informality and Contributory and NonContributory Programmes. Recnt Reforms of the Social-Protection System in Uruguay". Development Policy Review, 31(5).

Berlinski, J. (1994). "Post Trade Liberalization Institutional Issues in Argentina", mimeo, Instituto Di Tella Working Paper No 182.

Bernard, A. y Jensen, J. (1999): "Exceptional Exporter Performance: Cause, Effect, or Both?". Journal of International Economics, 47, pp. 1-25.

Boeri, T. y Garibaldi, P. (2006): "Shadow Sorting". CEPR Discussion Paper 5487.

Boeri, T. y Terrell, K. (2002): "Institutional Determinants of Labor reallocation in Transition". The Journal of Economic Perspectives, 16(1), pp. 51-76. 
Bosch, M., Goñi, E. y Maloney, W. (2012): "Trade liberalization, labor reforms and formal-informal employment dynamics" . Labour Economics, Elsevier, vol. 19(5), pages $653-667$.

Brambilla, I., Lederman, D. y Porto, G. (2010): "Exports, Export Destinations and Skills". The American Economic Review, 102(7), pp. 3406-38.

Bound, J., Jaeger, D. A y Baker, R. M. (1995): "Problems with Instrumental Variables Estimation When the Correlation between the Instruments and Endogenous Explanatory Variables Is Weak". Journal of the American Statistical Association, 90, pp. 443-450.

Bustos, P. (2011): "Trade Liberalization, Exports, and Technology Upgrading: Evidence on the Impact of MERCOSUR on Argentinian Firms". American Economic Review, American Economic Association, 101(1), pp. 304-40.

Carneiro, P. y Heckman, J. (2002): "The Evidence on Credit Constraints in Postsecondary schooling". Economic Journal, 112, pp. 705-734.

Chaudhuri, S. y Banerjee, D. (2007): "Economic liberalization, capital mobility and informal wage in a small open economy: A theoretical analysis". Economic Modelling, 24, pp. 924-940.

Cosar, K. (2013): “Adjusting to Trade Liberalization: Reallocation and Labor Market Policies". University of Chicago Booth School of Business.

Cruces, G. y Gasparini, L. (2009): "Una Distribución en Movimiento: El Caso de Argentina". Revista Desarrollo Económico, 192(48).

Cruces G., Galiani, S. y Kidyba, S. (2010): "Payroll Taxes, Wages and Employment: Identification through Policy Changes". Labour Economics, 17(4), pp. 743-749.

Cunningham, W. y Maloney, W. (2001): "Heterogeneity in the Mexican microenterprise sector: an application of factor and cluster analysis". Economic Development and Cultural Change, 50(1), 131-156.

Currie, J. y Harrison, A. (1997): "Sharing the Costs: The Impact of Trade Reform on Capital and Labor in Morocco". Journal of Labor Economics, University of Chicago Press, 15(3), pp. 44-71. 
Davidson, C., Martin, L. y Matusz, S. (1999): "Trade and search generated unemployment". Journal of International Economics, 48, pp. 271-299.

Davidson, C. y Matusz, S. (2004): International Trade and Labor Markets: Theory, Evidence, and Policy Implications. WE Upjohn Institute.

de Paula, A. y Scheinkman, J. (2011): "The informal sector: An equilibrium model and some empirical evidence". Review of Income and Wealth, 57, S8-S26.

de Soto, H. (1989): The Other Path: The Invisible Revolution in the Third World. Harper Row, New York.

Dix-Carneiro, R. (2011): "Trade Liberalization and Labor Market Dynamics", University of Maryland. Mimeo.

Dix-Carneiro, R. (2012): "Trade Reform and Reallocation: What Have We Learned and What is Next?", University of Maryland. Mimeo.

El Badaoui, E., Strobl, E. y Walsh, F. (2008): "Is there an informal employment wage penalty? Evidence from South Africa". Economic Development and Cultural Change, 56(3), pp. 683-710.

Falco, P., Kerr, A., Rankin, N., Sandefur, J. y Teal, F. (2011): "The returns to formality and informality in urban Africa". Labour Economics, 18, s23-s31.

Feliciano, Z. (2001): "Workers and Trade Liberalization: The Impact of Trade Reforms in Mexico on Wages and Employment". Industrial and Labor Relations Review, 55(1), pp. 95-115.

Fields, G. (1975): "Rural-Urban Migration, Urban Unemployment and Underemployment, and Job Search Activity in LDC's". Journal of Development Economics, 2, pp. 165-188.

Fields, G. (2005): "A guide to multisector labor market models". Paper prepared for the World Bank Labor Market Conference.

Fiess, N. and Fugazza, M. (2008): "Trade liberalisation and Informality: New Stylized Facts". Policy Issues in International Trade and Commodities. Study Series 43. 
Fiess, N., Fugazza, M. y Maloney, W. (2010): "Informality and Macroeconomic Fluctuations". Journal of Development Economics, 91, pp. 211-226.

Fortin, B., Marceau, N. y Savard, L. (1997): "Taxation, Wage Controls and the Informal Sector". Journal of Public Economics, 66, pp. 293-312.

Freeman, R. y Katz, L. (1991): "Industrial Wage and Employment Determination in an Open Economy, Immigration, Trade and the Labor Market". En Abowd, J. y Freeman, R. Eds., University of Chicago Press.

Fuest, C. y Scheider, F. (2012): "Tax evasion, tax avoidance and shadow economy: introduction". International Tax and Public Finance, 19(1), pp. 1-4.

Galiani, S. y Porto, G. (2010): "Trends in Tariff Reforms and Trends in the Structure of Wages". The Review of Economics and Statistics, 92(3), pp. 482-494.

Galiani, S. y Sanguinetti, P. (2003): "The impact of trade liberalization on wage inequality: evidence from Argentina". Journal of Development Economics, 72, pp. 497-513.

Galiani, S. y Weinschelbaum, F. (2011): "Modeling Informality Formally: Households and Firms". Economic Inquiry.

Gasparini, L. y Tornarolli, L. (2009): "Labor Informality in Latin America and the Caribbean: Patterns and Trends from Household Survey Microdata". Revista Desarrollo y Sociedad, 63(1), pp. 13-80.

Gaston, N. y Trefler, D. (1993): "The Labor Market Consequences of the Canada-U.S. Free Trade Agreement". Canadian Journal of Economics, 30(1), pp. $18-41$

Goldberg, P. and Pavcnik, N. (2003): "The Response of the Informal Sector to Trade Liberalization". Journal of Development Economics, 72, pp. 463-496.

Goldberg, P. y Pavcnik, N. (2004): "Trade, Inequality, and Poverty: What Do We Know? Evidence from Recent Trade Liberalization Episodes in Developing Countries". Brookings Trade Forum 2004, 223-269.

Goldberg, P. y Pavcnik, N. (2005): "Trade, Wages, and the Political Economy of Trade Protection: Evidence from the Colombian Trade Reforms". Journal of International Economics, 66, pp. 75-105. 
Goldberg, P. and Pavcnik, N. (2007): "Distributional Effects of Globalization in Developing Countries". Journal of Economic Literature, 45(1), pp. 39-82.

Gong, X. y Van Soest, A. (2001): "Wage differentials and mobility in the urban labor market: A panel data analysis for Mexico". Labour Economics, 9(4), pp. 513-529.

Gonzaga, G., Maloney, W. y Mizala, A. (2003): "Labor Turnover and Labor Legislation in Brazil". Economía, 4(1), pp. 165-222.

Grossman, G. (1987): "The employment and wage effects on import competition in the United States". Journal of International Economic Integration, 2, pp. 1-23.

Guha-Khasnobis, B., Kanbur, R. y Ostrom, E. (2006): Linking the Formal and Informal Economy: Concepts and Policies. Oxford University Press, New York.

Haltiwanger, J., Kugler, A., Kugler, M., Micco, A. y Pagés, C. (2004): "Effects of Tariffs and Real Exchange Rates on Job Reallocation: Evidence from Latin America". Policy Reform, 7(4), pp. 191-208.

Harris, J. y Todaro, M. (1970): "Migration, Unemployment, and Development: A Two Sector Analysis". American Economic Review, 40, pp. 126-142.

Harrison, A. y Hanson, G. (1999): "Who Gains From Trade Reforms? Some Remaining Puzzles". Journal of Development Economics, 59, pp. 125-154.

Heckman, J. (1979): "Sample Selection Bias as a Specification Error". Econometrica, 47(1), pp. $153-162$.

Helpman, E. y Itskhoki, O. (2009): "Labor Market Rigidities, Trade and Unemployment". Review of Economic Studies, 77(3), pp. 1100-1137.

Helpman, E., Itskhoki, O. y Redding, S. (2010): "Inequality and Unemployment in a Global Economy". Econometrica, 78(4), pp. 1239-1283.

Hibbs, D. y Piculescu, V. (2010): "Tax Toleration and Tax Compliance: How Government Affects the Propensity of Firms to Enter the Unofficial Economy". American Journal of Political Science, 54(1), pp. 18-33.

Hopenhayn, H. y Rogerson, R. (1993): "Job Turnover and Policy Evaluation: A General Equilibrium Analysis". Journal of Political Economy, 101(5), pp. 91538. 
Juarez, L. (2008): "Are Informal Workers Compensated for the Lack of Fringe Benefits? Free Health Care as an Instrument for Formality". Working Papers 0804, Centro de Investigacion Economica, ITAM.

Kletzer, L. (2001): "Job Loss From Imports: Measuring the Costs". Peterson Institute.

Kletzer, L. (2002): "Imports, Exports and Jobs: What Does Trade Mean for Employment and Job Loss?". Kalamazoo, Michigan: W. E. Upjohn Institute for Employment Research.

Kleven, H., Kreiner, C. y Saez, E. (2009): "Why can modern governments tax so much?. An agency model of firms as fiscal intermediaries". NBER Working Paper.

Krebs, T., Krishna, P. y Maloney, W. (2008): Trade, Globalization and Poverty. Chapter Human Capital, Trade Liberalization, and Income Risk. Routledge.

Krishna, P. y Senses, M. (2009): "International Trade and Labor Income Risk in the United States". NBER Working Paper.

Krugman, P. (1979): "Increasing Returns, Monopolistic Competition, and International Trade". Journal of International Economics, 9, pp. 469-479.

Kumler, T., Verhoogen, E. y Frías, J. (2012): "Enlisting Workers in Monitoring Firms: Payroll Tax Compliance". NBER Working Papers 19385, National Bureau of Economic Research.

La Porta, R. y Shleifer, A. (2008): "The unofficial economy and economic development". Brookings Papers on Economic Activity, 2008: 275-352.

Levy, S. (2008): Good Intentions, Bad Outcomes: Social Policy, Informality, and Economic Growth in Mexico. Brookings Institution Press.

Lewis A. (1954): "Economic Development with Unlimited Supplies of Labour". Manchester School, 22, pp. 139-191.

Loayza, N. (1996): "The Economics of the Informal Sector: a Simple Model and Some Empirical Evidence from Latin America". Carnegie Rochester Conference Series on Public Policy, vol. 45. North Holland, pp. 129-162. 
Loayza, N. y Rigolini, J. (2006): "Informality Trends and Cycles". Mimeo, Banco Mundial.

Lundberg, Sh. (1988): "Labor Supply of Husbands and Wives: A Simultaneous Equations Approach". The Review of Economics and Statistics, MIT Press, 70(2), pp. 224-35.

Maloney, W. (1999): "Does informality imply segmentation in urban labor markets? Evidence from sectoral transitions in Mexico". The World Bank Economic Review, 13(2), 275-302.

Maloney, W. (2003): "Informality Revisited". World Bank Policy Research Working Paper 2965.

Marcouiller, D., Ruiz de Castilla, V. y Woodruff, Ch. (1997): "Formal Measures of the Informal Sector Wage Gap in Mexico, El Salvador, and Peru". Economic Development and Cultural Change, 45(2), pp. 367-392.

Marjit, S. (2003): "Economic reform and Informal wage A General Equilibrium Analysis". Journal of Development Economics, 72(1), pp. 371-378.

Marjit, S., Kar, S. y Sarkar, P. (2003): "Trade Reform, Internal Capital Mobility and Informal Wage-Theory and Evidence". mimeo, CSSSC, India.

Marjit, S., Kar, S. y Beladi, H. (2007): "Trade Reform and Informal Wage". Review of Development Economics, 11(2), pp. 313-320.

Marjit, S. y Kar, S. (2007): "Labor productivity growth, informal wage and capital mobility: A general equilibrium analysis". MPRA Paper 23912, University Library of Munich, Germany.

Marshall, A. y Groisman, F. (2005): "Sindicalización en la Argentina: Análisis desde la Perspectiva de los Determinantes de la Afiliación Individual". Estudio preparado para el 7 mo. Congreso Nacional de Estudios del Trabajo, ASET.

Melitz, M. (2003): "The Impact of Trade on Intra-Industry Reallocations and Aggregate Industry Productivity". Econometrica, 71, pp. 1695-1725.

Melitz, M. y Ottaviano, G. (2008): "Market Size, Trade, and Productivity". Review of Economic Studies, 75, pp. 295-316. 
Menezes-Filho, N. y Muendler, M. (2011): "Labor Reallocation in Response to Trade Reform". NBER Working Papers 17372, National Bureau of Economic Research.

Mussa, M.: "The Adjustment Process and the Timing of Trade Liberalization". NBER Working Paper.

Olson, C. (2002): "Do Workers Accept Lower Wages in Exchange for Health Benefits?". Journal of Labor Economics, 20(2) pp. S91-S114.

OIT (1991): "El dilema del sector no estructurado", Memoria del Director General, CIT, 1991, Ginebra.

Pagés, C., Pierre, G. y Scarpetta, S. (2009): Job Creation in Latin America and the Caribbean. World Bank.

Papageorgiou, D., Michaely, M. and Choksi, A. (Eds.) (1991): Liberalizing foreign trade. Basil Blackwell Publishers for the World Bank, Cambridge, MA.

Park, A., Yang, D., Shi, X. y Jiang, Y. (2010): "Exporting and Firm Performance: Chinese Exporters and the Asian Financial Crisis". The Review of Economics and Statistics, 92(4), pp. 822-842.

Paulson, A. y Townsend, R. (2005): "Financial constraints and entrepreneurship: evidence from the Thai financial crisis". Economic Perspectives, 3Q, 34-48.

Pavcnik, N., Blom, A., Goldberg, P. and Schady, N. (2003): "Trade liberalization and labor market adjustment in Brazil". Policy Research Working Paper Series 2982, The World Bank.

Paz, L. (2013): "The Impacts of Trade Liberalization on Informal Labor Markets: A Theoretical and Empirical Evaluation of the Brazilian Case". MPRA Paper 45726 .

Peluffo, C. (2010): "Costos de Movilidad Intersectorial del Empleo, Shocks Comerciales y Tecnológicos: Resultados para Argentina en base a un Modelo Estructural". Revista Económica, La Plata, Vol. LVI, Enero-Diciembre 2010.

Perry, G., Maloney, W., Arias, O., Fajnzylber, P., Mason, A. y Saavedra-Chanduvi, J. (2007): "Informalidad: Escape y Exclusión". Estudios del Banco Mundial sobre América Latina y el Caribe. 
Pradhan, M. y Van Soest, A. (1995): "Formal and informal sector employment in urban areas of Bolivia". Labour Economics, 2, pp. 275-297.

Pratap, S. y Quintin, E. (2006): "Are labor markets segmented in developing countries? A semiparametric approach". European Economic Review, 50(7), pp. $1817-1841$.

Rauch, J.E. (1991): "Modelling the informal sector formally". Journal of Development Economics, 35, pp. 35-47.

Revenga, A. (1992): "Exporting Jobs?: The Impact of Import Competition on Employment and Wages in U.S. Manufacturing". The Quarterly Journal of Economics, 107(1), pp. 255-284.

Revenga, A. (1997): "Employment and Wage Effects of Trade Liberalization: The Case of Mexican Manufacturing". Journal of Labor Economics, 15, pp. 520-543.

Roberts, B. (1989): "Employment Structure, Life Cycle, and Life Changes: Formal and Informal Sectors in Guadalajara". En The Informal Economy: Studies in Advanced and Less Developed Countries (Portes, Castells y Breton ed.). The John Hopkins University Press.

Roberts, M. y Tybout, J. (1996): "Industrial Evolution in Developing Countries". Oxford University Press, New York.

Rosen, S. (1986): "The Theory of Equalizing Differences". Handbook of Labor Economics, Ashenfelter O. y Layard, R. (ed.), vol 1, capítulo 12, pp. 641-692.

Sanchez, G. y Butler, I. (2004): "Market institutions, labor market dynamics, and productivity in Argentina during the 1990s". Journal of Policy Reform, 7(4), pp. 249-278.

SEDLAC (2013): Socio-Economic Database for Latin America and the Caribbean. CEDLAS y Banco Mundial. Disponible en http://sedlac.econo.unlp.edu.ar/esp/.

Staiger, D. y Stock, J. H. (1997): "Instrumental Variables Regression with Weak Instruments". Econometrica, 65, pp. 557-586.

Tansel, A. (1999): "Formal versus informal sector choice of wage earners and their wages in Turkey". Paper 9927, Economic Research Forum. 
Tannuri-Pianto, M. y Pianto, D. (2002): "Informal employment in Brazil - a choice at the top and segmentation at the bottom: a quantile regression approach". Mimeo.

Tonin, M. (2011): "Minimum wage and tax evasion: Theory and evidence". Journal of Public Economics, 95(11-12), pp. 635-1651.

Topalova, P. (2007): "Trade Liberalization, Poverty and Inequality: Evidence from Indian Districts". NBER Chapters, En: Globalization and Poverty, pages 291-336 National Bureau of Economic Research.

Topalova, P. (2010): "Factor Immobility and Regional Impacts of Trade Liberalization: Evidence on Poverty from India". American Economic Journal: Applied Economics, 2(4), pp. 1-41.

Torre, J. C. y Gerchunoff, P. (1999): "La Economía política de las Reformas Institucionales en Argentina. Los Casos de la Política de Privatización de Entel, la Reforma de la Seguridad Social y la Reforma Laboral". Banco Interamericano de Desarrollo, Red de Centros de Investigación, Working Paper R-349.

Tybout, J. R. (2000): "Manufacturing firms in developing countries: How well do they do, and why?". Journal of Economic Literature, 38(1), pp. 11-44.

Ulyssea, G. (2010): "Regulation of Entry, Labor Market Institutions and the Informal Sector". Journal of Development Economics, 91(1), pp. 87-99.

Ulyssea, G. (2011): "Formal and informal firms' dynamics". Working Paper.

Ulyssea, G. (2013): "An Anatomy of Informal Firms". Institute for Applied Economic Research (IPEA).

UN Comtrade (2012): "The United Nations Commodity Trade Statistics database". Banco Mundial, Washington DC. Disponible en http://comtrade.un.org/db/default.

Wacziarg, R. and Wallack, J. (2004): "Trade liberalization and intersectoral labor movements". Journal of International Economics, 64(2), pp. 411-439.

Waisgrais, S. y Sarabia, M. (2008): "La heterogeneidad de la informalidad". En Aportes a una nueva visión de la informalidad laboral en la Argentina, Banco Mundial y Ministerio de Trabajo, Empleo y Seguridad Social. 
Wooldridge, J. M. (2010): "Econometric Analysis of Cross Section and Panel Data". MIT Press Books, The MIT Press, edition 2, volume 1, number 0262232588.

World Development Indicators (2012): "World Development Indicators Database on-line version". Banco Mundial, Washington DC. Disponible en http://data.worldbank.org/data-catalog/world-development-indicators. 